\title{
Revealing Judy Chicago's "The Dinner Party": An Analysis of the Curatorial Context
}

\author{
Sally Deskins
}

Follow this and additional works at: https://researchrepository.wvu.edu/etd

\section{Recommended Citation}

Deskins, Sally, "Revealing Judy Chicago's "The Dinner Party": An Analysis of the Curatorial Context" (2016). Graduate Theses, Dissertations, and Problem Reports. 5479.

https://researchrepository.wvu.edu/etd/5479

This Thesis is protected by copyright and/or related rights. It has been brought to you by the The Research Repository @ WVU with permission from the rights-holder(s). You are free to use this Thesis in any way that is permitted by the copyright and related rights legislation that applies to your use. For other uses you must obtain permission from the rights-holder(s) directly, unless additional rights are indicated by a Creative Commons license in the record and/ or on the work itself. This Thesis has been accepted for inclusion in WVU Graduate Theses, Dissertations, and Problem Reports collection by an authorized administrator of The Research Repository @ WVU. For more information, please contact researchrepository@mail.wvu.edu. 
Revealing Judy Chicago's The Dinner Party: An Analysis of the Curatorial Context

Sally Deskins

Thesis submitted

to the College of Creative Arts

at West Virginia University

in partial fulfillment of the requirements for the degree of

Master of Arts in

Art History

Kristina Olson, M.A., Chair

Rhonda Reymond, Ph.D.

John Bernard Schultz, Ph.D.

Melissa Bingmann, Ph.D.

School of Art and Design

Morgantown, West Virginia, 2016

Keywords: Judy Chicago, The Dinner Party, curating, art exhibition, feminist curating,

feminist art, museum studies, contemporary art, women in art

OCopyright 2016 Sally Deskins 


\section{Abstract \\ Revealing Judy Chicago's The Dinner Party: An Analysis of the Curatorial Context}

Sally Deskins

Research on Judy Chicago's The Dinner Party, (1974-79; completed with the assistance of more than 400 volunteers), is abundant and generally focuses on the monumental table of thirty-nine place settings acknowledging the contribution of women throughout Western history. Scholars have examined, praised and criticized the installation from various feminist and formal aesthetic perspectives. By contrast, this thesis considers what has essentially been overlooked until now, Judy Chicago's curatorial framework for the entire The Dinner Party exhibition experience. Using my own interviews with the artist, team members, and contemporary curators, as well as consulting the artist's installation manuals from Harvard University Archives, and examining the reception of the curation, I highlight the essential curatorial features that made The Dinner Party such an international phenomenon. The artist's curatorial elements were research-oriented, inclusive and activist-leaning with interactive, multi-media structures to achieve her feminist message. Considering The Dinner Party's current installation at the Elizabeth A. Sackler Center for Feminist Art, my thesis argues that Chicago's successful yet overlooked methods offer the most proactive, critical and approachable curatorial presentation. The current installation that has been stripped of these curatorial elements, while perhaps institutionally practical, compromises much of the message and feminist intent. This study contributes to the field by focusing on this notable exhibition, providing discourse into Chicago's curating and offering considerations for contemporary curating practice, with the goal of contributing to the growing area of curatorial research focused on feminist artists and curatorial projects. 


\section{Acknowledgements}

Without the encouragement of Professor Kristina Olson, I may not have given The Dinner Party the rightful initial observation it deserves to discover its true broad appeal that led me to this examination. Without The Dinner Party itself and all of those people involved in the creating of this vastly important installation, primarily the conceiver, Judy Chicago, and team leaders Diane Gelon, Susan Hill and Donald Woodman, I would not have been fortunate to experience and study the piece. I thank them as well as Ms. Chicago's forthright curatorial assistant, Katie Schroeder, for their continuous encouragement and quick response to all of my contemporary queries, for all of their interviews, emails and generosity with fact-checking, memories and insight. I also thank Professor Olson and Dr. Rhonda Reymond for their ongoing and prompt guidance when I hit difficult blocks. I thank the generous and quick librarians at Schlesinger Library at Harvard University for scanning the hundreds of pages of Chicago's original installation manuals. I thank the other interviewees and email respondents; founding Sackler Center curator Maura Reilly, current curator Catherine Morris, Sexual Politics curator Amelia Jones, and former Hite Art Institute associate John Begley, as well as the enthusiastic scholars on Facebook, for their contributions and willingness to allow me to use their comments, and their help with finding contacts. I was honored and fortunate to create such a tremendous, rich and significant appendix of interviews! Thanks as well to Dr. J. Bernard Schultz and Dr. Melissa Bingmann for your spirited insight, especially Dr. Schultz for helping me with my presentation skills. Thanks to Linda Rosefsky for editing my big original thesis and Dr. Jennifer Orlikoff and the WVU Center for Women's and Gender Studies for inviting me to present this early on to get feedback. Thanks Dr. Janet Snyder for your encouragement of travel and the University Margaret Tavenner Rajam Art History Endowment for supporting my travel to New York to see The Dinner Party at the Elizabeth A. Sackler Center for Feminist Art, in February and November of 2015; as well as funding my other travels that contributed to this scholarship including attending the Feminist Art History Conference in Washington D.C. in 2014, and participating in the Southeast College Art Conference in 2015. Thanks to WVU for awarding me the Teaching Assistant position so that I could do this important work.

Thanks John for your enthusiasm for the project, encouragement and support, my kids for cheerleading and patience, my parents for modeling creative diversity and hard work, and my inlaws for their support and babysitting. Thanks Wanda Ewing for your inspiration to go back to school and for showing me how rad feminist art is. I hope this is just the beginning. 
Table of Contents

Table of Contents $\quad$ iv

List of Figures $\quad$ vi

Introduction 1

Background 3

Why Focus on the Curating of The Dinner Party? 5

Literature Review and Research Sources 9

Chapter One: Judy Chicago's Context Evolution to The Dinner Party 13

From Minimalism to Feminist Studio Workshop 13

Test Exhibition: Ruth Schaffner Gallery, 1977

Chapter Two: Creating The Dinner Party Curatorial Structure 23

Other Installation Elements to The Dinner Party 26

Chicago's Original Permanent Placement Design 37

Chapter Three: The Dinner Party Exhibitions \& Curatorial Reception 39

Sexual Politics: The Dinner Party in a Group Feminist Exhibition, $1996 \quad 56$

Elizabeth A. Sackler, The Sackler Center Obtains The Dinner Party 59

Chapter Four: The Dinner Party and Feminist Curating Considerations 64

Collaboration and Networking $\quad 65$

Work Selection $\quad 67$

Assembly $\quad 70$

Exhibition Text $\quad 74$

Accessibility and Interactivity $\quad 77$

Acknowledging Limitations $\quad 79$

Challenges to Feminist Curating $\quad 81$

Chapter Five: Looking at The Dinner Party Now: Curatorial Implications 86

Susan Rodriguez' Architectural Design for The Dinner Party's Permanent Home 87

November 2015 Visit, Curatorial Observations 99

Recent The Dinner Party Reception: The Experience and Observations 107 
List of Figures

Figure Page

1. The Dinner Party (table) (1974-79, Judy Chicago and volunteers) 117

2. Rainbow Pickett (1966, Judy Chicago) 117

3. 3.5.5 Acrylic Shapes (1967, Judy Chicago) 118

4. Pasadena Lifesavers Red \#5 (1970, Judy Chicago) 118

5. Queen Victoria (1972, Judy Chicago) 119

6. Ruth Schaffner Gallery, Los Angeles (1977) 119

7. Ruth Schaffner Gallery, gallery entrance to Judy Chicago solo exhibition (1977) 120

8. Ruth Schaffner Gallery, installation view (1977, Judy Chicago) 120

9. Ruth Schaffner Gallery, installation view (1977, Judy Chicago) 121

10. The Dinner Party (table), photograph by Donald Woodman 121

11. Diagram from The Dinner Party exhibition installation manual/instructions (1978-80) 122

12. The Dinner Party, Documentary Panels, installation view, Brooklyn Museum (1980) 123

13. The Dinner Party, Entryway Banners, installation view Armand Hammer Museum (1996) 123

14. The Dinner Party, Entryway Banners, installation view, Brooklyn Museum (1980) 124

15. The Dinner Party, The Heritage Panels, installation view Armand Hammer Museum (1996) 124

16. The Dinner Party, The Acknowledgement Panels 125

17. International Honor Quilt, installation view, Melbourne, Australia (1988) 125

18. The Dinner Party, exhibition pamphlet, Boston (1980) 126

19. The Dinner Party, exhibition flier, Boston (1980) 126

20. The Dinner Party, Permanent Housing (1979, Judy Chicago) 127

21. Axiomatic drawing of the Elizabeth A. Sackler Center for Feminist Art (C) Polshek Partnership Architects, 2007) 128

22. The Dinner Party (table), installation view Elizabeth A. Sackler Center for Feminist Art (2007)

23. The Dinner Party, The Heritage Panels, installation view

Elizabeth A. Sackler Center for Feminist Art (2007)

24. The Dinner Party, exhibition wall text at Elizabeth A. Sackler Center for Feminist Art photographed by the author (February 22, 2015) 130

25. The Dinner Party, instructional gallery sign at Elizabeth A. Sackler Center for Feminist Art photographed by the author (November 6, 2015) 130

26. The Dinner Party, The Heritage Panels, installation view, Elizabeth A. Sackler Center for Feminist Art, photographed by the author (November 6, 2015)

27. The Dinner Party wall text, Elizabeth A. Sackler Center for Feminist Art, Brooklyn Museum, New York, photograph by the (November 6, 2015) 
Introduction

“...the increased visibility of women artists should not necessarily be viewed as a feminist victory; the tension between the terms 'woman' and 'artist' persists and is troublingly exacerbated by curators and critics alike....recognition has been largely tokenistic and/or has come with suspect and damaging generalisations and misrepresentations." -Alexandra Kokoli, Feminism Reframed ${ }^{1}$

“...Women's art must be seen in the larger context of both women's history and women's struggle for self-expression. Without that framework, each woman's achievement threatens to be seen as an exception, rather than another link in the long chain of accomplishments that will one day be recognized..." Judy Chicago, The Dinner Party: From Creation to Preservation ${ }^{2}$

Judy Chicago's monumental installation, The Dinner Party (1974-79), has been

examined and criticized from many perspectives predominantly focused on the table artwork including an installation of thirty-nine place-settings dedicated to women throughout Western history. ${ }^{3}$ After the original record-and-boundary-breaking international tour in the $1980 \mathrm{~s}$, The Dinner Party finally gained permanent placement in 2007 at the Elizabeth A. Sackler Center for Feminist Art. Currently, however, the installation is divorced from its original exhibition structure designed by Chicago and her team. As such, the experience of viewing The Dinner Party in its intended environment has been lost and scholarship has been narrowly focused on the sculptural table. In considering The Dinner Party from a curatorial perspective by examining the original installation plans, early curatorial reception and new and original interviews with Chicago and her team, I bring a fuller, more nuanced grasp of the nature of Chicago's truly broad achievement via The Dinner Party, and how her now overlooked curatorial strategies made The Dinner Party the broadly accessible phenomenon that it was.

\footnotetext{
${ }^{1}$ Alexandra Kokoli, Feminism Reframed, (Newcastle: Cambridge Scholars, 2008), 14-15.

2 Judy Chicago, Dinner Party: From Creation to Preservation (London/New York: Merrell Publishers, 2007), 288.

${ }^{3}$ See Jane Gerhard's The Dinner Party (University of Georgia Press, 2013); Amelia Jones' Sexual Politics: Judy Chicago's Dinner Party in Feminist Art History (University of California Press, 1996) or Judy Chicago's The Dinner Party: From Creation to Preservation (Merrell Publishers, 2006) for in-depth examinations of the controversy around these aspects of The Dinner Party.
} 
Moreover, this reexamination proves timely, as recent curatorial scholarship has gained footing within feminist discourse as a method to challenge continuing underrepresentation of women artists, though within general contemporary curatorial discourse feminist curating remains at the margins. No one has examined this essential aspect of The Dinner Party. This study proves a strong correlation with regards to Chicago's feminist ideas and contemporary curatorial methods, and serves as a major contribution to these fields.

Research along these lines has escaped close analysis as it may not fit with traditional models of art historiography. A main achievement of The Dinner Party emerges through examining its curatorial structure to convey threads of history perhaps previously ignored. In this discussion, curating is understood as the tasks of researching and selecting, organizing and designing an exhibition, including educational resources, events and wall text, as multi-layered and structured by invitations to the viewer for engagement and collaborative thinking. I examine the curatorial elements that have perhaps been perceived as "filler" and thus treated lightly or passed over without remark. The specific curatorial elements of The Dinner Party that I consider here are: collaboration and networking; work selection; positioning and assembly; wall text; accessibility and interactivity; and institutional acknowledgement. Each of these points are discussed in this study for their specific illuminations of curating within The Dinner Party as well as in the broader concept of feminist curating. While such curatorial elements are evident elsewhere in Chicago's work and beyond, ${ }^{4}$ the aforementioned aspects are so uniquely

\footnotetext{
${ }^{4}$ Judy Chicago as well as other artists during this innovative time-period such as Adrian Piper and Mary Kelly, used, and continue to use, curatorial tactics to explore context and audience experience in their work. This thesis, while concentrating on Chicago's work, acknowledges the many other artists exploring such methods, like Chicago, before curators recognized them as such, and that thus, there is ample further research and discussion necessary.
} 
concentrated within The Dinner Party, and so cannot be separated from the power of the event at

its center - the symbol of women's' contribution to Western society throughout history. ${ }^{5}$

\section{Background}

Artist Judy Chicago (American, b. 1939) ${ }^{6}$ is well known in the art world for The Dinner

Party (fig. 1). The collaboratively produced installation includes thirty-nine porcelain place-

settings on a triangular table (each side 48 feet long) set on 2,034 floor of tiles with 999 names of

women in history and legend, Heritage Panels displaying information on all 1,038 women, and

six welcoming Entryway Banners. ${ }^{7}$ Originally, the installation included acknowledgement panels

and Documentary Panels as well as the International Honor Quilt. The work has received mixed

reactions since its inception. Deemed by art historian Jane Gerhard as "the most monumental

work of the feminist art movement of the 1970s," ${ }^{8}$ it has been criticized by feminist theorists, art

historians, critics and politicians, ${ }^{9}$ while also celebrated by the public and viewers of the work. ${ }^{10}$

Art historians have examined The Dinner Party thoroughly for its content, aesthetics and

\footnotetext{
${ }^{5}$ The context of Chicago's own feminism can be (and has been laboriously) examined with regards to issues such as essentialism, which is a completely different discussion from the purview of this paper. It can be argued that Chicago's work defines "woman" broadly, instead of in the narrow fields, as she repeatedly calls for a fluidity in defining gender. Moreover, the "woman" who Chicago speaks of in her writings can perhaps be applied contemporarily to other populations who are also under and misrepresented; minority populations and perhaps artists of varied sexual orientations. Further discussion on this would be beneficial and significant.

6 Judy Chicago, "Judy Chicago to Judy Cohen," in The Dinner Party: Restoring Women to History, ed. Judy Chicago, (China: The Monacelli Press, 2014), 248.

7 “The Dinner Party,” Elizabeth A. Sackler for Feminist Art, accessed April 22, 2015, http://www.brooklynmuseum.org/eascfa/dinner_party/heritage_panels/.

${ }^{8}$ Jane Gerhard, "From Controversy to Canonization: The Dinner Party's Journey to Brooklyn," in The Dinner Party: Restoring Women to History, ed. Judy Chicago (China: The Monacelli Press, 2014), 265.

9 Hilton Kramer was one of the first to call The Dinner Party 'kitsch', and Kay Larson, was of the first to call it vulgar. The essentialism debate ensued with British feminist Griselda Pollock, Rozsika Parker and Lisa Tickner, who had already identified Chicago's earlier work as problematic due to vaginal imagery that is an essentialist or biologically determined identity for woman. Hilton Kramer, "Judy Chicago's Dinner Party Comes to Brooklyn Museum," New York Times, 17 October 1980, Kay Larson, "Under the Table: Duplicity, Alienation," Village Voice, 11 June 1979, Rozsika Parker and Griselda Pollock, "Painted Ladies," in Old Mistresses: Women, Art, and Ideology (New York: Pantheon Books, 1981), 127-33.

${ }^{10}$ Gerhard, "From Controversy to Canonization: The Dinner Party's Journey to Brooklyn," 265.
} 
feminist legacy. This paper examines this piece with a curatorial lens and considers it was originally installed throughout its tour in the 1980s, briefly at its 1996 inclusion in the Sexual Politics exhibit, and in comparison with its recent installations at the Sackler Center. New and original interviews about the curatorial decisions with the artist herself and team members Susan Hill, Diane Gelon and Donald Woodman informed this study, as well as interviews with art historians and curators Catherine Morris, Alexandra Kokoli, Maura Reilly and Hilary Robinson, among others.

Chicago's strategy broke down the dominant mainstream structure of the singular-genius, white-walled display, lacking of explanatory text, to focus on providing a different, new context $^{11}$ and curatorial framework that could not only be beneficial to artists who are women, but also artists who are under and misrepresented. I examine in depth the formulating of the inclusive and accessible curatorial structure of The Dinner Party, an experience created for observers to ponder the artwork in the design of structures arranged around it. The littlediscussed but integral aspect of The Dinner Party is the intense planning that went into these curatorial elements. Chicago asserts in Through the Flower ${ }^{12}$ that her conception of the installation was to honor women who had been erased or overlooked throughout Western history. The idea began while working on Womanhouse (with Miriam Schapiro, 1971) and progressed through several exhibition experiments in the 1970s to the formal exhibition design for its 1979 debut at San Francisco Museum of Modern Art. I examine the curatorial implications of the feminist artwork by looking at Chicago’s original curatorial plans. In addition, I also briefly examine the exhibition development over the international tour (1980-1988), and Amelia Jones'

\footnotetext{
11 Throughout this paper, "context" will be used to describe the environment in which the art is displayed; whether physical, informational, written, or visual.

12 Judy Chicago, Through the Flower: An Autobiography of a Feminist Artist (USA: Penguin Books, 1997).
} 
curatorial framework in Sexual Politics: Judy Chicago's Dinner Party in Feminist Art History, the group exhibition of feminist artwork held in $1996 .{ }^{13}$ Elizabeth A. Sackler's purchase and 2002 installation (with coordination by Chicago's installation team) ${ }^{14}$ of the piece before the Sackler Center opened is summarized. Finally, after evaluating contemporary research into feminist and contemporary curating, I relate the research to The Dinner Party's permanent installation plan in 2007 as designed by Susan Rodriguez with aid from Sackler founding curator Maura Reilly (without consultation from Chicago's team ${ }^{15}$ ), to its altered structure in November 2015 (also without Chicago team consultation). ${ }^{16}$ The transitions from February to November of 2015 include altering of placement of both The Heritage Panels and Entryway Banners. The changes disrupt Chicago's original curatorial intentions and moreover alter the perception of the work from a cohesive organization, to a confusing state — which, ironically, rehashes the intent of Chicago's feminist and curatorial work. Lastly, I consider reception of its recent installations and provide considerations for continuing to examine The Dinner Party's installation and the significance of such projects within contemporary curating scholarship.

\section{Why Focus on the Curating of The Dinner Party?}

Even as there has been a recent surge of feminist exhibitions ${ }^{17}$ in mainstream American museums,${ }^{18}$ feminism tends to be misunderstood. It is essential that exhibitions go beyond

\footnotetext{
${ }^{13}$ Sexual Politics: Judy Chicago's Dinner Party in Feminist Art History, was on view at University of California Los Angeles Armand Hammer Museum of Art and Cultural Center, April 24-August 18, 1996.

${ }^{14}$ Susan Hill, interview by the author via email, November 9, 2015.

${ }^{15}$ Donald Woodman, interview by the author via telephone, November 8, 2015.

${ }^{16}$ I viewed The Dinner Party at the Elizabeth A. Sackler Center in February and November, 2015.

${ }^{17}$ Such as WACK! Art and the Feminist Revolution at The Museum of Contemporary Art, Los Angeles, 2007 and Global Feminisms at Sackler Center for Feminist Art in the Brooklyn Museum, 2007, to name a few.

${ }^{18}$ I am defining mainstream museums as the dominant, visible, large art institutions that general populations typically know.
} 
consciousness-raising ${ }^{19}$ for women in art by simply providing wall space; they must move toward the imperative of addressing critical feminist curatorial practice. This paper contributes to this scholarship by examining the significant feminist artwork, The Dinner Party, and the conceiver, Judy Chicago's early development of curatorial thought, which provides implications for her exhibition design of The Dinner Party.

Maura Reilly, the founding curator of The Elizabeth A. Sackler Center for Feminist Art who installed The Dinner Party as well as the concurrent exhibition, Global Feminisms, has argued for the need for a deeper examination of The Dinner Party and its vast impact. ${ }^{20}$ Scholar Hilary Robinson, emphasizes the significance of understanding the context around artworks including the production process, exhibition spaces, and education systems, in truly realizing the wider implications of a piece. ${ }^{21}$ Thus, perhaps, research on curating and exhibition context such as this can also translate into greater acknowledgement in the art world, one of Chicago's goals with The Dinner Party itself.

Research into contemporary curatorial scholarship and history reveals a large gap related to recognizing the work of feminist artists and organizers. ${ }^{22}$ Still, though pointing to statistical disparity may encourage museums to improve gender equality, it does not present the wider and more deeply imbedded issue. ${ }^{23}$ In fact, as recent statistics suggest, second wave feminist art history research has not resulted in statistical equality in exhibitions, art sales or representation in

\footnotetext{
${ }^{19}$ I use the term "consciousness raising" to mean exhibitions with an intent to bring attention to underrepresented populations in the arts.

${ }^{20}$ Maura Reilly, interview by Lynn Hershman, “!Women Art Revolution: Interview with Maura Reilly," Stanford University Libraries Collection, Feb. 7, 2007.

${ }^{21}$ Hilary Robinson, "Reframing Women," Circa, 72 (1995): 22.

22 See Maura Reilly, "Taking Measure of Sexism: Facts, Figures and Fixes in the Art Industry," ArtNews, 26 May 15, accessed November 12, 2015, http://www.artnews.com/2015/05/26/taking-the-measure-of-sexism-facts-figures-and-fixes/.

${ }^{23}$ Siona Wilson, “Destinations of Feminist Art: Past, Present and Future,” Women's Studies Quarterly, 36 (2008): 325.
} 
art collections. ${ }^{24}$ Even when women artists gain exposure through exhibitions, the work is often positioned in relation to male artists. ${ }^{25}$ Thus, contemporary feminist art scholars have posed a potential to focus more on women's or feminist curating in order to make gains. ${ }^{26}$ Scholars have noted a lack of research in terms of determining the impact of the feminist art movement on the functions within curatorial practice. ${ }^{27}$ By understanding how exhibits are presented and interpreted perhaps we can learn how to approach curating in such a way that the artists are understood and recognized rather than marginalized, leading to perhaps appropriate presence in mainstream art museums, collections and sales. This curatorial examination of The Dinner Party may also have wide implications for all exhibitions, beyond those featuring women, in terms of informing curation for an enriching experience for audiences.

Exhibitions play a major role historically as people visit museums and learn in shaping perceptions of culture, the past and gender; thus curatorial decisions such as inclusion, presentation and exhibition text that might seem like minor impacts beyond gallery walls. Judy Chicago realized this early in her career, and through her projects explored creating a context for her work and art by other women in order to be understood by the broadest audience possible and to change the well-documented cycle of erasure of women in history (as well as other marginalized populations). Not only did Chicago and her 400-plus volunteers go to great lengths to find and record information on the 1,038 women throughout history to make this multi-media installation, but she, along with her collaborative team designed an installation plan in order for this work to reach the broadest audience possible. This includes, for example, the Entryway Banners, The Dinner Party artwork, lighting and design, the written research presented on the

\footnotetext{
${ }^{24}$ Susan Bee, "Frames," The Brooklyn Rail, 4 September 2014, accessed September 9, 2014, http://www.brooklynrail.org/2014/09/criticspage/frames-bee.

25 Bee, "Frames," 2.

${ }^{26}$ Angela Dimitrakaki and Lara Perry, Politics in a Glass Case (Liverpool: Liverpool University Press, 2013 ), 17.

${ }^{27}$ Kokoli, Feminism Reframed, 1-2.
} 
Heritage Panels and documentary information of the process of making the piece, community quilt projects and concurrent community events. From the 1979-1988 tour, to the inclusion in the 1996 Sexual Politics exhibition to the installations at the Elizabeth A. Sackler Center for Feminist Art, inside the Brooklyn Museum, the curatorial framework that Chicago developed has not been fully acknowledged. Arguably, curation played a large role in The Dinner Party's overall impact inside and outside the art world (for curating and for reaching broad audiences with the feminist message), starting with her primary goal of bringing attention to previously overlooked women in history. ${ }^{28}$ The relevance of curating has grown as evidenced with recent art history and feminist scholarship, for example, the Sydney College of the Arts presented the conference, "Curating Feminism" in $2014,{ }^{29}$ and in 2015, Amelia Jones referred to Chicago's practice as "what we would now call curatorial" during the opening weekend of Why Not Judy Chicago?. ${ }^{30}$ Maura Reilly was one of the founders of Feminist Curators United in 2014, a network of "curators and scholars dedicated to developing feminist curatorial practice through the sharing of ideas and resources with programs encompassing public events, publications and mentorships." 31 This developing discourse on feminist curating indicates the growing significance of such scholarship.

\footnotetext{
${ }^{28}$ Other artists during the 1970s also used curatorial techniques in their work, such as Adrian Piper and Mary Kelly which constitute subjects and areas for future research.

${ }^{29}$ At the conference, feminist scholar and founding curator of the Sackler Center, Maura Reilly, presented "Activist Curating," in which she explored the significance of curating with activist intent. "Sydney College of the Arts: Curating Feminism Conference, 2014" The University of Sydney, accessed November 12, 2015, http://sydney.edu.au/sca/research/contemporary-artfeminism/curating-feminism-conference.shtml. This was probably a precursor to her forthcoming book, Curatorial Activism: Towards an Ethics of Curating. "Maura Reilly: Books," Maura Reilly, accessed November 12, 2015, http://maurareilly.com/books.html.

30 Jones' recent presentation and as-yet unpublished essay, “Judy Chicago's 'Will to Power' and the Invention of Feminist Art as a Curatorial Practice in 1970s Los Angeles," reveals similar mindedness and the timeliness of my project with regards to curating. In it, Jones keenly described her consideration of Chicago's work as "less about Judy's 'curatorial ideas' and a rereading of her overall practice as what we would now call 'curatorial.'” However, Jones' essay looks at Chicago's entire career-long work in a broader way, concerning her personal initiative. Amelia Jones, 'Judy Chicago's 'Will to Power' and the Invention of Feminist Art as a Curatorial Practice in 1970s Los Angeles" (presented at Feminist Perspectives in Art Productions and Theories of Art public seminar series, organized by Xabier Arakistain and Lourdes Méndez, Centro Cultural Alhóndiga and Azkuna Zentroa, Bilbao, Spain, October, 2015). Amelia Jones, interview via email by author, November 15, 2015.

31 "Feminist Curators United," Feminist Curators United, accessed November 12, 2015, http://www.feministcurators.org/.
} 


\section{Literature Review and Research Sources}

Judy Chicago's two autobiographies, as well as books she has written concerning The Dinner Party reveal her evolving concern for curatorial context. Gail Levin's biography of Chicago provides clues to some of the artist's test exhibitions, as well as many of the community events around the original The Dinner Party tour. Jane Gerhard's significant overview of placing The Dinner Party within feminist art history and Amelia Jones' Sexual Politics book of essays critically examining The Dinner Party within the larger feminist art context helped in understanding the overall content and reception of the piece.

I examined The Dinner Party original diagrams and specific installation plans, as well as the manual further detailed by Donald Woodman in 1987, scanned from the boxes of Judy Chicago papers at Schlesinger Library at Harvard Library. I conducted personal email interviews with Judy Chicago, Susan Hill and Diane Gelon for fact-checking, personal inquiries and resource queries into specific time-lines and installation details. My telephone interviews with Donald Woodman and Diane Gelon provided extensive insight regarding The Dinner Party's installation and Judy Chicago's conception for the viewer experience which greatly aid in allowing one to understand the original curatorial structure. My personal observations and photographs during visits to the Sackler Center in February and November of 2015 were used in my analysis of its recent installations. Susan Rodriguez' design book outlining her intent and structure of The Dinner Party in the Elizabeth A. Sackler Center gives a clear idea of her architectural concept, and an interview with current Sackler Center curator Catherine Morris reveals her perception of The Dinner Party's curatorial place in the institution.

In reviewing recent literature on contemporary and feminist curating, this thesis relies on the scholarship of a number of curators and art historians. I glean from their observations of 
feminist exhibitions and feminist curatorial thought, and the ties to the contemporary curatorial considerations earlier in Chicago's planning for The Dinner Party. I utilize a combination of theories to reflect on The Dinner Party's framework and how such frameworks impact the interpretation of art and artists including art historian Hilary Robinson's examination of the curating of recent feminist surveys ${ }^{32}$ selection, informational text, and assembly; ${ }^{33}$ Alexandra Kokoli's collection of academic essays, examining contemporary curating with a feminist lens; ${ }^{34}$ Angela Dimitrakaki and Lara Perry's collection of essays ${ }^{35}$ analyzing specific curatorial aspects. Katy Deepwell's study, “Feminist Curatorial Strategies and Practices Since the 1970's,” provides a context of feminism's recent curatorial history ${ }^{36}$ from which to understand The Dinner Party. Other essays such as Helen Molesworth's "How to Install Art as a Feminist"37 and Julie Kearney’s “The Plural Gaze: Reflections on a Contemporary Feminist Curatorial Practice,"38 provide specific methodological insight which I referred to in regards to The Dinner Party. Devon P. Larsen's 2006 thesis, Rethinking the Monumental: The Museum as Feminist Space in the Sexual Politics Exhibition, $1996,{ }^{39}$ provides a view of that exhibition. A recent article, "Feminist Thought and Curating: On Method," serves as a more theoretical and pedagogical consideration regarding collaboration, archives, networking and spatial arrangement, as it looks

\footnotetext{
${ }^{32}$ Hilary Robinson, "Feminism meets the Big Exhibition: Museum Survey Shows since 2005,” Anglo Saxonica, Ser. III, N. 6 (2013).

${ }^{33}$ Hilary Robinson, "Within the Pale in from: Beyond the Pale: the construction of femininity in the curating of an exhibition season at the Irish Museum of Modern Art, Dublin," Journal of Gender Studies, Vol. 6, No. 3 (1997).

${ }^{34}$ Alexandra Kokoli, Feminism Reframed (Newcastle, UK: Cambridge Scholars Publishing, 2008).

${ }^{35}$ Angela Dimitrakaki and Lara Perry, Politics in a Glass Case: Feminism, Exhibition Cultures and Curatorial Transgressions (Liverpool, UK: Liverpool University Press, 2013).

${ }^{36}$ Katy Deepwell, "Feminist Curatorial Strategies and Practices Since the 1970's," New Museum Theory and Practice: An Introduction, ed. Janet Marstine, (USA: John Wiley \& Sons, 2005).

${ }^{37}$ Helen Molesworth, "How to Install Art as Feminist," in Modern Women: Women Artists at the Museum of Modern Art, ed by Cornelia Butler, Griselda Pollock and Alexandra Schwartz. (New York: The Museum of Modern Art, 2010): 500-01.

38 Julie Kearney, "The Plural Gaze: Reflections on a Contemporary Feminist Curatorial Practice," Hecate, (1997): 152-157.

${ }^{39}$ Devon P. Larsen, "Rethinking the Monumental: The Museum as Feminist Space in the Sexual Politics Exhibition, 1996,"

Scholar Commons, University of South Florida, (April 4, 2006).
} 
at The International Dinner Party in Feminist Curatorial Thought. ${ }^{40}$ These feminist art and

curatorial scholars and practitioners are significant for recording and discussing feminist

curating, and offering feminist approaches to curating as noted in Chapter Four.

Terry Smith's Thinking Contemporary Curating, ${ }^{41}$ and Paul O'Neill's The Culture of

Curating and the Curating of Culture $(s)^{42}$ provided a look into contemporary approaches to

curating and Jean-Paul Martinon and Irit Rogoff's The Curatorial ${ }^{43}$ examines contemporary

curating through many different lenses by curators and artists. This scholarship most notably

confirms the earlier suggestion that general contemporary curatorial scholarship glosses over

feminists working with curatorial methods and the potential impact thereof. Not only are

\footnotetext{
${ }^{40}$ Elke Krasney, "Feminist Thought and Curating: On Method," Curating Degree Zero Archive 26, (September 2015): 51-69. This article differs in scope as I look at Chicago's specific plans with an intention of isolating curatorial methods.

${ }^{41}$ Smith's writings focus on the curator's perspective and the profession; whereas Chicago and other feminist scholars seek to use curating to make changes outside the space. A commonality is a focus on a contemporary, complex space. Smith recognizes the often changing nature of infrastructure within operations of institutionalization. Smith discusses various contemporary curatorial accomplishments and briefly a history of curating, calling the 1960s and 1970s "the frontier days of the curator as artist" though does not point to feminism during this period. Smith's mention of the Artists Meeting for Cultural Change which included the work of five women artists' collectives and the Black Emergency Cultural Coalition picketing the museum with a total absence of art by women, blacks and other minorities in the collections, was the only recognition of any feminist artist or artist who is a woman curating or self-curating during these years, until Andrea Fraser in 1989. Smith does note the significance of rethinking recent histories to enrich historical records of the sometimes overlooked portions of collections, pointing to Hilary Robinson's survey regarding a set of contemporary feminist or all-women's exhibitions. Lucy Lippard is mentioned as a critic. Smith's marginal note about feminism and curating: "Like all other critical perspectives, feminism thrives on institutional critique and seeks structural transformation, not simply a seat at someone else's table. Forty years of struggle, however, has produced significant gains and some outstanding practitioners. The lineaments of a history of feminist curating are becoming visible. The terms of the current struggle are, however, quite different from what they were in the 1970s. Just how these terms might be formulated is a pressing challenge.” Smith, 151. Terry Smith, Thinking Contemporary Curating (New York: Independent Curators International, 2012).

${ }^{42}$ In The Culture of Curating and the Curating of Culture(s), many of Smith's ideas are addressed; though overlooked again was feminism's role in the development of curating. O'Neill did use Lucy Lippard's landmark 1969 exhibition 557,087 at Seattle Art Museum which Lippard installed with instructions of absent artists. O'Neill recognized the emerging cooperative, processoriented, discussion-based view of exhibitions as forming in the 1990s. Paul O'Neill, The Culture of Curating and the Curating of Culture(s) (Cambridge, Massachusetts: Massachusetts Institute of Technology, 2012). Though considering the curating of The Dinner Party, and that of other feminists as well, all of these methods were present before the 1990s.

${ }^{43}$ The authors of The Curatorial point out the duality in the contemporary practice of curating - provocateurs and experts - and views curating as "an event of knowledge." This parallels with Chicago's building of a new structure, a new context with which to view and understand art. Contemporary feminist curating scholars such as Dimitrakaki and Perry as well acknowledge this, but, here there is a lack of regard for feminism, which is one of the ongoing challenges with studying and examining feminist work in history, being overlooked by the mainstream. Twenty-eight articles in this volume explore various approaches to curating without giving a specific history or framework. Profound, illuminating and important texts with diverse voices throughout, though the implications to the earlier contextual work of Chicago and other feminist organizers during the 1960s to present is absent. It is clear that Chicago was onto something, as her as yet overlooked curatorial ideas are reflected in these intelligent and contemporarily understood, and researched writings. We can reflect on each of these contemporary themes when considering The Dinner Party today. Jean-Paul Martinon and Irit Rogoff, The Curatorial: A Philosophy of Curating, (New York: Bloomsbury Academic, 2013).
} 
women's contributions mostly skipped in the histories of curating but curatorial methods which were utilized by feminists during the 1960s and 1970s as Chicago, are not recognized. Several aspects are overlapping, and contemporary feminist exhibitions are noted by Smith, but feminism seems to still be at the margins of mainstream curatorial discourse ${ }^{44}$, when in fact, as I suggest, feminists such as Judy Chicago, were innovating these very concepts before they were labeled as such. $^{45}$

In terms of my approach, I draw from Chicago's emphasis on reaching a broad audience with the exhibition experience inside and outside the gallery, to the critical, relational curatorial outlook as expressed by Molesworth, Reilly, Kokoli and others. Thus, my contributions reveal a fresh examination of The Dinner Party in light of contemporary and feminist art scholarship with regards to her specific curatorial structuring of the piece to reveal methods that have implications within history, scholarship and curatorial practice.

\footnotetext{
${ }^{44}$ I am defining mainstream discourse as the dominant, most widely used publications and textbooks that scholars generally refer to as simply curatorial or art historical discourse.

${ }^{45}$ Other recent books that do not regard curating explicitly but which provide curatorial discussions are Barbara Pollock and Joyce Zeman's Museums After Modernism: Strategies of Engagement emphasizing working through institutions instead of outside them, and ways of organizing archives, exhibitions and engagement programs to ignite a new method of museology mindful of "gender, difference, otherness, trauma, history, delivery, learning, exile, encounter, transformation, and archive." Barbara Pollock and Joyze Zemans, Museums After Modernism: Strategies of Engagement (UK, USA and Australia: Blackwell Publishers, 2007), xxi. Too, Hans Ulrich Obrist's collection of interviews, A Brief History of Curating, recognizes the fluidity of the contemporary curator's roles and professions. Hans Ulrich Obrist, A Brief History of Curating (Zurich, JRP: 2008).
} 


\section{Chapter One: Context Evolution to The Dinner Party}

"Although I do not see myself as a curator, in the 1970's it became clear to me that there was no context for female-centered art, at least not yet. As a result, I began to experiment with installation of my

exhibitions, writing on the walls, controlling the color and lighting. It wasn't something I wanted to do but rather, something that I felt compelled to do in order to help viewers understand my intentions as an artist." - Judy Chicago, personal email, April 22, 2015

Before Judy Chicago conceived The Dinner Party, she realized the importance of context, or the environment in which art is experienced or understood. In this section I examine Chicago's early artwork and projects in relation to context, how they impacted the curatorial framework of The Dinner Party and their implications beyond her work regarding feminism in general. The Dinner Party can be viewed as a culmination of her evolution from minimalist artist to feminist art educator, artist and curator.

\section{Judy Chicago Before The Dinner Party: From Minimalism to Feminist Studio Workshop}

It was in college at the University of California Los Angeles in the 1950s, when she was active in civil rights activities, that Chicago discovered there was a "serious gap between the way I saw myself and the way I was seen by the world." 46 As Chicago realized the "second-class status" of women in academia, she began to see how the historical and cultural context grew out of academia and into the art world, and vice versa. ${ }^{47}$

Wanting to fit in and succeed, Chicago worked within the style of minimalism in her early years (early-to-mid 1960s), internalizing the idea that female identity or femininity were not compatible with fine art. ${ }^{48}$ She shared a studio with her second husband, Lloyd, for a short

\footnotetext{
${ }^{46}$ Chicago, Through the Flower, 28-29.

${ }^{47}$ Ibid, 31-32.

${ }^{48}$ Ibid, 11.
} 
time (1965-66). ${ }^{49}$ She eventually got her own studio after realizing that viewers would either ignore her and her work, or see her work in relation to his,${ }^{50}$ another recognition of the impact of the environment on interpreting art. What came from this period, were large minimalistic pieces that encouraged viewer interaction, for example Rainbow Pickett (fig. 2) ${ }^{51}$ and Multicolor Rearrangable Game Board (1965-66). ${ }^{52}$ Chicago explained, "When I made the small, rearrangable pieces and the large sculptures through which one walked, I was trying to give voice to my own feelings of 'moving through' and 'out into' an unfamiliar world, trying to gain control of my life, expand my capacities. ${ }^{53}$ One can see how her early minimalistic training from the University of California Los Angeles, and feminist desires began to merge into a language and helped formulate a curatorial context that led to a structure for exhibiting The Dinner Party. On the cusp of her transition from minimalist to feminist, content-filled work were her Atmomspheres (1969), ${ }^{54}$ events where she transformed natural or constructed places with colored smoke to "feminize the environment." ${ }^{.55}$ Such an aspect is clearly related to making an impact on the physical context of an artwork and how the work was received and experienced by viewers, which foreshadows the experience of The Dinner Party.

\section{Chicago's 1970 exhibition at California State College marked her declaration of} independence with the change of her last name from Gerowitz to Chicago, a revelation to no longer hide her femininity in her work, and a growing exploration with curation. ${ }^{56}$ Exhibiting

\footnotetext{
${ }^{49}$ Ibid, 38-41.

${ }^{50}$ Ibid, 41.

51 “Judy Chicago's Rainbow Pickett,” Brooklyn Museum, accessed April 17, 2015,

http://www.brooklynmuseum.org/eascfa/feminist_art_base/gallery/judy_chicago.php?i=1564.

52 “Early Minimal Works," Judy Chicago, accessed March 9, 2016, http://www.judychicago.com/gallery/early-workminimal/ewartwork/.

${ }^{53}$ Chicago, Through the Flower, 44.

54 “Chicago in LA: Judy Chicago's Early Work, 1963-74,” Brooklyn Museum, accessed April 17, 2015, http://www.brooklynmuseum.org/exhibitions/judy_chicago_los_angeles/\#!lb_uri=purple_atmosphere.php.

55 Ibid.

${ }^{56}$ Frances Borzello, “An Art History Sit-In: The Dinner Party in Its Artistic Context," in The Dinner Party: Restoring Women to History, ed. Judy Chicago, The Monacelli Press (2014): 259-260.
} 
her dome sculptures (fig. 3), paintings from the Pasadena Lifesavers series (fig. 4), and

Atmospheres in photograph and film form, Chicago also displayed a posted written statement at the exhibition that connected her work to her "femaleness." Still, many people continued to interpret her work abstractly. She reflected:

...Although I was trying to make my images clearer, I was still working in a frame of reference that people had learned to perceive in a particular, non-content-oriented way...I was expecting the art community to actually 'see' my work differently...Fundamental to my work was an attempt to challenge the values of the society, but either my work was not speaking, society didn't know how to hear it or both...I had tried to deal with the issues that were crucial to me 'within' the structure of male art language and a maleoriented art community. ${ }^{57}$

Chicago re-iterated that to fully grasp the intention of her work, and perhaps all artwork by women at this time, a change in cultural values was needed because there was no frame of reference to understand a woman's perspective. ${ }^{58}$ Out of this experience, Chicago became passionate not only about working with other women, but also building a new context for which the work of women could be properly understood. ${ }^{59}$ This is another step in her evolution towards the curatorial framework she would later design for The Dinner Party.

Chicago educated herself about women artists and developed a feminist art course while teaching at Fresno State College. ${ }^{60}$ Part of her goal was to create a new context where women might have more roles and recognition, ${ }^{61}$ again foreshadowing her creation of exhibition context for The Dinner Party. It is here that she instigated her "circle method" of asking for everyone's thoughts, ${ }^{62}$ a method she would again use while creating The Dinner Party. ${ }^{63}$

\footnotetext{
${ }^{57}$ Chicago, Through the Flower, 64-65.

${ }^{58}$ Ibid, 65.

${ }^{59}$ Ibid, 67.

${ }^{60}$ Chicago, Institutional Time, 8.

${ }^{61}$ Chicago, Through the Flower, 82.

${ }^{62}$ Ibid, 77-78.

${ }^{63}$ Chicago also referred to this method in Institutional Time, as a prime method for education, artistic development, a method of which was developed early on in her life and used while teaching at Cal Arts and later on. Though this may have been a popular
} 
With curator Dextra Frankel, Chicago curated an all-women art exhibition in Los Angeles, Invisible/Visible (1971), and traveled around the West Coast visiting artists' studios. ${ }^{64}$ These visits had a great impact on Chicago's contextual awareness, as she realized her own bias toward studio environment. Chicago and Frankel found that many of the spaces where women were working were bedrooms, dining rooms, and porches, where their life and art intermeshed, whereas typically a professional "studio" or "loft" meant designated work space removed from the domestic context. Chicago recognized the prejudice of space which they had to overcome to fully appreciate the work. ${ }^{65}$ As this exhibition came to fruition, Chicago recognized that many artists wished to ignore the situation of women in the exhibition wall text. However, Chicago suggested that directly identifying women's situations with exhibition context could provide a better environment for the artwork of women. Of her work in the exhibition, Chicago noted, "It was the first time my work appeared in an all-female context, and I felt that it helped the content become more visible." ${ }^{\prime 66}$ The first experience seeing the work of women in such a context undoubtedly built upon Chicago's growing thoughts on curatorial framework that would impact The Dinner Party.

With Miriam Schapiro (1923-2015), ${ }^{67}$ Chicago started the first Feminist Art Program at California Institute of the Arts in 1971, and they and their students produced Womanhouse (1972), ${ }^{68}$ a woman-centered art installation of a refurbished abandoned house. ${ }^{69}$ It received a

\footnotetext{
method during this era, Chicago formulated and outlined it as a working method. Chicago, Institutional Time: A Critique of Studio Art Education.

${ }^{64}$ Chicago, Through the Flower, 98.

${ }^{65}$ Ibid, 98.

66 Ibid, 101.

67 “Miriam Schapiro," National Museum of Women in the Arts, accessed April 18, 2016, http://nmwa.org/explore/artistprofiles/miriam-schapiro.

68 "Womanhouse," Womanhouse, accessed April 20, 2015, http://womanhouse.refugia.net/.

69 "Womanhouse," Women's History, accessed April 18, 2016,

http://womenshistory.about.com/od/feminism/a/womanhouse.htm.
} 
plethora of national media attention, signaling the momentum of the American feminist art

movement. ${ }^{70}$ In formulating the idea for Womanhouse, Chicago thought a lot about spatial context and how the work by women would and could be received: "Even if a new kind of work was made by women, it would still have to funnel back into an art system controlled by men. It was imperative to make another step in developing a female art community, one that would allow the work made by women to be seen in a context other than the male system."71 Attention to spatial and cultural context was perhaps heightened with Womanhouse, a project artist Paula Harper suggested they design a house, making the art the entire environment. ${ }^{72}$ She described: "Room after room took shape until the house became a total environment, a repository of female experience."73 There were mixed reactions from Womanhouse visitors, ranging from comfort, excitement and compassion, to fear from women of the direct confrontation, and confusion by many men. ${ }^{74}$ Chicago recognized a potential for "women's art in the world at large" through Womanhouse and "wondered if there was a way for abstract art to have the same kind of impact on values" as Womanhouse, ${ }^{75}$ foreshadowing her contextual structuring of The Dinner Party.

\section{Seeing Art by Women in Context: Collaboration, Research and Exhibition Text}

Throughout her artwork and research, Chicago began to formulate a concept for a physical context that would impact The Dinner Party installation. She realized that "new aspects

\footnotetext{
${ }^{70}$ Jane Gerhard, The Dinner Party, 48.

${ }^{71}$ Chicago, Through the Flower, 97.

${ }^{72}$ Ibid, 103-4.

${ }^{73}$ Ibid, 113.

${ }^{74}$ Ibid, 115.

75 Ibid, 132.
} 
of their work... appeared" when art was viewed next to work by other women instead of men. ${ }^{76}$ Chicago found women artists throughout history, but without any relationships or cultural context that defined the lives of women or attitudes toward women during their time. These insights, realized Chicago, altered perspectives and even enriched understanding, when viewing their artwork, a revelation which no doubt impacted The Dinner Party. ${ }^{77}$ She further developed her curatorial exploration with The Great Ladies series of abstract spray painted works in 197273, that would lead to The Dinner Party ${ }^{78}$ (see fig 5: Queen Victoria). She reflected on her motivation for including historical context into her artwork:

I had discovered my heritage as a woman. However, my knowledge existed in somewhat of a vacuum, as the society certainly does not reflect the fact of women's achievements, women's perceptions, and all of the work women have made. I recognized that my work could only be accurately understood against the background of female history, and I wanted to find a way to incorporate that history into my work so that the viewer would be forced to confront my work in the context of other women's work.$^{79}$ [my emphasis]

Clearly, Chicago recognized the importance of textually and visually contextualizing exhibitions and even she created her artwork with it in mind. The Great Ladies series began as non-objective abstracted visual paintings named after various women in history "who transcended the female role through the fact that they were rulers or women of great achievement." 80 After giving a lecture about the series in the early 1970s, Chicago asked for audience feedback; she learned that while the intent was exciting, the abstract vocabulary made it less approachable and understandable. ${ }^{81}$ In order for the audience to better comprehend her intent and to make her work

\footnotetext{
${ }^{76}$ Chicago, Through the Flower, 145. Chicago reflected: “Each woman's work, seen only in juxtaposition with men's work, has been rendered impotent by being separated from the work of other women. Seen together, women's work can challenge our most fundamental ideas about women, men, our roles, our potential, our identities, and our priorities.” Ibid, 159.

${ }^{77} \mathrm{Ibid}, 148-151$. This, as with most of her work and statements, could be applied to contextualizing other underrepresented people in museums, and is reminiscent of Angela Dimitrakaki and Lara Perry's recent suggestion that perhaps a response to such underrepresentation is largely in the hands of contextualization, or curating. Angela Dimitrakaki and Lara Perry, Politics in a Glass Case, Liverpool: Liverpool University Press: 2013, 17.

${ }^{78}$ Chicago, "Introduction: Restoring Women to History," 10.

${ }^{79}$ Chicago, Through the Flower, 178.

${ }^{80}$ Ibid.

${ }^{81}$ Chicago, "Introduction: Restoring Women to History," 10.
} 
"accessible," she began writing text on the images, descriptions of the women's lives and why she chose them. ${ }^{82}$ It was in this process she made a crucial turn in her work in terms of didactic context that would impact The Dinner Party and later installations.

By writing about the idea I was working with visually, perhaps the viewer would then be able to recognize the meaning of the image. That way, I would be educating people to understand my work while they're looking at it. This was a big step in making my content clear and comprehensible without having to deny my own artmaking process. ${ }^{83}$

Subsequently, she began thinking of context in terms of a female audience, which would help the building of her new curatorial structuring. Specifically, she explored via Womanspace, by organizing a group exhibition about female sexuality in $1973 .{ }^{84}$ In discussing the formation of such a space, she again reflected that:

...women were included in the context of men's ideas, and men's past... Whatever information lay outside of the perspective of that culture didn't count. Thus all the material in women's work that grew out of women's experience, even if it was clearly expressed, could not be important within the context of a male-dominated institution, because only those things that were relevant to men were seen as important. ${ }^{85}$

So her creation of a curatorial structure for art was building.

In 1973, the Feminist Studio Workshop opened in Los Angeles by Chicago, designer Sheila DeBretteville and art historian Arlene Raven to afford women an alternate art working environment, and help the artists maintain control of the art after it left the studio. ${ }^{86}$ As Raven also realized: “...women's work had to be seen in its own context or it would be diminished."

\footnotetext{
${ }^{82}$ Chicago, Through the Flower, 178.

${ }^{83}$ Ibid, 179.

${ }^{84}$ Ibid, 180.

${ }^{85}$ Ibid, 185.

86 "Judy Chicago: Through the Archives," Radcliffe Institute for Advanced Study, accessed April 18, 2016, http://www.radcliffe.harvard.edu/schlesinger-library/exhibition/judy-chicago-through-the-archives. Wrote Chicago "Unless we could control what happened to our art after we made it, we would all be subjected to the same distortion, devaluing, and discrimination that the women before us had suffered." Chicago, Through the Flower, 188.

${ }^{87}$ Ibid, 191.
} 
The significance placed on the way in which the art would be viewed after it was made, is a clear indication of a curatorial significance by Chicago and her peers at this time.

Collaboration was a key aspect in their plan for the Feminist Studio Workshop to build women's confidence, create new work, and aid in developing a "context for it, secure its effectiveness, and help other women do the same..." ${ }^{98}$ This first class at the Workshop, a nonprofit organization, included professional women from around the country. Chicago deemed it "the first step in establishing an alternate art structure." 89 To further build such an alternative to a rigid dominating art structure, the Workshop rented a large building called the Woman's Building and sublet out spaces to Womanspace, as well as a women's art co-operative, a private women's gallery, a feminist bookstore, performance groups, journalists and other women or feminist centric-minded organizations, providing many ways "to make women visible."90 This method also set the collaborative groundwork for curating The Dinner Party.

At the same time that the Woman's Building opened, Chicago's Great Ladies series exhibition opened in Womanspace, which she installed with help from various volunteers in the building. She found this a welcomed change from installing a previous show, Flesh Gardens, at a “prestigious male owned gallery" which was unpleasant due to the male-installers persistent gender commentary. ${ }^{91}$

These early workings of the artist show her great attention to visual and written context in almost all things: her artistry including text to convey her messages as well as creating an entire new art structure to house the work of women so it could be properly understood, and founding

${ }^{88}$ Chicago, Through the Flower, 195.

${ }^{89}$ Ibid, 200.

${ }^{90}$ Ibid, 202.

${ }^{91}$ Ibid, 203. 
the programs and workshops to help other women learn how to put their own work into the world. As The Dinner Party ideas were developing it is clear that her passion for making art was coupled with one for changing the structure of the art world with curatorial methods (though not stated as such), so that it might allow for the appreciation and inclusion of artists who are women who had been left out of exhibitions and art discourse for so long.

\section{Test Exhibition: Ruth Schaffner Gallery, 1977}

Along with the Great Ladies Series, Chicago experimented with wall text and installation in Butterfly Room, a 1976 exhibition at Seattle's And/Or Gallery, ${ }^{92}$ and notably, in 1977, in an exhibition of china painting at Ruth Schaffner Gallery in Los Angeles. She was already at work on The Dinner Party, and some of the volunteers helped her install the work (again a collaborative installation). The artwork was installed surrounded by pastel satin that she said “depicted six stages of women's aspiration," as well as six lit blue candles and a red silk cloth embroidered by Susan Hill and Arla Hesterman, "celebrating female spirituality.",93

Chicago's intention with this show was to "create a sense of the sacred in a 'nonintimidating environment.",94 Of the exhibition's implications for The Dinner Party installation, Chicago reflected:

The installation of The Dinner Party grew out of the experiments I was doing with context, specifically, an exhibition I did at the Ruth Schaffner Gallery in L.A while I was still working on The Dinner Party. I showed a series of porcelains in a darkened space with halogen lights spotlighting the pieces. By then, I was working with an industrial

\footnotetext{
${ }^{92}$ Edward Lucie-Smith, Judy Chicago: An American Vision (New York: Watson-Guptill Publications, 2000 ), 40.

${ }^{93}$ Gail Levin, Becoming Judy Chicago: A Biography of the Artist (New York: Random House, 2007), 295.

${ }^{94}$ Levin, 295.
} 
designer named Ken Gilliam who contributed a lot of the systems to The Dinner Party, and with me, designed the exhibition of the piece. ${ }^{95}$

In photographs of this exhibition supplied by Chicago's studio, her curatorial care is evident. The windows displayed photographs of the artist working with the porcelain, already visually contextualizing the exhibition before entry with artistic process (fig. 6). Upon entry viewers saw wall text (fig. 7) literally scripted by Chicago briefing the intent and context of the work, and others involved with the exhibition. The installation of the artwork demonstrates a similar approach to that of The Dinner Party table room, dark and reverent, with specific lights shining individually on each ceramic piece, so that the sole focus is on the artwork (fig. 8). There was also alternative the wall paint and reflection of the butterfly figure (fig. 9), evoking the theme of the exhibition (butterflies, of course, were also a prominent icon in The Dinner Party). This exhibition is one precursor and example of Chicago's experimentation with curation that informed her structure of The Dinner Party.

Two reviewers commented on the space, which implies the spatial aspect of the exhibition experience was notable. Ruth Askey in Artweek observed: “...all the sheets (spaces) are brutally shattered—a metaphor of women's aspirations as well as her own." ${ }^{.96}$ William Wilson in the Los Angeles Times interestingly called the show "overinstalled," again noting the space rather than the work. ${ }^{97}$ The opening was, according to Levin, "mobbed," pointing to its popularity, ${ }^{98}$ clearly a precursor with implications to The Dinner Party's environment and installation seeking to reach a broad audiences with a planned exhibition experience.

\footnotetext{
95 Judy Chicago, interview by author via email, April 22, 2015.

${ }^{96}$ Ruth Askey, "Judy Chicago: Pride in Women and in Herself," Artweek January 1977, JCCSL, Box 1, Folder 33, quoted in Levin, 295.

${ }^{97}$ William Wilson, “Art Walk: La Cienega Area,” Los Angeles Times, 28 January 1977, sec. 4, p.6, quoted in Levin, 295.

${ }^{98}$ Levin, 295.
} 


\section{Chapter Two: Creating The Dinner Party Curatorial Structure}

“....another explanation for The Dinner Party's impact was that viewers entered an installation that extended a woman-centered perspective into an environmental space. This allowed women to experience their own bodies, their everyday work, their crafts, and their history in a public arena, sharing this space with others and thereby seeing themselves and their lives validated in ways that were entirely new. For men, the viewing experience was every bit as unusual, albeit in other ways. For probably the first time in their lives, they were not at the center of the viewing experience; for some, this was altogether unpleasant, for others, fascinating. However, both women and men experienced something quite unusual, which was seeing female subject matter in a female context rather than in relation to male art history." $\quad$ Judy Chicago, Beyond the Flower ${ }^{99}$

This chapter will summarize the content and analyze the detailed structuring of the various parts including the Entryway Banners, artwork, Heritage Floor, Heritage Panels, Acknowledgement Panels, Documentary Panels and International Honor Quilt, of The Dinner Party. The Dinner Party was produced throughout $1974-79$ with over 400 volunteers. ${ }^{100}$ This collaborative method came out of Chicago's liberal activism and feminist pedagogical methods in her teachings and collaborative forming of Womanhouse. In the broader feminist art context, collaboration of 400 contributors was a move against the traditional celebration of the individual, heroic artist in Modernism. ${ }^{101}$

The feminist collaborative method extended to each part - there were team leaders for needlework (Susan Hill), research, promotions and fundraising (Diane Gelon), installation (Peter Buznik) and ceramics (Ken Gilliam). Though the ultimate design was Chicago;s, at each step, conversations were held at weekly meetings using Chicago's circle method, and throughout as issues arose - whether discussing The Dinner Party technical aspects or ideas, feminism or

\footnotetext{
${ }^{99}$ Chicago, Beyond the Flower, 121-122.

${ }^{100}$ Chicago was also a volunteer, as she did not take a salary and paid lead workers when donations were received. Judy Chicago, Dinner Party: From Creation to Preservation (London/New York: Merrell Publishers, 2007), 14-15.

${ }^{101}$ Chicago continued her collaborative methodology in her later series including The Birth Project (with several women across the country, 1980-85) ${ }^{101}$ and The Holocaust Project (with her husband, Donald Woodman, 1985-93). Ibid, 279.
} 
personal life. Volunteers included men and women from around the nation, and inclusivity was extended outside of the project volunteers with the International Honor Quilt project.

Chicago designed The Dinner Party plates with feminine iconography in mind (the vulva), that had evolved from her previous work. ${ }^{102}$ Chicago not only used vaginal threedimensional form (also merged with the butterfly, the symbol for liberation) in many of the ceramic plates of The Dinner Party, but used many layers of visual female iconography throughout, including the design of the table itself, a triangle, the ancient symbol for woman and goddess (see fig. 10). ${ }^{103}$ The three equal sides also represent "the goal of feminism-an equalized world." 104 The attention to this big-picture installation emphasizes her attention to exhibition experience.

Originally, Chicago aimed to display the 39 porcelain plates (each honoring a woman in history) on the wall. During a two-year apprenticeship on china painting, she saw a set of dishware on an artist's dining room table and decided The Dinner Party plates needed to be arranged on a table. ${ }^{105}$ Reinterpreting Leonardo da Vinci's The Last Supper of thirteen individuals at a long rectangular table, Chicago made hers three times that at thirty-nine, again calling attention to the significance of installation. Moreover, her decision to exhibit the plates on a table where people can walk around and look down on, as opposed to looking at on a white wall as typically in an art gallery, creates an accessible and approachable experience; if viewers

\footnotetext{
102 Many other artists during this time of the feminist movement, up until today, continue to depict the female anatomy in their work, such as Carolee Schneemann and Jenny Saville.

Chicago's aim was not to essentialize, as many feminist theorists criticized later, but "to transform the physical defining characteristic of women into an aesthetic and metaphysical exploration of what it meant to be a woman historically, experimentally and philosophically, as well as to challenge the prevalence of phallic forms in society which are so common no one notices" and to seek claim to female agency, Chicago, Dinner Party: From Creation to Preservation, 12.

103 Judy Chicago, Dinner Party: From Creation to Preservation (London/New York: Merrell Publishers, 2007), 20.

${ }^{104}$ Chicago, Through the Flower, 211.

105 The idea reminded Chicago of Leonardo da Vinci's famous and art-historically canonized The Last Supper which led her to think about The Dinner Party as "a reinterpretation of the Last Supper from the point of view of those who've done the cooking throughout history." Chicago, "Introduction: Restoring Women to History," 10.
} 
do not see the art historical connection to Leonardo da Vinci, most Americans will recognize the dining table experience itself. Looking over and walking around the table again echoes

Chicago's interactivity, creating an active experience rather than passive. ${ }^{106}$ This attention to the significance of installation and experience of the artwork suggests a keen curatorial understanding when constructing The Dinner Party.

Chicago's installation context was coupled with flipping traditional artistic norms through select media in The Dinner Party. Along with using porcelain and the domestic dinner table as her platform, Chicago used the traditional feminine craft of needlework to further extend the embrace of women's contribution to history. ${ }^{107}$ This complex thought and design shows Chicago's dedication to technique, as well as her devotion to the complexity of the history of women $^{108}$ and encouraging multiple perspectives to enrich understanding of artwork. By installing the plates over the runners, as opposed to separately along a wall, she provided a challenging, critical display of the artwork.

Scholars such as Jane Gerhard observe the significance of The Dinner Party table installation, ${ }^{109}$ focusing on the way the intricately crafted artwork comes together on the table,

\footnotetext{
106 Chicago's reference to The Last Supper can be criticized for falling back on a canonized object, however it can also be viewed as appropriating it ironically. To make a feminist point, she emulated the religious act of communion with altar cloths and wine glasses to echo the interaction by "taking in" the "body" or information of the women, while recognizing that while Jesus Christ has been a household name in western culture for centuries, these women have been long lost. As Chicago writes: "...The guests at this dinner party were to be presented as images on plates, a reference to the way in which history had consumed rather than revered women of this achievement." Chicago, Through the Flower, 210.

107 Judy Chicago, Dinner Party: From Creation to Preservation (London/New York: Merrell Publishers, 2007), 18-19. Many other artists such as Miriam Schapiro and Faith Ringgold were also utilizing traditionally feminine media and therefore deemed inferior such as quilting and sewing to bring it to the fine art forefront. Each setting and each altar runner works together to tell a deeper story about the woman it represents.

108 The amount of work and detail in each place setting can be read about in Chicago's other studies. Although she did write books on the place-settings and various details of making The Dinner Party, Chicago's little known original intention was to complement the installation with an elaborate illuminated book, to provide even further context for the content. According to Edward Lucie-Smith these pages remain in manuscript form, although unknown to many. Lucie-Smith, 66.

109 "When we look closely at the main artistic components of the exhibit, design choices become windows into the literal embedding of 1970s feminist theory, with its glaring blind spots and brilliant insights, into The Dinner Party. The embroidered runners, the ceramic floor, the china plates, and the staging of the piece each distinctively embodied a feminist insight about history and women that, when taken as a whole, constituted a material rendering of 1970s sisterhood at its most ambitious." Gerhard, 111.
} 
though the accompanying elements around the table also play a primary role in understanding and experiencing The Dinner Party. Gerhard discusses the "religious staging" of The Dinner Party table artwork at length as a "religious ritual for and about women."110 The content and symbolism of The Dinner Party regarding religious aspects has been keenly reviewed by Gerhard and others and is not under the purview of this paper. ${ }^{111}$ Instead this paper reveals the extension of The Dinner Party beyond the artwork to the encounter, via the curatorial aspect to the entire piece, which is outlined in the next section.

\section{Around The Dinner Party Table: Other Installation Elements to The Dinner Party}

The idea was for people to walk through the banners. So you come out of the world, go into this museum show, where you eventually go through a series of quietness, as you walk through the banners, to come into a darkened space that is illuminated. This is an exhibit that is reading as if it is all porcelain, that has quite a shimmer to it, created through the lighting and the quality of the work. That was the image that she had: essentially this floating piece that transcended the space. You felt you were in some other world...this was the general layout: walk into the space through the banners, then walk into a darkened room with the artwork, then back out to the documentary information and Heritage Panels. - -Diane Gelon, installation coordinator of The Dinner Party, 1979-1987, interview with the author, September 4, 2015

The Entryway Banners, Heritage Floor, Heritage Panels, acknowledgement and

Documentary Panels each play an important role in conceptualizing and interpreting The Dinner Party. The Heritage Floor includes 2,304 hand-crafted triangle tiles beneath and in between The Dinner Party tables. Painted with the names of 999 women in history, ${ }^{112}$ the named tiles were

\footnotetext{
${ }^{110}$ She notes: "Practically, this meant moving crowds around an installation that appeared to be a sanctuary, with dimmed lights, long altars, and low, protective rails. Artistically, the staging embedded a female-centered origin story into the viewing experience... When combined, these elements of Chicago's staging of The Dinner Party ideally enhanced the ritual significance of the art and the transformative experience of encountering it." Gerhard, 142.

111 Gerhard, 142-148.

112 The names were written in Palmer script, which Chicago chose as a representation of $20^{\text {th }}$ century penmanship.
} 
placed in historical and/or subjective relation to the place-settings. ${ }^{113}$ These names, along with the 39 women acknowledged in the place settings, were selected out of more than 3,000 that were discovered through research done by Chicago and her research team consisting of art history graduate students and volunteers (no professional art historians would participate). ${ }^{114}$ Chicago and the team came to 999 names for the Biblical reference, and the ability of the number to be divided by three, a number of significance throughout the artwork as well. ${ }^{115}$

Hundreds of pages of The Dinner Party exhibition description, installation diagrams, instructions, and exhibition manuals obtained from the Schlesinger Library at Harvard University Libraries holds several boxes of Judy Chicago's papers throughout her career. ${ }^{116}$ A close look at Chicago's installation intentions and strategy makes clear that the structure and experience of the entire exhibit was just as important as the place-settings and table. The sheer volume of pages and detail that went into the manuals displays the significance and care which went into curating and structuring of The Dinner Party. Diane Gelon confirmed that when she was head of installation in the early years of the tour, she carried along the original exhibition manual written by Chicago and Peter Bunzik. ${ }^{117}$ Susan Hill, head of needlework, recalled in an email:

...Diane [Gelon], Peter [Buznik] and I knew the packing, unpacking, condition reports, installation and de-installation processes really well...we relied on our teamwork and the orderly processes that had been worked out. It was a very smooth progression of work, very logical, aided by the crate numbers, and the marks on the flooring system. I

\footnotetext{
113 Judy Chicago, Dinner Party: From Creation to Preservation (London/New York: Merrell Publishers, 2007), 21-21. Subjective context might imply that the women were both involved in the same professional fields such as art, literature or science.

114 These 999 women were also written about and displayed for viewers on the Heritage Panels, which were updated before the 2007 installation in the Sackler Center. Poignantly, in re-researching the 1,038 women some 25 years later, Chicago found things had not changed; not only were many of her findings still the citations used in current research, but recently-written historical texts had altered or erased many of the findings. Ibid, 288.

115 Judy Chicago, The Dinner Party (New York: Penguin Group: 1996), 12.

116 Schlesinger Library holds Judy Chicago papers from 1947-2004, accessed November 3, 2015 , http://oasis.lib.harvard.edu//oasis/deliver/deepLink?_collection=oasis\&uniqueId=sch00326.

${ }^{117}$ Diane Gelon, email with the author, November 10, 2015.
} 
remember notebooks with diagrams and information being available. I remember doing the work following the processes we knew, not consulting the manual. ${ }^{118}$

In an interview with Donald Woodman, ${ }^{119}$ I learned that he wrote a second installation manual while installing the exhibition in 1987 in Frankfurt, Germany, which is also included in the Papers obtained from Schlesinger Library. According to Woodman, the group of installation assistants were theatre technicians, well-versed in lighting, design and construction, which, with Woodman's extensive installation photographs and background in architecture, led to the detailed installation manual which was meant to codify Judy Chicago’s installation conception. $^{120}$

The original manual includes instructions for installing each piece of the exhibition, from the distance from the table to the wall, lists of materials from mops to lights, number of people required for installation, angle of the lights, instructions for each part of the table, maintenance and take-down, daily tasks for installation and de-installation, and even what color socks to wear while installing the tiles (white). ${ }^{121}$ Other instructions included electrical requirements, diagrams for the table, daily tasks and personnel required for each day of installation and take-down as well as maintenance instructions, detailed materials lists for installation, maintenance and takedown, pages of instructional diagrams for installing the table and lighting, and detailed lists of shipping (what each crate held, and descriptions of each item). ${ }^{122}$ The most detailed aspect regards the lighting and the structure of the table. Woodman's photographs of the installation

\footnotetext{
118 Susan Hill, email with the author, November 10, 2015.

${ }^{119}$ Chicago's husband since 1985, Donald Woodman was the photographer of many of The Dinner Party exhibitions, and coordinator of exhibitions 1987-88, 1996 and 2002. Donald Woodman, interview with the author, November 8, 2015.

${ }^{120}$ Donald Woodman, interview with the author, November 8, 2015.

There are also papers listed in the Schlesinger Library online that indicate specific instructions for each exhibition stop, as well as follow-ups, some blue-prints, correspondence, detailed shipping information, and contracts. This could provide for future research, and further indicates the detail and effort that went into trying to ensure a consistent exhibition experience at each venue.

${ }^{121}$ Judy Chicago, The Dinner Party Exhibition, installation diagrams [and instructions], n.d., Judy Chicago Papers, 20.45, Schlesinger Library, Radcliffe Institute, Harvard University

122 Ibid.
} 
process at the Frankfurt exhibition are included in the later manual ${ }^{123}$ Every light's angle is diagramed and explained for individual control on each place setting. Lights were to hit the runners in front of the settings in order for viewers to be able to read the names clearly, as well as to highlight the ceramic plate on the table. Moreover, a special lighting system allowed for rainbow reflection on the runner backs from the luster glaze used on the floor (fig. 10), which viewers could see as they walked around the table. ${ }^{124}$ This lighting plan, although little (if at all) recognized in scholarship around the piece, was extremely important to Chicago's conception as it contributed to the reverent atmosphere, respect to the women featured in the piece, ultimate focus and contemplation for the work and perhaps even her desire for peaceful ideal-world implications. ${ }^{125}$

The exhibition manuals for The Dinner Party included "the work of art" (table), "the Entryway" (Entryway Banners), "Documentation” (documentary and acknowledgment panels), a 20-minute video tape that traveled with the exhibition about the making of The Dinner Party, a ten-page brochure, and, after the original exhibition, the "International Honor Quilt." ${ }^{26}$ It also lists the various optional books, posters and slide sets to sell, as well as the guardrail that surrounds the table, and lighting tract system that comes with the exhibition. ${ }^{127}$ As the "Introduction to the Installation Manual" reads, "This manual begins at the point when the exhibition space has been prepared and the exhibitor is ready to begin actual installation of The

\footnotetext{
${ }^{123}$ Donald Woodman, interview with the author, November 8, 2015.

124 The rainbow luster was very difficult to photograph, according to Woodman, though he did capture it for the 1996 and 2014 The Dinner Party books. Also see fig. 10. Donald Woodman, interview with the author November 8, 2015. For a photograph see Donald Woodman's, p. 183-184 in The Dinner Party, by Judy Chicago (New York: Penguin Group: 1996).

${ }^{125}$ As an aside, the rainbow also recalls her early minimalistic sculpture, Rainbow Pickett (1966, fig. 2), which would be another interesting topic of investigation.

126 Judy Chicago, The Dinner Party Exhibition, installation diagrams [and instructions], n.d., Judy Chicago Papers, 20.45, Schlesingler Library, Radcliffe Institute, Harvard Library.

127 Ibid.
} 
Dinner Party and its adjunct materials. Prior to this, there must be an installation design and complete installation drawings provided by the exhibitor and approved by the artist or TTF." 128

Jane Gerhard's account mentions the "short clips" of a video being shown as visitors waited in line at the San Francisco Museum of Art, ${ }^{129}$ and Gelon recalled that the video would play on occasion for special events during the other stops. ${ }^{130}$ Gerhard also mentions an optional audio tour for additional cost, on cassette tape, available after $1980 .{ }^{131}$ These multi-media and interactive curatorial aspects no doubt added to the understanding and broad appeal of The Dinner Party's message.

The Documentary Panels (Documentary Panels) included: "23 Documentary Panels which describe the process of making the exhibition all are 4' x 6' panels with photographs and text mounted on Formica backed with Masonite; with metal frames; 6 portrait/acknowledgement panels; 1 group photo mural.”132 Photographs from the Brooklyn Museum Archives (fig. 10) show the Documentary Panels during the 1980 exhibit. As Gerhard notes, these Documentary Panels, as they traveled through the original tour, proved fundamental to the full exhibition experience of The Dinner Party, and as I argue, were part of the curation of the exhibition. Gerhard keenly reflected on the importance of the Documentary Panels to interpreting The Dinner Party's message:

These images, prominently displayed during the opening and subsequent tour, underscored that volunteer labor mattered to Chicago and mattered to what the viewer would soon see... Chicago broke with the tradition of apprentices whose work commonly went unnoted and unrecorded. These snapshots also oriented audiences to the range of technical skills employed to bring The Dinner Party to completion, ideally readying them

\footnotetext{
${ }^{128}$ Ibid. TTF is short for Through the Flower, the nonprofit organization formed to manage The Dinner Party.

${ }^{129}$ Gerhard, 166-167.

${ }^{130}$ Diane Gelon, interview with the author, September 4, 2015.

131 Gerhard, 167.

132 Judy Chicago, The Dinner Party Exhibition, installation diagrams [and instructions], n.d., Judy Chicago Papers, 20.45,

Schlesinger Library, Radcliffe Institute, Harvard Library.
} 
to see with new appreciation the art, not just the craft, of the needleworker and the china painter. ${ }^{133}$

Indeed, the original exhibition's inclusion of these panels - they are listed in the "Components of The Dinner Party" in Chicago's original papers, along with the table and tapestries, serve as a curatorial choice by Chicago which fostered a greater appreciation of the work in its entirety.

The "Components" required an additional "350 linear feet of wall space" (on top of the space for the artwork table of 60x60 feet) for the documentation, Heritage and acknowledgement panels, as well as the separate entryway for the Entryway Banners ${ }^{134}$ emphasizing the importance of all of the aspects. The other requirements for the exhibition space included the ceiling height of 18 feet, and ability to accommodate a "triangular lighting grid...weighing approximately 3000 pounds and must be supported at 4 points along each of its 3 sides." It notes that if the site already contains a "high quality theatrical lighting system, it may be used, subject to the artist's or Through the Flower's approval. The room must also be able to be entirely darkened."135

The requirements for the Entryway Banners were a bit more flexible, but required some sort of entryway which could vary in size and allow the six, 3 by 5 feet, banners to be installed in a sequence to create "an antechamber/approach to the Main Exhibition Hall. It is preferable that the entryway lighting be controlled and natural light be excluded." ${ }^{136}$ In the interview with Diane Gelon, she relayed that sometimes the Entryway Banners were installed against the wall as twodimensional works (fig. 13), and other times, as preferred, from the ceiling so that viewers might enter through them, as shown in the Brooklyn Museum exhibition in 1980 (fig. 14). This reveals a slight flexibility, also evidenced in the instructions for the Documentary Panels, which were

\footnotetext{
133 Gerhard, 168.

${ }_{134}$ Judy Chicago, The Dinner Party Exhibition, installation diagrams [and instructions], n.d., Judy Chicago Papers, 20.45, Schlesinger Library, Radcliffe Institute, Harvard Library.

${ }^{135}$ Ibid.

136 Ibid.
} 
required to be displayed on walls outside the main exhibition hall, but could be arranged before or after the artwork. Moreover, if the space did not have room to exhibit all of the Documentary Panels, a selection could be displayed (grouped by subject matter), but all of the Heritage Panels (in consecutive order, see fig. 15) and acknowledgement panels (see fig. 16) were required to be shown after exiting the table. ${ }^{137}$

The lighting plan is detailed with various diagrams for exact angling and installation, as are instructions for the table artwork, which was created almost like a puzzle. Instructions are summarized for the whole installation, in The Dinner Party fact sheet. Stipulations include wheelchair accessibility, and in the table gallery: black walls, low, soft lighting and guardrails at arm's length for the "chapel-like" room housing the artwork positioned so that viewers "feel comfortable in the space." The lighting for the entryway with the Entryway Banners was instructed to be the same as this room. Though the lighting in the photo-documentation area was more flexible and could have "normal exhibition lighting," there was to be no ambient light from this area flooding back into the artwork room. ${ }^{138}$

Moreover, signage was listed as “essential.” Instructions included a welcome sign in the entryway to the artwork, as well as identifying signs and explanatory labels provided by Through the Flower, for the Heritage Panels, Portrait Panels, Process Panels and Quilts. A significant point was a requirement of translating these signs and the banners into the language of the host country when the exhibition was held in a non-English speaking country. These signs, as well as the use of any color used in them were required to be approved by Chicago or Through the Flower. ${ }^{139}$ This requirement of the several textual elements, including the interpretation of the

\footnotetext{
137 Ibid.

138 Ibid.

139 Ibid.
} 
text into the country's speaking language, and wheelchair accessibility, ${ }^{140}$ reiterates the significance of the viewer experience, and her conception of the exhibition as a curated space. As Diane Gelon noted, for every stop that the exhibition eventually made, Gelon toured at least three to ten venues; if the venues could not hold The Dinner Party in the way that they had outlined, they would not have an exhibition there. This, again, points to the significance of the space and structure of the entire exhibition. The Dinner Party was understood by the original team as an entire experience, not "just" the artwork.

Two other items to note in terms of curating are the exhibition brochure (fig. 18), and the contract including an exhibition "liaison." Briefly, The Dinner Party exhibition manual relays that a "10-page brochure of the exhibition, prepared by the San Francisco Museum of Modern Art, must be reprinted. SFMOMA will make available the plates from which it can be reprinted each museum should strip in their own name and dates." ${ }^{141}$ SFMOMA sold the brochures for $\$ .25 /$ ach to cover printing costs, and let the organization decide whether to sell or give for free, allowing organizations to sell for up to $\$ .50$ "to make a profit" for the organization, not Judy Chicago or Through the Flower. The exhibition catalog was to be for resale in the bookstore, along with optional posters, postcards, and slide sets. On the Budget page, there is also listed "Museum participation fee" which includes a share of shipping, insurance, installation, a lecture during the opening weekend, and Diane Gelon working as Through the Flower liaison with the exhibiting organization. Gelon's role included working with volunteers, coordinating educational programs, helping with promotion and administration. ${ }^{142}$ This multi-media exhibition design including the various methods of interpretation with audio, visual and textual formats, that, as

\footnotetext{
${ }^{140}$ Ibid.

${ }^{141}$ Ibid.

142 Ibid.
} 
Gerhard mentioned, "offers viewers a preferred reading of itself and a specific way to make sense of the images and names. In short, it presents them with a feminist standpoint that they can resist or embrace." $" 143$

Moreover, as revealed by Gelon and the installation manuals, there was a traveling exhibition that often accompanied The Dinner Party, From the Dining Table to The Diner Party: A View of Traditional China-Painting, curated by Juliet Myers, Diane Gelon and Judy Chicago. The description reads:

This exhibition honors the women and men who have persevered the glorious techniques of porcelain painting. Specially commissioned plates by the twenty-four finest traditional china-painters working today demonstrate such styles as still life, portrait, landscape, raised paste and enamel work. Additionally, the show traces Judy Chicago's development of the unique china-painting techniques that led to the creation of The Dinner Party. ${ }^{144}$ This exhibition then further contextualized a primary media Chicago selected for making The Dinner Party artwork, as well as creating agency for individual contemporary china painters, demonstrating a curatorial mindset as thought was not primarily on the individual artwork, but how it is understood in a broader way, amongst other artwork. According to Diane Gelon, this exhibition traveled with The Dinner Party throughout stops in the U.S. and Canada. ${ }^{145}$ A website archiving the exhibition in Chicago in 1981-82, indicates the china-painting exhibition was on view at Artemisia Gallery (a woman's co-operative gallery) during The Dinner Party's run. ${ }^{146} \mathrm{~A}$ flier indicates that the China-painting exhibition was shown in Boston during the exhibition at the Boston Center for the Arts, as well as another concurrent exhibition featuring photographs from The Dinner Party process by The Dinner Party workers and volunteers (fig.

\footnotetext{
143 Gerhard, 168.

144 Judy Chicago, The Dinner Party Exhibition, installation diagrams [and instructions], n.d., Judy Chicago Papers, 20.45, Schlesinger Library, Radcliffe Institute, Harvard Library.

${ }^{145}$ Diane Gelon, interview with the author, September 4, 2015.

146 "The Dinner Party in Chicago," The Dinner Party in Chicago, accessed November 4, 2015, http://www.dinnerpartyprojectchicago.org/PageExhibition/Exhibiton.html.
} 
19). ${ }^{147}$ Though in-depth research is needed regarding these complementary exhibitions, the significance to curating and creating a multi-layered context for The Dinner Party is clear as her intent was not just to view the sole artwork but see it as part of a larger art discourse. The photographs and Documentary Panels also recorded the diversity of the workers on The Dinner Party, ${ }^{148}$ further promoting a broader and richer understanding of the entire project.

Collaboration was key to promotion and fundraising for The Dinner Party, aspects that today oftentimes go hand-in-hand with curating. The hype for The Dinner Party began with Chicago's call for volunteers, bringing together the various graduate student experts. Their fundraising received media attention before the completion in 1979, as Chicago already had become known after her involvement with Womanhouse. ${ }^{149}$ The amount of fundraising and networking Chicago and Gelon did between 1977-79 to gain momentum for The Dinner Party was vast. They lectured to groups at universities, art museums, bookstores and in living rooms, gave interviews with local and national media and art and feminist publications, and arranged for studio tours with notable curators, feminists, women's groups and connected politicians. They received donations and sold sketches, test plates and tickets to the symposia to raise money. Before The Dinner Party's first installation, as a result of this networking work, they had plans for a grand tour in American museums including the Washington Women's Art Center in Washington D.C., the University of Rochester Art Gallery, and the Seattle Art Museum. ${ }^{150}$ The then-director, Henry Hopkins, a longtime supporter of Chicago's, played a major role in bringing

\footnotetext{
147 “The Dinner Party Photographs,” RAW Art Archives, accessed November 4, 2015, http://rawarchives.tumblr.com/post/22719048959/the-dinner-party-judy-chicago-photographs-of-the.

148 Judy Chicago, The Dinner Party Exhibition, installation diagrams [and instructions], n.d., Judy Chicago Papers, 20.45,

Schlesinger Library, Radcliffe Institute, Harvard Library.

${ }^{149}$ Gerhard, 11.

${ }^{150}$ Ibid, 182-188.
} 
The Dinner Party to the SFMOMA for its debut exhibition, and before it opened in 1979, several organizations, galleries and museums inquired about hosting The Dinner Party at their venue. ${ }^{151}$

This networking, managed by Gelon, coupled with, as Jane Gerhard puts it, “Chicago’s skills of inspiring audiences" prompted national audiences to wait in line and finance the exhibit. ${ }^{152}$ This important aspect, considered too commercial by some art critics for its massappeal, kitsch, and marketing, ${ }^{153}$ was necessary, because of the tendency of society in the era to overlook work by women and female perspectives. As Gerhard noted: "The Dinner Party, with its popularity (trendiness), its self-promotion (commodification), and its attention to the divine, rendered in female form (religious) offered many provocations to the art establishment."154

Curatorial intent beyond the artwork is understood from the diagrams, exhibition manuals and letters sent from the studio regarding the potential exhibition sites. As opposed to the traditional individually-designed exhibition by a curator and provided by museums, Chicago and her team chose a community-oriented context around women's history and lives from the start. Their original ideas included mandatory child-care and a local women's community announcement board in alliance with every venue. Jane Gerhard relates Chicago's methods to the 1970s feminist art movement, to make the art accessible and relevant in a non-elitist way. ${ }^{155}$ These curatorial aspects, though as yet overlooked in curatorial scholarship, continue to be relevant, as museums and institutions struggle to remain relevant in this hyper-technological age

\footnotetext{
${ }^{151}$ In all there were at least forty inquiries from venues to exhibit The Dinner Party by the end of 1979, including: Seattle Art Museum, University of Rochester Art Gallery, Los Angeles County Museum, the University of Cincinnati, Rochester Institute of Technology, Aldrich Museum of Contemporary Art and Contemporary Arts Center in Cincinnati. Gerhard, 161.

152 Gerhard, 150-151.

${ }^{153}$ Ibid, 221-223.

154 Ibid, 223.

155 Ibid, 162.
} 
and as they breakdown traditional roles associated with curators, designers and marketing specialists.

\section{Chicago's Original Permanent Placement Design}

Chicago's original idea for the permanent installation of The Dinner Party was a design included in the Documentary Panels as part of the original tour throughout the 1980s (fig. 15). The lithograph was coupled with text about the permanent plan (fig. 20). Chicago worked with structural designer Peter Pearce and artist/planner Carlos Diniz to design a building merging industrial technology with "personal content"156 that appears to be solely dedicated to housing The Dinner Party. The triangular building would include a second floor with the Entryway Banners, and space for people to look down upon The Dinner Party table. The plan shows benches in the porcelain-walled table gallery, and a library surrounding, perhaps with information on the women featured. The text reads:

To sustain the vision of the Dinner Party it is important to create a special environmentone that is consistent with the imagery, the esthetic processes, and the implicit values of the piece. I envision a ceramic room whose walls extend the yearning toward liberation that the plates embody. I imagine that the shape of the building that houses the Dinner Party would become - like the Dinner Party itself - a symbol for the future. ${ }^{157}$

With this evidence, the significance of the entire exhibition experience is restated with the emphasis on the environment, as well as the implied significance from the fact that Chicago and her team had a plan laid out for The Dinner Party's permanent installation before it went on tour. Achieving the goal of a permanent home was in their minds consistently throughout the tour, as they installed the exhibit in various venues, planned programming, and welcomed hundreds of

\footnotetext{
${ }^{156}$ Wall text, The Dinner Party Permanent Housing, Through the Flower and Judy Chicago, 1979.

${ }^{157}$ Judy Chicago, The Dinner Party Permanent Housing, lithograph, 1979.
} 
thousands of visitors to the experience from at each stop. The next chapter examines how the installations were installed by the various venues, and how the exhibition was received by media with an attention to the exhibition experience as a whole. 


\section{Chapter Three: The Dinner Party Exhibitions \& Curatorial Reception}

“..These are not DESIGN decisions that had to do with 'how big is the room'...they were decisions allied with both the aesthetics and the politics of The Dinner Party... of welcoming the visitor and transporting them to a 'new vision' of history. These choices are as much a part of The Dinner Party as the plates and the history panels." - Susan Hill, email with the author, August 25, $2015^{158}$ [my emphasis]

In this chapter, I summarize the installation reception and curatorial aspects specific to the original tour of The Dinner Party (1979-1988). The American tour, organized and fundraised for with local women's groups, included five community shows: in Houston, Boston, Chicago, Cleveland and Atlanta; and two museums: SFMOMA and the Brooklyn Museum. ${ }^{159}$ The original exhibition at the San Francisco Museum of Modern Art took two weeks to install, including assembling the special lighting system, assembling the 2,400 floor tiles and plates, the eight Heritage Panels, and the photo documentation of the studio workers, which at the time included both the acknowledgement panels and a series of photographs of women creating The Dinner Party. ${ }^{160}$ This installation let visitors to first see the Documentary Panels, then pass through the Entryway Banners, and then into the dark space of the artwork installation, and finally to view The Heritage Panels. The written pamphlet accompanied the exhibition as well as optional audio narratives. Viewers entered at the first side of the table, starting with the Primordial Goddess, and proceeded through to the second and third wings to the Georgia O’Keeffe place-setting. ${ }^{161}$ This experience echoed the one outlined in Chicago's exhibition manuals (see fig. 11).

\footnotetext{
${ }^{158}$ Susan Hill, email with the author, August 25, 2015. The email interviews are included in the appendix of this thesis in complete form; the initial confusion by Hill and Gelon in response to my questions about curating in particular, demonstrates not only their work outside of formal institutional "curating" but the fact that to the original creators The Dinner Party includes all of the elements.

159 Gerhard, "From Controversy to Canonization: The Dinner Party’s Journey to Brooklyn," 275.

${ }^{160}$ Gerhard, The Dinner Party: Judy Chicago and the Power of Popular Feminism 1970-2007, 163.

161 Ibid, 168-176.
} 
A number of community events supported The Dinner Party's feminist intent. Suzanne Lacy, former Chicago student, along with The Dinner Party studio artist Linda Preuss, organized The International Dinner Party at a nearby Los Angeles venue, inviting participants worldwide to hold celebrations to honor historical women in their local communities. ${ }^{162}$ This is a prime example of how The Dinner Party inspired other curatorial events. The SFMOMA hosted a soldout crowd opening night March 14, 1979. ${ }^{163}$ An all-day conference that took place the next day, “A Celebration of Women's Heritage," included poetry readings, panels, lectures, and even a workshop for children. ${ }^{164}$ This outreach activity displays the extension of curatorial definitions beyond the sole task of wall display, with an emphasis on audience participation and appreciation. The plans seemed to result successfully as the exhibition was immensely popular to public viewers. The opening brought in 5,000; throughout the three-month exhibition, over 100,000 waited in some five-hour lines to experience the piece, surpassing Museum visitor records. ${ }^{165}$

The installation, as the content, ${ }^{166}$ was met with both praise and criticism. Regarding the reception of the exhibition experience, one reviewer noted that some viewers expressed excitement even in the long line by getting to know one another. Of the table installation, viewers felt part of The Dinner Party. Henry Hopkins remarked: "The audience found it a real

\footnotetext{
${ }^{162}$ As telegrams came in that night, Lacy and Preuss pinned small red triangles on a map including over 200 parties in West Africa, New Zealand, Ontario, Edinburgh, Ohio and Greece among others. Elke Krasny shows how this exhibition is an early example of transnational feminism in curating, in examining complexities and contradictions among associations between women across the world "with regard to politics of location and situated knowledge." Elke Krasny, "Feminist Thought and Curating: On Method," Curating Degree Zero Archive 26 (September 2015), 63.

163 “The Dinner Party,” Elizabeth A. Sackler Center for Feminist Art, accessed April 19, 2016, https://www.brooklynmuseum.org/eascfa/dinner_party/tour_and_home/.

${ }^{164}$ Gerhard, The Dinner Party: Judy Chicago and the Power of Popular Feminism, 1970-2007, 164.

165 Judy Chicago, Dinner Party: From Creation to Preservation, (London/New York: Merrell Publishers: 2007$), 27$.

${ }^{166}$ As previously noted, the content of The Dinner Party has been examined and criticized at length from feminist and art scholars as well as journalists and other critics.
} 
experience. That's art." ${ }^{\prime 67}$ Mark Stevens for Newsweek noted the sense of engagement viewers enjoyed in viewing The Dinner Party. ${ }^{168}$ Critic Eunice Lipton expressed her dismay at the "controlling" instructions of the viewer experience: "Why the reverence, the awe, the overwhelming ambience of authority at The Dinner Party? Walk this way, not that! Whisper! Admire! Believe! Where is the invocation to question, to explore, to disagree?"169 Lipton's disapproval reflects criticism of the structure of the piece. Though many critics, including Lucy Lippard, emphasized the significance of the work's broad reach and recognized the ensuing respect from people who had never encountered anything like it. ${ }^{170}$ Lippard defended the whole of The Dinner Party and its effect on viewers, suggesting its strong curatorial impression as well as its marketability. ${ }^{171}$

Susan Diehl wrote positively of the whole exhibition experience: "The acknowledgements and documentation showed photo after photography of women with their tools in their hands: tools — not babies or typewriters. A videotape (at the exhibit) pictured interviews with a number of people who were mainstays of the project. Each told a moving story of how she came to the project, why she stayed, and how it had transformed her." ${ }^{172}$ She also pointed to the positive outcome of meeting like-minded people at the exhibition itself. Alternatively, art critic Hal Fisher negatively reviewed The Dinner Party's installation and accompanying instruction: "Chicago's conception originates in her own interpretation of medieval art: just as art taught the Bible to illiterates, so should The Dinner Party instruct us. To

\footnotetext{
${ }^{167}$ Henry Hopkins quoted in Mildred Hamilton, “The Dinner Party' Left without a Second Sitting," San Francisco Sunday Examiner and Chronicle, 1 July 1979, 6.

${ }_{168}$ Mark Stevens, "Guess Who’s Coming to Dinner?," Newsweek, 2 April 1979, 92.

${ }^{169}$ Eunice Lipton, “Ain’t Misbehavin’: At Chicago’s Dinner Party,” Cleveland Beacon 1, no. 5, June 1981, 6.

${ }^{170}$ Gerhard, The Dinner Party: Judy Chicago and the Power of Popular Feminism, 1970-2007, 232-233.

${ }^{171}$ Lucy Lippard, "Dinner Party a Four-Star Retreat: A Feminist Counterpart of the Sistine Chapel," Seven Days, April 27, 1979, 27-29.

172 Sue Diehl, “The Dinner Party, San Francisco Museum of Modern Art, March 17-June 17, 1979,” Frontiers: A Journal of

Women's Studies 4, no. 2, summer 1979, 75.
} 
this end, the presentation is obsessively literal and cloyingly ecclesiastic." ${ }^{173}$ Both negative and positive reviews reveal the impact of the structure, or the curating, on various levels, and the controversy between art as commodity, fine art or feminist politics. ${ }^{174}$

The popular response proved significant for the SFMOM run, so much so that Chicago formed Through the Flower, a nonprofit organization dedicated to coordinating and fundraising for The Dinner Party's additional exhibitions and permanent placement for visitors wanting to donate to its future. ${ }^{175}$ Through the Flower managed the exhibitions, promotions and future of The Dinner Party from 1979 until 2007. ${ }^{176}$ Still, despite its popularity, after the first few days at SFMOMA, the planned tour collapsed. ${ }^{177}$ Reasons for cancellation included the educational programming requirements, and interpretation of the installation as being political rather than fine art. ${ }^{178}$ As Chicago intentionally designed the work to be challenging traditional museum modes of exhibition curating, it was difficult for some people to view it as art. The entirety of the exhibition including the brochures, and the other "non-fine art" aspects of the Heritage Panels, Acknowledgement and Documentary Panels, as well as the controversy over the media and content, created a complex and boundary-breaking exhibition situation. ${ }^{179}$

\footnotetext{
${ }^{173}$ Hal Fisher, "Review: The Dinner Party," Artforum, Summer 1979, 6.

${ }^{174}$ Gerhard, The Dinner Party: Judy Chicago and the Power of Popular Feminism, 1970-2007, 179.

175 With the encouragement of Hopkins and with help from her The Dinner Party committee, Chicago formed Through the Flower. Chicago, Dinner Party: From Creation to Preservation, 26.

176 Through the Flower is still a nonprofit feminist organization based in Belen, New Mexico, with the mission to "educate a broad public about the importance of art and its power in countering the erasure of women's achievements." "Through the Flower," Through the Flower, accessed April 19, 2016, http://www.throughtheflower.org/.

177 Gerhard, The Dinner Party: Judy Chicago and the Power of Popular Feminism, 1970-2007, 180.

178 The Memorial Art Gallery at the University of Rochester canceled its exhibition due to the educational programming requirement by Chicago and Through the Flower for exhibiting The Dinner Party. The Seattle Art Museum canceled, claiming the space had been preempted by another project, though the director had visited The Dinner Party studio with a positive experience before its SFMOMA debut in 1979. Gerhard, The Dinner Party: Judy Chicago and the Power of Popular Feminism, 1970-2007, 183-84. Seattle's curator of modern art, Charles Cowles, publicly shared his stance: "I do not consider it fine art, but an interesting project by a group of women whom the leader was an artist. I saw it more as a political statement than art." Mildred Hamilton, “The Dinner Party' Left Without a Second Sitting," San Francisco Examiner and Chronicle, 1 July 1979 , Scene 6.

${ }^{179}$ Gerhard, The Dinner Party: Judy Chicago and the Power of Popular Feminism, 1970-2007, 185.
} 
The ensuing debate-including media criticism, praise and community-organizational support-kept the conversation alive. ${ }^{180}$

Gelon continued to write inquires to museums, cultural centers, and universities about showing The Dinner Party. She received many rejections for its size, cost, and "unfit" to regular programming, ${ }^{181}$ again calling to this resounding challenge of regular museum exhibitions and curatorial implications. A few spaces who wanted to host the exhibit did not have enough space to accommodate all of the piece. Director of the Museum of Contemporary Art in Chicago, John Neff, noted that he had no artistic reservations about The Dinner Party but simply lacked the right space, adding: "It's a moving installation with a great deal of historical interest and an impressive anthology of approaches." ${ }^{182}$ His comment refers to various aspects of the entire installation.

To Chicago, the negative institutional response to The Dinner Party was part of a larger pattern of discrimination against women and women's art. "I had deliberately set out to test the art system — to see if it would respond to art with female subject matter — but I had firmly (though naively) believed that there would be a positive outcome." 183 The content was subject to intense scrutiny from popular and academic media alike; but the challenging curatorial approach, from the art displayed on the table, to the educational and documentary components, also provoked institutional resistance. ${ }^{184}$ After the first stop at the San Francisco Museum of Modern Art, ${ }^{185}$ an article in the New York Times poignantly relayed:

\footnotetext{
${ }^{180}$ Gerhard, The Dinner Party: Judy Chicago and the Power of Popular Feminism, 1970-2007, 185.

181 Ibid, 187.

${ }^{182}$ Ann Marie Lipinski, "Public May Never Again Feast on Paean to Women," Chicago Tribune, 19 August 1979, L2.

183 Judy Chicago, The Dinner Party (New York: Penguin Group, 1996), 213.

${ }^{184}$ Popular and academic media alike covered the exhibition extensively with intense criticism for its table content being both overtly feminist and "non-art" coupled with the conservatives distaste for the vaginal imagery. Gerhard, 212.

${ }^{185}$ Gerhard, "From Controversy to Canonization: The Dinner Party's Journey to Brooklyn," 270.
} 
Though it's caught the attention of the public, The Dinner Party has not received rave notices from critics, some of whom have perceived in it more message than esthetics. But Miss Chicago, in New York last week on a promotion tour, insists that she seeks a wider audience than the 'elitist' art world that hers is an art that is meant to 'encourage social change.' 186

Chicago's outlook for not just the artwork, but its presentation and aim to affect those outside the gallery walls, a feminist intent to curating, is asserted. Chicago pointed out that despite the exhibition's popularity and profitability, institutions still would not display it, revealing "that the war is on the level of symbols and values. Women have never been the symbolmakers of the culture - they've participated in symbolmaking but they have not created the symbols from their own perspective," 187 thus pointing to the implications of the entire project.

Still, Gelon did not pause in finding alternate venues for the tour. ${ }^{188}$ Houston bookstore owner and philanthropist Mary Ross Taylor contacted Chicago about bringing The Dinner Party to University of Texas-Houston's theatre in Clear Lake City. ${ }^{189}$ The alternative, grassroots tour of The Dinner Party began. After months of networking and fundraising by Taylor, ${ }^{190}$ The Dinner Party opened March 9, 1980 inside the Developmental Arts Building, an industrial, freestanding building that was large and climate-controlled. ${ }^{191}$ Chicago was not completely content with the location, which lacked the lighting status of a museum setting, but was regardless happy to see it out of storage and in front of a new audience. ${ }^{192}$ In this location, the Entryway Banners and table were displayed in one building, and viewers crossed a small courtyard to another building to see the Heritage and Documentary Panels and the Through the

\footnotetext{
${ }^{186}$ Grace Glueck, “Judy Chicago and Trials of 'Dinner Party,' New York Times, 30 April 1979, D10.

${ }^{187}$ Chicago, personal journal, vol. 8, 17 June 1979, 151, from Levin, 319.

188 Gerhard, The Dinner Party: Judy Chicago and the Power of Popular Feminism, 1970-2007, 195.

${ }^{189}$ Chicago, From Creation to Preservation, 271.

${ }^{190}$ Former UHCL dean of sciences and humanities, Calvin Cannon helped Taylor fundraise, pointing to the popularity among men and women. Gerhard, The Dinner Party: Judy Chicago and the Power of Popular Feminism, 1970-2007, 193.

${ }^{191}$ Gerhard, The Dinner Party: Judy Chicago and the Power of Popular Feminism, 1970-2007, 193.

192 Levin, 320.
} 
Flower store. ${ }^{193}$ The Houston exhibition also included several community and educational programs throughout its run, including a panel, ${ }^{194}$ lectures on women's history and feminist art history, concerts of women's music, the debut of The Dinner Party documentary, Right Out of History, an evening of an all-women country band dance, and a quilting demonstration. ${ }^{195} \mathrm{~A}$ UHCL history faculty member created a history course around it titled, "Women in Europe."196 Chicago and Henry Hopkins met viewers and community members at the opening. ${ }^{197}$ Income from ticket sales paid for exhibit costs, with proceeds donated to Houston women's groups, a testament to Chicago and the team's authentic feminist intent. In fact, all of the factors- the educational affiliation, community fundraising, and programming — point to the significance placed by Chicago and her team on the message and experience of the artwork, impact that went beyond the gallery.

Another curatorial aspect grew out of the Houston exhibition. Exclusivity was a feminist criticism of the project's content. ${ }^{198}$ Chicago and The Dinner Party team immediately addressed this criticism by instigating the ongoing "International Honor Quilt"199 (fig. 17). To "emphasize the inclusive intentions of my art, ${ }^{, 200}$ Chicago, Through the Flower, and local groups invited the public to send small 24 " triangular quilt pieces honoring a woman of the quiltmaker's choice, which expanded and was exhibited throughout the tours in the 1980s. ${ }^{201}$ The Quilt began at the

\footnotetext{
193 Gerhard, The Dinner Party: Judy Chicago and the Power of Popular Feminism, 1970-2007, 193.

${ }^{194}$ One panel was entitled "Sexuality or Iconography: The Dinner Party Plates." Gerhard, The Dinner Party: Judy Chicago and the Power of Popular Feminism, 1970-2007, 193.

195 Ibid, 194.

${ }^{196}$ Faculty member Jean Quataert. Levin, 320.

${ }^{197}$ Gerhard, The Dinner Party: Judy Chicago and the Power of Popular Feminism, 1970-2007, 191.

${ }_{198}$ Ibid, 224-226. The criticism remains due to the fact that the project focuses on Western civilization.

199 The International Honor Quilt was originally called “The International Quilting Bee.” Levin, 320.

200 Judy Chicago, The Dinner Party, 213.

201 "Projects: International Honor Quilt," Through the Flower, accessed April 17, 2015,

http://www.throughtheflower.org/projects/international honor quilt. In 2013, it was donated to and is now housed at the University of Louisville Hite Art Institute.
} 
Houston exhibit in 1980, as another flexible but required component to the exhibition. ${ }^{202}$ The exhibition manual (see fig. 11 for example) provides instructions for hanging selections with Velcro, and venue staff were invited to select portions "in conjunction with the TTF needlework supervisors." ${ }^{203}$ Some of the eventually over five hundred quilts were exhibited at every stop after San Francisco, throughout the original 1980s tour. ${ }^{204}$ This highly inclusive contextual element spoke to the community-oriented intent of Judy Chicago's design for The Dinner Party.

Reception of the Houston exhibit varied. The Houston Chronicle responded positively to the exhibition and film: "No matter how many superlatives are used, no matter how many mind boggling statistics are quoted, mere words cannot prepare one for the impact and beauty of this monumental work of art,"205 stating the influence beyond the galleries. At this time, Lucy Lippard remarked on the environment and wall text in her cover article on The Dinner Party in Art in America. She wrote: “...For all its didactic content, The Dinner Party is first and foremost a work of visual art.... One perceives the major form, the major symbol — a shimmering white triangle looming in the darkness." ${ }^{206}$ Lippard set aside the context for the artwork, yet still remarked positively on the installation - the triangle in the darkness - revealing, once again, the impact of the curatorial structure of the piece.

The next exhibition was in Boston. A Judy Chicago fan, April Hankins, contacted Through the Flower, and was immediately tasked with finding a venue that would fit the various parts of The Dinner Party and fulfill other requirements like wheelchair accessibility and lighting

\footnotetext{
202 Judy Chicago, The Dinner Party Exhibition, installation diagrams [and instructions], n.d., Judy Chicago Papers, 20.45, Schlesinger Library, Radcliffe Institute, Harvard Library. 
specifications. ${ }^{207}$ Hankins and three other young women formed the Boston Women's Art Alliance (BWAA), modeled their office after The Dinner Party studio and managed volunteers for publicity, fundraising, installation, and staffing. ${ }^{208}$ They located the Boston Center for the Arts building, an affordable space for artists, and built new walls, resurfaced the floors, repaired bathrooms, and built a wheelchair accessible ramp. ${ }^{209}$ The BWAA also built an office, shop and security system. ${ }^{210}$ Fundraising events, letters and a sponsor program paid for the exhibition. They organized the exhibition's promotions around Boston's $350^{\text {th }}$ anniversary resulting in high attendance for the opening. ${ }^{211}$ The organization offered free admittance on Sundays including a lecture series encouraging personal discussion and agency among women. ${ }^{212}$ The events offered an overlapping point of contact between various feminist and women's groups throughout the activist and academic communities of Boston, spreading The Dinner Party's message far and wide. $^{213}$

Though the exhibition again proved popular among audiences, ${ }^{214}$ an interesting situation occurred with regards to its installation, instigated by a local review by the Boston Globe. ${ }^{215}$ Robert Taylor called it a "monumentally grotesque agitprop installation...the lunatic, obsessive vulgarity of full-scale model of a Gothic cathedral built from toothpicks." ${ }^{216}$ Taylor continued to criticize the content and aesthetics, but significant here is his scrutiny of the installation as ugly propaganda, and even further, a poor copy of a Gothic cathedral. It seems his distaste for the

\footnotetext{
207 Gerhard, The Dinner Party: Judy Chicago and the Power of Popular Feminism, 1970-2007, 199-200.

${ }^{208}$ Ibid.

${ }^{209}$ Ibid.

${ }^{210}$ Levin, 322.

211 Ibid, 322.

${ }^{212}$ Gerhard, The Dinner Party: Judy Chicago and the Power of Popular Feminism, 1970-2007, 201-202.

213 Ibid, 202.

${ }^{214}$ Ibid, 202.

${ }^{215}$ Levin, 322.

216 Robert Taylor, “'The Dinner Party' Somewhat Unappetizing,” Boston Globe, 3 July 1980, sec. 3,2.
} 
feminist message led to his heightened negative response to the unconventional approach to installation. As a letter to the editor keenly responded, Taylor "expressed in totality the defensive and threatened response that the male establishment has used throughout history in an attempt to repress and suppress expressions of loving and humanism." ${ }^{217}$ This public conversation moved Diane Gelon to write an editorial about Chicago's open art-making process inviting artists and non-artists “...to redefine the relationship of art and society, to break down barriers between fine art and the crafts traditionally practiced by women." ${ }^{218}$ This interaction regarding the installation reveals intent beyond the artwork to society.

These mixed reviews exemplify the local and national response to The Dinner Party. National attention echoed the hostility and suspicion towards Chicago, The Dinner Party and its popularity $^{219}$ with the second and last mainstream institution exhibition at the Brooklyn Museum (October 1980-February 1981). ${ }^{220}$ This installation ${ }^{221}$ included the Documentary Panels, followed by the Entryway Banners hallway, the table, the Heritage Panels, and sections of the International Honor Quilt. While content was at the height of criticism, so was the attention to the record-breaking crowds.

Hilton Kramer complained in a lengthy negative review of the Brooklyn show: “...it is failed art, it is so mired in the pieties of a political cause that it quite fails to acquire any independent life of its own,"222 suggesting a negative connotation with the supposedly "political" information observed in the installation. Presenting an opposite interpretation, Sheryn

\footnotetext{
${ }^{217}$ Betty Kaufman, "Celebrating the History of Women," Boston Globe, 15 July 1980, letters to the editor.

${ }^{218}$ Diane Gelon, “The Critic's Voice: Who Speaks for Us?” Sojourner, Oct. 1980, 5.

${ }^{219}$ Gerhard, The Dinner Party: Judy Chicago and the Power of Popular Feminism, 1970-2007, 213.

220 "The Dinner Party," Through the Flower, accessed April 19, 2016,

http://www.throughtheflower.org/projects/the_dinner_party.

${ }^{221}$ October 1980-January 1981.

${ }^{222}$ Hilton Kramer, “Judy Chicago’s ‘Dinner Party’ Comes to Brooklyn Museum,” New York Times, 17 October 1980, C1.
} 
Goldenhersh remarked positively on Chicago's apparent “community responsibility and respect for the intellect, ${ }^{, 223}$ referencing the multiple layers of curatorial and educational context. Another reviewer also complimented the popularity, pointing to the curating: “...Chicago has achieved one of her stated goals: to create a new audience for women's art by making it accessible to people generally uninterested in abstract works." ${ }^{224}$ Two other differing reviews of the Brooklyn installation exemplify the scrutiny of the sacred aspect to the installation. SoHo News described it as "Commemorative, ritualistic, holy," and also "polysemic" pointing to its multiple modes of communicating (or curating) the message. ${ }^{225}$ While Laura Holland of the Valley Advocate called it a "pretentious atmosphere [that] infects its shrine-like installation,"226 suggesting the sacred atmosphere undermined the artwork.

After Brooklyn, the Cleveland exhibit was next (May-August 1981). ${ }^{227}$ Here it was located in a former (Jewish) Temple. ${ }^{228}$ Much like the other community exhibitions, this was organized and fundraised for by the self-formed organization Ohio-Chicago Art Project, including community members as well as students and professors from the University of Akron. ${ }^{229}$ This committee overhauled the space including furnishing a new lighting system. ${ }^{230}$ They helped Gelon, Hill and Bunzick install The Dinner Party and the accompanying chinapainting exhibition. ${ }^{231}$ Local and national reviews commented positively and negatively about the content. One of the most negative reviews of the Cleveland installation was written by

\footnotetext{
${ }^{223}$ Sheryn Goldenhersh, “Judy Chicago Hosts Her 'Dinner Party' at the Brooklyn Art Museum,” St. Louis Jewish Light, 5 November 1980, 7.

${ }^{224}$ Marta Hallowell, "Chicago Comes to Brooklyn,” New York Times, 20 October 2 1980, 50.

225 John Perault, “No Reservations,” SoHo News, 22 October 1980, 19.

${ }^{226}$ Laura Holland, “It's Art! It's Feminism! It's 'The Dinner Party!!!’” Valley Advocate 3, no. 9, 23 July 1980, 18-19.

${ }^{227}$ Levin, 326.

${ }^{228}$ Ibid, 326.

${ }^{229}$ Ibid.

${ }^{230}$ Gerhard, The Dinner Party: Judy Chicago and the Power of Popular Feminism, 1970-2007, 204.

231 The exhibit brought 33,000 people and raised $\$ 58,000$ beyond its costs. This surplus was donated to Ohio nonprofit women's groups including a rape crisis center and batter women's shelter. Levin, 327
} 
Lolette Kuby. She deemed it "profoundly misogynous" and suggested that it "works best as a joke." She called it sterile, and a "stylized arrangement of stylized details, a last supper at which no guests arrived." 232 The bitter content critique continues, however, and does comment subtly on the curatorial choices: "The long view did not disappoint me. Dramatically lighted, the huge triangle glowed with the play of texture and color-porcelain, satin, china, white, deep crimson, purple." She also noted: "Its presentation asserts that it is a work of art of great importance. But the presentation cannot infuse the work with what it lacks...." At the end, she backhandedly complimented the written context: "Without the written names and the reams of written addenda, The Dinner Party would be only a moderately successful piece of moderately offensive art."233 The reference to the "written names and reams of written addenda" is likely in reference to the Heritage Panels explaining the women's role in history, again pointing to the seemingly overlooked yet keen and significant installation.

During the run, the Cleveland feminist journal Beacon dedicated an entire issue to The Dinner Party, presenting opposing sides to the debate. Both positive and negative articles referred to the way the exhibit was structured. ${ }^{234}$ The positive angle emphasized the "safe space" of transformation that allowed visitors with little or no understanding of feminism or the artistic process to come to understand the context and the collaborative aspect. ${ }^{235}$ The negative review found the installation overly instructional and a "monumental homage to the status quo" for its emphasis on reverence. ${ }^{236}$ Again these counter-examples reveal the controversy and the

\footnotetext{
${ }^{232}$ Lolette Kuby, “The Hoodwinking of the Women's Movement: Judy Chicago's 'Dinner Party,'” Frontiers: A Journal of Women's Studies 6, No. 3 (Autumn 1981): 127.

${ }^{233}$ Ibid, 127-129.

${ }^{234}$ Gerhard, The Dinner Party: Judy Chicago and the Power of Popular Feminism, 1970-2007, 230-231.

${ }^{235}$ Ibid, 231-232.

236 Ibid, 230.
} 
significance of the curatorial aspects in interpreting and experiencing The Dinner Party as conceived by Chicago.

The next stop was in Chicago's hometown, Chicago (in a donated space, September 1981-February 1982). ${ }^{237}$ This location was due to Gelon's persistence in communicating with community members ${ }^{238}$ who raised the money and found the space after viewing over 150 sites. ${ }^{239} \mathrm{~A}$ developer donated the site in the hopes of gentrifying the neighborhood, ${ }^{240}$ and the group renovated the thirteenth floor of the old Printing House Row building. ${ }^{241}$ As with the shows in Cleveland and Boston, the community organizers held fundraisers, networked and contributed personal donations. ${ }^{242}$ Again, this exemplifies the collaborative fundraising strategy of putting the exhibition together throughout the tour.

Over 100 volunteers managed the crowds that lined the streets for the opening which the artist attended. A professional dance group performed in the street, an all-women orchestra played, and a slide-exhibition featuring women in Chicago's history was presented across the street. ${ }^{243}$ People needed to board the elevator to view this exhibition that included the Entryway Banners, the Documentary Panels, the table, the Heritage Panels and the International Honor Quilt, to which "Chicago artists contributed enthusiastically." 244 The exhibition included the documentary shown next-door, so that viewers could see it first to understand the artistic and collaborative process beforehand. A bookstore was also included in the exhibition, which held

\footnotetext{
237 The show was extended from Jan. 3 due to its popularity. Levin, 328.

${ }^{238}$ Mostly bankers or developers who called themselves "The Rosyln Group." Gerhard, The Dinner Party: Judy Chicago and the Power of Popular Feminism, 1970-2007, 205.

${ }^{239}$ Levin, 328.

${ }^{240}$ To which it did contribute. Gerhard, The Dinner Party: Judy Chicago and the Power of Popular Feminism, 1970-2007, 208.

${ }^{241}$ Ibid., 206.

242 Ibid., 207.

243 "The Dinner Party in Chicago," The Dinner Project in Chicago, accessed December 2, 2015, http://www.dinnerpartyprojectchicago.org/PageExhibition/Exhibiton.html..

${ }^{244}$ Ibid.
} 
The Dinner Party and Judy Chicago items, as well as artwork by regional artists. ${ }^{245}$ Artesemia Gallery, a Chicago gallery for women-artists, hosted the china-painting exhibition. Chicago gave a tour to the mayor Jane Byrne, another community aspect that extended the context of the exhibition as well as made it localized. Several additional community events were planned around the Chicago exhibition. ${ }^{246}$ All of these outreach activities point to the outward and collaborative process of organizing and curating the exhibit, as well as creating an accessible context for viewing the exhibition itself.

Again, media reception in Chicago was mixed, including a notably negative review in Chicago Tribune, where it was called "foolishly developed and poorly executed,"247 a slight on the process and installation. Still, the exhibition was another ticketed-success, with money left over that The Roslyn Group invested in women in art throughout the city, again emphasizing the exhibit's work beyond the artwork. ${ }^{248}$

Beyond the United States, as The Dinner Party international tour lasted eight years and included exhibitions in three Canadian Museums, at the Fringe Festival in Edinburgh, The Warehouse in London, Frankfurt's Schirn Kunsthalle (a contemporary art museum), and the Royal Exhibition Building in Melbourne, Australia in $1988 .{ }^{249}$ Though the exhibitions continued

\footnotetext{
245 Ibid.

${ }^{246}$ Including "Women's Heritage: Celebration and Challenge" a conference organized by the Roslyn Group, coinciding with two other conferences being held in Chicago at the time in reference to the 1893 Chicago World's Columbian Exhibition, and the tenth anniversary of the Chicago area women's history conference. Gerhard, The Dinner Party: Judy Chicago and the Power of Popular Feminism, 1970-2007, 207.

An interesting review complemented the connections with the historical event. "Like the later work [The Dinner Party], the [Woman's Building at the 1893 Exposition] building represented a prodigious effort, and also showed the kinship between the two works is further apparent on the panels that lined the grand rotunda of the Woman's Building: Listed were the 'golden names of women who in past and present centuries of done honor to the human race,' a roll-call echoed in the names on the floor of 'The Dinner Party."” Nancy Cott, “An Experiment of Women, 1893,” New York Times, 19 July 1981, A9.

${ }^{247}$ Alan G. Artner, "Inanity Outweighs the Controversy of 'Dinner Party,"” Chicago Tribune, 14 September 1981, B8, quoted in Gerhard, The Dinner Party: Judy Chicago and the Power of Popular Feminism, 1970-2007, 329.

${ }^{248}$ Atlanta was the other United States stop - though it occurred after two Canadian exhibitions in 1982. The High Museum refused to show The Dinner Party but the mayor's wife, Jean Young, brought it to Atlanta with sponsorship from the Sculptural Arts Museum to hold it in the Egyptian Ballroom of the Fox Theatre, "one of the grand theatres from the golden age of movie palaces.” The exhibition ran from July 23-October 3, 1982. Levin, 331.

${ }^{249}$ Gerhard, "From Controversy to Canonization: The Dinner Party’s Journey to Brooklyn," 273.
} 
to meet derogatory reviews for content, the viewership remained extremely high and brought in funding for the organizations and venues in which it was hosted. ${ }^{250}$

The exhibition at the Museum of Contemporary Art in Montreal (March-May 1982), brought more viewers than the Museum normally saw in a year and received warm local reviews. ${ }^{251}$ In Toronto, the venue's management did not acknowledge The Dinner Party as a work of art. From its success in Montreal, The Art Gallery of Ontario expected large crowds ${ }^{252}$ and recognized it officially as a "fundraiser" without declaring its merits as a work of art. ${ }^{253}$

They popularity proved successful; the summer 1982 exhibit sold out in its second week, and had to limit the viewing to 125 people per hour; the gallery raised $\$ 65,000$ for their purchase fund. It was here that Chicago had dinner with Canadian senator, and met with the Prime Minister and author Margaret Atwood. Two critics warmly regarded The Dinner Party's entire structure. 254 John Bentley Mays recognized the importance of "collective creation" and its "vast narrative,"255 and Robert Fulford noted the audience participation and called it "one of the most stirring events in the recent history of public art." ${ }^{, 256}$ The last Canadian exhibition was at Glenbow Museum, Calgary, Alberta, Canada (December 1982-February 1983). ${ }^{257}$

The Dinner Party went into storage for a little over a year until theatre producer Diane Robinson brought it to the Edinburgh Fringe Festival in 1984, known for hosting cultural events in nontraditional spaces. ${ }^{258}$ Chicago was not present for this opening, but sent Mary Ross Taylor

\footnotetext{
250 Ibid.

${ }^{251}$ March 11-May 7, 1982. Levin, 330.

252 Ibid, 330.

253 John Bentley Mays, "Epic Dinner Party strikes to the core," The Globe and Mail (Canada), May 22, 1982.

${ }^{254}$ Levin, 331.

255 Mays.

${ }^{256}$ Robert Fulflord, "Dinner Party’s Sweep is Breathtaking,” Toronto Star, 12 June 1982.

${ }^{257}$ December 1982 - February 1983. Though not much can be found about the Edinburgh exhibition in available texts. "The Dinner Party tour," Through the Flower, accessed December 4, 2015, http://www.throughtheflower.org/projects/the_dinner_party.

${ }^{258}$ Levin, 343.
} 
to speak on her behalf. ${ }^{259}$ Next the exhibition traveled to London's Warehouse, another alternative space. ${ }^{260}$ Feminist philosopher Germaine Greer presented at this exhibition opening ${ }^{261}$ which was met with various reviews once again. ${ }^{262}$ Regarding the installation, Richard Cork remarked on its "strong theatrical presence," and "awesome" execution and the significant history it relays. ${ }^{263}$ These exhibitions maintained Chicago's installation concept along with community inclusive practices.

The last European stop in 1987 took place in Frankfurt's Schirn Kunstalle, a contemporary art museum, ${ }^{264}$ a year after The Dinner Party festival took place in a restored Opera House in Frankfurt. ${ }^{265}$ The three-day festival to raise money to exhibit The Dinner Party was organized by Dagmar von Garnier, a self-described "folkorist dance expert." 266 Women were invited to research and dress up as a woman inscribed on the floor of The Dinner Party, while an all-female orchestra played during the opening. ${ }^{267}$ Over 1,000 women participated ${ }^{268}$ exemplifying the tremendous excitement over the piece and its message.

Despite the popularity, there was a point of contention regarding the contextual events in relation to Chicago's conception. Chicago spoke about the Holocaust during her opening lecture, and planned to also refer to it during another presentation on the third day of the festival, in relation to the persecution of witches, but von Garnier did not allow it. ${ }^{269}$ This disagreement

\footnotetext{
${ }^{259}$ Mary Ross Taylor was the instigator of the Houston exhibition, who was now working in Chicago's studio. There is also not much written about the London Warehouse exhibition (further research into the Judy Chicago papers could provide insight). Levin, 343.

${ }^{260}$ In the spring of 1985. Chicago, The Dinner Party: from Creation to Preservation, 276.

${ }^{261}$ Ibid, 277.

${ }^{262}$ Levin, 344-345.

${ }^{263}$ Richard Cork, "Monumental,” Listener, 21 March 1985. Levin, 344.

${ }^{264}$ Levin, 360.

265 Ibid, 358.

266 Ibid, 358.

267 Chicago, The Dinner Party: From Creation to Preservation, 277.

${ }^{268}$ Gerhard, "From Controversy to Canonization," 272.

${ }^{269}$ Levin, 358-59.
} 
resulted in a public falling-out between the two. ${ }^{270} \mathrm{In}$ fact, some reviewers and participants found the festival's folklore-programming reminiscent of Nazi era rituals. ${ }^{271}$ Today, the festival's vast participation is remembered by Chicago with warm regard, as she wrote in 2014: "In 1986, a group of women, under the leadership of Dagmar von Garnier, put on a fabulous festival at the restored Opera House in Frankfurt, Germany, as part of its effort to get The Dinner Party exhibited there...."272 Though The Dinner Party exhibit in Frankfurt the following year was deemed "the most popular" exhibition of the year for the Museum, ${ }^{273}$ it was met with negative criticism from German media (perhaps due to the controversy with von Garnier), which focused on the content and Chicago's personal feminism. ${ }^{274}$ This controversy echoes today with its recent installations, revealing how an exhibition might be promoted by curators and interpreted by viewers — or without—regard for the artist's intentions.

Finally, The Dinner Party's international tour ended in Melbourne, Australia in $1988 .{ }^{275}$ Following Frankfurt's festival, this opening, at the Royal Exhibition Building, included a celebratory "Dinner for 1000 Women." 276 This exhibition, now nine years after The Dinner Party was completed, took place during Melbourne's bicentennial celebrations. This proved a controversial context for local critics who emphasized its supposed out-of-date feminism and lamented local artists who were doing just as notable work. ${ }^{277}$ Organizers, too, highlighted "the affirming aspects of the work rather than its status as a work of art." ${ }^{278}$ Thus, it seems the local

\footnotetext{
${ }^{270}$ Ibid, 359.

${ }^{271}$ Ibid.

272 Chicago, The Dinner Party: From Creation to Preservation, 277.

${ }^{273}$ Levin, 360.

274 Ibid, 361.

275 Chicago, The Dinner Party: From Creation to Preservation, 277.

276 Ibid.

${ }^{277}$ Kate MacNeill, “When Historic Time Meets Julia Kristeva's Women's Time: The Reception of Judy Chicago's The Dinner Party in Australia," Outskirts: Feminisms Along the Edge 18 (May 2008): 18.

278 Ibid, 1.
} 
context of Australia impacted the curatorial structure and interpretation of the exhibition. Still, as MacNeill notes: "It was for these purposes that Judy Chicago had conceived such an ambitious project, and in her speech in Melbourne, Chicago described the work as enabling the viewer to understand their personal experience as 'part of a larger, universal female experience'."279 Once again, the exhibition proved so popular that they had to extend gallery hours to field the number of people in line for the exhibition. ${ }^{280}$

Overall, over one million visitors viewed The Dinner Party during the International tour, 1979-1988. ${ }^{281}$ In 1988, The Dinner Party went back into storage, and Through the Flower focused on finding a permanent home. One of Chicago's preliminary goals with The Dinner Party was to find it a lasting location in order "to overcome the repeated erasure of women's achievements." ${ }^{282}$ Chicago's plan for the permanent home included all of the structures of The Dinner Party experience - the banners, table, Heritage Panels, acknowledgment and Documentary Panels, documentary film and the International Honor Quilt. Though she became flexible with certain aspects later on, she and her team always understood that The Dinner Party needed all of these elements to get its message across and have the broadest impact possible.

\section{Sexual Politics: The Dinner Party in a Group Feminist Exhibition, 1996}

The Dinner Party was back in storage until 1996, when Henry Hopkins initiated another exhibition of the monumental piece at the University of California Los Angeles' Armand Hammer Museum of Art; this time in Sexual Politics: Judy Chicago's The Dinner Party in

\footnotetext{
279 Ibid, 18.

280 Ibid, 18.

${ }^{281}$ Gerhard, "From Controversy to Canonization," 273.

${ }^{282}$ Chicago, "Introduction: Restoring Women to History," 13.
} 
Feminist Art History, a group exhibition of fifty-seven artists' feminist artworks, curated by art historian Amelia Jones. ${ }^{283}$ This exhibition included the artwork table, the banners, the acknowledgement panels, the seven Heritage Panels and portions of International Honor Quilt, in context with other work "to expand upon the popular art and historical understanding of issues raised by the piece by showing how they have been addressed in other feminist work." ${ }^{284}$ Five prominent feminist artists asked that their work not be included in the exhibition due to the focus on The Dinner Party, revealing the controversy even inside the art and feminist sphere regarding Judy Chicago's seminal work. ${ }^{285}$

Sexual Politics also stood as an important reflection on The Dinner Party with regards to feminist art, and to feminist curatorial interventions. ${ }^{286}$ Jones described her intentions as both examining feminist discourse as contemporary, and as critiquing the dismissal of The Dinner Party within this discourse:

... I wanted to challenge the tendency in mainstream media to proclaim feminism and feminist art gone and done with (the 'post' feminism discourse). I also wanted to look critically at the tendency within the discourses of feminist art history and criticism...to dismiss works such as 'The Dinner Party' in one stroke as 'essentialist.' This approach, and the implicit dismissal of the hundreds of thousands of women who loved the piece, seemed hypocritical...I wanted to challenge the refusal in these discourses to acknowledge a binarism in a critical model that functioned by 'othering' a particular kind of practice as unacceptable by over-simplifying its meanings, contexts and reception. When the UCLA Armand Hammer Museum of Art approached me with the project of curating 'The Dinner Party,' it was my dissatisfaction with this state of affairs that prompted me to accept the challenge, while insisting on restaging this work only within much broader context that honored the other practices developing at the same time and that foregrounded the complexity of debates surrounding these works...In re-presenting

\footnotetext{
283 Ibid, 275.

${ }^{284}$ Amelia Jones, Sexual Politics: Judy Chicago's The Dinner Party in Feminist Art History, 255.

285 Gerhard, 268.

286 Angela Dimitrakaki wrote, "The exhibition and its accompanying publication proved to be a critical exercise on how to narrate an artwork's political history through research and display." Angela Dimitrakaki, "The Lessons of Sexual Politics: From the 1970s to Empire, An Interview with Amelia Jones," Politics in a Glass Case, ed. Angela Dimitrakaki and Lara Perry, Liverpool: Liverpool University Press (2013): 93.
} 
'The Dinner Party' I wanted to suggest that perhaps the populist strategies of a feminist such as Chicago can be equally effective, if in different ways, in activating spectators. ${ }^{287}$ By Jones' reference to Chicago's populist strategies to activate spectators, with Sexual Politics, it seems Jones was not just presenting a critical exhibition, but also recalling the methods of Chicago's that might be beneficial to exhibitions in reaching broad audiences.

Sexual Politics came under scrutiny by art and feminist critics alike. The LA Times' Christopher Knight called its curation "a fiasco...Art is...misused, its efficacy undermined by curatorial trivialization. You must run screaming from the room." 288 Though again, the exhibition was enormously popular and brought in over 55,000 viewers over four months. ${ }^{289}$ It was after this exhibit that Judy Chicago poignantly reflected on criticism of the content:

It is true that I understood the irony of using women's crafts to express women's history, but The Dinner Party actually crosses crafts. Nobody ever talks about the industrial design of the table, the technological structure of the floor, the way it's engineered...It's as if the plates and the runners exist off the structure, out there in some space! ${ }^{290}$

Chicago's recounting of the significance of the structure and installation of The Dinner Party reveal the artist's concept of The Dinner Party as the entire exhibition, and moreover, exemplifies how it has been overlooked. After Sexual Politics, The Dinner Party again went back into storage, and Through the Flower continued to search for a permanent home. The 2002 purchase of The Dinner Party table and some of the elements, provided a home to some extent, with the Elizabeth A. Sackler Center for Feminist Art inside the Brooklyn Museum which is examined in the next section.

\footnotetext{
${ }^{287}$ Ibid, 94-5.

288 Gerhard, 269.

${ }^{289}$ Ibid.

${ }^{290}$ Judy Chicago quoted in Judith Lewis, "The Trouble with Judy: Reflections on The Dinner Party and the Artist Who Created It," Los Angeles Weekly, 18 April 1996, 32.
} 


\section{Elizabeth A. Sackler, The Sackler Center Obtains (most of) The Dinner Party}

When Elizabeth A. Sackler, philanthropist and longtime patron of Chicago's, envisioned a center dedicated to feminist art, she acquired and donated The Dinner Party to the Brooklyn Museum along with funds to create the Elizabeth A. Sackler Center for Feminist Art in 2002 (opened in 2007). ${ }^{291}$ The Dinner Party was exhibited in the Brooklyn Museum in 2002 to celebrate the establishment of the Center. The exhibit included the items they purchased: the Entryway Banners, the table artwork, the Heritage Panels and the Acknowledgement Panels. An exhibition pamphlet (fig. 18) describing the project was available at no additional cost. Judy Chicago, Donald Woodman, Susan Hill and Diane Gelon were present for this 2002 installation as coordinators. ${ }^{292}$ The installation at this point took place in the Brooklyn Museum's Rotunda, before the Elizabeth A. Sackler Center was designed and built. ${ }^{293}$

Arnold Lehman, the then-director of the Brooklyn Museum, said his goal for acquiring The Dinner Party was: "to produce a 'comfort level' for 'a cross section of the community that doesn't feel at home in a museum.' This involves banishing 'the authoritative voice...that determines 'this is the way it is, and if you don't understand it, get out of here." ${ }^{294}$ His statement acknowledges his role in the display of The Dinner Party as well as the privileged point of view of the museum by referring to the welcoming ambience of the exhibit and indirectly referencing the informational panels, allowing for people to understand the work and its meaning, rather than the 'authoritative' way he refers to, in leaving information out, carrying an elite attitude toward

\footnotetext{
${ }^{291}$ Gerhard, "From Controversy to Canonization: The Dinner Party's Journey to Brooklyn,” 275.

292 Diane Gelon and Susan Hill emails with the author, November 10, 2015.

${ }^{293}$ Donald Woodman, interview with the author, November 8, 2015.

${ }^{294}$ MG Lord, "The Table is Set, At Last, in a Home," New York Times, 8 September 2002, 78A.
} 
the high-end art. It also suggests that hosting The Dinner Party would impact the experience of the entire museum, implying a curatorial respect.

Seeking a democratic process for forming the Center and installing The Dinner Party, the Center opened up an architectural design competition for the space that led to the selection of architect Susan T. Rodriguez' designs. ${ }^{295}$ Rodriguez wrote of her design process with regard to The Dinner Party:

...In the past, temporary installations of The Dinner Party were events in themselves. I felt that as the heart of the new Center, the artwork could be made even more influential if the piece was encouraged in a variety of ways. The design strategy intentionally opposes the "white box" gallery approach typically applied to housing contemporary art. Instead the architecture actively engages the art, with the distinct purpose of deepening the visitor's appreciation of and connections to it. ${ }^{296}$

Rodriguez explained that the organization of The Dinner Party and its galleries related to the rest of the Sackler Center spaces. Rodriguez' structure for The Dinner Party was similar to its installation at San Francisco Museum of Modern Art in $1979^{297}$ with regards to the order of Entryway Banners, artwork table and Heritage Panels. The installation as designed by Rodriguez with curator Maura Reilly did not, however, involve consultation with Judy Chicago or any of the original team members. ${ }^{298}$

In Chicago's book complementing the opening of the Center, The Dinner Party: From Creation to Preservation, the artist relayed the importance of attention to curatorial decisions for art by women and the significance of the Sackler Center's mission in housing The Dinner

\footnotetext{
${ }^{295}$ Susan T. Rodriguez, “A Triangular Gallery,” Brooklyn Museum: Elizabeth A. Sackler Center for Feminist Art, New York: Polshek Partnership, LLP (2009): 7.

${ }^{296}$ Ibid.

297 Gerhard, The Dinner Party, 169.

${ }^{298}$ Donald Woodman, interview with the author, November 8, 2015. This is detailed in Chapter Five.

I attempted to obtain a formal agreement from various parties but was unable to determine if there is one; if there is one, I was not allowed access to it.
} 
Party. ${ }^{299}$ "There is an ongoing problem; women's art is generally shown in a strictly patrilineal environment....The Sackler Center will foreground the history of feminist art. ${ }^{" 300}$ She asserted that the challenge for displaying work by women is to provide an appropriate context without ghettoizing the work and that this is not just an issue for women, but to African American artists, Native American artists, and other underrepresented groups in mainstream museums and art galleries. The importance of creating such a context, according to Chicago, is essential to encourage viewers to decide for themselves what is a "great work of art." ${ }^{\text {"301 }}$ She wrote:

...Women's art must be seen in the larger context of both women's history and women's struggle for self-expression. Without that framework, each woman's achievement threatens to be seen as an exception, rather than another link in the long chain of accomplishments that will one day be recognized....Re-researching the 1,038 women of The Dinner Party (for the 2007 re-installation) made it clear that erasure continues to be a threat - because in large part—at this point, there are so few institutions devoted to preserving women's achievements. ${ }^{302}$

It is clear Chicago, some twenty-eight years after designing the original The Dinner Party exhibition design, still saw the context around the exhibit as essential in experiencing artwork and for reaching broad audiences. Her artwork and research between these times, as well, demonstrated her continued emphasis placed on curatorial structures, such as The Birth Project $(1980-85){ }^{303}$ In her second autobiography she reflected on this time, "Who is the audience for my art and how can I best reach it while remaining true to myself, my ideas, and my aesthetic intentions? How can I exhibit (distribute) my work so that the varied audience I have built will be able to see it? And how can I ensure that my work will be presented so that its larger context

\footnotetext{
${ }^{299}$ Chicago, The Dinner Party: From Creation to Preservation, 286.

${ }^{300}$ Ibid.

301 Ibid.

302 Ibid, 288.

303 "Birth Project," Judy Chicago, accessed July 28, 2015, http://www.judychicago.com/gallery.php?name=Birth+Project+Gallery.
} 
will be clear?" ${ }^{304}$ On designing The Birth Project series after The Dinner Party, Chicago

reflected in a personal email:

... I was still outside the art system in my content, my goals as an artist and my ideas which were to make art accessible to the viewers, an idea that was anathema to the modernist paradigm that prevailed. I was working on my imagery and on installation to achieve this. I brought these same goals to the "Birth Project", my next collaboration. On that project, I worked with a very gifted designer named Steven Hamilton who designed all the "BP" exhibition units so that they could be easily installed by anyone (as I didn't want another battle with the art world in terms of having my work shown - which, as you know - I had with "The DP" which was exhibited around the world via an unprecedented grass-roots tour). The result with the "BP" was over 100 shows in venues from birthing centers to museums. Still today, there is resistance by museums to including the Documentary Panels that I created to establish context for the viewing experience in that many people know little about needlework and there's still considerable ignorance about the subject of birth. ${ }^{305}$

She wrote directly about how the structure of installation and promotion of The Dinner Party impacted her later exhibitions in The Dinner Party: From Creation to Preservation. Regarding creating a context of Documentary Panels with information on needlework and the birth experience, so viewers could "understand both the art and all that went into its creation." ${ }^{306} \mathrm{Her}$ work has been included in several exhibitions recently. ${ }^{307}$ In relation to curating, the exhibition Why Not Judy Chicago? at Azkuna Center in Bilbao, Spain, ${ }^{308}$ included works from across

\footnotetext{
${ }^{304}$ Chicago, Beyond the Flower, 122.

Chicago's other work, such as The Birth Project (1980-85) and Holocaust Project (1985-93), were also created with collaboration and with the aim of bringing social justice ideas to the forefront in a visual manner that can be understood by mass audiences through the curatorial instructions included in her exhibitions.

305 Judy Chicago, personal email with author, April 22, 2015.

306 Judy Chicago, The Dinner Party: From Creation to Preservation, 278.

Of course, Chicago's work spans various other series. Her most recent work listed on her website, Heads Up (2012), include glass paintings on glass acrylic stands, and bronze and glass sculpture exploring genderless physiognomy. "Judy Chicago: Heads Up," Judy Chicago, accessed November 10, 2015, http://judychicago.com/gallery.php?name=Holocaust+Project+Gallery. ${ }^{307}$ Chicago's work was included in 2011/2012 and Pacific Standard Time (the Getty funded initiative documenting and celebrating southern California art from 1945-1980, and the 2014 nationwide exhibitions and events celebrating her 75th birthday. "Chicago Corner," Judy Chicago, accessed November 10, 2015, http://judychicago.com/news/chicago-corner.php.

${ }^{308}$ Curated by feminist curator Xabier Arakistain.
} 
Chicago's career, emphasizing the artist's intent of transforming art institutions. ${ }^{309}$ This presents impetus for further examination into the curating of this contemporary exhibition and Chicago's potential curatorial input or inspiration. Still, The Dinner Party remains her most known and monumental artwork, standing at the forefront curatorially and contextually of feminist artwork past, present, and future. Chicago's curatorial methods can offer a significant model for feminist curating. ${ }^{310}$ This points to the significance and timeliness of this study, which details Chicago's curatorial methods in the next chapter.

309 “Why Not Judy Chicago?” Art Agenda, accessed November 10, 2015, http://www.art-agenda.com/shows/why-not-judychicago-at-azkuna-zentroa/.

${ }^{310}$ It is telling to also examine the parallel with curating in her book, Institutional Time, as she recounts her experience returning to academia at six different educational institutions after a 25-year hiatus 1999-2005. Missing still, she emphasized, was young women's knowledge of women's history, Chicago asserts that without this knowledge, they cannot "draw on the experiences of earlier women to guide them." She called for a key inclusion of women's history, specifically the feminist art movement, "because it marked when women were first able to claim the right to express their experiences clearly." Judy Chicago, Institutional Time: A Critique of Studio Art Education (China: The Monacelli Press: 2014), 12. This clearly has implications for curating, including integrating art by women and minority artists into exhibitions and collections, and not ignoring the history of feminist art. 


\section{Chapter Four: The Dinner Party and Feminist Curating Considerations}

Judy Chicago's structuring of The Dinner Party provides several specific curatorial implications. In this chapter, consulting contemporary curatorial scholarship, I outline the following specific facets of curating gleaned from Chicago and The Dinner Party: collaboration and networking; work selection; assembly; exhibition didactics; accessibility and interactivity; and institutional acknowledgement. These aspects, if addressed, can lead to a feminist curated exhibit. In this paper, feminist curating is broadly defined as collaboratively organizing a critically rich and regionally contextualized exhibit that questions status quo, while attempting to reach the broadest audience possible. This definition was created with a combination of definitions from Chicago and scholars outlined in this chapter. The chapter also highlights issues regarding curating feminist or women-centered exhibitions which The Dinner Party exemplifies. Lastly, some challenges to feminist curating and contemporary issues in feminist curating are discussed to recognize potential limitations when considering the methods.

There are various feminist approaches to curating, many of which are understood with Judy Chicago's development decades ago, in her artistic practice, and as conceiver of The Dinner Party. ${ }^{311}$ In an email, Chicago recently defined feminist curating as: "providing a context to allow the broadest audience to understand and appreciate the content." ${ }^{\prime 12}$ This belief serves as a foundation for the more specific planning and structuring of The Dinner Party outlined in this chapter while relating to contemporary discourse. Chicago has also acknowledged that she hopes someday not to need "special attention" drawn to women artists because "their

\footnotetext{
311 Of course, many of Chicago's methods (though unrecognized as such) are applied in contemporary curatorial practice in general, along with those of other artists of the 1960s-1970s suggesting a topic for further discussion. The focus of this paper on feminist curating is not meant to separate, but to rather highlight the innovation and significance of feminist curatorial scholarship as it is typically overlooked.

312 Judy Chicago, email with the author, April 22, 2015.
} 
contributions become a permanent and fluid part of our history and experience as a human race;" but until then, such attention must be paid in terms of exhibitions, artworks and critical context. ${ }^{313}$ What follows is an outline of curatorial methods gleaned from The Dinner Party.

\section{The Dinner Party Curating Consideration: Collaboration and Networking}

A main component of Chicago's feminist mindset in organizing The Dinner Party was collaboration - in making the artwork, structuring the exhibition, and networking for grassroots exhibition coordination (including fundraising, finding a venue, promotion, and community programs). Chicago used an alternative strategy to the curator-as-director, or as being the sole eye of the exhibition organization. Contemporary scholarship asserts this method as significant to creating a feminist exhibition context.

Several contemporary scholars point to collaboration as a major part of feminist curating. Curator Bojana Pejic discusses curating ${ }^{314}$ informed through a transnational curatorial collaboration of discussions across departments and outside the museum. ${ }^{315}$ Pejic also expressed her enthusiasm for the curating of Gender Check (2009-10), ${ }^{316}$ in bringing together professionals who might not have worked together otherwise to initiate new contacts and networks for future projects. Authors Alicia Villeneuve and Pat Viera also point to collaborative curatorial process, suggesting that conversations within the museum across departments, and outside the museum

\footnotetext{
313 Judy Chicago, The Dinner Party: Restoring Women to History, 27.

314 The exhibition Gender Check: Femininity and Masculinity in the Art of Eastern Europe, Museum Moderne Kunst Stiftung Ludwig, Vienna, 2010.

${ }^{315}$ Katrin Kivimaa and Bojana Pejic, "Gender Check, Feminism and Curating in Eastern Europe, An Interview with Bojana Pejic," in Politics in a Glass Case, ed. by Angela Dimitrakaki and Lara Perry (Liverpool: Liverpool University Press, 2014), 173183.

316 “Gender Check," Erste Foundation, accessed April 19, 2016, http://www.erstestiftung.org/project/gender-check-femininityand-masculinity-in-the-art-of-eastern-europe/.
} 
help embrace cultural autonomy in exhibitions. ${ }^{317}$ LEVEL feminist art collective members point to collaboration and collectivity as one of their main aspects of feminist curating in forming their exhibitions with evolving group discussions, as well as with the community. ${ }^{318}$ Julie Kearney observed that the exhibition "impact lies as much in its process, for it is the work of many" 319 and Nancy Proctor asserts a key aspect to feminist organization is collaboration. ${ }^{320}$

Collaborations with community organizations can broaden audiences for both parties, and see a greater impact for both causes. These scholars view curating as emphasizing mutuality with different knowledge and recognize collectivity as a feminist method. ${ }^{321}$

Even before these curators and scholars, Chicago instigated a collaborative approach with her weekly meetings to discuss The Dinner Party (as well as other matters), and in consulting with her various team leaders in organizing the physical structure of the exhibition. Moreover, with every exhibition stop, the team appointed a leader to work as a liaison between the venue or organizing committee and The Dinner Party to encourage community programming, promotion and, of course, fundraising and finding the venue. This also offered professional experience and networking to everyone involved, a feminist aspect which aims to help everyone involved not just with the project at hand, but in their lives in the future.

These notions of collaboration and networking are now part of contemporary curatorial scholarship and practice. ${ }^{322}$ As they were part of Chicago's process of exhibiting The Dinner

\footnotetext{
${ }^{317}$ Pat Viera and Alicia Villeneuve, "Embracing Cultural Diversity Through Inclusive Art Exhibitions," In Multiculturalism in Art Museums Today, ed. by Joni Boyd Acuff and Laura Evans (New York and London: Rowman and Littlefield, 2014 ): 93.

${ }^{318}$ Courtney Pederson and LEVEL, "Curating Feminism: Speaking to the Exhibit" (paper presented at Contemporary Art and Feminism Conference, October 25, 2014).

319 Julie Kearney, “The Plural Gaze: Reflections on Contemporary Feminist Curatorial Practice,” Hecate (1997): 155.

${ }^{320}$ Nancy Proctor. "Feminism, Participation and Matrixial Encounters: Towards a Radical, Sustainable Museum (Practice)," in Politics in a Glass Case, eds. Angela Dimitrakaki and Lara Perry (Liverpool: Liverpool University Press, 2013 ), 49.

${ }^{321}$ Ibid.

${ }^{322}$ Such as in Berlin, where curator Tina Sauerlander founded peer-to-space, a platform for artistic exchange, and Saloon, "a network of women working in Berlin's art scene as artists, curators, gallerists and journalists." Nora Kovacs, "An Interview with Tina Sauerlander," Berlin Art Link, 24 June 2015, accessed July 24, 2015, berlinartlink.com/2015/06/25/artfeminism-an-
} 
Party with team members and local community groups as early as the call for volunteers to create the artwork in 1974, Chicago can be viewed as one of the pioneers of contemporary curatorial practice. Thus, considering collaborating inside and outside of the exhibition institution when curating is a key aspect of The Dinner Party's curatorial structure.

\section{The Dinner Party Feminist Curating Consideration: Work Selection}

The Dinner Party is not technically a group exhibition, featuring single artworks from several different artists, though it is a large-scale work of installation created by several different individuals. Still, The Dinner Party research team, led by Diane Gelon, participated in a selection process that is somewhat comparable to selecting artists for a group show. The team went through great lengths to research and select the women from Western history to include in the thirty-nine place settings, and 999 names inscribed on the Heritage Floor. Careful consideration of the subjects included was taken. Members of each The Dinner Party team, such as those responsible for ceramics and needlework, along with all of the 400 (male and female) volunteers, mostly participated through passion, networking and skill, though team leaders with expertise were promoted. As research is a key item for contemporary curating, and The Dinner Party is viewed as a curatorial project, then The Dinner Party utilized this method to the utmost. When selecting the subjects, and curating the entire exhibition, conducting research to make selections was a main strategy, one that feminist curators and scholars continue to uphold. Like contemporary curators, Chicago and her team had stipulations for selection: the person had to be

interview-with-tina-sauerlander/. Maria Lind also stresses the importance of mutual support among curators who are women: "Particularly in relation to younger women, it is quite important that as a middle-aged woman you share your experiences and also, if possible, give some support." Katy Deepwell, Maria Lind and Rosa Martinez, "Curatorial Strategies and Feminist Politics, Part 2: an interview with Maria Lind," n.paradoxa, 18 (July 2006): 15. 
a woman, and they had to have made some documented impact for women, or at least tried.

Similarly, as one of Chicago and the team's main goals for exhibiting The Dinner Party was to obtain a permanent home for the piece, their commitment to displaying the work of women as artists and part of history, was clear. Thus, although the installation is not an exhibition of separate works by several different artists, the process of selecting and arranging the women acknowledged in the piece, as well as the commitment to honoring women, demonstrates similar methods used by contemporary curators of group exhibitions.

These curatorial strategies resonate vastly in contemporary feminist curatorial scholarship. Scholar Nancy Proctor cites two main strategies for feminist museum curators as $\mathrm{g}$ inclusive and empowering new voices, and shaping collections and programs to expand and dismantle marginalized institutional structures. ${ }^{323}$ Similarly, scholar Katy Deepwell suggested methods include: working to accommodate a sense of multiple perspectives and aesthetic strategies that women employ, developing a framework avoiding artificial constructs, and negotiating the tension in acknowledging each women's individuality without establishing "women's art," can convey meaning and moreover work as a necessary form in itself. ${ }^{324}$ Rosa Martinez, who shared the position as the first woman Venice Biennale director with Maria de Corall in $2005,{ }^{325}$ also asserted, "Presenting and defending the work of women artists, which most curators, male and female, do not do, is a thesis by itself." ${ }^{326}$

Still, just the inclusion of women does not make a space feminist in working towards equality. ${ }^{327}$ In this way, curators Maria Lind and Rosa Martinez point to research as a primary

\footnotetext{
${ }^{323}$ Proctor, "Feminism, Participation and Matrixial Encounters," 50.

${ }^{324}$ Deepwell, "Feminist Curatorial Strategies and Practices Since the 1970s," 74.

${ }^{325}$ Deepwell, Lind and Martinez, "Curatorial Strategies and Feminist Politics: Part 1: an interview with Rosa Martinez," 8.

${ }^{326}$ Ibid, 5.

327 Jeannine Tang, "The Problem of Equality, or Translating 'Woman' in the Age of Global Exhibitions," in Politics in a Glass Case, eds. Angela Dimitrakaki and Lara Perry (Liverpool: Liverpool University Press, 2013): 252.
} 
factor in curating in terms of institution, social ideas and methods to be used, ${ }^{328}$ again recalling the vast research conducted by Chicago and her team in creating and exhibiting The Dinner Party. Similarly, Maura Reilly emphasized research in selection and narrative, and intersectional dialogue in forming her idea and assembling works for Global Feminisms: New Directions in Contemporary Art, which was displayed concurrently at the opening of The Dinner Party's 2007 permanent installation in The Elizabeth A. Sackler Center for Feminist Art at the Brooklyn Museum, ${ }^{329}$ emphasizing that careful consideration of artists inclusion, research and context is crucial. Reilly also noted the exhibition was not intended to be comprehensive, and even encouraged subsequent venues to install the works with different themes to provoke new conversations. ${ }^{330}$ This recalls the regional contextuality of the various venue installations of The Dinner Party's original tour.

Regarding work selection, Alexandra Kokoli also points out the importance of including "non-feminist responses to feminism...the very nature of feminist intervention is dynamic and expansive: it either brings on a radical reshuffling of social and semiotic systems on the whole, or it is ineffective." 331 This can be found in The Dinner Party, as Chicago and her team's selection of women throughout Western History was not solely for their female gender but for their documented accomplishment, speaking to a larger conversation within the exhibition as a

\footnotetext{
${ }^{328}$ Deepwell, Lind and Martinez, 5-15.

329 'In the 1970s' and 1980s' Second Wave feminism, the war against sexism often took precedence over concern with racism or homophobia in the ranks. There was a general fear that a focus on differences other than sex and/or gender would result in the dissolution of the larger feminist agenda against sexism and that the goal of female empowerment would be diminished. This precise argument, although under a different academic guise, is being used today by many against those who are interested in pursuing a multicultural or transnational feminism for fear that its focus on multiple differences (race, class, sexual, religious, and so forth) 'isms' with no central focus. Instead of discovering power in the differences of our shared struggles as women, to some difference has come to mean disunity. Global feminisms countered that by demonstrating that difference does not have to pose an a priori danger to unity and alliance. It is only through the understanding of our 'common differences' as we have visually emphasized through the careful placement of diverse cross-cultural works in the exhibition, that solidarity is achieved. In the end, Global Feminisms hopes to have contributed productively to this end and other dialogues about racism, sexism, and EuroAmerica-centricism in contemporary art." Reilly, "Curating Transnational Feminisms," 172.

${ }^{330}$ Hershman interview with Maura Reilly, 10-11.

${ }^{331}$ Kokoli, "Looking On, Bouncing Back," 7.
} 
whole. The time period in which Chicago and her team were working limited their historical scope of scholarship. However, Chicago and the research team conducted a lot of research themselves, finding thousands of women which they narrowed down to three time periods in order for the selection to function more as a symbol for women in western history, than as a representation. Chicago's feminist inclinations and strategies to dedicate the installation to underrepresented (or ignored) people in history recounting through in-depth research are now typical in contemporary curating scholarship. Though it is a different atmosphere, her mode of instigating new conversations in mainstream institutions via intentional curating, is clear.

\section{The Dinner Party Feminist Curating Consideration: Assembly}

As The Dinner Party exhibition instructions affirm, the assembly and structure of The Dinner Party was extremely important to Chicago, not just to showcase the work in the best way possible, but to relay the message to the broadest audience possible. This attention to exhibition design, including the Entryway Banners, table, Heritage Panels, Acknowledgment and Documentary Panels, as well as the International Honor Quilt, is strongly curatorial. Chicago's early exploration with exhibition placement starting with her minimalist work, through Womanhouse, along with her test exhibitions signify the importance she placed on the layout and exhibition experience. The multi-media of The Dinner Party experience designed by Chicago and her team, invokes a challenging approach to the representation, exhibition and understanding of women and art. 
The significance of assembly, or the way in which an exhibition is grouped and arranged, is evidenced today by several scholars. ${ }^{332}$ Hilary Robinson's examination of several recent feminist survey exhibitions looked intently at the arrangement of each, and whether it allowed for critical thinking. ${ }^{333}$ The Dinner Party's multi-layered presentation offered various perspectives to challenge the category of woman through the entire experience including the Heritage Panels presenting textual and photographic history, the multi-media ceramic and needlework, the juxtaposed experience of installation of the table, as well as the Entryway Banners, Documentary Panels and International Honor Quilt which was all outlined in her manuals.

Thoughtfully designed arrangement provoking conversation is another aspect gleaned from The Dinner Party, and implied in contemporary scholarship. ${ }^{334}$ Deepwell suggests that a framework that avoids fixed constructs, while conveying meaning and acknowledging the women's individuality, can avoid the mark of "the other." 335 Indeed, The Dinner Party presented a history of women in western civilization in an experimental way, challenging the dominant story of mostly men throughout history as displayed in museums.

Joanne Heath points out a similar impact of display in reference to the 2005 retrospective of Frida Kahlo at the Tate Modern. ${ }^{336}$ With perhaps an authentic intent, the chronological display

\footnotetext{
${ }^{332}$ For example Alexandra Kokoli, in her examination of Ruth Hemus' look into the structural layout of the large-scale 'Dada' exhibition (National Gallery of Art, Washington and travelling, 2005-6) "The woman artist as curatorial effect," 3, after Ruth Hemus, "Why have there been no great women Dadaists?" in Feminism Reframed: Reflections on Art and Difference, ed. Alexandra Kokoli (Newcastle: Cambridge Scholars, 2008), 56.

${ }^{333}$ Robinson, "Feminism Meets the Big Exhibitions: Museum Survey Shows Since 2005," 146-7.

${ }^{334}$ Katy Deepwell examined curator Catherine de Zegher's Inside the Visible: An Elliptical Traverse of Twentieth Century Art In, $O f$, and From the Feminine and found the international and conversational assembly of works ranging from era to subject in this all-female exhibition "to show how women artists had generated distinct practices which explored, critiqued, and questioned concepts of the feminine and 'otherness' in aesthetic terms. Deepwell, "Feminist Curatorial Strategies and Practices Since the 1970s," 73-74.

${ }^{335}$ Deepwell, "Feminist Curatorial Strategies and Practices Since the 1970s," 74.

${ }^{336}$ Heath, "Beyond the Blockbuster Retrospective," 23.
} 
did not transform into an honorary interpretation due to the separate room and lack of political context. $^{337}$ Heath also recognizes the habit of critics and arts writers to use biography to affirm male genius, but for women, to "confirm the age-old stereotype that women artists are incapable of transcending the limitations of their sex and the constraints of their lived experiences in order to make great art... and positioned by critics as shows of 'women's art' unworthy of serious consideration. ${ }^{\prime 338}$ Heath suggested to alleviate such habits by coupling ancient and contemporary art forms alongside the work at hand; and moreover, "the critical framework that might have been provided by feminism, as a method of working with art that recognizes both its historical conditions of emergence and its continuing semantic resonance."339 Thus, as Chicago's arrangement and contextualization of The Dinner Party juxtaposed women and ideas from prehistory to the mid- $20^{\text {th }}$ century, so in following this precedent, the mixture of arrangement of exhibitions can provoke a more critical view of the work at hand.

Scholar and curator Helen Molesworth suggested a feminist way of organizing art nonchronologically, providing an organization of discussion: "Assembling works of art synchronically through alliance permits them to 'talk to each other' about what does matter in our struggle for cultural expression." 340 Curator Maria Lind mentioned escaping the "white cube” norm of curating, though admit: “...the white cube works well for certain works at certain

\footnotetext{
${ }^{337}$ Heath writes: “. ...although 'national identity' was conceded to be a significant concern within Kahlo's work, it was bracketed off from her self-portraiture and instead afford its own (much smaller) themed room. The exhibition's hang thus downplayed the extent to which Frida Kahlo's self-portraits were in themselves intimately concerned with and informed by contemporary Mexican politics and culture, allowing them instead to stand alone as a major "theme" in her work, thereby at once producing and confirming the critical tendency to view Frida Kahlo's work as largely autobiographical in content...Despite the curators' avowed intentions to focus solely on the aesthetic qualities of the artworks themselves...newspaper art reviewers were able to view the paintings only through the prism of biography...this fact also served to raise serious questions as to the quality of the artworks on display." Ibid, 24-25.

338 Ibid, 28-29.

${ }^{339}$ Ibid, 30 .

${ }^{340}$ Molesworth continues: "...telling history that incorporates the challenges of feminism beyond enumerating which women worked when....Such a room might instead suggest something about how women artists have often forged connections over disjointed periods of space and time, about moving laterally in order to revolutionize the deepest aspects of our lives." Helen Molesworth, "How to Install Art as a Feminist," in Modern Women: Women Artists at the Museum of Modern Art, eds. Cornelia Butler, Griselda Pollock and Alexandra Schwartz (New York: The Museum of Modern Art, 2010): 508.
} 
points in time but to impose it on everything is clumsy and somewhat simple-minded." 341

Notably, Chicago's design did not include white walls, but instead gold walls behind The Heritage Panels, red walls as background for the Entryway Banners, and black walls in the table gallery. Though her instructions allowed for leniency with regards to the documentation and acknowledgement panels, her choice of specific hued walls for these aspects of The Dinner Party display her intentional break from traditional, white-walled exhibitions that might evoke the patrilineal past.

Griselda Pollock’s ideal “virtual feminist museum (VFM) also employs a more conversational approach to collections, and sees the museum as more of a "research laboratory" that does not give solid answers and "counters heroic, nationalist and formalist art history to discover other meanings by daring to plot networks and transformative interactions between the images differently assembled in conversations framed by feminist analysis and theory." 342 This assertion recalls Chicago's early inquiries with Womanhouse, Womanspace, and test exhibitions in the 1970s, up to The Dinner Party, in an attempt to find a new structure for viewing the work of art by women. Pollock's emphasis on the encounter is also reflected in Chicago's emphasis on the interactive experience of the entire The Dinner Party exhibition.

Maura Reilly employed a strategy of "relational analysis" when assembling works for Global Feminisms with Linda Nochlin ${ }^{343}$ that arranged diverse and similar works in dialogue, without following a linear chronology, or a geographic delineation, but was rather organized in four sections. ${ }^{344}$ Reilly emphasized that these sections were not to be understood as universal, but

\footnotetext{
${ }^{341}$ Deepwell, Martinez and Lind, 12.

342 Pollock, Encounters in the Virtual Feminist Museum: Time, Space and the Archive, 11.

${ }^{343}$ Maura Reilly, “Curating Transnational Feminisms,” Feminist Studies 36, no. 1 (Spring 2010), 159.

${ }^{344}$ Ibid, 157-58.
} 
as broad concepts that arose during their research, and even encouraged subsequent venues, viewers and scholars to initiate different relationships to create new associations and connections. ${ }^{345}$ As viewers walk around The Dinner Party, they are met first with the chronological arrangement of the settings, but also, a juxtaposition of views of the backs of place-settings across the room, as well as integrated inscribed names on the Heritage Floor, meant to provoke further conversations among the histories of the women honored.

Sexual Politics was the notable exhibition in the 1990s that included The Dinner Party with all of its curatorial structures, though this time in conversation with other feminist art of its time. Dimitrakaki and Perry reference the critical curating of Amelia Jones' Sexual Politics organized in nine sections, stating: “... it focused on the fine grain detail of historic placement, which could be interpreted as investigating and clarifying relationships between works of art of the same era, or else mobilizing what her interviewer...recognizes as a horizontal—as opposed to vertical - art historical paradigm." ${ }^{346}$ It is complex to consider the implications of curating The Dinner Party as its own exhibition within another later feminist exhibition. Briefly, the fact that the exhibition was curated around the entire The Dinner Party, implies the primacy of Chicago's innovations of structuring and assembly as key considerations for an accessible, feminist exhibition experience.

\section{The Dinner Party Feminist Curating Considerations: Exhibition Text}

Another major aspect of Chicago's structuring of The Dinner Party was the exhibition text, including prominent informative wall text as well as complementary catalogs and

\footnotetext{
${ }^{345}$ Ibid, 158.

${ }^{346}$ Dimitrakaki and Perry, 14.
} 
pamphlets. Text was also used on the Entryway Banners in the form of a poem by Chicago, and on the table runners and porcelain floor with the names of the women. The most notable exemplar from The Dinner Party comes from The Heritage Panels which give historical information, photographs and images on all of the 1,038 women included in The Dinner Party artwork. The original Heritage Panels were hand-produced and collaged by Chicago and her team members. Another aspect of The Dinner Party text were the pamphlets designed by Chicago and her team for the initial tour, and the exhibition catalog sold in venue stores. The exhibition pamphlets included explanatory information about the Entryway Banners, Heritage Panels and every place-setting, as well as space for localized text written by regional committee organizers. Venues sold this pamphlet at a low fee to pay for its printing or offered it free of charge. This additional written context gave another educational layer to the exhibition. The catalog, (only available to those who could afford it), provided ample historical information regarding The Dinner Party as well as the process of making it, and was written by Chicago. This aspect of Chicago's curating has contemporary implications that are echoed in feminist curatorial scholarship. The text also raises contemporary issues of exhibition text language pertaining to feminist or all-women exhibitions.

Chicago never shied away from The Dinner Party as an exhibition specifically about women. The recognition of feminism or womanhood, in an all-woman exhibition is an aspect that must be addressed in exhibition text, according to scholars. Without it, exhibitions can appear haphazard and disconnect the artists from history rather than situate them in contexts. ${ }^{347}$ Thus, another textual element set by The Dinner Party was the overt recognition of feminist agenda, along with the recognition of women's history and experience.

${ }^{347}$ Robinson, "Feminism Meets the Big Exhibition: Museum Survey Shows Since 2005," 147-48. 
Contemporary scholars insist that exhibition text must not make assumptions about audience experience and knowledge, as this can lead to a notion of "the other."348 Text should avoid generalization and oversimplification and instead use rich, specific contextual information. Language should be consistent throughout the exhibition (not different depending on the works or culture described); visitors should be encouraged to consider the complexity and fluidity of various cultures, definitions and implications of dominant and non-dominant cultures. ${ }^{349}$ Chicago, too, aimed for the broadest audience possible to understand The Dinner Party by using multiple layers of written context. Moreover, the written context was to be interpreted into the main language of the country where it was exhibited, if the primary language was not English. Through her multi-modes of written context, Chicago aimed to provide such rich contextual information for each of the women featured throughout the different histories and cultures researched, for people to understand and appreciate.

Chicago's 2007 catalog for The Dinner Party was reviewed as "both assertive and sassy, qualities that are much more useful to feminist revolution." 350 Written framework by Chicago's catalog is implied when comparing it to the WACK! Art and the Feminist Revolution catalog review which "needed to go deeper with providing written context." The 2007 The Dinner Party catalog includes detailed information on the social and cultural context of each woman featured in the artwork, as did Chicago's original exhibition catalog published in 1979. Chicago's development of a curatorial structure places a heavy emphasis on research and written context,

\footnotetext{
${ }^{348}$ Such as in Susan Platt's review of WACK! Art and the Feminist Revolution exhibition catalog, where she asserts: that while the exhibition might breaking of the traditions of museum inclusion, they needed to go deeper with providing written context and thus a formula for transforming the world outside the Museum, otherwise, "it is simply mannerism." Susan Platt, "Review: The Dinner Party: From Creation to Preservation; Global Feminisms: New Directions in Contemporary Art; and Wack! Art and the Feminist Revolution," Journal of Compilation 15 (May 2008): 42.

${ }^{349}$ Andrea Severin Goins, "Thoughtful Words," in Multiculturalism in Museums Today, (Eds. Joni Boyd Acuff and Laura Evans, New York and London: Rowman and Littlefield, 2014): 256.

${ }^{350}$ In comparison to WACK! Art and the Feminist Revolution catalog, Platt, 43.
} 
something that contributes to its broad reach, a method that continues to have relevance and create controversy today. ${ }^{351}$

\section{The Dinner Party Feminist Curating Considerations: Accessibility and Interactivity}

Judy Chicago was thinking of the significance of the art experience in structuring The Dinner Party, with assembly, exhibition text, and with regard to accessibility and interactivity. Along with the qualifications for space to house the entire The Dinner Party, was the requirement for wheelchair accessibility. This was long before the American Disabilities Act of 1990 required business and government organizations to meet such specifications. Along with the wall text translation stipulation for exhibition in foreign countries, this was another way that Chicago wanted The Dinner Party to be accessible to the broadest audiences possible. The documentary played at certain venues, as well as the audio guide, provided more exhibition interactivity. The table installation was designed so one could walk around it, looking over and across the table, bringing an intimacy of interaction, as opposed to being at a distance from the wall of traditional art displays. All of these curatorial aspects have contemporary parallels in recent scholarship, some of which are outlined below.

Technology was limited compared to today, during the initial exhibition and tour of The Dinner Party. Connecting with twenty-first century viewers can be done through cell-phone applications or digital interactions, but nonetheless, Chicago's multi-media elements including an audio tour, documentary film, and various informative panels fulfilled this interactive function. Nancy Proctor examined new media ways that museums are using to connect with

\footnotetext{
${ }^{351}$ See for example Ann Landi, "Wall Talk: What should museum wall labels tell us? Who writes them? Do we even need them?" ArtNews (December 2015): 42-29.
} 
visitors. Instead of “innovating for innovation's sake" or ignoring technological change, Proctor suggested using feminist strategies with technology in museums to radically restructure and even leverage museum sustainability. ${ }^{352}$ Proctor recognized how these 'new' participatory methods are actually a legacy of feminist and other social movements seeking to give voice to those usually silenced and that feminism specifically offers beyond a way to comprehend the restructuring of the museum in this age of social media. ${ }^{353}$ These methods were employed by Chicago in The Dinner Party to create a space of encounter and a challenge of traditional exhibition structures. Proctor's new ways to connect with communities and individuals in a more flexible, modular structure to enhance the museum experience with alliance with multiple voices, includes crowd-sourcing and participatory curating. ${ }^{354}$ This echoes Chicago's community-driven and broad-reach strategies of curating The Dinner Party. Moreover, the encouragement for educational and community programs with each exhibition stop in the original tour, too, is evidenced of this contemporary desire for engagement and interactivity beyond the museum walls. Proctor recognizes the balance of the authority of institutions along with such inclusivity, allowing experts to guide viewers. ${ }^{355}$ Similarly, as Chicago conceived and perhaps "directed" The Dinner Party, she worked collaboratively and invited insight and participation from team members and viewers.

\footnotetext{
352 Proctor notes: "As museums increasingly adopt a more conversational mode and tools for engaging with visitors and the broader online public - for example, through the use of blogs, social media, and more participatory programming...they are actively transforming the museum from a rather forbidding treasure house on a remote hill to an open community space." 352 This is surely a timely query, as technological visual culture is making it easier to find and see art not just in books but immediately online, even some museums calling to online 'citizen curators,' using mobile app games and more; but, as Proctor queries, will these strategies maintain museums or do they need more of a feminist intent? Proctor, "Feminism, Participation and Matrixial Encounters: Towards a Radical, Sustainable Museum (Practice)," 49.

${ }^{353}$ Proctor, 50.

${ }^{354}$ Proctor developed an articulation of this vision for the Smithsonian via three apps: Smithsonian Mobile, which invites "visitors to collaborate in the development of a dynamic, evolving guide to visiting the Smithsonian;" Stories on Main Street, which invites visitors to "share and add oral histories about life in small town American to the Institution's collections"; and Access American Stories, "crowd-sourced verbal descriptions of exhibits and objects to enhance the experience of visuallyimpaired visitors and others. Proctor, 54-56.

355 Ibid.
} 
Community engagement is a large part of contemporary feminist artistic and curatorial thought. Members of LEVEL, an Australian feminist art collective, ${ }^{356}$ express their commitment to community engagement when they organize exhibitions, noting that the artwork is secondary to the mission. ${ }^{357}$ They intentionally invite community-focused individuals to work with the exhibition, while focusing on educational programming with schools, community workshops, and producing documentary information and digital resources so that viewers can interact, engage, and learn in an "open and accessible atmosphere." They stress the importance of the "impact beyond the exhibit." ${ }^{358}$ For example, their 2014 exhibit, The Is Not the Work, acted as a "basecamp" for community engaged projects, like "One Million Stars to End Violence" where the public was invited to come and create woven stars as part of the Australian community-based project to symbolize "solidarity to end all forms of violence." ${ }^{359}$ These contemporary feminist intentions definitely echo the original intentions of Chicago with The Dinner Party regarding accessibility and interactivity, most notably with the International Honor Quilt.

\section{The Dinner Party Feminist Curating Considerations: Acknowledging Limitations}

Another curatorial strategy that Chicago practiced, albeit indirectly, was acknowledging the limitations of the scope of The Dinner Party. She asserted in interviews and books that the exhibition was meant to be a symbol of the history of women in Western history, not a

\footnotetext{
${ }^{356}$ LEVEL was founded in 2011. "Level," Level, accessed April 19, 2016, https://levelari.wordpress.com/.

${ }^{357}$ Pedersen and LEVEL, "Curating Feminism: Speaking to the Exhibit."

358 Ibid.

359 "This is Not the Work," Level, accessed April 19, 2016, https://levelari.wordpress.com/2014-projects/this-is-not-the-work/. "One Million Stars to End Violence," One Million Stars to End Violence, accessed April 19, 2016, http://www.onemillionstars.net/\#!about/c1enr.
} 
comprehensive history of women. Within the exhibition the most evident acknowledgment of limitations came in the form of the International Honor Quilt. Although The Dinner Party team eventually selected thirty-nine women for the place-settings and 999 additional names inscribed on the tiles and mentioned in the Heritage Panels, the International Honor Quilt opened up the project to women throughout history and today. Women from around the world submitted quilt patches that formed the over 400 quilts that traveled with the original tour, honoring women they knew, women in history, or women's groups. The quilts were displayed throughout the tour after the debut exhibition, and in Sexual Politics. There was written wall text describing the significance of the Quilt, a blurb about it in the exhibition pamphlet, and descriptions in the exhibition catalogs by Chicago.

Contemporary feminist art historian Hilary Robinson also examined how the curatorial framework impacts the viewer interpretation and its ability to "lull" viewers "into unquestioning acceptance. ${ }^{360}$ Robinson presented a curatorial challenge of celebratory versus critical display, and artist's wishes versus curatorial freedom, one that is emphasized in the chapter in this study regarding The Dinner Party's current placement. Also, Robinson laments the significance of written informational context, as well as acknowledgement of institutional limitations so that viewers rarely question an exhibition's authority. The International Honor Quilt worked as a display of acknowledgement of the limitations, as did the organized community and regional events and written texts. As will be explored in the Chapter Five, many of these important elements of The Dinner Party are now absent from its current installation, removing some of its

\footnotetext{
${ }^{360}$ Robinson: "Unless s/he has a deep knowledge of an exhibition's subject of enquiry, the visitor will be unlikely to see the gaps and the choices...even less will s/he see the active choices of exclusion made by the curator...." Robinson, "Feminism meets the Big Exhibition: Museum Survey Shows Since 2005," 130-132.
} 
original institutional challenge and feminist message. Of course, institutions face limitations in acknowledging these very limitations, a challenge discussed in the next section.

\section{Challenges to Feminist Curating}

"A principal challenge of the feminist project in art history is to simultaneously campaign for women artists and other erased voices to be included in the museum and the art history canons, even as it interrogates and undermines the very structure and power of the canon itself." -Nancy Proctor, "Feminism, Participation and Matrixial Encounters" 361

As Proctor notes, a significant challenge to curating with feminist intent is incorporating feminist strategy within an institutional context, which might not have feminism at the core of its mission. In fact, these spaces may have been a site for feminist critique as patriarchal institutions, marginalizing artists who are women. ${ }^{362}$ Just as the Guerilla Girls ${ }^{363}$ have now been in "the paradoxical position of being embraced by the very institutions that they have so consistently critiqued," 364 so Chicago has found herself—and The Dinner Party—in these very discourses. Still, perhaps with feminist curatorial considerations, as Chicago's via The Dinner Party, within institutions, such paradoxes can be addressed. However, there remains a point of contention between artist and institution, when it is out of the artist's hands.

Another challenge within the institution deals with the separation of organizational or curatorial tasks. For example, a curator is tasked to find and select the work; the preparatory installs it; the educator creates programs and the marketer promotes it. Dimitrakaki and Perry call it "the problem of 'silo' cultures within museums that divide the work of exhibition

\footnotetext{
${ }^{361}$ Proctor, 51.

362 Dimitrakaki and Perry, 7. Heath, 20.

363 The Guerilla Girls, founded in 1985, use "provocative text, visuals and humor in the service of feminism and social change. They have written several books and create projects about the art world, film, politics and pop culture. They travel the world, talking about the issues and their experiences as feminist masked avengers, reinventing the " $\mathrm{f}$ " word into the 21 st century." "Guerilla Girls," Guerilla Girls, accessed April 19, 2016, http://www.guerrillagirls.com/\#groups.

${ }^{364}$ Heath, 21.
} 
organizing from marketing and from education, making it difficult to create coherently feminist offerings; the casualization of 'professional' labour and degrading employment practices that affect women in all areas of employment including curators and academics; and feelings of isolation and lack of solidarity in sustaining a politicized practice." 365 They also explore the issue of how processes of curating tend to already have in place "others" in exhibition making. ${ }^{366}$ Whereas with The Dinner Party, Chicago and her team took it all on. ${ }^{367}$ Though undeniably working across departments and collaboratively curating within institutions can prove difficult for various issues of practicality, time, and job responsibilities, this challenging strategy no doubt contributed to The Dinner Party's broad appeal, something institutions can consider.

Another issue is that art establishments tend to show insecurity for accommodating women because of feminism's implicated complexities, so much so that they simply leave such issues out. ${ }^{368}$ For example, in Total Art: Contemporary Video, an exhibition of ten video artists who are women at the National Museum of Women in the Arts in Washington D.C. (JuneOctober $2014^{369}$ ), the exhibition wall text, though it mentioned "Women artists were among the pioneers of video art" ${ }^{370}$ did not mention the role of the feminist art movement with video art during this era. Katy Deepwell asserts that in order to avoid marginalization, women artists' exhibitions "need to be polemical and informed by feminism, yet they must also reassess not just women's presence as artists but their contribution to art itself." ${ }^{371}$ Though the curator was

\footnotetext{
${ }^{365}$ Dimitrakaki and Perry, 4.

${ }^{366}$ Ibid, 6.

${ }^{367}$ Dimitrakaki and Perry lament: “...the problem of 'silo' cultures within museums that divide the work of exhibition organizing from marketing and from education, making it difficult to create coherently feminist offerings; the casualization of 'professional' labour and degrading employment practices that affect women in all areas of employment including curators and academics; and feelings of isolation and lack of solidarity in sustaining a politicized practice," 4.

${ }^{368}$ Heath, 36-7.

369 "Total Art: Contemporary Video," National Museum of Women in the Arts, accessed April 19, 2016, http://nmwa.org/exhibitions/total-art-contemporary-video.

${ }^{370}$ Museum wall label for Total Art: Contemporary Video, Washington D.C., National Museum of Women in the Arts, 12 September 2014.

${ }^{371}$ Deepwell, 79.
} 
unavailable for interview about this exhibition, and the omission could have been for spatial reasons, it is significant to note that the wall text did, however, include the relation to conceptual art of the 1960s and 1970s. As Deepwell points out, the "work of women with the use of new media" are "modes of the feminist avante garde." 372 Moreover, as Siona Wilson asserts in her writing, it is hard to imagine being a woman artist today without acknowledging the feminist revolution. Thus by leaving out such a critical piece of context, the works in the exhibition were left unconnected to their feminist artistic precedents. Though this example may not be overt, it does exemplify a curious overlooking of the feminist movement's role within art exhibitions, especially in one that feminism certainly played a role with developing the media on display. As previously discussed, there have perhaps been advances in exhibiting all-women and/or feminism exhibitions in notable mainstream museums recently, there is still an overlay of discriminatory curatorial practice. Heath recalls such exhibition advances and notes: “...curators have in fact either ruthlessly ignored or willfully misunderstood the nature of the feminist challenge to existing histories of art." ${ }^{, 373}$ Perhaps the curator did not want to provoke controversy with the contemporarily misunderstood terminology, even within an institution dedicated to women artists.

Fear of controversy is no doubt a looming issue of institutions small and large, but art is meant to provoke conversation, as did The Dinner Party, proving both popular and moving. There is also an opposing challenge - that of intensifying controversies, or focusing on the "feminist blockbuster," such as WACK! Art and the Feminist Revolution (2007, Museum of Contemporary Art, Los Angeles); Kiss Kiss Bang Bang: 45 Years of Art and Feminism (2007,

\footnotetext{
${ }^{372}$ Ibid, 78.

${ }^{373}$ Heath, 36.
} 
Bilbao); or REBELLE. Art and Feminism 1969-2009 (2009, Arnhem), instead of necessitating thoughtful feminist curation. ${ }^{374}$ Terry Smith points out "These exhibitions also register the fact that the aspirations of the 1970s have had a marked quantitative impact (in the proportion of women regularly active as artists), but more ambiguous qualitative outcomes (art institutions and structures remain as subject to others to antifeminist pushback and business as usual.)"375

Thus, perhaps the real necessity for exhibitions is outlining considerations of feminist curating, rather than debating meanings, content and theories. To be sure, institutions and museum professionals tend to operate under increasingly commercial constraints-Heath suggested that many have adopted an "overly populist approach to exhibition-making and have by and large proved hesitant to embrace the critical questions posed by the revisionist art history that has so transformed the discipline within its university setting." 376 This statement may be debatable, depending on the definition of "populist" as reaching a broad audience, which can be considered feminist. Certainly Chicago spoke of feminism with her team and in the impetus for creating The Dinner Party, did not shy away from controversy; but in her structuring of the exhibition, her thoughts focused on the experience and broad appeal.

As there have perhaps been advances in exhibiting all-women and/or feminism exhibitions in notable mainstream museums recently, and certainly this is exemplified by the eventual purchase of The Dinner Party in 2002, there is still an overlay of discriminatory curatorial practice. Heath wrote: “...curators have in fact either ruthlessly ignored or willfully misunderstood the nature of the feminist challenge to existing histories of art." ${ }^{377}$ Griselda

\footnotetext{
374 Ibid.

375 Smith, 149.

${ }^{376}$ Heath, 36.

${ }^{377}$ Ibid, 36. Also see Eunsong Kim and Maya Isabella Mackrandilal, "The Whitney Biennial for Angry Women," The New Inquiry, 4 April 2014.
} 
Pollock too critically addressed the "largely tokenistic" recognition of feminism by the mainstream. ${ }^{378}$

After nearly forty years of intense thinking about gender and its role in the art system premised on inclusion and exclusion, The Dinner Party stands almost as a visual monument of this time, the teachings of feminist art history inquiry and how it has or has not transformed itself into practice, is yet to be determined. ${ }^{379}$ Perhaps, as contemporary scholars suggest, a visual transformation then, lies in a feminist theory and inquiry of curating. ${ }^{380}$ As ever, there is a battle for curatorial ideas, the top tension being the push between the need for specialization and the aim for normalizing. ${ }^{381}$ The need of feminist criticality remains. ${ }^{382}$ Instead of merely pointing to the work of a specific artist like Judy Chicago, criticality on the feminist curatorial tactics of projects, like The Dinner Party, will hopefully evolve the discourse. Deconstructing the aspects gleaned from Chicago and her team in structuring and exhibiting The Dinner Party contribute to this growing and significant discourse within feminist art history, and the broader curatorial and art historical discourse. With this in mind, the next section examines the recent installations of The Dinner Party which were alternatively made without Chicago or her team's insight, furthering the complex issues.

\footnotetext{
${ }^{378}$ Kokoli, “Looking On, Bouncing Back," 15.

${ }^{379}$ Ibid, 13-14.

${ }^{380}$ As Dimitrakaki and Perry assert, “...to argue that the problem of even measuring equality, the rhetorical equation of numerical representation with equality, and the leap from a politics of equality to a transformative feminist politics' are major issues in an emerging (we hope!) feminist theory of curating," Dimitrakaki and Perry, 16.

${ }^{381}$ Deepwell, "Feminist Curatorial Strategies and Practices Since the 1970s," 80.

382 As Tang laments, instead of (or even in addition to) simply demanding and perhaps achieving greater wall space for women, and moreover instead of deconstructing greatness, "the exposition of power...[is] not to normalize existing forms of symbolic power in the art world, but to hijack them into more prickly proximity with the critique of institutions.” Tang, 251.
} 
Chapter Five: Looking at The Dinner Party now: Curatorial Implications

The permanent installation of The Dinner Party is not as Chicago originally conceived it, as a purpose built building for the entire installation with ceramic walls. Chicago noted in an email April 22, 2015: "Elizabeth Sackler thought about that but it proved too expensive. The glass walls create a similar dematerialization of the space which I love." ${ }^{383}$ The recent installation as of February 16, 2016, also lacks the International Honor Quilt, the acknowledgement panels, Documentary Panels, and the Heritage Panels. ${ }^{384}$ Still, inside the Brooklyn Museum, on the fourth floor of the Elizabeth A. Sackler Center, The Dinner Party Entryway Banners and monumental table stand as a testament for continuing to challenge the artistic and historical narrative regarding women's history within and without such institutions. They also, significantly though somewhat paradoxically, stand for the continuing challenges of curating. In this chapter, I examine Susan Rodriguez's architectural plans, the recent installations, reception by team members and curators, and provide a critical reflection regarding Chicago's original curatorial intentions. Complexity in the curatorial issues were intensified in November of 2015, when again, the installation had changed; the discrepancy between February and November of 2015, and changes to Rodriguez' plans are distinguished in the analysis.

The two installations under review are: the installation designed by Susan Rodriguez and installed in 2007, including the Entryway Banners, table and Heritage Panels, which I viewed in February 2015; and the altered installation I experienced in November 2015, with the Entryway Banners and Heritage Panels rearranged significantly and not in keeping with either Chicago's or Rodriguez' plans. The Acknowledgement Panels are owned by the Sackler Center but were not

\footnotetext{
383 Judy Chicago, email with the author, April 22, 2015.

${ }^{384}$ Katie Schroeder, assistant to Judy Chicago, personal email with author, February 16, 2016.
} 
designed to be on permanent display (though they are online, including an outline of all of the volunteers, on the Sackler Center website). ${ }^{385}$ The International Honor Quilt, including 539 quilts of thousands of patches, were donated to the Hite Art Institute in Louisville, Kentucky in 2013, ${ }^{386}$ and were on display for the first time January through March 2016. The Documentary Panels were recently acquired by the National Museum for Women in the Arts in Washington D.C., where they will be held and maintained. ${ }^{387}$ It is unknown as to why the Sackler Center did not purchase the quilts or the Documentary Panels. ${ }^{388}$

\section{Susan Rodriguez' Architectural Design for The Dinner Party (February 2015 Visit)}

There was a design competition in 2004 for the installation of The Dinner Party and final design of the Elizabeth A. Sackler Center for Feminist Art, including the changing exhibition galleries on the fourth floor of the Brooklyn Museum. ${ }^{389}$ Susan Rodriguez' design was chosen and the Center opened in 2007. Rodriguez wrote of her design intentions:

In the past, temporary installations of The Dinner Party were events in themselves. I felt that as the heart of the new Center, the artwork could be made even more influential if the piece was encountered in a variety of ways. The design strategy intentionally opposes the "white box" gallery approach typically applied to housing contemporary art. Instead, the architecture actively engages the art, with the distinct purpose of deepening the visitor's appreciation of and connection to it. Essential to this is the reinforcement of the triangular geometry of the piece. ${ }^{390}$

\footnotetext{
385 “The Dinner Party: Acknowledgement Panels," Elizabeth A. Sackler Center for Feminist Art, accessed October 6, 2015, https://www.brooklynmuseum.org/eascfa/dinner_party/acknowledgement_panels.

386 "International Honor Quilt," University of Louisville, Hite Art Institute, accessed October 7, 2015, $\underline{\text { http://louisville.edu/art/facilities-resources/international-honor-quilt. }}$

${ }_{387}$ Donald Woodman, interview with the author, November 8, 2015. The Documentary Panels are not currently on display.

${ }^{388}$ Attempts to find out why the Sackler Center did not obtain these elements of The Dinner Party were unsuccessful. I could not reach Elizabeth Sackler for comment; other Sackler Center contacts could not give me an answer, either.

${ }^{389}$ Susan Rodriguez, "A Triangular Gallery," in Brooklyn Museum: Elizabeth A. Sackler Center for Feminist Art (New York:

Polshek Partnership Architects, 2009): 7.

390 Ibid.
} 
Rodriguez used The Dinner Party artwork table as the literal centerpiece of the Sackler Center exhibition space (fig. 21). Temporary galleries surround The Dinner Party table room in a circular fashion, too opposing the traditional museum style of east-west axis. ${ }^{391}$ Both of these factors challenge traditional museum design as asserted by Molesworth and others in previous chapters, of not subscribing to the "white-walls" or a linear, square structure. Thus, the design sets visitors inside an irregular and thereby critically engaged museum experience. Although perhaps a somewhat jarring confrontation of alternate spatial arrangement for viewers accustomed to traditional museum arrangements, the alternative perspective works to increase the reflection and criticality of The Dinner Party and the Center as a whole.

As was in Chicago's original conception, The Dinner Party experience as designed by Rodriguez started with the Entryway Banners backed by red walls. ${ }^{392}$ Diane Gelon pointed out in an email that the red walls were intended to bring out and showcase the Entryway Banners in the best light possible. ${ }^{393}$ The red walls were definitely a welcome change from the white walls throughout the rest of the institution. The red also brought about a feeling of respite, coupled with the Entryway Banners foreshadowing the colors and symbols of the artwork the viewer is about to encounter. Chicago's conception of this red wall entryway, as a curatorial strategy against the traditional installation structure, is very historical and significant both symbolically and formally.

\footnotetext{
${ }^{391}$ Susan Strauss, Brooklyn Museum: Elizabeth A. Sackler Center for Feminist Art (New York: Polshek Architects, 2009 ): 8.

392 Red is one of the common colors throughout the place settings as well, most notably in the setting for Margaret Sanger, for which "red hue serves as a reminder of the bloodshed of many women who died during childbirth or as a result of illegal and unsafe abortions. It also signifies the struggle of early reproductive rights activists, who risked arrest and jail time for their participation in the movement." "Margaret Sanger," Elizabeth A. Sackler Center for Feminist Art, accessed April 26, 2016, https://www.brooklynmuseum.org/eascfa/dinner_party/place_settings/margaret_sanger.

${ }^{393}$ Diane Gelon, email with the author, September 2015.
} 
The Sackler Center space for the Entryway Banners, as Diane Gelon pointed out in our interview, is tight. While in the hallway, one has a glimpse above of the Herstory Gallery behind it, as The Heritage Panels served as the separating screen, but did not reach the ceiling. In this way, the Entryway Banners hallway does not operate as it did in Chicago's original tours with a different and closed space of reflection. It was a calming space for contemplation before arriving in the table space.

Rodriguez' designed the space so that the entrance to The Dinner Party table could then come after walking through the Entryway Banners (though it was also possible to enter The Herstory Gallery first, then the table and Banners, as there were not major instructions and visitors might wander a different way into the space, see fig. 21 for diagram). The Dinner Party table room, like Chicago's original concept, has black walls. Unlike the original, the installation designed by Rodriguez has "sloped walls" that are "lined with large glass tablets" 394 creating mirror-like, infinite reflections. Wrote Rodriguez of this feature:

The surrounding enclosure is a specific response to that geometry, and its reflective glass liner, a vehicle to expand the power of the piece beyond the immediate walls of the gallery itself...a carefully choreographed sequence of spaces draws one literally within the glass vitrine to participate and become part of The Dinner Party experience. Once inside, the counterclockwise sequence around the table is animated by the reflectivity of the surrounding enclosure, not only expanding the space, but capturing subtle reflections that sponsor viewers' considerations of themselves in the context of the women honored in the artwork. ${ }^{395}$

Rodriguez emphasized the contrast of the surrounding galleries in the museum as viewing the art through the restricted lens of glass frames at a distance. The glass-lined walls surrounding The Dinner Party artwork, then, present an intimacy, inviting viewers into the work itself. Though this is a different effect than Chicago's original lighting allowing absolutely no reflections in the

\footnotetext{
${ }^{394}$ Strauss, 18.

395 Rodriguez, 7.
} 
gallery, Chicago appreciates the glass-lined walls of Rodriguez' design: “The glass walls accomplish something the porcelain would have also achieved, that is, a dematerialization of the space which I like very much." ${ }^{396}$ Chicago's original lighting also created rainbow reflection on the runner backs from the luster glaze used on the floor. ${ }^{397}$ In fact, it is difficult to find a photograph of the original The Dinner Party installation that includes the room around itpointing again to the overwhelming focus by historians, scholars and writers on the place-setting artwork.

At the Sackler Center in February and November of 2015, the reflection of the glass walls was so strong that it appeared that the walls were mirrors. When I first visited the piece in February, I had not researched or known of Chicago's original intent with the lighting. However, I recognized the reverential quality, which was another function of Chicago's all-black walls and the entire piece, to emphasize the significance of these women. The reverential quality was present, as the lights were fairly low; due to the fact that the table installation is on display permanently for long hours, a stronger light source might not be advisable for conservation. ${ }^{398}$ The awed quality is felt even through the enormity of the piece—as current Sackler Center curator Catherine Morris noted in her interview—simply seeing this monumental piece in person provokes an awed response. The low lighting, black walls, monumentality and stillness, along with the content of the piece, emphasize its aura of importance, much as Chicago originally conceived.

\footnotetext{
396 Judy Chicago, email with the author, May 21, 2015.

${ }^{397}$ Susan Hill, email with the author, September 2015. Judy Chicago, email with the author, May 21, 2015.

398 To read more about the conservation concerns of The Dinner Party table at the Sackler Center, visit "Conservation," Brooklyn Museum accessed March 4, 2016, https://www.brooklynmuseum.org/eascfa/dinner_party/conservation/environment/.
} 
Regarding the table and artwork, the content has been criticized by feminists and historians for its exclusion and focus on Western societies and women of royal status. ${ }^{399}$ Chicago maintains that The Dinner Party installation in its entirety was meant to be a symbol of the history of women in Western civilizations, not a comprehensive history. ${ }^{400}$ With regards to the focus on higher-class women, Chicago asserts that it was part of history's bias in general, and that it was in part due to the limits of scholarship in the era from which she was originally working. ${ }^{401}$

Thinking of the table in terms of it being an exhibition in itself - the approach of exhibiting the artworks on a table, allowing viewer's to look over it and interact with it, instead of at a horizontal distance on the wall, is significant. Each place setting has its own layers of content and symbolism. It is also important to note the critical relationship of the runners to the plates and to the inscribed names on the floor, is an installation tactic in itself. The place-settings are arranged in chronological order, although the installation in its entirety works against the traditional historical narrative. Chicago did not insert their stories into the already written history, but created for them an alternative structure of history from which the table and the entire project was built. As previously noted, oftentimes art by women is still displayed in relation to men's. ${ }^{402}$ The Dinner Party artwork table, installed as Chicago conceived it, acts as a curatorial structure against the traditional framing of women and art even by women in mainstream institutions.

\footnotetext{
399 For example in Hilary Robinson, "Reframing Women," Circa, 72 (1995): 18-23.

${ }^{400}$ Chicago, From Creation to Preservation, 19.

${ }^{401}$ Ibid.

The work has been criticized for other issues such as essentialism and aesthetics, though this does not fit into the curatorial purview of this paper.

402 Susan Bee, "Frames," The Brooklyn Rail, 4 September 2014, accessed September 9, 2014, http://www.brooklynrail.org/2014/09/criticspage/frames-bee.
} 
Another critical aspect of The Dinner Party table room by Rodriguez are the glimpses into the surrounding contemporary galleries. Originally, Chicago had designed one entry/exit door to journey around the table. There is one proper door currently in the table room, but there are also glass windows at the other two corners of the room. Rodriguez explained:

The open corners at the vertices allow glimpses into the space from the changing exhibits that envelop the gallery, provoking consideration of contemporary feminist art in the context of the movement's legacy. These glimpses actively challenge preconceptions established by the Museum's adjacent period rooms. ${ }^{403}$

These anticipatory peeks into the surrounding galleries can provide further critical reflection of both The Dinner Party with contemporary art and vice versa. The corner gaps of The Dinner Party table gallery provide further feminist perspective in comparison to the traditional mainstream chronological mode of art organization, ${ }^{404}$ displaying art from the earliest work made to the latest. The arrangement provides an element for discussion, forging connections among space and time with viewers and art, as described by Molesworth in the previous chapter. ${ }^{405}$ In February of 2015, I saw glimpses of Judith Scott: Bound and Unbound, ${ }^{406}$ allowing me to fluidly consider the cultural, historical and visual context of both exhibits' artists and content. Thus, the installation of The Dinner Party table itself does prove critically relevant today, for its ever-present challenge to patriarchal institutional structure, as well as its reflective enhancements and corner glimpses, encouraging individual criticality and contemporary experience. While viewing it, the temporary exhibition provided another level of critical reflection seeing The Dinner Party in abstract visual context with contemporary feminist work. The open corners create a triangle with the reflection of light from outside (fig 22). This created

\footnotetext{
403 Rodriguez, 7.

${ }^{404}$ Molesworth, 500-01.

${ }^{405}$ Ibid, 508.

406 Judith Scott: Bound and Unbound, ran Oct. 24-Mar. 29, 2015 at Elizabeth A. Sackler Center, accessed April 22, 2015, http://www.brooklynmuseum.org/exhibitions/judith_scott/.
} 
a further consideration of Judy Chicago's triangular iconography and hope for an ideal, equalized world.

Perhaps the most contemporary and critical aspect of the curating of The Dinner Party in the Sackler Center as Rodriguez designed it, lay in the Herstory Galleries with the display of The Heritage Panels. Here is where the main discrepancy lies between my two visits. During my February 2015 visit, as originally intended, the information displayed on the Heritage Panels (fig. 23) in the Herstory Gallery (see gallery diagram, fig. 21) historically contextualized the piece with information about the 1,038 total women (including 39 on place-settings and 999 on Heritage Floor). The seven hand-colored and photo-and-text collaged large scale panels show photographs, information and images of related art and artifacts. ${ }^{407}$ In February, they were presented in chronological order after having viewed the table, as designed by Chicago and installed by Rodriguez. The didactic aspect is unconventional yet allows information and a broad understanding by audiences, "to contextualize the importance of their [the women featured] legacies, Chicago also included brief passages describing the circumstances against which women had to struggle for equity throughout history." ${ }^{408}$ Additionally, the February exhibit included flat screen monitors providing additional information about the artwork and biographies of The Dinner Party guests. The Museum wall text displayed gave a brief history of the piece itself, its production, context in the feminist movement, and architectural plan (fig. 24). During the November visit, the Herstory Gallery had significantly changed; the Entryway Banners were closer together and moved to a smaller area in the corner of the Herstory Gallery, and the

${ }^{407}$ Elizabeth A. Sackler for Feminist Art: "The Dinner Party: Heritage Panels," http://www.brooklynmuseum.org/eascfa/dinner party/heritage panels/, accessed April 22, 2015 ${ }_{408}$ Ibid. 
Heritage Panels were installed before the Banners in reverse chronological order, on white walls (fig. 26).

The Herstory Gallery was designed as a space for changing exhibits inspired by aspects of The Dinner Party. Current head curator Catherine Morris noted the curatorial inspirations lie not necessarily in the women featured in the place-settings, but come from "moments" in The Dinner Party to tell a larger story. ${ }^{409}$ In the "Herstory Gallery" in February of 2015, on view were the Heritage Panels, and, on the opposite wall, artwork by Chitra Ganesh (b. 1975). Along with her work was a selection by Ganesh from the collection to contextualize her own work. ${ }^{410}$ The temporary exhibit explored the theme of "female power and plurality," and drew inspiration from both The Dinner Party as well as the museum's collection, and provided further alternative perspectives on feminism and history, multiplying The Dinner Party effect. Alternative exhibitions across and in alignment with The Dinner Party provide another layer of conversation. The Herstory Gallery wall, painted by Ganesh with a mural, also opposed the "white box" mainstream museum approach thus invoking more critical thought. The juxtaposition of The Dinner Party Heritage Panels with Sackler Center traveling exhibitions, and the corner gaps of The Dinner Party installation proper provided further feminist perspective in comparison to the

409 "I am interested in finding within the narrative of people in The Dinner Party, moments that have significance to tell a larger story. The first show I curated at the Sackler Center was Healing the Wounds of War: Brooklyn Sanitary Fair of 1864 (2010), which grew out of Elizabeth Blackwell, the first woman to graduate from medical school in the United States and co-founder of the US Sanitary Commission. I did another exhibition on Lorraine Hansberry, ${ }^{409}$ including letters and publications addressing her identities as a feminist, a lesbian and a political playwright. ${ }^{409}$ These are the kinds of the almost historical footnotes that I'm interested in finding out. I curated an exhibit on Djuna Barnes, the moment at which she was a new reporter, ${ }^{409}$ these kind of projects. There are also collaborations with artists--historical examinations and projects with contemporary artists. The recent exhibit, Shared Dining, originated with a workshop with incarcerated women, who made a collective project inspired by The Dinner Party ${ }^{409}$. The next exhibit with be organized collectively with the staff - Agriprop - including historical and contemporary references to The Dinner Party." Catherine Morris, interview with the author, September 25, 2015.

${ }^{410}$ Chitra Ganesh: Eyes of Time, was on view at Elizabeth A. Sackler Center Dec. 12-July 12, 2015, accessed April 22, 2015, https://www.brooklynmuseum.org/exhibitions/chitra_ganesh/. 
traditional mainstream chronological mode of art exhibition organization, reminiscent of Chicago's original intentions.

As Morris asserted, the installation of The Dinner Party is significant to the Sackler Center's mission: “to raise awareness of feminism's cultural contributions, to educate new generations about the meaning of feminist art, to maintain a dynamic and welcoming learning environment." ${ }^{\not 11}$ Morris also pointed out its broader significance:

The Dinner Party is central literally and figuratively to the Sackler Center itself. It's important because it situates The Sackler Center within a history and within the institution this is the most successful function of it. This is a historical institution that reflects a similar type of history that Judy Chicago was correcting - visually important that we point to this and continue to correct. The Dinner Party is becoming a historical document. It's an interesting and important kind of object, and to see new generations discover it is enormously important. ${ }^{412}$

Morris' comment solidifies Rodriguez' intentions in extending The Dinner Party's story through the layering of spaces, and asserts a powerful identity for the Center and a feminist point of view. ${ }^{413}$ In this way, The Dinner Party, is literally a curatorial framework for the Sackler Center.

Unfortunately, there was no wall text regarding the curatorial framework and installation of The Dinner Party so that viewers might understand and see these various levels of connection. Chicago and her team were not consulted for this recent curatorial design, so there was a lack of collaboration on the part of the institution with the artist. ${ }^{414}$ The accompanying Ganesh exhibit did entail conversation between Ganesh and the Sackler Center curator about The Dinner Party, Sackler collection, and installation. ${ }^{415}$ So, collaboration is perhaps part of the current and future

\footnotetext{
411 “About the Center,” Brooklyn Museum: Elizabeth A. Sackler Center for Feminist Art, accessed April 22, 2015, http://www.brooklynmuseum.org/eascfa/about/index.php.

${ }^{412}$ Catherine Morris, interview with the author, September 25, 2015.

413 Rodriguez, 7.

${ }^{414}$ Donald Woodman, interview with the author, November 8, 2015.

415 "Chitra Ganesh," Brooklyn Museum: Elizabeth A. Sackler Center, accessed May 1, 2015, http://www.brooklynmuseum.org/exhibitions/chitra_ganesh/.
} 
curatorial framework of the Herstory Gallery, although paradoxically, not with the artist or team that designed the original installation which inspired it all. Moreover, while certainly Chicago conceived The Dinner Party, she was not the sole creator, researcher, installer, nor fundraiser for the original The Dinner Party. This brings the curatorial choice of not displaying and bringing the acknowledgement panels into the discussion, as Chicago, Gelon and Hill understandably find that missing piece a major silence of agency for the hundreds of people who did work on the project. Moreover, it creates an alternative perspective when viewing The Dinner Party as less of an inclusive and community-oriented work. As the volunteers are literally not acknowledged, they are likely overlooked by viewers as well. The collaborative and collective aspect was so integral to Chicago's concept and execution of the project, that to not have this visible in the current installation removes this essential component. ${ }^{416}$ The Sackler Center owns the acknowledgement panels but does not have them on permanent display. Similarly, the elimination of the International Honor Quilts changes the interpretation of The Dinner Party. The Quilts added another layer of agency for artists and non-artists alike who created the patches, as well as the women honored in the quilts. Not only are the quilts missing from the current installation, ${ }^{417}$ but they are not even mentioned in the exhibition wall text. Space constraints are certainly understandable but perhaps another wall panel, digital application, or pamphlet could further make available these missing elements.

Diane Gelon, the original exhibition organizer for The Dinner Party tour, pointed out in an interview that the 2007 installation was in the smallest space it has ever been and that perhaps

\footnotetext{
416 There has been no response to queries made to members of the original The Dinner Party team, current Elizabeth A. Sackler Center curator Catherine Morris former founding curator Maura Reilly or Elizabeth A. Sackler regarding a contract for displaying The Dinner Party. Thus, if there was such a contract, I was not allowed access to it.

417 The International Honor Quilt is not owned by the Sackler Center. They were donated to the Hite Art Institute in Louisville, Kentucky in 2013.
} 
there is not room for the Quilt or acknowledgment and Documentary Panels. She expressed her disappointment for this, as these elements extend the idea behind The Dinner Party out to the public and provide visual honor to the many women involved. Though ultimately, Gelon is satisfied that the artwork finally has a home. ${ }^{418}$

Indeed, I agree with her assessment; the International Honor Quilt, acknowledgement panels and Documentary Panels would give an additional contextual perspective extending beyond the gallery, which the original tour provided. The quilts are a subtle response to the privileging stance of the museum. As artists and non-artists alike from all across the world contributed patches dedicated to living and deceased individual women and groups, it not only provided agency to the contributors, but an honor to the many other potentially lost women to history, that again, may not have been selected or acknowledged by museum exhibitions, art texts, etc. While The Dinner Party itself serves as this symbol for the history of women throughout Western civilization, so the quilt served as an extension of this idea by the openended contributors and women featured in the quilt. Though space may be a factor as well as funding, even an insertion of an image of some of the quilt, or one of the 540 quilts, would provide further reflection and criticality to the permanent installation. ${ }^{419}$

The same is true for the physical presence of the acknowledgement panels, which although they listed on the website, would provide another level of agency for those involved as well as a deeper understanding of the immensity of making The Dinner Party. There were video

\footnotetext{
${ }^{418}$ Diane Gelon, interview, with the author, September 4, 2015.

419 The Hite Art Institute at University of Louisville in Kentucky's website also holds images and information on all of the panels, and is in the process of compiling information on the creators of the individual patches. The Institution also offers a takeaway pamphlet, including a brief explanation of the Quilts, examples of patches and complementary narratives, how the Institute obtained the Quilts, and educational resources to go along with the Quilt, evoking Chicago's original outward intent. John P. Begley, Project Assistant, IHQ Project, email with the author, September 18, 2015. "International Honor Quilt Digital Collections," University of Louisville Hite Art Institute, accessed October 6, 2015, http://uofl.me/intl-honor-quilt.
} 
screens in the Herstory Gallery when I visited in February, next to the Heritage Panels which provided further information about the artwork and women featured, though visitors had to take the time to scroll through it. ${ }^{420}$ Again, while space is perhaps a factor; an accompanying pamphlet or digital application might provide context about the process and other people involved in the making of The Dinner Party.

In February, introductory wall text was at the start of the Entryway Banners hallway and briefly introduced the work placing it in context with art and feminist history (fig. 24). The panel itself was red, matching the walls behind the Entryway Banners as originally conceived by Chicago. This immediately provokes an opposition, to traditional "white box" (or white label rather) setting literally, from the start of The Dinner Party experience. The text on this introductory wall panel was most likely written and created by Sackler Center curators, though it is not noted on the panel. It contextualizes The Dinner Party within American art, feminist art and within the museum. The making-of the artwork with the hundreds of collaborators was mentioned and the work described as "the most significant icon of 1970s American feminist art." ${ }^{\prime 21}$ This is strong and more typical museological language, framing it with utmost praise in a more modernistic, individualistic sense; however, the agency given to the collaborators and reminder of the dual tribute to the reclaimed women featured in the artwork as well as the "women who have been lost to history" reminds viewers of the privileged museum position.

An interesting point lay in the second paragraph which described The Dinner Party as the banners, Heritage Panels, Heritage Floor, and ceremonial banquet (table artwork). There was a

\footnotetext{
420 “Gallery Design,” Brooklyn Museum: Elizabeth A. Sackler Center, accessed October 7, 2015, https://www.brooklynmuseum.org/eascfa/about/gallery_design/.

${ }^{421}$ Museum label for Judy Chicago, The Dinner Party, Brooklyn Museum: Elizabeth A. Sackler Center for Feminist Art, February 22, 2015.
} 
physical description regarding the significance given to the reclamation of craft artwork through the media selected. However, as this research reveals, this is not the entirety of The Dinner Party. In fact, as the Sackler Center website reveals, The Dinner Party elements also include the acknowledgement panels, the International Honor Quilt and the Documentary Panels. Not noted by the website or the wall text are the Documentary Panels which displayed the various contributors during the process of making the artwork. Perhaps text space is a factor. However, as these missing aspects contextualize The Dinner Party further, it seems to be significant in their absence-ironically, a portion of The Dinner Party, meant to bring symbolic awareness to the traditionally silenced population, is silenced. The last paragraph of the wall text points to the original exhibition of The Dinner Party in 1980 at the Brooklyn Museum and to the benefactor Elizabeth A. Sackler's Foundation, for preserving this "visual symbol that the artist created specifically 'to end the ongoing cycle of omission in which women were written out of the historical record." $" 422$

\section{November 2015 Visit, Curatorial Implications}

Entering the exhibit on November 6, 2015, resulted in quite a different viewing experience of The Dinner Party in the Sackler Center. The positioning and organization of The Dinner Party structure had been altered by November 2015. When first entering the Sackler Center doors from the Brooklyn Museum galleries on the fourth floor, to the right was the Herstory Gallery and entrance into The Dinner Party. There was a glimpse of the table through one of the triangular glass corners. There was no arrow or designated instructions at this point of

\footnotetext{
${ }^{422}$ Museum label for Judy Chicago, The Dinner Party, Brooklyn Museum, Elizabeth A. Sackler Center for Feminist Art, February 22, 2015.
} 
entry, so one could go straight through and around the temporary exhibition, to enter The Dinner Party table room before reading the wall text for The Dinner Party, which is probably not uncommon. This provides an experience almost backwards to that Chicago intended. However, at the opening of the table room, there stood a sign giving instructions for how the artist intended the piece to be experienced (Entryway Banners, artwork/table, then Heritage Panels, fig. 25). Yet now, this mode of viewing the entire piece was an impossible experience given the new layout.

Examining the Herstory Gallery November 6, 2015, showed The Dinner Party wall text written by the Sackler Center staff, followed by The Heritage Panels, in reverse chronological order, on white walls (fig. 26). This of course, opposes the artist's original intention of displaying the Heritage Panels after viewers see The Dinner Party table, in chronological order, on gold walls, to match the Panels and work against a traditional "white box" gallery setting. It is also different from Susan Rodriguez' design, where the Heritage Panels were installed afterward on walls which divided the Entryway Banners from the Herstory Gallery.

Whether or not it was intended to be a practical change, or a more thoughtful, critical one, was not stated. ${ }^{423}$ Considering either, it is a confusing installation. The wall text itself is identical to the wall text in February, except the map had been removed, and it was printed on a white panel, not red (fig. 27). This change to the typical "white box" was disappointing considering Chicago's original red walls at the entrance. Also, in considering feminist curatorial scholars challenge to the "white box" curatorial style, as it can encourage a privileged perspective. It could be thought to match the other walls in the Herstory Gallery, and it could be temporary, but in November, in all white, it was nothing short of disappointing. In February

\footnotetext{
${ }^{423}$ Email queries sent to Catherine Morris were not answered after our original telephone interview and my November visit.
} 
2016, Chicago's assistant emailed me to relay that The Heritage Panels had been taken completely down from the exhibition space. ${ }^{424}$

Though not stated on the Sackler Center website prior to this visit, the structure of the Herstory Gallery had changed, thus The Dinner Party and Sackler Center experience changed as well. It was quite a surprise as the Rodriguez/Polshek Architects design book states that the structure they designed would be permanent. ${ }^{425}$ Moreover, it left me wondering about the understanding of the entire installation regarded as one piece as conceived by Chicago, artist's rights, and whether other curators/prepators/institutions have felt as free to restructure installations by artists, or, if because of the multi-layered, educational way The Dinner Party was created, it is not considered to be one conceived piece, and instead considered as various, interchangeable, and flexible parts. As Susan Rodriguez' design did consider Chicago's original intention and design, the structure as experienced on November 6, 2015 somewhat opposed it. Was this an exercise of placing it in a new, critical context for viewing? Was it a restructuring to allow more space in the Herstory Gallery, as a security guard relayed, without regard the viewing experience of The Dinner Party? Was it permanent or temporary? Neither Chicago nor any of The Dinner Party original team were consulted on this change, which asserts a lack of collaboration between the artist and the institution. ${ }^{426}$ Reflecting on feminist curatorial aspects, involving collaboration between the artist and curator, was not practiced with this current installation. This is not to say that there were not other collaborative discussions or networking

\footnotetext{
${ }^{424}$ Katie Schroeder, assistant to Judy Chicago, personal email with author, February 16, 2016.

425 “Gallery Design,” Brooklyn Museum: Elizabeth A. Sackler Center for Feminist Art, accessed November 9, 2015, https://www.brooklynmuseum.org/eascfa/about/gallery_design/.

${ }^{426}$ Donald Woodman, interview with the author, November 8, 2015.
} 
going into this restructuring between departments or among outside sources, but such information has not been made available.

Moreover, Chicago's conception of The Dinner Party experience, never intended for the Heritage Panels to be viewed before the table,${ }^{427}$ nor were the walls behind The Heritage Panels to be white, as they were in November. The white walls break with the artist's original intention. As the table is most definitely considered the key (or only) aspect of The Dinner Party, as evidenced in the standard discourse, perhaps this alternation was considered acceptable, if not ideal. Current Sackler Center Curator Catherine Morris asserted in our interview that to her, the Entryway Banners and table are the most important aspects of The Dinner Party, ${ }^{428}$ which may or may not be linked to the restructuring of the installation.

Because of Chicago's original conception of the table as something to walk around and look over, the table itself still promotes spatial interactivity. The table room had not changedSusan Rodriguez's original reflective glass walls, glimpsed corners and dim lighting were still intact. An interview with Donald Woodman in November, revealed that the lighting was originally conceived to be individually controlled on each place-setting, providing more light on the front of the runners, as well as a specially designed light which created reflected rainbow luster on the backs of the runners as viewers walked around the table (fig. 10). ${ }^{429}$ Woodman explained that he and Judy Chicago understand the concern for balancing preservation with lighting, as it is now lit most days of the week.

\footnotetext{
427 Judy Chicago, email with the author, November 8, 2015. At the time of this writing, March 4, 2016, The Heritage Panels were completely removed from the exhibition space.

${ }^{428}$ Catherine Morris, interview with the author, September 20, 2015.

${ }^{429}$ Donald Woodman, interview with the author, November 8, 2015.
} 
The wall text written by the Sackler Center claims the aspects of The Dinner Party as only including the Entryway Banners, the table and the Heritage Panels and excludes the other parts. To create a more accessible informational context, it would be ideal to include the artist's original conception for the installation, since it is currently so different. If viewers come in with no knowledge of The Dinner Party, and they read this laudatory but simple wall text, they might not quite comprehend what they are looking at next, or why it is deemed significant. In November, there was no label for the Panels, and although the plate design images are along the top of The Heritage Panels. Without having seen The Dinner Party yet, and without knowledge of this project, viewers would be lost and perhaps disinterested. It is not only against the artist's conception, but it creates a confusing experience. There were no written materials readily available, and the video screen with additional information about the volunteers and history, was gone.

On the other hand, if the viewer was well-versed in feminist or contemporary art history and on The Dinner Party specifically, the November installation could have instigated a new, critical viewing experience. It could be seen as a literal "count-down" to history before entering the banner hallway and table artwork, to go back and spend more time with The Heritage Panels thereafter. Still, The Dinner Party was not designed by Chicago for necessarily educated audiences; it was designed for the broadest audience possible to understand. It is hard to reconcile knowing Chicago's admirable and atypical intent with the altered installation. Much of the historical information on The Heritage Panels, today, is still new to many. This is not only because of the information, but the way in which it is presented - through other women's lives and narratives, not inserted into the "history" as is more familiar in textbooks. This contextualization which is still opposed to the norm in books and in museum collections, is so 
important role in The Dinner Party's experience and interpretation, that having it before the banners and tables removes some of its significance. Viewers may not know what they are looking at, so they may glance at The Heritage Panels quickly to move on to more renowned The Dinner Party table. After having seen the artwork, they may go back to read and understand the information on The Heritage Panels, or, having seen "the main" part of The Dinner Party, may move on to the contemporary galleries. These changes do not serve the purpose of the work well in reaching out to viewers from the broadest audience possible. Moreover, with the current state of not having the Heritage Panels displayed at all, this is not even an option.

In November, the compactly installed Entryway Banners were viewed after The Heritage Panels. There was a highlighted The Dinner Party text on the wall as one turns the corner, perhaps signifying the proper start to The Dinner Party experience. The wall in the banners hallway was still red, in accordance with Chicago's original intensions. The banners were hung closer to each other, on both walls, so it was more difficult to have a contemplative experience compared to the original conception. There was still a separate hall for the Banners. After going through this hallway, viewers could enter the table room, or move onto the temporary galleries. In November, there was a Zanele Muholi (b. 1972) film with sound in the gallery next to The Dinner Party table gallery, which was loud and quite disruptive to The Dinner Party viewing experience. I could not help but think of Chicago's original conception for a quiet, contemplative experience. Perhaps this new more jarring experience causes more critical thought on how The Dinner Party remains relevant amongst the literal and figurative noise.

Spatial or institutional limitations that perhaps came into play with the current installation could be acknowledged with wall text. This could alleviate some of the tension between the current display and the artist's conception. It would not provide the same experience, but it could 
provide viewers with a deeper understanding of what they are looking at and the original structure Chicago had in mind, from the acknowledgement and Documentary Panels to the Entryway Banners, table and Heritage Panels. This understanding might slow visitors down as they are viewing, allowing for a more meaningful and impactful experience beyond just the main gallery, as Chicago intended.

There was not an informational pamphlet available for The Dinner Party or Herstory Gallery in neither February nor November. Making such a pamphlet available could extend the impact and understanding of the piece as Chicago's original 12-page pamphlet provided historical and local context. There were recent books by Chicago on the history of The Dinner Party in the Brooklyn Museum bookstore, which provide an ample informational context, but these must be purchased and are probably not accessible to a broad audience. The feminist curatorial goal of actively reaching the audience and creating a regional context, was lacking, though to note, it is now housed in an internationally recognized mainstream Museum. ${ }^{430}$ There are programs, educational resources for teachers, public events and tours that can be arranged with regard to the exhibitions and Center in general. However, for the average The Dinner Party viewer, there was nothing readily available, even when asking the front desk and security staff. $^{431}$

As far as accessibility, most galleries are now wheelchair accessible since the American Disabilities Act in $1990 .{ }^{432}$ There is no offer of the exhibition text in different languages and the comprehension of the exhibit as conceived by Chicago is impossible. Moreover, the change

\footnotetext{
${ }^{430}$ As The Dinner Party is now housed in an international Museum in a major U.S. city, further discussion here would be significant with regards to a regional versus international context.

431 "The Dinner Party, Educational Resources," Elizabeth A. Sackler Center for Feminist Art, accessed October 14, 2015, https://www.brooklynmuseum.org/exhibitions/dinner party/.

432 "About," American Disabilities Act, accessed April 20, 2016, http://www.ada.gov/ada_intro.htm.
} 
apparently removed the in-gallery video application which gave more information on the women featured in The Dinner Party. So this level of accessibility and interactivity was gone.

The Brooklyn Museum does have a new application, ASK Brooklyn Museum, which invites viewers to identify artwork with Bluetooth and text questions to their art historians and educators. ${ }^{433}$ The application is free but it did not work on my phone. As of the editing of this paper, the most popular searched-item for the Museum's application is The Dinner Party. ${ }^{434}$ This displays a desire to connect with audiences, and regarding The Dinner Party could help them grasp its vastness is in progress.

The Dinner Party remains popular; it accounts for $20 \%$ of the traffic to the Brooklyn Museum. ${ }^{435}$ Elizabeth Sackler explained its impact in 2012: "In the first five years after it was installed, over half a million visitors have circled The Dinner Party in awe. To some it is an education; to others, a beacon; for another, a magnet; for tourists, a destination; to women who remember it well, it is a shrine." ${ }^{436}$ Imagine the different impact gleaned, however, from the amount of information and regional context in the original tour, compared to its current installation.

\footnotetext{
433 "Itunes: ASK Brooklyn Museum,” Itunes, accessed November 10, 2015, https://itunes.apple.com/us/app/ask-brooklynmuseum/id949540325? mt=8.

${ }^{434}$ Meredith Deliso, "ASK Brooklyn Museum app engages visitors with the artwork," amNewYork, 17 April 2016, accessed April 19, 2016, http://www.amny.com/lifestyle/ask-brooklyn-museum-app-engages-visitors-with-the-artwork-1.11701295.

${ }^{435}$ Stephanie Wolf, "Denver gallery surveys art trailblazer Judy Chicago's five-decade career," Colorado Public Radio, 23 October 2014.

${ }^{436}$ Chicago, The Dinner Party: Restoring Women to History, 13.
} 


\section{Recent The Dinner Party Reception: The Experience and Observations}

Reception of The Dinner Party since its 2007 installation seems to focus on the entire experience. Slate reviewer Mia Fineman wrote about visiting The Dinner Party in the Sackler Center in 2007 after having seen it in Brooklyn originally in 1980:

... As I rode the subway out to Brooklyn a few weeks ago, I was ready to dismiss Chicago's project as historically significant kitsch. But when I entered the darkened gallery and began to make my way around the table, I changed my mind...The Dinner Party is, as Chicago intended, a powerful pedagogical tool meant to raise awareness of women's contributions throughout history. Like a great teacher, she gets her point across by appealing to the senses and the imagination, by entertaining, provoking, and engaging the viewer in a pleasurably interactive learning process. ${ }^{437}$

Significantly, Fineman's comments allude to the entire viewing experience and educational aspect including The Heritage Panels.

Alternatively, curator and feminist scholar Alexandra Kokoli felt the reverential installation quality in the Sackler Center was not critical enough:

I saw it at the E. Sackler Museum in Nov. 2008 and thought the installation really emphasized the religious (or rather ritualistic) dimension of the work. Dimmed lights, everyone speaking in hushed tones... The plates looked quite sensual and very beautiful but the curatorial approach did not facilitate a critical (re)consideration of the work, opting rather for a promotion of its historical significance and its undeniable prettiness. My students loved it. ${ }^{438}$

Of course, Kokoli is reminding us of the importance of a critical display and reflection of artwork with regard to feminist curating. Indeed, as noted above, the wall text defined the artwork as highly regarded, and the display emphasized the reverential quality that Kokoli relayed was less critical and more celebratory. However, this reverential quality was part of Chicago's original conception, so Kokoli's comment reveals either a lack of this understanding,

\footnotetext{
${ }^{437}$ Mia Fineman, “Table for 39: The Dinner Party, Judy Chicago's Iconic Work of Feminist Art, Stands the Test of Time,” Slate, 25 April 2007.

438 Alexandra Kokoli, interview with the author, July 24, 2015.
} 
or a growing sense of authorship by curators. It is interesting to note Kokoli's comment that her students loved it---again pointing to the fact that this piece still has the ability to connect to broad audiences.

Artist Felicity Allen had a similar reaction to its recent installation:

As a Londoner I'm interested in thinking about how it was shown in London in the 80s. It was in a kind of pop-up warehouse space without any of the grandeur it now has, and there was a smaller exhibition curated in a space within the warehouse which showed, I think, 4 contemporary British women artists (I was one of them). There was an irritation that none of the museums would show it, and therefore women organized the pop-up space, but equally I think it felt more gritty and less hallowed (and therefore better) for that. The reverential quality that I've seen since that is more problematic. I am sure that the London show affected my curatorial/educational thinking, but not in a way that can be directly attributed. ${ }^{439}$

Art historian Hilary Robinson also relayed a fondness for the way it was installed in the 1980s:

"I saw it in Edinburgh also in 1985, also in a warehouse, which was great - overheating

Morningside ladies sounding like Jean Brodie talking about the stitches and ignoring the imagery." ${ }^{440}$ Understandably, it was thrilling to see this artwork in the 1980 s as it was such a tremendous, well-known exhibition that instigated wide-ranging community and activist efforts. Moreover the raw, grounded feeling of seeing the artwork in a warehouse, or alternative venue, as opposed to a mainstream museum, certainly provoked a more down-to-earth connection with the piece, as did the regional events that went along with the original exhibition. As previously noted, a stipulation of some feminist curators is to stay away from mainstream institutions. Thus, coupled with the more celebratory installation of The Dinner Party table, the recent installation could be viewed as privileged instead of critical installation. There are definitely points of both. Rodriguez' contemporary reflective design, the Herstory Gallery's critical display (though now

\footnotetext{
${ }^{439}$ Felicity Allen, interview with the author, July 24, 2015.

${ }^{440}$ Hilary Robinson, interview with the author, July 24, 2015.
} 
lacking The Heritage Panels) and banner, works to provide a somewhat critical display. The fact that it is not installed as Chicago originally designed, already makes it a bit critical (though, paradoxically, this is not noted anywhere in the installation). Moreover, the fact that there are aspects missing (acknowledgement panels, Documentary Panels, International Honor Quilts and now The Heritage Panels), makes it much less celebratory. Again, these facts are unknown to visitors, sadly, creating almost a falsely celebratory presentation.

Regarding again the reflective glass walls, though they do take the viewer's focus away from the table proper, they also provide another level of reflection, perhaps pointing to contemporary "selfie culture." As Rodriguez mentioned, it brings the viewer into the artwork, causing a pause for inspiration, as viewers become, even abstractly, part of The Dinner Party. Moreover, seeing the infinite tables in the glass is reminiscent of the many women throughout history and in the future, who the table symbolizes.

Regarding the mention of grittiness and the grounded nature of the original tour, although enjoyable and exciting in memory and perhaps in form, this strategy might not be feasible for preserving such an artwork. As it is now, an iconic artwork that stands for so much, perhaps a gritty environment might not serve its purpose well now, considering the contemporary feminist points of contention (essentialism, intersectionality, etc.); it is now a historical piece, and cannot be viewed contemporarily as an artwork just created. As Chicago's original intent was to have it as a permanent display in a widely visited institution for a broad impact, it is perhaps encouraging that it was placed in such a mainstream institution. Some feminists' disregard for mainstream institutions are significant and valid, but challenge inside institutions are also necessary. To challenge history and the vast understanding of it, a challenge of the mainstream is necessary, as Catherine Morris also suggested with regard to The Dinner Party's housing inside 
the Brooklyn Museum, and its impact on the curatorial framework as a form of challenging the canon.

Recent reviews of the work suggest a positive outlook now that it is installed permanently, understood as canonized, perhaps ironically due to its literally physical kinship to "traditional" and canonized art displayed in the Brooklyn Museum. Regarding its 2002 debut at the Sackler Center, Roberta Smith wrote in the New York Times: "So how does Ms. Chicago's "Dinner Party" look now? Moving, illuminating, irritating, flawed, powerful. It is, as the artist intended, a highly informative, entertaining teaching device, designed to raise consciousness in a single bound by providing an unforgettable glimpse of the tremendous contribution of women through history. No one is knowledgeable enough not to learn from it, and most viewers will enjoy the process. ${ }^{241}$ Certainly, Smith's comments imply a regard for the entire experience including the information gleaned from The Heritage Panels. Art historian Jane Gerhard wrote of the impact of her feminist training and surprising awe when encountering the piece: "Let's just say I hold my training as a postmodern gender historian a little differently as a result of my encounter with The Dinner Party. I can now see the ways that sexual difference is a fertile ground for popular engagement with feminism and just possibly the only starting point for a lively understanding of what the next women's revolution might entail." ${ }^{442}$

With regard to the feminist curatorial elements summarized in this study, the curating of The Dinner Party with its combined original conceptions by Chicago and the contemporary designs of Rodriguez as seen in February, did reveal working feminist curatorial methods: critical selection and assembly, exhibition wall text and informational context, collaboration,

\footnotetext{
${ }^{441}$ Roberta Smith, "For a Paean to Heroic Women, a Place at History’s Table," New York Times, 20 September 2002.

${ }^{442}$ Gerhard, The Dinner Party: 286-287.
} 
accessibility, institutional challenge and viewer reflection. Much of this feminist curatorial framework is due to Chicago's curatorial innovations in the original installation and tour derived from her original exhibition design, research, written and documentary text and display, and community events. Since The Dinner Party's restructuring as seen in November 2015, the curating is different and to a degree, opposes Chicago's original conception. The results are almost as confusing as the unknown reason for its alteration. ${ }^{443}$ It could be viewed as a critical experience, or as a lack of respect for the artist's original intent, as there is no visual indication of Chicago's original structure. Is this restructuring a continued challenge toward traditional museum display to which feminist curatorial considerations aim? Or is this a reversion to traditional museum displays, with the white walls, and lack of in-depth informational context, exactly which Chicago was working against? Poignantly, Chicago observed in 2013:

...The problem is that the institutions haven't caught up or are determined to erase this reality. For example, in the newly installed Museum of Modern Art, there are very few women artists in the early galleries. Then suddenly, as if by magic, women artists appear after the 1980's with no mention of the Feminist art movement that accomplished their visibility. As a result, young women don't have the opportunity to learn about their predecessors, which means there is a lot of art being made that looks like earlier work without its power. Fortunately, the Sackler Center for Feminist Art provides an antidote to this institutional amnesia though young people still have to seek it out. Sadly, the institutions are failing to provide education about the history of feminism and Feminist art to EVERYONE even though these represent a significant cultural heritage that needs to be integrated into our art and educational institutions in a major way... ${ }^{444}$

This points to the poignant yet paradoxical legacy of The Dinner Party as an exhibition meant to inform and inspire, within an institution with perhaps different curatorial perspectives. This important research bringing attention to Chicago and her team's original curatorial structure and experience of The Dinner Party, though currently absent from display, has now entered the

\footnotetext{
${ }^{443}$ Email inquiries made to current Sackler Center curator Catherine Morris about the recent alterations were unanswered. 444 "Judy Chicago Birthday: Celebrating The Feminist Art Pioneer," Huffington Post, 20 July 2013, accessed April 22, 2015, www.huffingtonpost.com/2013/07/20/judy-chicago-birthday_n_3623420.html. It is notable to recognize that the nature of this significant scholarship has changed, and further discourse into the question of either preserving The Dinner Party scholarship produced in The Heritage Panels, or in continuing to update it, as Chicago did in 2007, in the future.
} 
discourse. Continued attention and research is necessary, as The Dinner Party may continue to shift as perspectives change with its future curators.

\section{The Dinner Party: Content and Collaborative Curatorial Inspirations}

Contemporary curators and educators have taken direct inspiration from The Dinner Party with collaborative methodology and content in mind, as with Penn State University's 2014 Out of Here exhibition. It included participatory art and participatory performance, as an example of feminist art curatorial practice facilitated in the course taught by Karen Keifer-Boyd, employing Chicago's participatory art pedagogy. Out of Here began with self-reflexivity, collective memory-work, feminist consciousness-awakenings, and content-searches, which were the generative forces for collaboration and creativity learned from Judy Chicago's approach to The Dinner Party. ${ }^{445}$ Penn State also initiated the The Dinner Party Institute Curriculum Project because of the popularity of projects created after the piece, providing resources to teachers to utilize Chicago's educational methods and format of The Dinner Party. Chicago reflected:

Although there are many ways of approaching The Dinner Party, it is important to note that The Dinner Party is built on a solid foundation of research into history, art history, feminism, and the obstacles women faced (and continue to face) as they struggled to participate fully in the societies in which they lived...The Dinner Party Curriculum Project Team has attempted to provide a range of possibilities for the integration of The Dinner Party into K-12 classrooms. ${ }^{446}$

This project demonstrates the ongoing impact of The Dinner Party beyond the artwork. The real impact of Chicago's curating of The Dinner Party is undetermined, but it is clear than many of her curatorial methods that were new for her time, continue to challenge the norm. The

\footnotetext{
445 “Studio,” Judy Chicago, accessed January 22, 2016, http://judychicago.arted.psu.edu/dialogue/studio/.

446 "Introduction by Judy Chicago: The Dinner Party Curriculum Project," Judy Chicago, accessed January 22, 2016, http://judychicago.arted.psu.edu/dpcp/.
} 
implications of the curator, exemplified by contemporary feminist scholarship, can provide a considerable curatorial model, with the understanding that it cannot possibly be "the" answer, to stopping the cycle of erasure of women and minorities in (art) history. Though many curators today and in the past focus on the esteemed institutionalized individual profession, and the pristine glamour of minimalistic designed exhibitions of one perspective, displaying one unexplained genius to the next; who are they curating for, and what is the point? Curating with Chicago's strategies can create a greater understanding for exhibited art, to further enrich the experience, perhaps making an impact beyond the gallery walls. 


\section{Conclusion}

"...when some women argue that museums devoted only to the achievements of women ghettoize us, I always wonder why they don't say this about all the museums that feature only, or primarily, work by men. To be kind, I might suggest that they have not counted the paltry number of women artists included in most museum collections, but for those who have observed the reality of our exclusion and still put forth this argument, all I can say is that they qualify for the 'I like their ghetto better than my own' award (though I, of course, long for the end of ghettos of any sort)." -Judy Chicago, Beyond the Flower ${ }^{447}$

Over The Dinner Party's history from conception by Chicago in the early 1970s, to finding its permanent home in 2007 at the Sackler Center, the artist's original feminist intentions were pervasive. Even in the age of so-called "post-feminism", Chicago asserts in her 2014 book, The Dinner Party: Restoring Women to History: “...Women’s art must be seen in the larger context of both women's history and women's struggle for self-expression. Without that framework, each woman's achievement threatens to be seen as an exception, rather than another link in the long chain of accomplishments that will one day be recognized."448

Feminist and art scholars continue to debate The Dinner Party's purported essentialism, Eurocentrism, craft aesthetic and populism among other topics regarding the artwork table. This current examination of the entire artwork experience from a curatorial perspective shed light on the insightful ways that Chicago designed it so that the broadest audience possible might be impacted. Judy Chicago's creation of a curatorial context and structure of installation has yet to be fully recognized as a strong exemplar in the history of feminist curating that has implications for contemporary curating. The recent restructuring of The Dinner Party at the Sackler Center raised more questions: how much have other installations followed or not followed the artist's original intent? Is this a common occurrence, or is it because of the nature of The Dinner Party educational aspects? Should installations be altered as time moves on, and perspectives change?

\footnotetext{
${ }^{447}$ Chicago, Beyond the Flower, 122-123.

${ }^{448}$ Chicago, "Introduction: Restoring Women to History," 27.
} 
As I have been editing this study, more scholarly and journalistic articles and conferences instigating discussion over contemporary and feminist curating, demonstrate the continuous relevance of the topic.

Chicago's other work, such as The Birth Project (1980-85) and Holocaust Project (198593), were also created with collaboration and highlighting social justice issues in a visual manner for mass audiences. Still, The Dinner Party remains her most renowned artwork, and stands as a model, curatorially and contextually, for feminist artwork. The curatorial decisions Chicago created at the start and as it progressed through Sexual Politics and to the Sackler Center can provide a model for feminist curating. These considerations include:

- curating with collaboration

- committing to selecting work by artists who have been silenced throughout the art institution and history

- assembling in a critical, conversational manner rather than chronologically

- providing accurate and enriching context that is legible for a broad audience

- acknowledging institutional limitations and/or privilege

- inviting, encouraging and/or organizing regional contextual elements/activities; and

- making the exhibition accessible not only to differently abled people, but interactive in a way that is engaging and invokes curiosity and further reflection into the topic, artist, process, etc.

From Chicago's early innovations with her detailed structuring of the entire exhibition, developing context through research and experimentation and creating a framework for understanding women in history, to its current contemporary and critical display, the curatorial implications of The Dinner Party are vast. This study has only just begun to consider the 
implications. If contemporary curators might consider some of these strategies and such feminist innovations are brought more into the contemporary curatorial discourse, perhaps the cycle of erasure of women in art and history, in history books and institutions could be halted faster. Though contemporary curators and academics looking into curatorial practice do not seem to recognize the significance of The Dinner Party and other feminist collective exhibition projects as providing models for curatorial insight and impact, they did. The hope is that this study contributes to redirecting this essential conversation. 


\section{Illustrations}

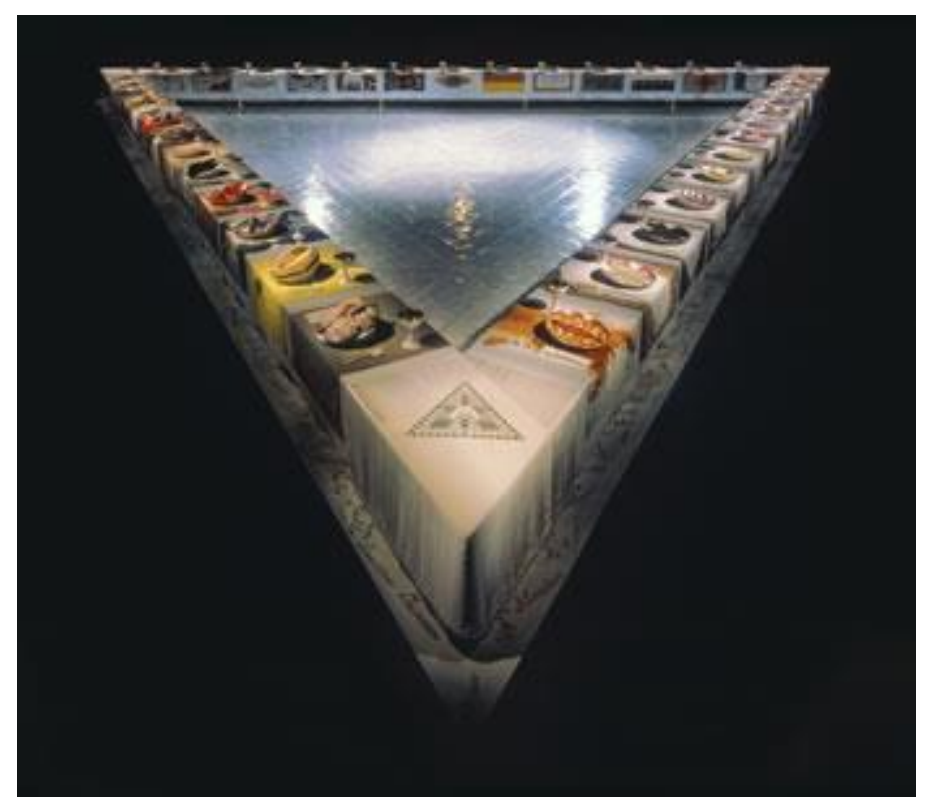

Figure 1: The Dinner Party (table) 1974-79 installation detail from Sexual Politics: Judy Chicago's Dinner Party in Feminist Art History exhibition (1996): Judy Chicago (American, born 1939); mixed media, 36" x 48', Collection of the Elizabeth A. Sackler Center for Feminist Art. Photograph courtesy of the artist.

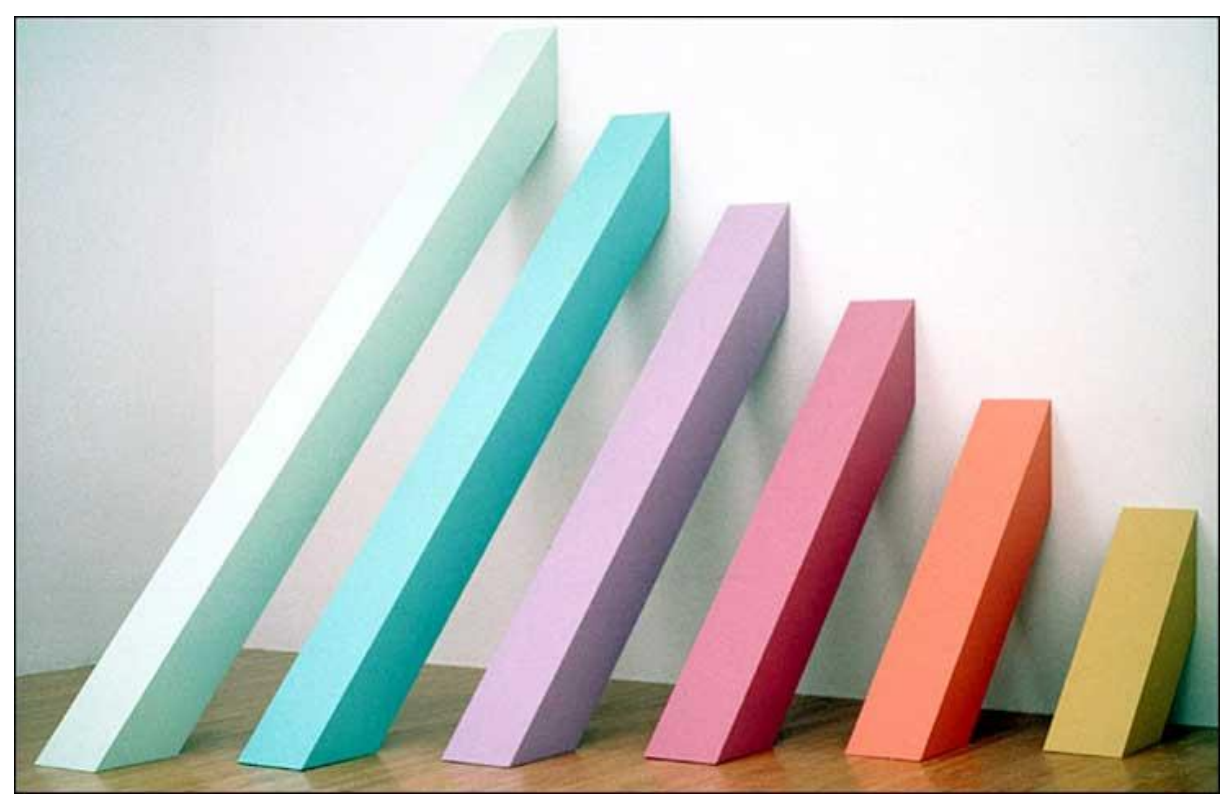

Figure 2: Rainbow Pickett, (1966): Judy Chicago (American, born 1939); acrylic on canvas on plywood. Photograph used with permission from the artist. 


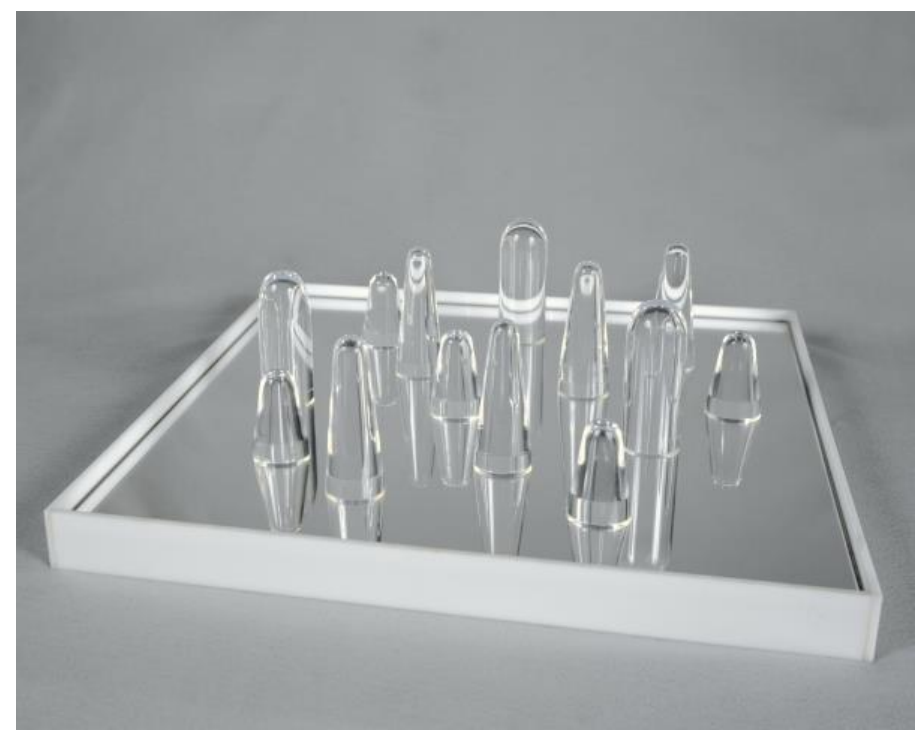

Figure 3: 3.5.5 Acrylic Shapes, (1967): Judy Chicago (American, born 1939); Formed acrylic, 10 " x 24" x 24". Collection of Penny Plotkin (C) Judy Chicago. Photo (C Donald Woodman. Photograph from Brooklyn Museum website, used with permission from the artist.

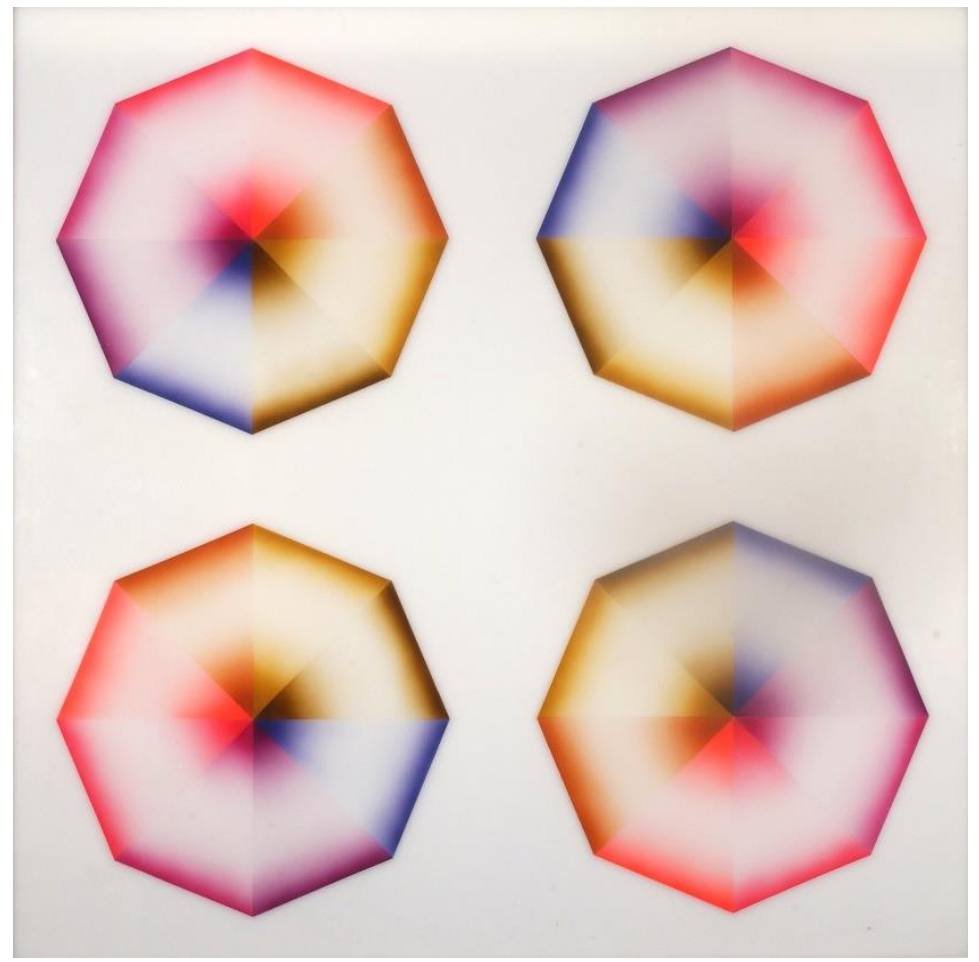

Figure 4: Pasadena Lifesavers Red \#5, (1970): Judy Chicago (American, born 1939); airbrushed acrylic, 60" x 60". Gift of Elyse and Stanley Grinstein, National Museum for Women in the Arts, http://nmwa.org/works/pasadena-lifesavers-red-5\#sthash.JUErsih8.dpuf. Used with permission from the artist. 


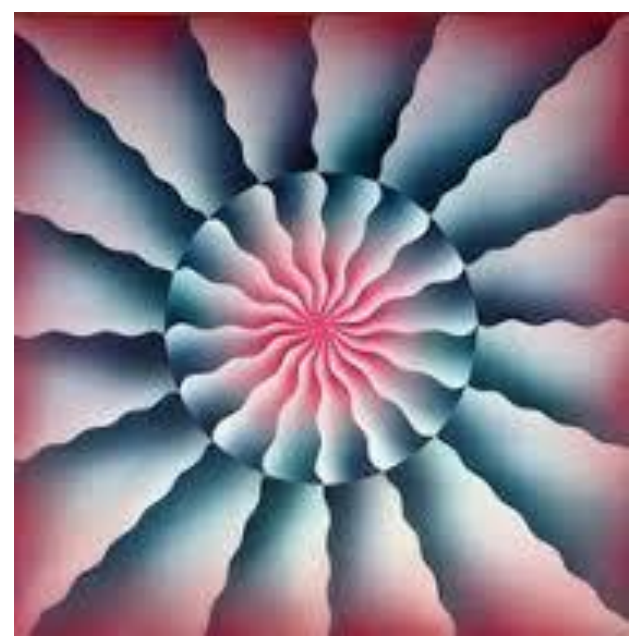

Figure 5: Queen Victoria, from The Great Ladies series, (1972): Judy Chicago (American, born 1939); acrylic on canvas, 40" x 40". Used with permission from the artist.

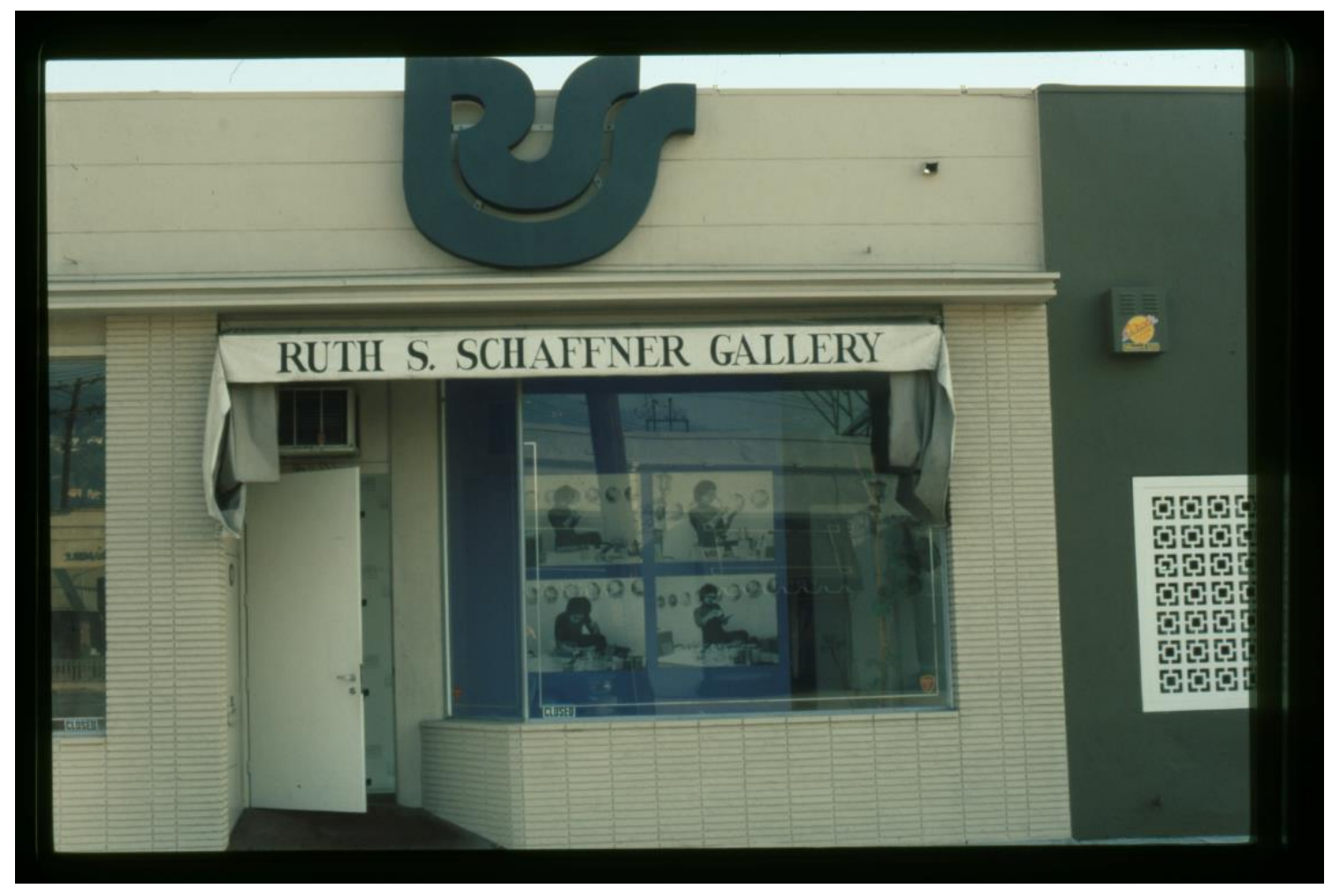

Figure 6: Ruth Schaffner Gallery, Los Angeles, gallery entrance to Judy Chicago solo exhibition, (1977). Photograph courtesy of the artist, used with permission from the artist. 


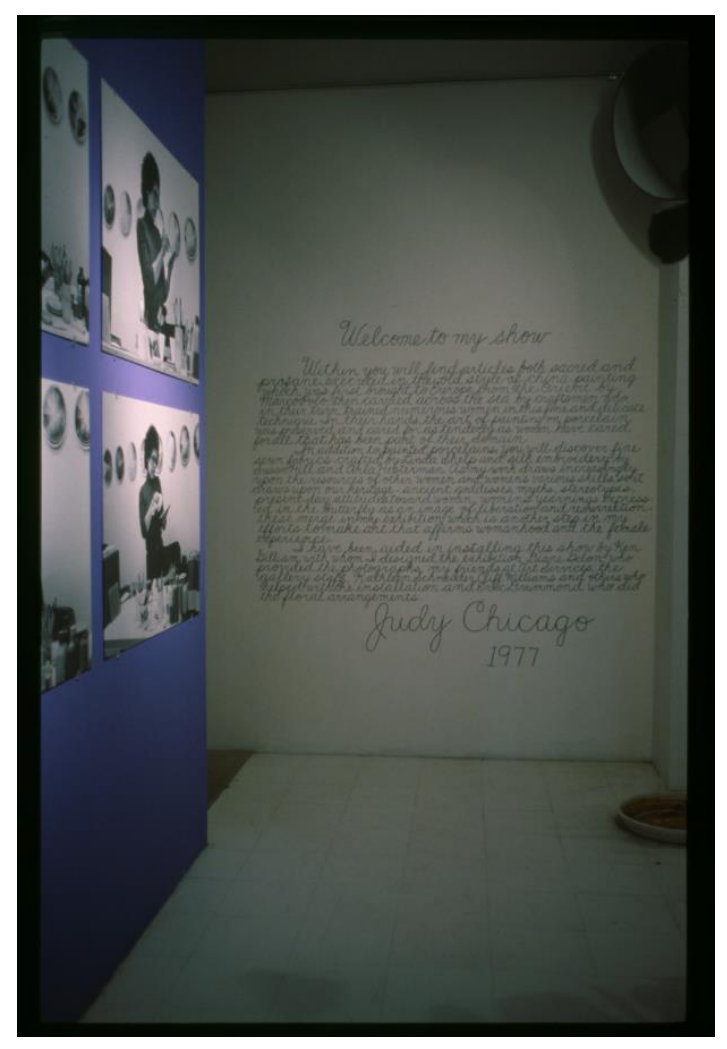

Figure 7: Ruth Schaffner Gallery, Los Angeles, gallery entrance to Judy Chicago solo exhibition (1977). Photograph courtesy of the artist, used with permission from the artist.

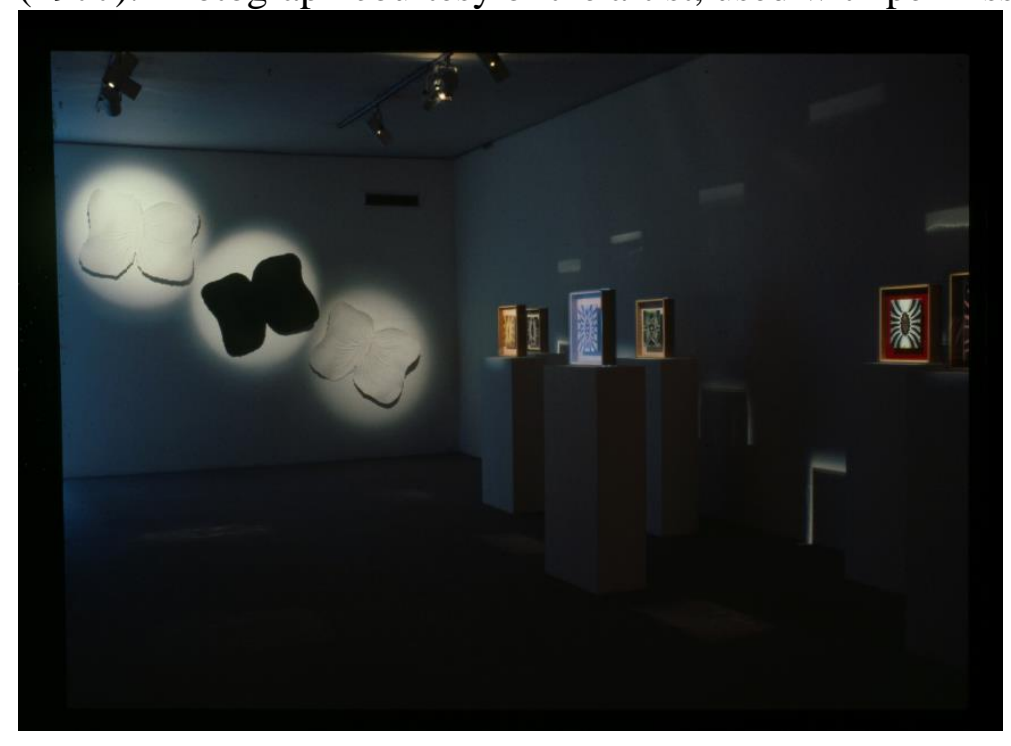

Figure 8: Ruth Schaffner Gallery, Los Angeles, Judy Chicago solo exhibition (1977), installation view of Six Views of the Womantree, (1976); Judy Chicago (American, born 1939): china paint on porcelain, 16" x 14" each, and Submerged/Emerged (1976); Judy Chicago: cast paper, 34" x 45 " each. Photograph courtesy of the artist, used with permission from the artist. 


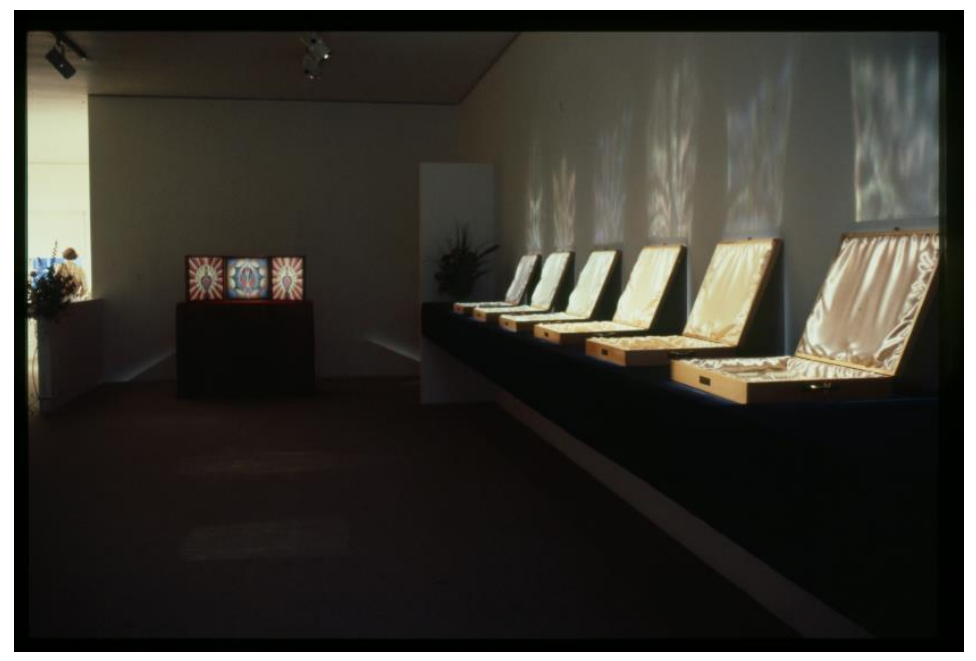

Figure 9: Ruth Schaffner Gallery, Los Angeles, Judy Chicago solo exhibition (1977); installation view of Broken Butterflies/Shattered Dreams \#1 - 6 (1976), and Did You Know Your Mother Had A Sacred Heart? (1976): mixed media. Photograph courtesy of the artist, used with permission by the artist.

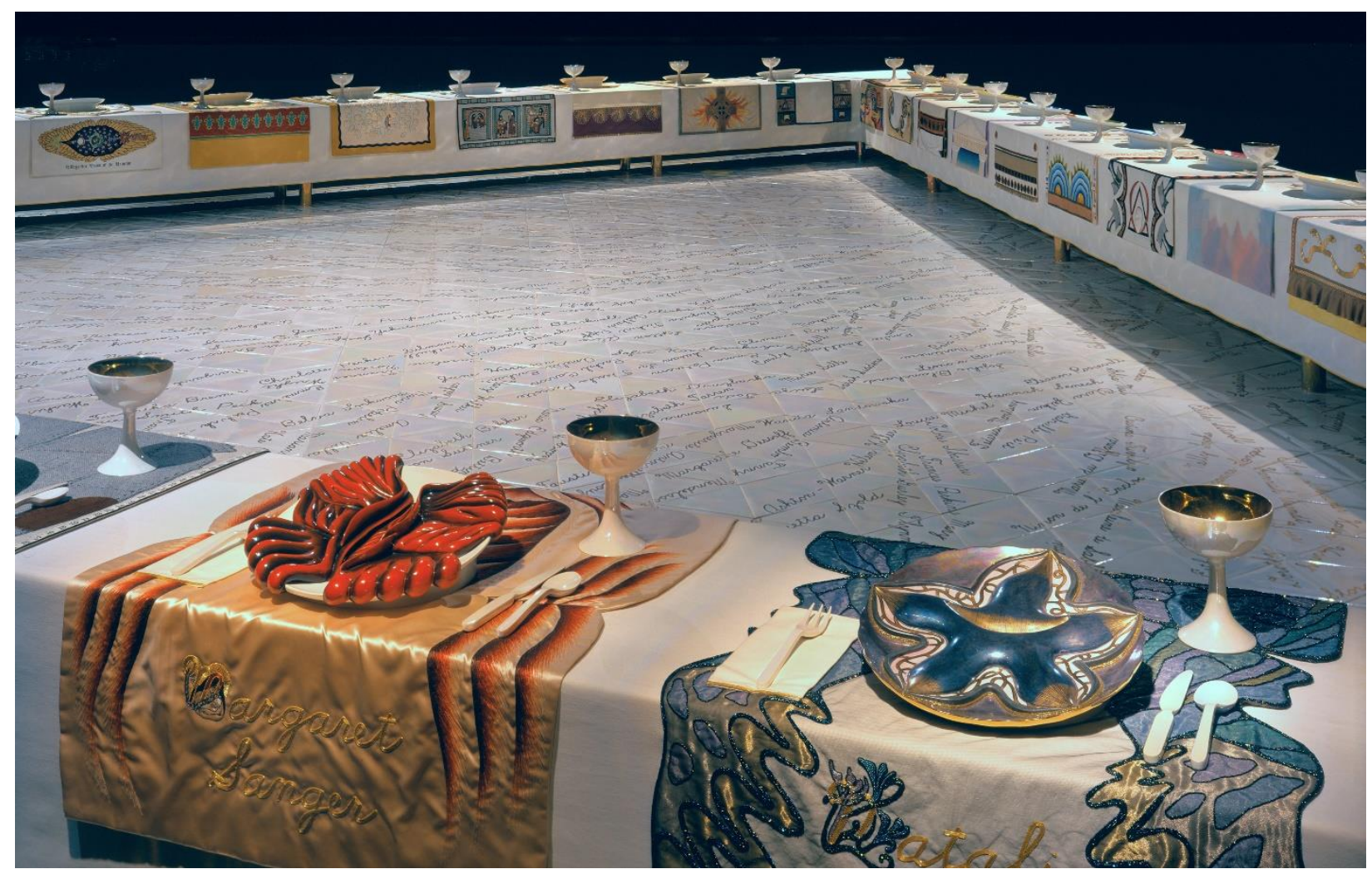

Figure 10: The Dinner Party (table) (1974-79); installation detail: Judy Chicago (American, born 1939); mixed media, 36" x 48'. Collection of the Elizabeth A. Sackler Center for Feminist Art. Photograph by Donald Woodman, courtesy of the artist, used with permission from the artist. 


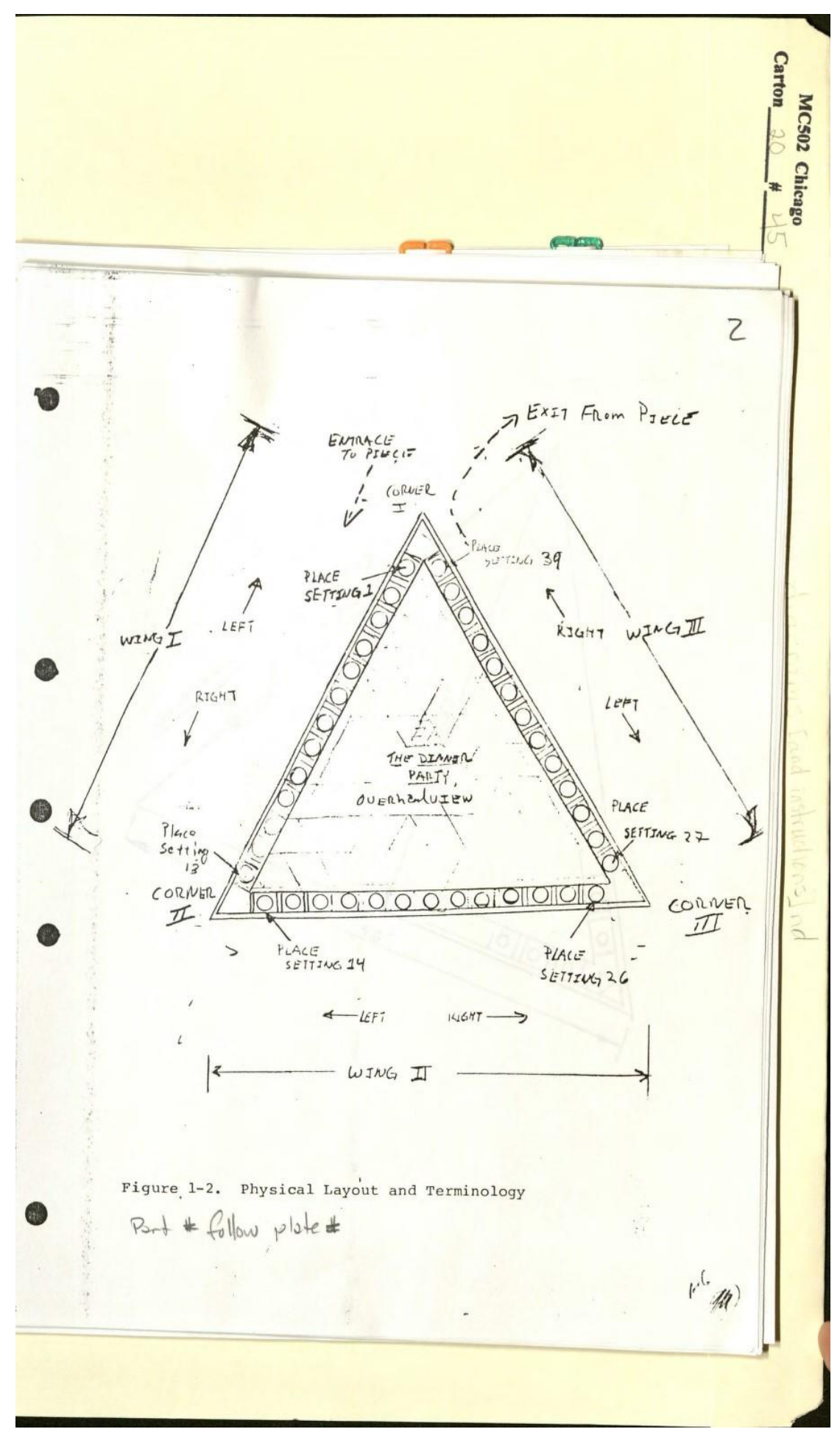

Figure 11: From Judy Chicago papers, The Dinner Party exhibition installation manual/instructions, drafts (1978-80): Judy Chicago (American, born 1939); Schlesinger Library, Harvard University Libraries. Used with permission by the artist. 


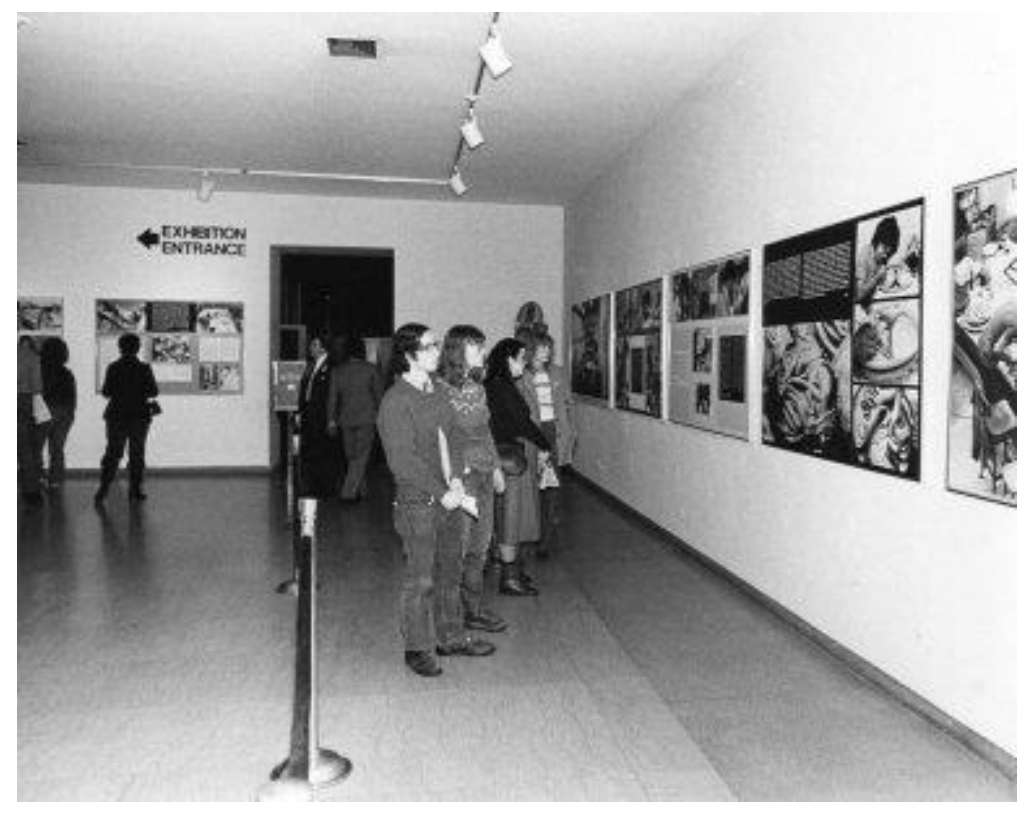

Figure 12: The Dinner Party, Judy Chicago (American, born 139) exhibition, 1980, Brooklyn Museum, visitors viewing the Documentary Panels, (Image: PSC_E1980i007.jpg. Brooklyn Museum photograph, 1980); Museum Archives. Records of the Department of Painting and Sculpture. (P\&S_E_1980_Chicago). Used with permission from the artist.

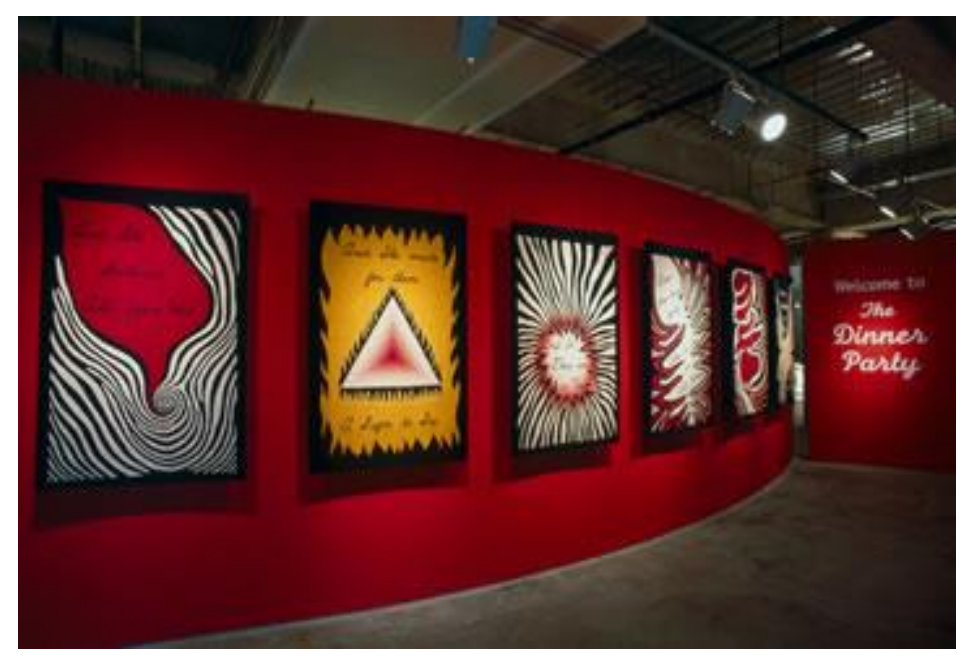

Figure 13: The Dinner Party, Entryway Banners, 1974-79 from Sexual Politics: Judy Chicago's Dinner Party in Feminist Art History exhibition (1996) at Armand Hammer Museum, Los Angeles: Judy Chicago (American, born 1939); six woven banners, 5' 6" x 3' 6" each. Collection of the Elizabeth A. Sackler Center for Feminist Art. Photograph used with permission of the artist. 


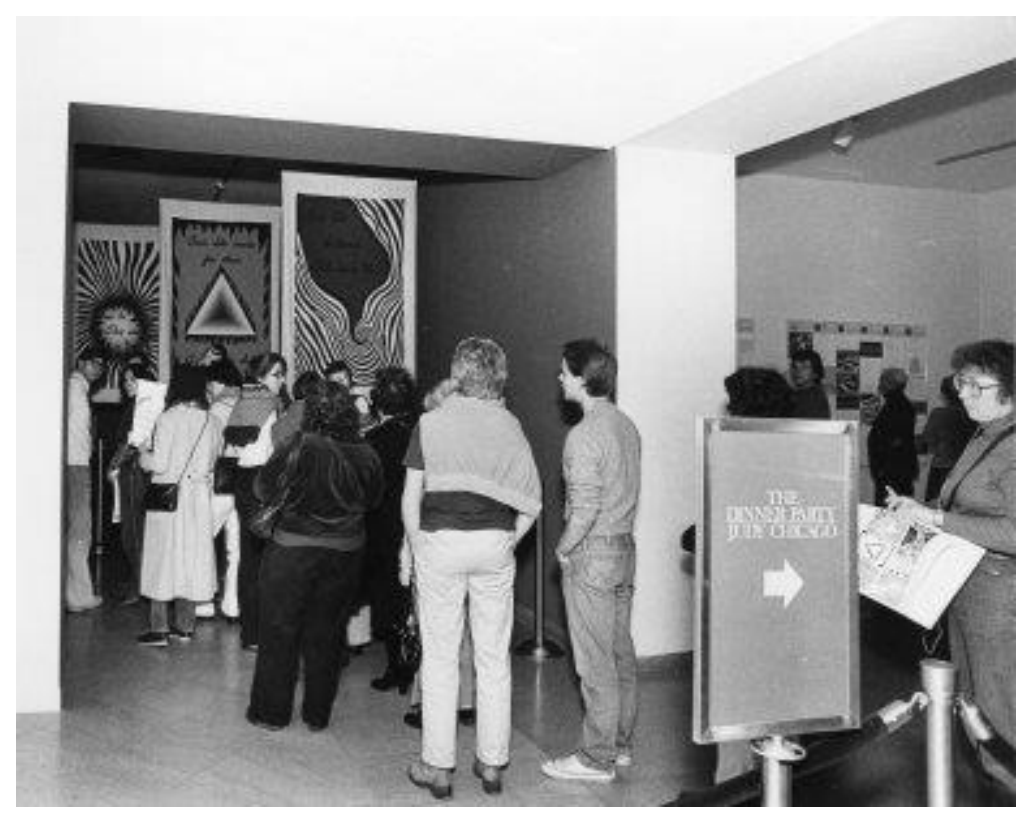

Figure 14: The Dinner Party, Judy Chicago, exhibition at Brooklyn Museum (1980), Brooklyn Museum photograph, 1980; Museum Archives. Records of the Department of Painting and Sculpture. (P\&S_E_1980_Chicago). Used with permission by the artist.

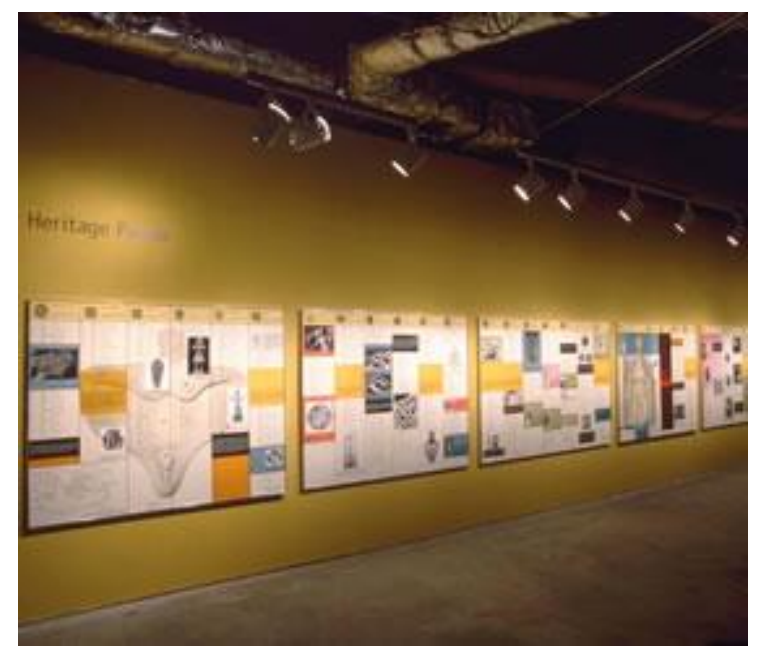

Figure 15: The Dinner Party, The Heritage Panels, 1974-79, from Sexual Politics: Judy Chicago's Dinner Party in Feminist Art History exhibition (1996): Judy Chicago (American, born 1939); seven large-scale hand-colored photo-and-text collages (ranging in size from 57 1/2" x 70 3/4" to 57 1/2 x 107". Collection of the Elizabeth A. Sackler Center for Feminist Art. Photograph used with permission of the artist. 


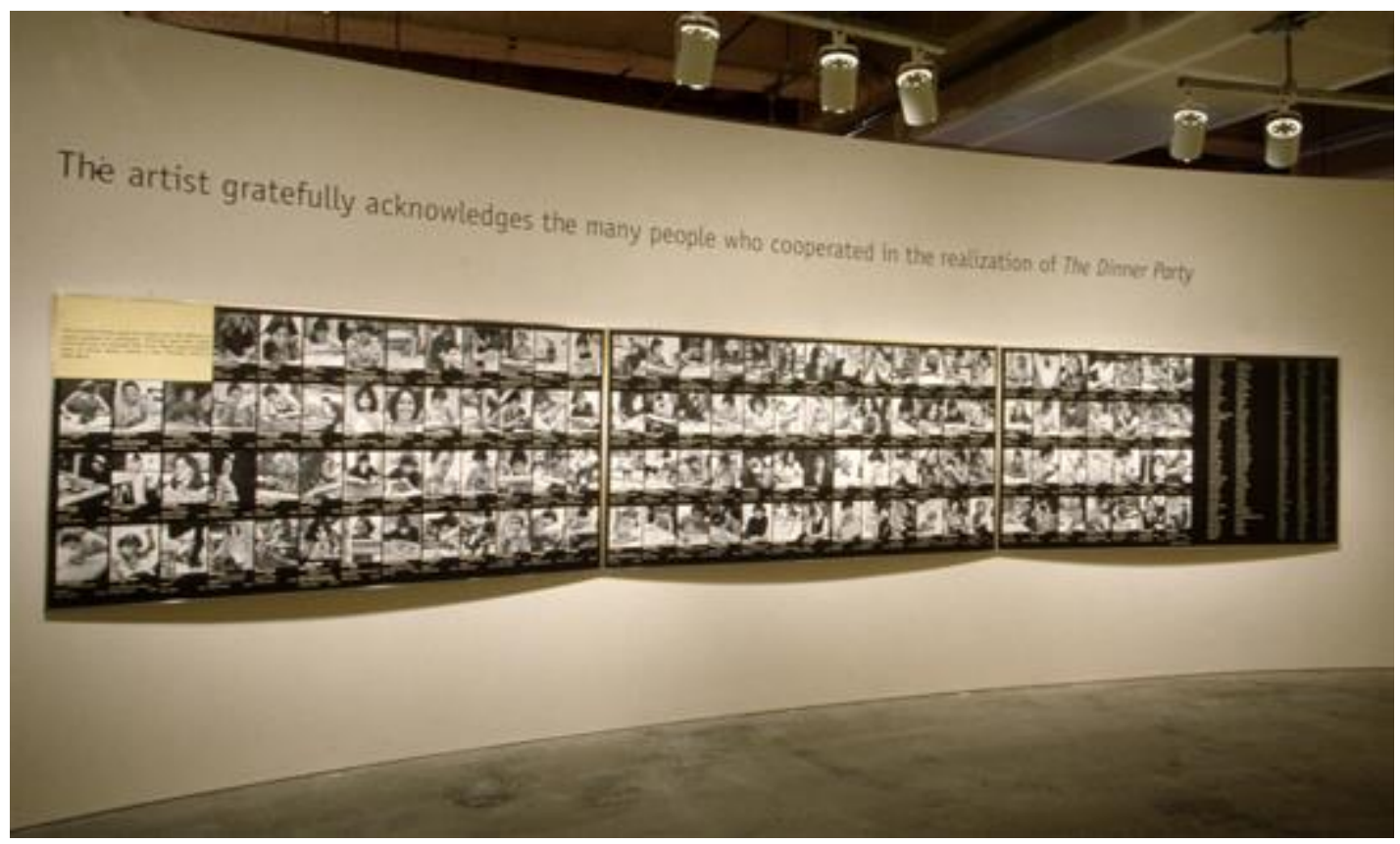

Figure 16: The Dinner Party, The Acknowledgement Panels, (1974-79): Judy Chicago (American, born 1939); three panels, 94 3/4" x 48 1/4 x 1" each. Collection of the Elizabeth A. Sackler Center for Feminist Art. Photograph used with permission of the artist.

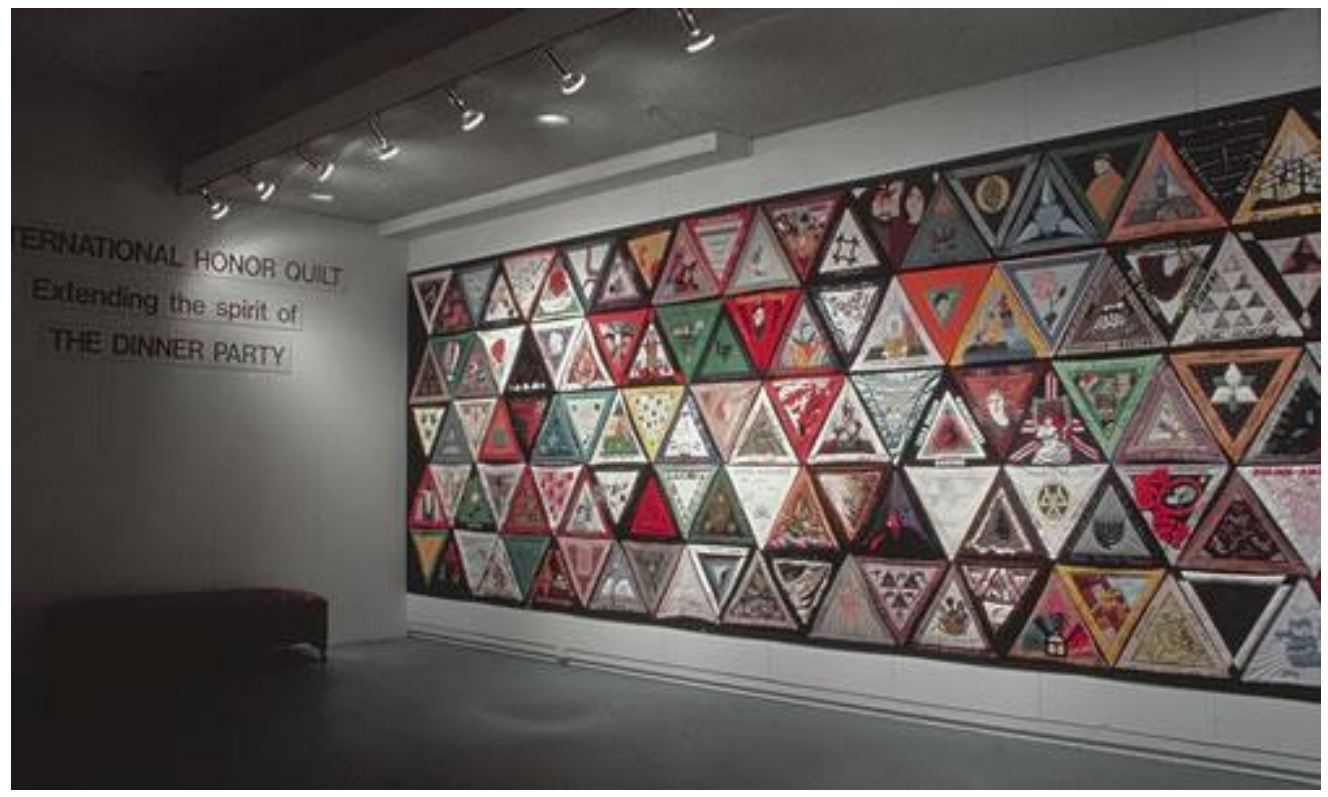

Figure 17: International Honor Quilt, detail (1980-88) installed in Melbourne, Australia (1988): Judy Chicago (American, born 1939). Collection of the Hite Art Institute, University of Louisville. Photograph used with permission of the artist. 


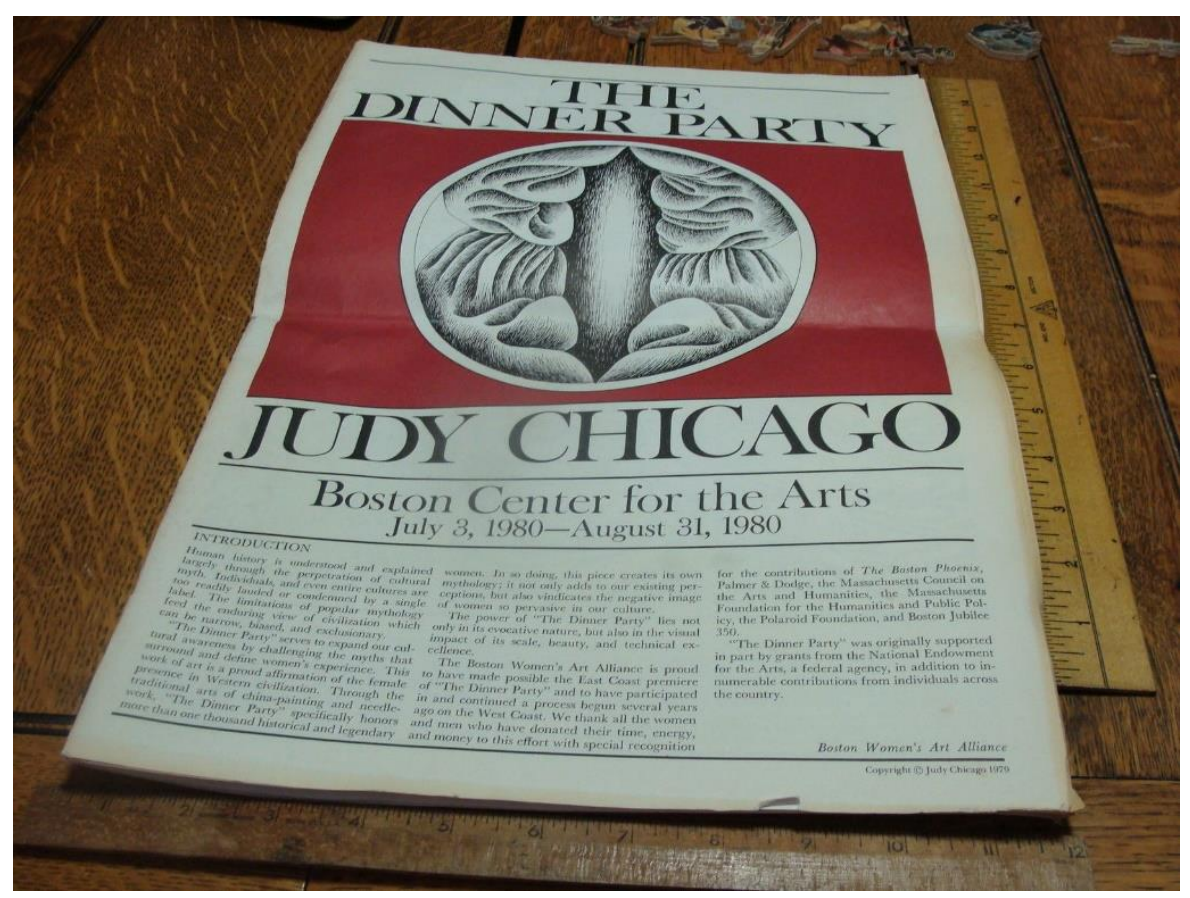

Figure 18: Exhibition pamphlet from The Dinner Party, Boston, 1980; accessed November 4, 2015, http://rawarchives.tumblr.com/post/22719048959/the-dinner-party-judy-chicagophotographs-of-the.
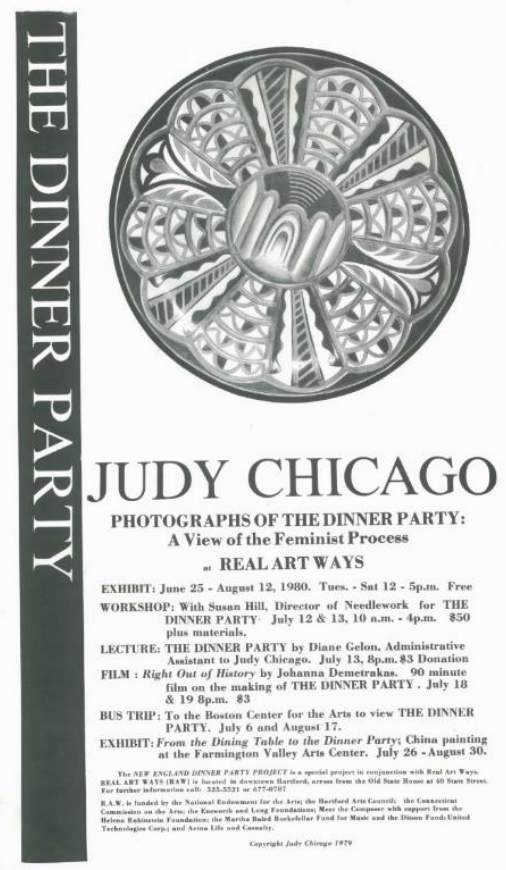

Figure 19: Exhibition flier from The Dinner Party, Boston, 1980; accessed November 4, 2015 , http://rawarchives.tumblr.com/post/22719048959/the-dinner-party-judy-chicago-photographs-ofthe. 


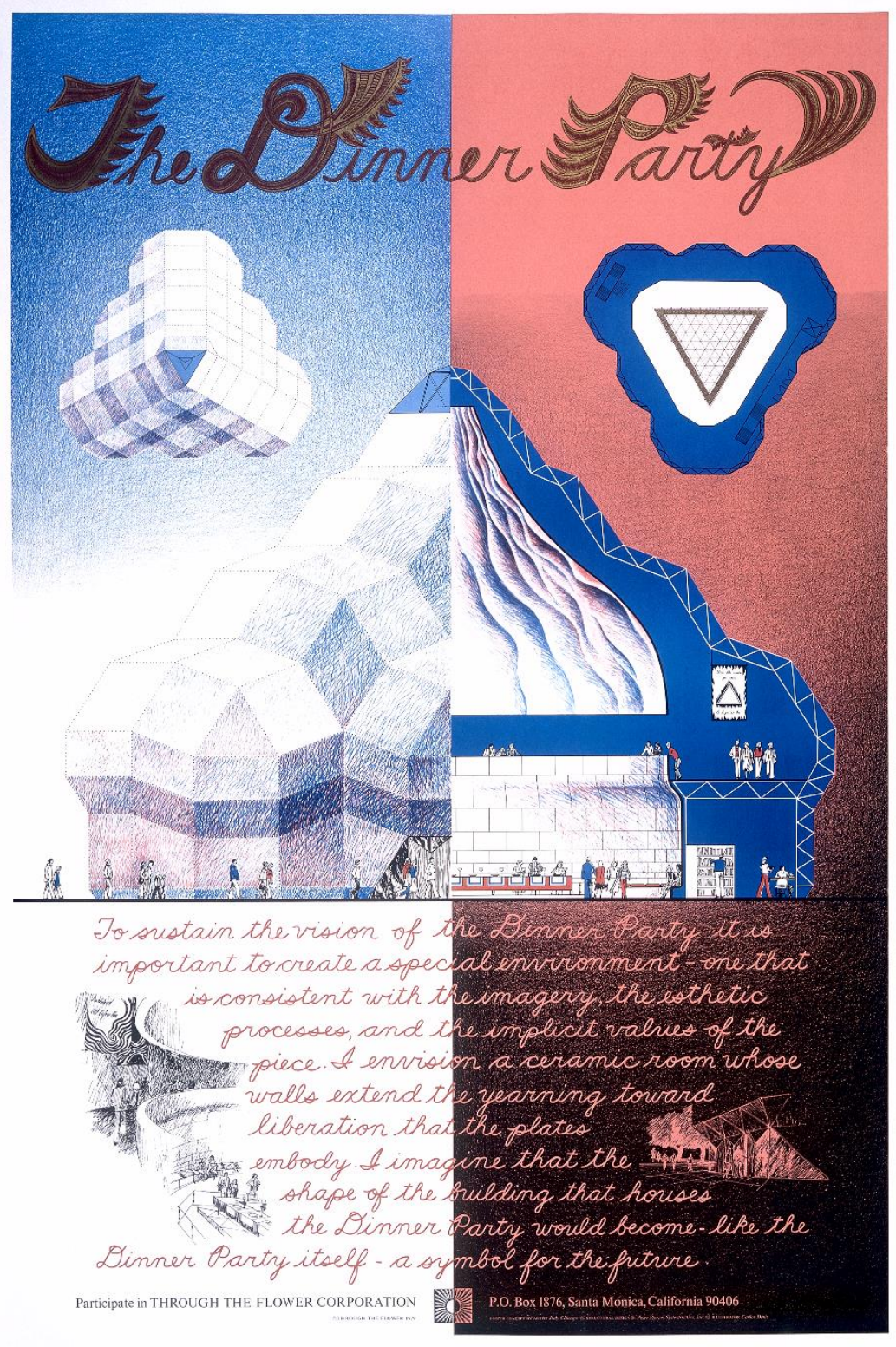

Figure 20: The Dinner Party Permanent Housing (1979), Judy Chicago (American, born 1939); offset lithography on paper, 36 " x 24". Photograph courtesy of the artist, used with permission by the artist. 


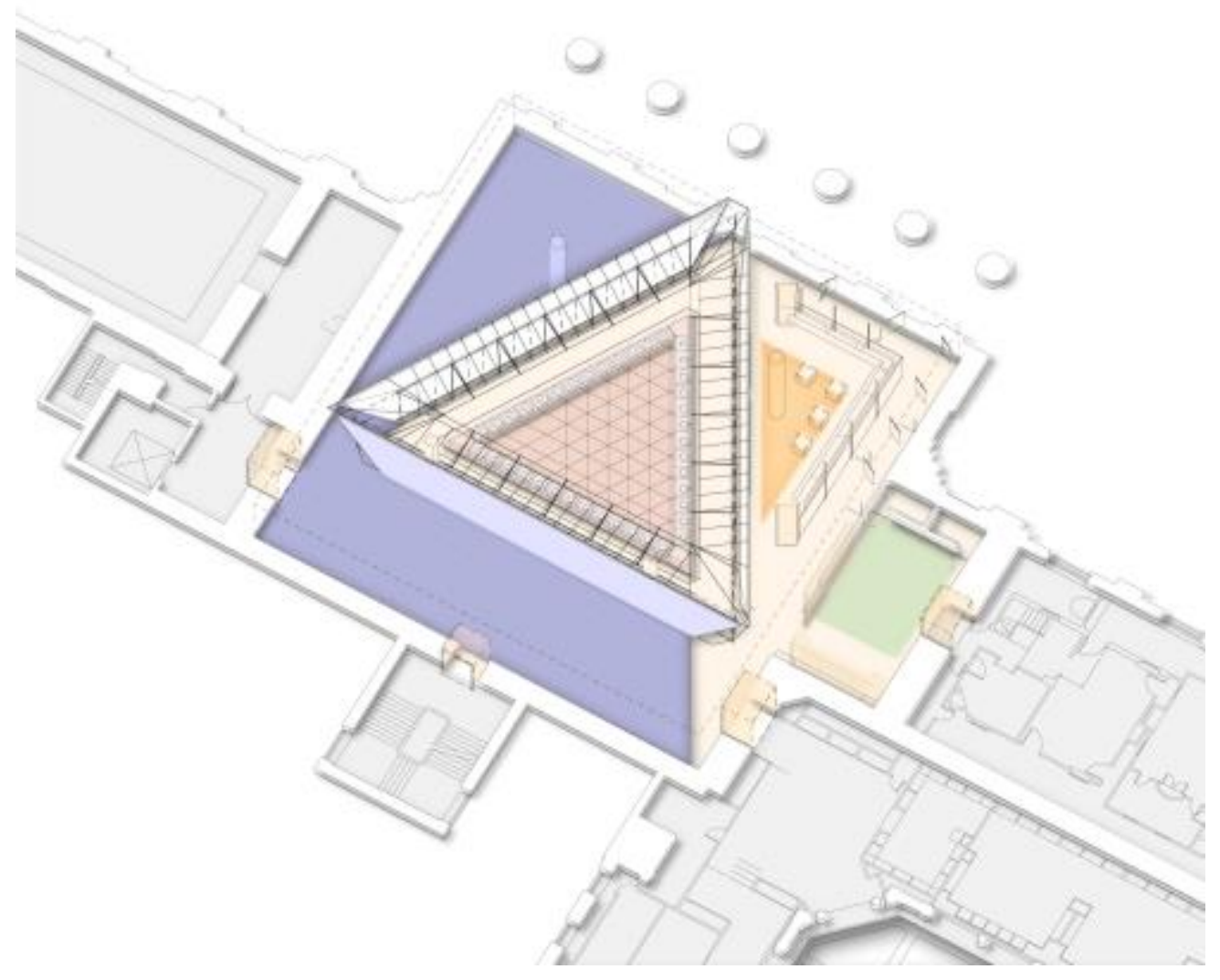

Figure 21: Axiomatic drawing of the Elizabeth A. Sackler Center for Feminist Art, including the gallery for The Dinner Party, changing exhibit galleries, and a study center. (C Polshek Partnership Architects. Accessed February 12, 2016, https://www.brooklynmuseum.org/eascfa/about/gallery_design/. 


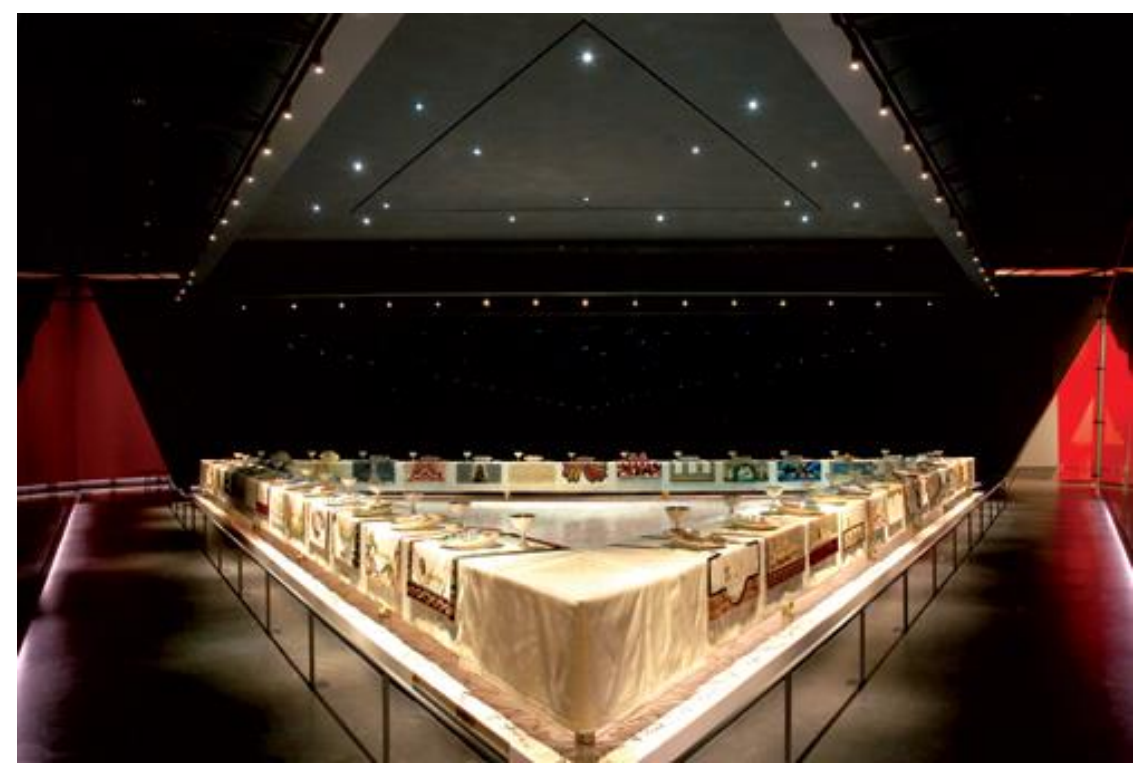

Figure 22: The Dinner Party (table) 1974-79 installation detail from Elizabeth A. Sackler Center for Feminist Art: Judy Chicago (American, born 1939); mixed media, 36 in. x 48 ft., Collection of the Elizabeth A. Sackler Center for Feminist Art. Photograph (C) Aislinn Weidele for Polshek Partnership Architects, used with permission from the artist.

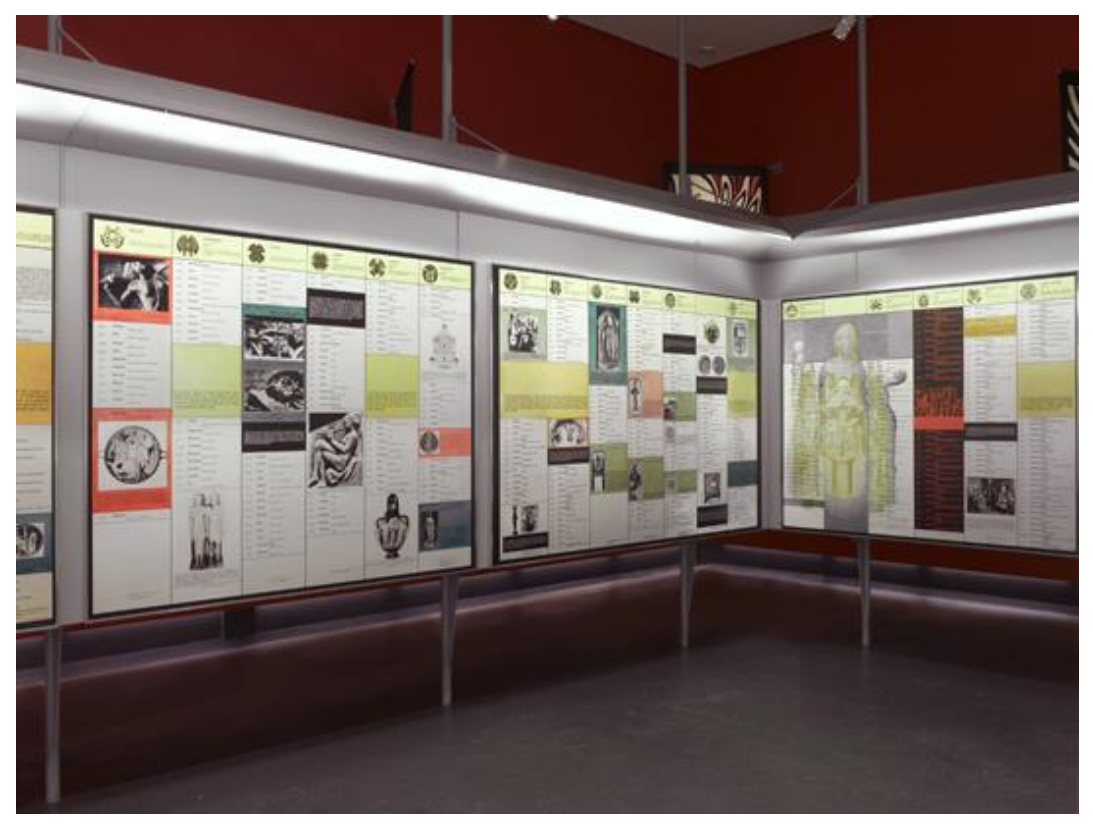

Figure 23: The Dinner Party, Heritage Panels (1979-2007), installed in the Elizabeth A. Sackler for Feminist Art, 2007; Judy Chicago (American, born 1939); photographic reproductions of hand-colored photo-and-text collages, ranging in size from 57 1/2 x 70 3/4 to 57 1/2 x 107"), 1979-2007. Collection of Elizabeth A. Sackler Center for Feminist Art. Photograph used with permission from the artist. 


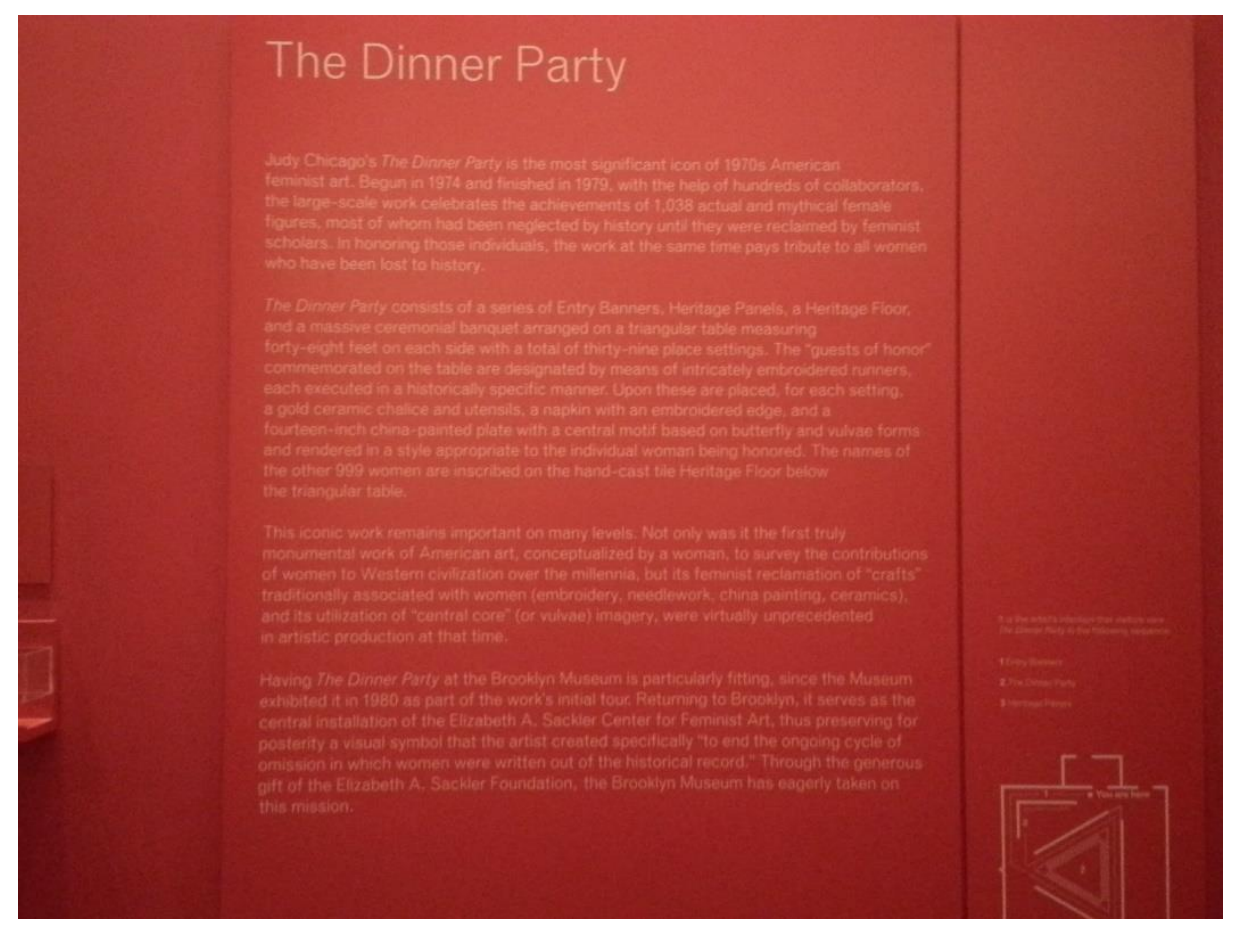

Figure 24: The Dinner Party, exhibition wall text, Elizabeth A. Sackler Center for Feminist Art, Brooklyn Museum, New York; photograph by author Sally Deskins, February 22, 2015.

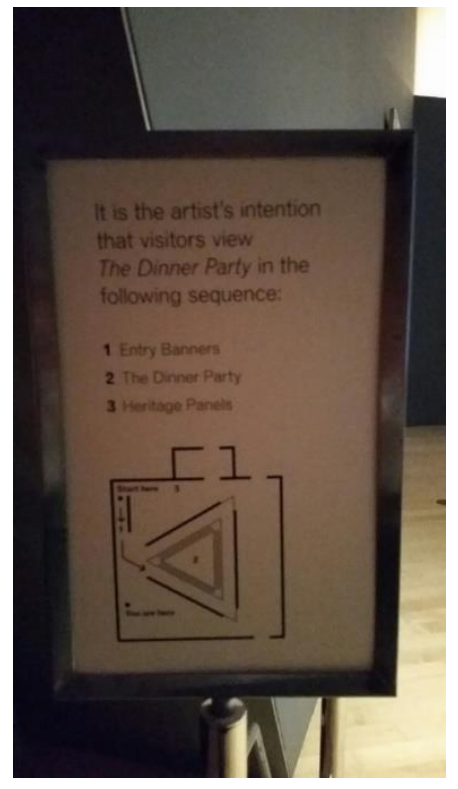

Figure 25: Sign that stood in front of The Dinner Party table room at the Elizabeth A. Sackler Center for Feminist Art, Brooklyn Museum, New York, November 6, 2015, photograph by the author, Sally Deskins. 


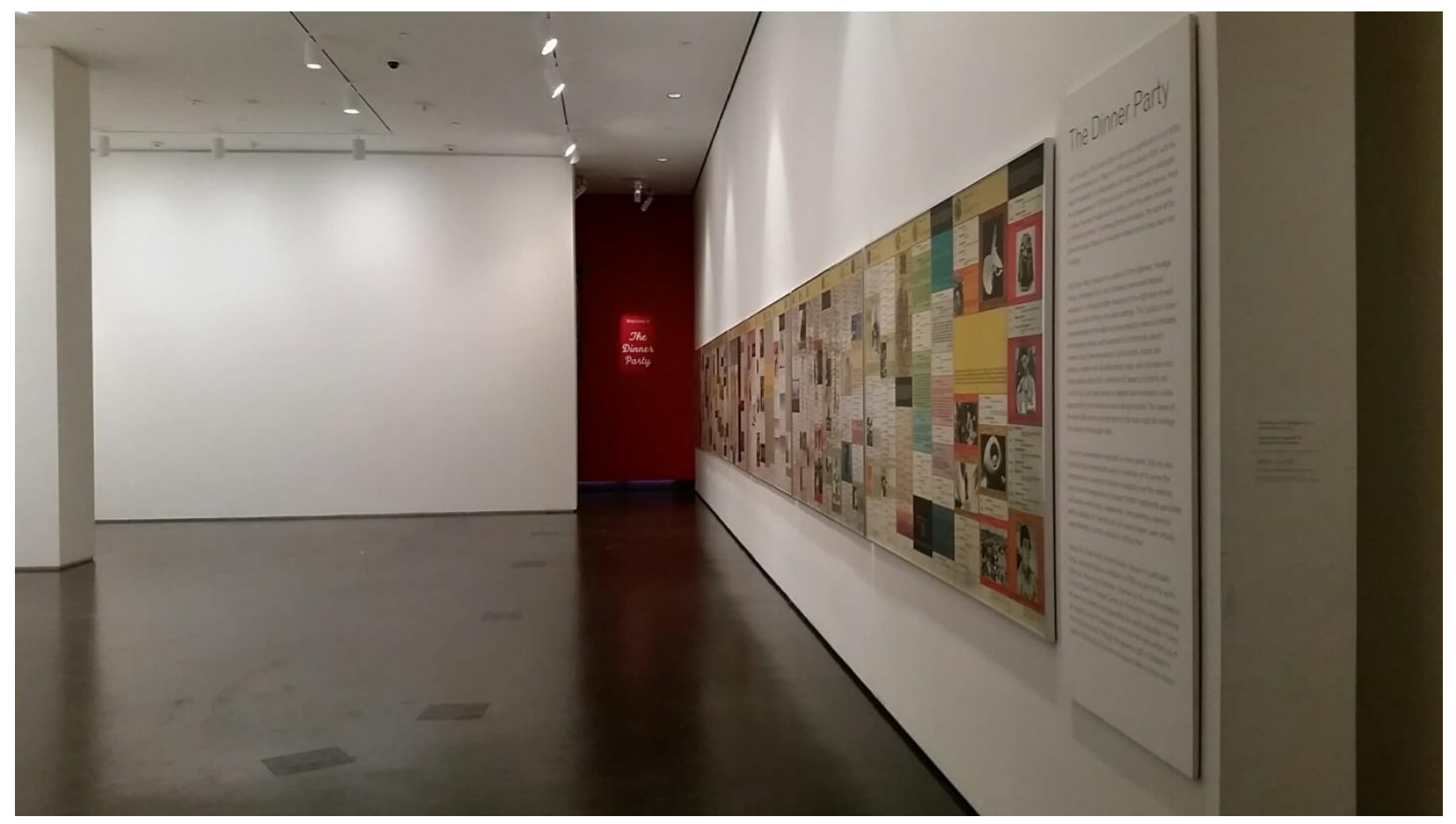

Figure 26: The Dinner Party Heritage Panels (photographic reproductions), Judy Chicago (American, born 1939); installation view of Herstory Gallery at Elizabeth A. Sackler Center for Feminist Art, Brooklyn Museum, New York, November 6, 2015, photograph by the author Sally Deskins. 


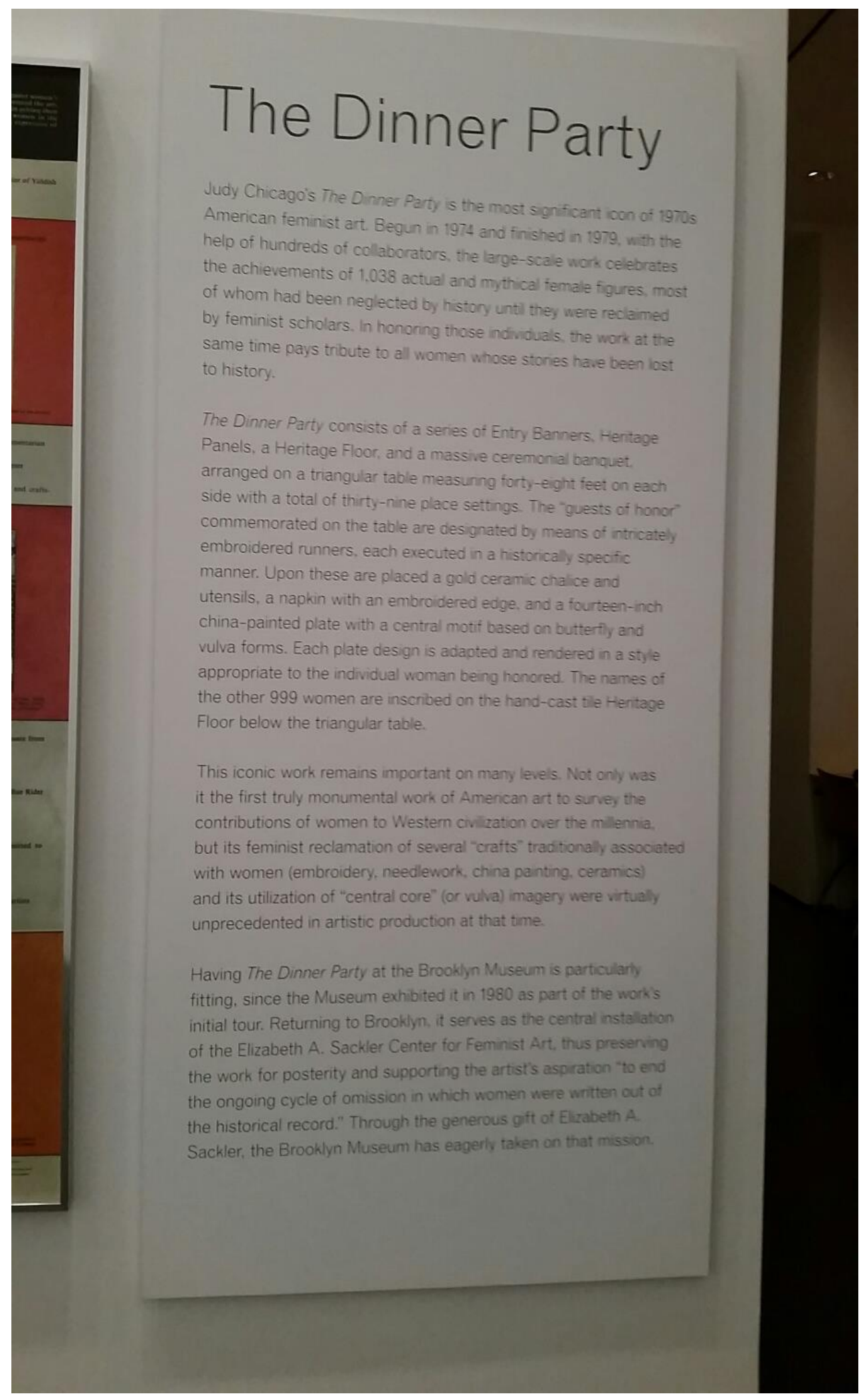

Figure 27: The Dinner Party wall text, Elizabeth A. Sackler Center for Feminist Art, Brooklyn Museum, New York, November 6, 2015, photograph by the author Sally Deskins. 
Appendix: Interviews

West Virginia University has acknowledgment of this research on file through the Institutional Review Board (IRB).

All Interviews included with permission by interviewees.

\section{Emails with Judy Chicago:}

Sally Deskins <

To:

Wed, Apr 22, 2015 at 9:51 AM

Dear Ms. Chicago,

I am an art history graduate student at West Virginia University. I was thrilled to be able to visit the Sackler Center and especially The Dinner Party while in NY in February for the College Art Conference (it was amazing and life changing, of course!). My thesis is examining the curatorial framework of a series of exhibitions featuring artwork by women and how that impacts the interpretation, in order to try and find a working feminist curatorial method. The Dinner Party for many reasons will be a starting point, and curator Maura Reilly, I am thrilled to say, has agreed to fill out a questionnaire about her curatorial methodology.

As I have been reading literature on TDP and your educational/artistic collaborative methods, it seems that you also developed a working feminist curatorial method or at least a contextual thought process in regards to curating. You mentioned it briefly in a few of your books in regards to TDP, Birth Project and Holocaust Project. I think this will aid greatly in my thesis and examination of other exhibitions.

I just thought I'd put myself out there, at any chance, that you might be available or interested in either a phone, or email about her curatorial decisions specifically (or maybe there is an article where you directly address curating that I haven't found yet). I realize it is a long shot, but, it is worth an ask. :)

At any rate, the (University approved) questions are attached. Thanks for your consideration!

Respectfully,

Sally Deskins

Judy Chicago $<$ To: Sally Deskins <

Wed, Apr 22, 2015 at 10:02 AM

Dear Ms. Deskins;

I don't believe that Maura Reilly designed the permanent housing of "The Dinner Party". There were certain essential parameters already that I developed and that were repeatedly used as the piece traveled around the world, i.e. the darkened triangular room, the entry hall for the banners, the red, black and gold walls and of course, the space for the 
"Heritage Panels". I believe that the glass walls in the triangular room, the lighting system and other architectural details were established by the architect Susie Rodriguez in tandem with Elizabeth Sackler. Best, Judy Chicago

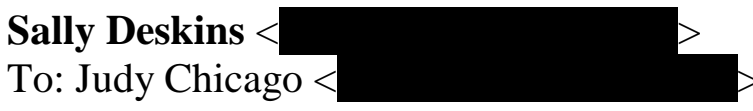

Wed, Apr 22, 2015 at 10:12 AM

Ms. Chicago,

Wow thank you for your prompt response! I wondered what exactly Ms. Reilly's role was with it as the "founding curator" of the Center with regards to TDP; I guess I will find out with her interview response, perhaps more of her role dealt with the Global Feminisms exhibition. I did find Rodriguez' essay about her design and your curatorial ideology in your books which were quite, of course, ahead of your time it seems. I appreciate your response and will definitely find resources in these books which I think can help provide a framework for curators; however if you ever did have the time in the next couple of months to expand on anything specifically with regards to your ideas on a (feminist) curating, of course I would jump at the chance.

Sincerely,

Sally Deskins

Judy Chicago

To: Sally Deskins <

Wed, Apr 22, 2015 at 11:02 AM

Ms. Deskins;

The reason I answered you so promptly is that no one has ever asked me how it happened that I began to 'curate' my own exhibitions. Although I do not see myself as a curator, in the 1970's it became clear to me that there was no context for female-centered art, at least not yet. As a result, I began to experiment with installation of my exhibitions, writing on the walls, controlling the color and lighting. It wasn't something I wanted to do but rather, something that I felt compelled to do in order to help viewers understand my intentions as an artist. If you have read my first autobiography, "Through the Flower", in the 1970's, I was very far outside the mainstream art system (where I remained - probably until the permanent installation of "The Dinner Party" which demonstrated that I might be outside that system but there was a large audience for wherever it was I was; "The DP" is responsible for $20 \%$ of the traffic to the Brooklyn Museum).

The installation of "The DP" grew out of the experiments I was doing with context, specifically, an exhibition I did at the Ruth Schaffner Gallery in L.A while I was still working on "The DP". I showed a series of porcelains in a darkened space with halogen lights spotlighting the pieces. By then, I was working with an industrial designer named Ken Gilliam who contributed a lot of the systems to "The DP" and with me, designed the exhibition of the piece. 
As I said, I was still outside the art system in my content, my goals as an artist and my ideas which were to make art accessible to the viewers, an idea that was anathema to the modernist paradigm that prevailed. I was working on my imagery and on installation to achieve this. I brought these same goals to the "Birth Project", my next collaboration. On that project, I worked with a very gifted designer named Steven Hamilton who designed all the "BP" exhibition units so that they could be easily installed by anyone (as I didn't want another battle with the art world in terms of having my work shown - which, as you know - I had with "The DP" which was exhibited around the world via an unprecedented grass-roots tour). The result with the "BP" was over 100 shows in venues from birthing centers to museums. Still today, there is resistance by museums to including the Documentary Panels that I created to establish context for the viewing experience in that many people know little about needlework and there's still considerable ignorance about the subject of birth.

By the time my husband, photographer Donald Woodman, and I set off on the 8 year "Holocaust Project", my position in the art world was firmly that of an outsider with intense hostility towards my work, in part because by establishing the viewing context I was making it possible for people to have a direct experience of the art, one not controlled by the 'curatorial distance' that was all the rage (i.e. no wall labels, no information or if there was information, it was and still is written in 'artese' making most of it incomprehensible). Donald and I designed the installation of the "HP" as a journey into the darkness of the Holocaust and out into the light of hope (Hope that we CHOSE after our personal journey took us into the heart of evil and made us understand something stated by a Holocaust survivor: "the world is not ruled by justice but rather, by power" (I'm paraphrasing). And the same world from which the Holocaust emerged is still with us.

The "HP" toured from 1987-2003 by which time my status in the art world was turning around. This meant that I began to be able to turn over to others. the curatorial duties that I had felt forced to take on, which has been a big relief. If you want to know if I think there is a feminist curatorial approach, I would say yes though not too many curators choose it; that is, help audiences understand the art and why it has relevance to their own lives. It's trendy now to use digital technology in the hopes of attracting more young people. I think that's a distraction; what my career demonstrates is that there is a large audience for art of meaning that people can understand. But that's a lesson that not too many people have understood - or accepted YET. There's always hope.

I'm sure you're surprised to receive so much information from me. As I said, no one ever inquired about how my exhibitions were structured. Moreover, since you're starting with "The Dinner Party", I felt it essential to provide you with the artistic and philosophical framework from which my work and its installation emerged. Even now, when I no longer 'curate', I insist on wall text. But of course, most of my work doesn't need much as I make it so that it can be understood. 
Best, Judy Chicago

Judy Chicago $<>>$ Thu, May 21, 2015 at 5:25 PM
To: Sally Deskins $<$ Greetings;

As I think Katie told you, I was tied up most of this week with a Spanish curator who is here finalizing his show of my work for Spain and France. I had a little time today and thought I'd try and answer your questions because next week, I'm going back into the studio and won't have much time. So here goes;

1. I don't know where you got the idea The DP was ever installed with gold walls. It was always installed in a dark room with black walls and a black ceiling. It traveled with its own triangular lighting grid which used halogen framing projectors that highlighted each place setting and also, when aimed at the backs of the runners, caused the rainbow lustre on the porcelain floor to reflect on the white tablecloths and runner backs. Even before the first exhibition at the San Francisco Museum of Modern Art in 1979, I had begun to think about permanent housing which was always my goal. I designed a room with porcelain walls that would extend the struggle towards liberation embodied in the increasingly dimensional plates as the images attempt to escape the confines of the table (a metaphor for female oppression and suppression). Elizabeth Sackler knew of my dream of a porcelain room and thought about it but it was too expensive. The glass walls accomplish something the porcelain would have also achieved, that is, a dematerialization of the space which I like very much.

2. Neither Elizabeth Sackler nor Susie Rodriguez consulted me or my husband, Donald Woodman, who had taken over the installation responsibilities after we got married as The DP was still touring then. He wrote an installation manual based on our approach which we can send you if you like. You can also talk to Diane Gelon, who was The DP administrator and/or Susan Hill, the needlework supervisor as they two (with the late Peter Bunzick) oversaw the installation as the piece toured the world. If you want to contact them, please ask Katie to give you their email addresses.

3. From the beginning, it was understood that there needed to be an entryway for the banners and a long wall for the "Heritage Panels" and that the colors black, gold and red were to be used; gold behind the panels and red and black for the banner hallway. The placement of the panels was deliberate as they are part of the "Herstory Gallery" where the Sackler Center curators organize exhibitions about the women on the table and/or the floor.

4. The only thing that influenced me about the Lautrec paintings was his use of reds. My interest in context grew out of my feeling that there was no appropriate aesthetic context for women's art (my own included) unless it mimicked the mainstream male centered narrative. If it focused on womens' experiences, it looked out of place in a gallery full of male art where it was usually a singular piece. Once I began to try to create a feminist art 
practice, I knew that I would have to address not only the creation of the art but also, the establishment of an appropriate viewing context, hence my foray into curatorial practice. As I told you, it was out of necessity rather than choice.

I hope this answers your questions. It's nice that you've decided to focus on "The Dinner Party" for your thesis.

Best Regards, Judy Chicago

Email Conversations with Susan Hill, Head of Needlework:

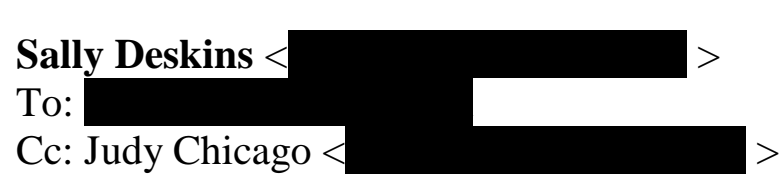

Thu, Jun 25, 2015 at 3:44 PM

Dear Ms. Gelon and Ms. Hill,

Judy Chicago's assistant was kind enough to give me your email addresses. I am an art history graduate student at West Virginia University. My thesis is examining the curatorial implications of The Dinner Party, from inception to the current installation at the Elizabeth A. Sackler Center. I have read a great deal about it, not everything of course, nor everything I plan on reading yet, but I am excited about this piece which pre-curated installation and context seemed to be beyond its time. I have asked Ms. Chicago a few questions about her intent and curatorial methodology and I thought if either of you have time, your input as leaders of the team would also be extremely valuable.

Attached are my formal questions I have approved by my University review board. I was specifically wondering, of course, about The Dinner Party, as you oversaw it throughout it's beginnings, your thoughts on the curating of all aspects from media to placement to the Heritage Banners, Panels and perspectives throughout. Was there any curatorial differences between the exhibitions as it traveled in the 1980s? Do you think this curatorial framework could be utilized in some way, for other exhibitions? How do you think it would be received differently if there were not any Heritage Panels? And why do you think (most? all?) history books do not discuss the Heritage Banners or Panels? Did this curating framework impact any other of your curatorial work? What did you think of its placement in Sexual Politics, and in its current housing? Any insight, any answers, brief or detailed, would be appreciated.

No rush, I am writing slowly throughout the summer; my draft is due in November.

Regardless, thanks for your time in reading this, and your awesome work for women in the arts!! 
Most respectfully,

Sally Deskins

On Mon, Jun 29, 2015 at 10:33 AM, Susan Hill

$>$ wrote:

Dear Sally,

I appreciate being considered and included in the curatorial research project.

I was a principle creator for The Dinner Party, worked in the studio from the very beginning of the project as Head of Needlework, and with Diane Gelon and Peter Bunzick, travelled to all exhibition sites except Australia to supervise and conduct the installations.

As you may know, in addition to the requirements we maintained in contracting with venues for exhibiting The Dinner Party, we had in place an excellent system for crating, shipping and storing the exhibition components .. as well as a definitive plan for the exhibition design, which included placement, lighting, guard rails, informative materials, and symposiums and/or events.

I am deeply fortunate to have been present throughout the ground-breaking planning, production, and implementation processes that brought The Dinner Party into the culture.

I have read the survey for curatorial specialists ... curatorial work is a different endeavor that my work for The Dinner Party.

If I may be of service in other ways, please let me know.

I wish you the best: Susan Hill

\section{Document sent by Susan Hill, June 29, 2015:}

DISCLAIMER: I've worked as a visual artist and activist. My chosen field is community work, rather than academic or institutional endeavors. I'll continue to speak from the perspective.

I am not familiar with the language being used, it is not a working vocabulary for me.

As a result, I am not sure we are speaking about the same concepts.

Please do not hesitate to contact me for clarifications. 
[Question by Author]: Was there any curatorial differences between the exhibitions as it traveled in the 1980s?

The installation design, including placement, lighting, guard rails, colors, as well as informational materials and allied events, were set prior to the first exhibition at the San Francisco Museum of Art. This design plan was adhered to in all venues while The Dinner Party was owned by Through the Flower.

Differences that did occur were factors of the building where The DP was exhibited, how the space could be configured to present the full exhibition and to welcome the public ... whether the plans were being formed was an institution or with a community group who would present the exhibition in an alternative venue.

Local issues, local resources were always considered in the planning ... so that community volunteers could be incorporated in the installation process (as possible) and in setting auxillary events in conjunction with The Dinner Party.

I expect it may have been unusual for the artist (and company) to have as much presence (or control) of an exhibition (and merchandise) as we did ... but, The Dinner Party had a proven track record for enormous audiences, high sales ... and ... in so many of the exhibition situations ... we worked with local groups who wanted the strong partnership and the guidance.

[Question by Author]: Do you think this curatorial framework could be utilized in some way, for other exhibitions?

YES

How do you think it would be received differently if there were not any Heritage Panels? YES, of course

And why do you think (most? all?) history books do not discuss the Heritage Banners or Panels?

History books have a history of leaving out important information.

The Dinner Party books all discuss the Heritage Banners and Panels, as well as document the people who came to the studio.

\section{Did this curating framework impact any other of your curatorial work?}

I loved the creative, collaborative, work focused environment of the studio, I loved working with and facilitating community groups participation in the installation of the exhibition: I have continued this essentially inclusive, feminist, creative way of working in all subsequent community arts projects.

What did you think of its placement in Sexual Politics, and in its current housing?

Loved The Dinner Party being at UCLA - thank you, again, and forever, Henry Hopkins. 


\section{Loved Sexual Politics.}

Its current housing at the Brooklyn Museum does preserve the work, and make it so very accessible.

The Brooklyn Museum is both a real "neighborhood" museum and a vibrant, contemporary, international museum ... so to have permanent housing in a dedicated wing there is grand.

The lighting is badly done.

The placement of the banners is unfortunate; they appear as an "afterthought" rather than a welcoming statement that sets both tone and scale for the table itself.

We all miss the inclusion of the panels that document all the people who worked on The Dinner Party.

Perhaps the new Director will re-think both the lighting and the inclusion of the panels.

On Aug 25, 2015, at 8:25 AM, Sally Deskins < > wrote:

Sally ... I'm glad to provide information ... I remain puzzled by why you are asking curatorial questions about The Dinner Party ...

The Dinner Party is such an odd choice to gain understanding of curatorial practices, as one of its great hallmarks is that it had to operate OUTSIDE the curatorial system.

I can see that you are asking about ALL the venues ... yet ... very few of them were actual museums ... and there were no curators at these alternative community venues.

When The Dinner Party was shown in an established arts institution, the installation design was set and agreed on per the contract.

The Dinner Party was VERY unusual in the way contracts were set with Museums (thank you, Diane) as The Dinner Party retained control of the installation design, and established terms for shared revenues.

Diane Gelon has all that information.

The design did not vary. The space was configured (and painted) to accommodate the exhibition as specified.

If the space could not accommodate the exhibition as it was intended to be presented, i.e., poles were in the "wrong" place, not enough space to present the Banners in front, and the Heritage Panels in a space entered after leaving the Table ... then, a different venue was found.

As I have written, the Banners at the Sacker Center are NOT placed in accord with the exhibition design that we created and followed. 
The Banners were always seen first ... BEFORE you entered the space with the Table, in a "front space" that created a hallway, a beautiful and ceremonial entry that allowed the visitor to enter the darkened, quiet space of the installation.

There was also just one entrance to the Table, while the Sackler Center has two entrances.

The banners were set as an entry ... hung a certain distance from the floor ... a certain distance between them.

They were hung perpendicular to the wall ... not flat against the wall ...

They may have been in the same space as the table ... I don't remember specifically ... but you never saw the banners and the table at the same time ... the Banners ALWAYS created a ceremonial, beautiful, quiet, poetic entry .. allowed the visitors to

enter a hushed, low light space ... preparatory for viewing the table ... and presented, in woven splendor, text and imagery preparatory to viewing the place settings.

These are not DESIGN decisions that had to do with "how big is the room" ... they were decisions allied with both the aesthetics and the politics of The Dinner Party ... of welcoming the visitor and transporting them to a "new vision" of history. These choices are as much a part of The Dinner Party as the plates and the history panels.

If you look at the gallery installations of Judy's artwork prior to The Dinner Party ... you will see that she (and Dextra Frankel) used gorgeous paint colors on the entry wall of the gallery ... and that Judy hand-wrote (in Prismacolor pencils) a welcoming statement on the entry wall.

[Question by Author]: How much curatorial decisions did the gallery/institution have, or did you, Diane and Peter manage it all?

The physical requirements of the exhibition was determined in advance, and helped determine if a proposed space was suitable.

NO ... the gallery / institution did not make decisions about the installation.

OF COURSE .. The Dinner Party was rarely shown in a museum ... it was shown most often in an alternative venue, which operated without a curatorial staff.

[Question by Author]: Also I have read of several concurrent symposia/events that happened along with the exhibitions in the 1980s; I was wondering about complementary exhibitions in the same institution; for example there was an exhibition of four women artists in the same gallery in the Warehouse in London. Did you/The Dinner Party crew have anything to do with this, or was this organized by the gallery?

The Warehouse was not a gallery. It was a warehouse. 
I did not have anything to do the concurrent symposia / events but I expect Diane was very involved, as she set the agreements with each place, and had to agree with proposals for other presentations.

Was there others at the other stops (in The Dinner Party readings this is not discussed, nor in the reviews)? If there were, how much of the display, if any, overlapped with The Dinner Party (were the Heritage Panels or anything in the same room as this exhibition?, etc.)?

The Dinner Party exhibition materials were always set in their own pre-determined spaces.

Auxiliary exhibitions and / or materials had their own spaces, and were not in the same room with Dinner Party exhibition pieces.

Each exhibition venue or sponsoring consortium did organize events and/or exhibitions that complemented and extended The Dinner Party, sometimes in the venue building, and sometimes in other locations.

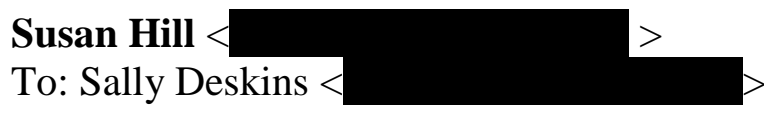

Mon, Sep 21, 2015 at 10:57 PM

Hi Sally,

Wishing you a great presentation on Thursday .... hope it goes really well.

Yes .. the color schemes were Judy's choices ... all carefully considered: the questions are really for her.

I'll add one thing: You say that the black walls were for framing the reverential quality of the artwork.

Yes ... this is true: it was always the intention that the floor, table and placesettings be radiant ... seem to "float" in a completely dark

space ... amplifying the reverential presentation.

In addition ... the matte black walls were an important factor technically. The lighting of the floor, table and placesettings was very very carefully designed ... and, painting the walls matte black made sure there was no other color, and no reflective surface in the room ... only the luminous materials of the artwork, ie, the lustrous floor, the fabrics, the porcelain plates and place settings.

Thank you for bringing the questions to Ms. Morris at the Brooklyn Museum.

With best regards, Susan Hill 
Susan Hill

To: Sally Deskins <

Hi ... No .. I don't any of us have seen this new installation ... do you know when the changes were made ..?

Like you, my hope is that the changes were made with the best of intentions ... with a focus on education and context.

I would understand a Museum thinking that it was not necessary or relevant to consult the artist .... but it's a dynamic that surprises me.

I remember a moment installing The DP in Brooklyn after it had been gifted to the Museum ... the celebratory installation, temporary exhibition before the permanent wing was built.

We had set the table ... everything was in place .. and I was going around the table looking closely at each setting ... making sure everything was "just so". You know ... like the butlers in Downton Abbey .... I noticed a tiny white thread at the edge of napkin ... and I flipped the napkin up to see more of the thread ... turned to a nearby table to get my tiny scissors to snip the loose thread. One of the Brooklyn staff stopped me ... said we had to send for the conservator and wait for her to deal with the thread.

I said .. why? .. it was just a loose thread ... we'd just clip it. Of course .. I was thinking .. "I made this. I have installed this for years. And I know how to deal with a loose thread.

What's this about a conservator .. a person who doesn't know The DP, is going to come from some other floor, from work she's doing, and SHE'S going to clip the thread?"

And .. the staff person, reading my mind said: "We own it: you don't".

Aaaahhhhh ....

Thanks so much for the information, and for your investment in these questions.

With best regards, Susan HIll

Interview with Diane Gelon, Head of Research and Installations, 1979-86

September 4, 2015: Telephone conversation transcribed by the author with permission

[Author]: You were the head of research and of the exhibitions tour of The Dinner Party, 1979-88; how much of the curatorial plan/installation plan was collaborative/did you have a role in this? 
Installation was - initially - all Judy. Working with a couple of people, she had idea of how she wanted this to look really early on, way before it was anywhere near completed. She had the idea for how she wanted people to look into the space to see the artwork. She worked with industrial designers, and to some extent, Henry Hopkins (at San Francisco Museum in 1979), to put it all together how one would move throughout the space. Primarily, Ken Gilliam, an industrial designer, worked on the fabrication of the piece to ship, move and break it down, and Peter (Bunzick) traveled with me, who installed the show with me.

We knew how we wanted people wanted to move through the space - the artwork, the banners, Heritage Panels, the acknowledgement panels, as well as the donor panels - (NEA, Ford Foundation, etc had donor requirements) -this was the general layout: walk into the space through the banners, then walk into a darkened room with the artwork, then back out to the documentary information and Heritage Panels.

The documentary film played in a few places - it didn't play continuously, it would play from time to time.

There were also two other components that grew after the original exhibition in San Francisco: the International Quilting Bee which grew as the work traveled. The International Quilt was recently given to Louisville. In the original exhibition, the International Quilting Bee was exhibited in yet another space so there were four spaces altogether-the Banners, the artwork, the Heritage Panels and Documentary Panels, and the Quilting Bee.

The quilt started in Houston and was relatively small, but by the time work had traveled, we had over 1,000 pieces of quilt. Some spaces, because of size, we couldn't put them all up.

[Author]: I've read that sometimes you would visit a space but had to turn it down, because the space would not fit The Dinner Party's various parts, is that right?

Yes, constantly - what I did was people would call or write, they'd say they wanted to show The Dinner Party, and had space in mind. We'd jump on a plane and go look at it. We did that for three or four years, and some spaces we said, no it wouldn't work, there's a column in the middle, it won't all fit right, etc. Primarily it went to alternative spaces, spaces where you had to build the museum environment in accordance with our specs. We didn't say "you need a hallway that was 20 feet long to hold banners," often times we were building walls to create our entry way, to create our spaces and walls and triangular room where artwork sat. So we're doing all of that - I can't tell you how many spaces that we saw that were not acceptable. For every city that showed the work, I probably saw about 3-10 spaces.

[Author]: There aren't many photographs of the Banners or Heritage Panels as they were originally installed; some have the banners hung on the wall like other 2-D work, though the Sackler has them hanging from the ceiling; can you tell me about how they were intended to be exhibited and were exhibited during the original tour?

The idea was for people to walk through the banners. So you come out of the world, go into this museum show, where you eventually go through a series of quietness, as you walk through the banners, to come into a darkened space that is illuminated. This is an exhibit that is reading as if 
it is all porcelain, that has quite a shimmer to it, created through the lighting and the quality of the work. That was the image that she had: essentially this floating piece that transcended the space. You felt you were in some other world.

\section{[Author]: So, as I understand, the Banners now are the way they were installed as Chicago planned it originally?}

The Banners (in the Sackler Center) almost share a space with The Heritage Panels - The Sackler Center has the least amount of space of any space we exhibited it in. The Heritage Panels almost intermingle with the Banners. There is no space to show the quilt (in the Sackler Center), which extends the idea of The Dinner Party out to the public - women around the world honored many other women.

One more component that many people don't realize: we also traveled with it a china painting show with traditional china painters - contemporary but traditional china painters - women who paint flowers on cups and saucers. It was a wonderful exhibit that traveled to almost every space - either in a separate gallery or with the quilts.

We referred to it as "the china painting show." In terms of how it was set out, it was up to Peter and me to organize the pieces that Judy had selected. It was curated with text panels about the process of china painting.

[Author]: Also I have read of several concurrent symposia/events that happened along with the exhibitions in the 1980s; I was wondering about complementary exhibitions in the same institution; for example there was an exhibition of four women artists in the same gallery in the Warehouse in London. Did you/The Dinner Party crew have anything to do with this, or was this organized by the gallery?

The exhibitions and events happened with our encouragement, because you have to remember that for those places where it wasn't in an art museum - Cleveland, Chicago, Atlanta, Boston, Houston, we were working with community group who took it upon themselves to fundraise money and put on the show. So of course, we encouraged them to create an exhibition that would last 3-4 months, so they'd want to do programs, highlight artists in their community, and we encouraged them to do that. Each exhibition became a plan for the next. Every place had an educational component, either about art or history.

[Author]: Do you think this curatorial framework could be utilized in some way, for other exhibitions?

You're asking me weird questions. I'm not sure what you mean by 'curating'....

What it stands for is more of a model for what a community action group can do when they decide to take-on large scale projects. None of these people were artists. They became artists and all of these things going into these communities. I spent weeks in these cities, working with a group of women to create museum environments because they cared about the work. The artwork is so strong visually, and took as much pride in showing it as we did in making it. They wanted to do the best that they could, give it the right space. They trained themselves as docents 
to give tours, made postcards, and made everything a museum has. Now we might call it a "popup show" that lasted for three months. We had a "pop up show" in a disused synagogue in Cleveland, in residential building in Chicago, and in a gymnasium at Houston. We didn't have that concept then, but that is what it was, a pop-up, instant museum.

When Judy first conceived this, she wanted to present the story of women's history in the different ways: one, through the work of art; two, through a book; and three, through a film. She thought if you could enter into the culture in three big ways, it would be less of a chance of being erased from history. To her, a lot of it was about education in the same way that medieval manuscript is about education. To educate an audience through visual imagery, it also needed a context, which all of it was new, 40 years ago.

[Author]: Can you tell me about your opinion on how The Dinner Party was installed in Sexual Politics in 1996?

I installed The Dinner Party - everything was included. The exhibition has always included all of the things except in this current installation (at The Sackler Center).

By this point in 1996, we had disbanded the china painting exhibition, we didn't take it to Europe either, too fragile and too expensive to travel with. We certainly had it all through Canada. We traveled the quilts, which were also in Sexual Politics. The film was not looped, and was never on a loop. It was always special event.

[Author]: Do you think The Dinner Party in its entirety has inspired other curatorial work?

I have no idea if it has inspired other curatorial work. I think it looks great. It was usually shown in black room which allowed the porcelain to shine more than it does now. The permanent display has the lighting lower. We lit it quite hot, to allow the porcelain to gleam, to sparkle. That's not how it is shown now, as it is under those lights constantly. It is quite a difference if you had seen it somewhere else. It still has a reverential feel.

In 2002, everything was displayed in the Brooklyn Museum main Rotunda. It had a completely different feel in the Rotunda - had walls built around the Rotunda.

[Author]: How do you feel about the way it is currently installed with regards to the glimpse in each corner of the Dinner Party artwork installation room?

We never had the glimpses, only one gap for the door. It's not my favorite, the glimpses. The Herstory Gallery changing exhibition adds to it. I like that The Dinner Party is a living exhibition that can change as times change. As it moved around the world, it did that - it changed depending on what the community was and who they wanted to focus on with their own history, who to highlight, etc.

Diane Gelon < > $\quad$ Mon, Sep 21, 2015 at 6:42 PM

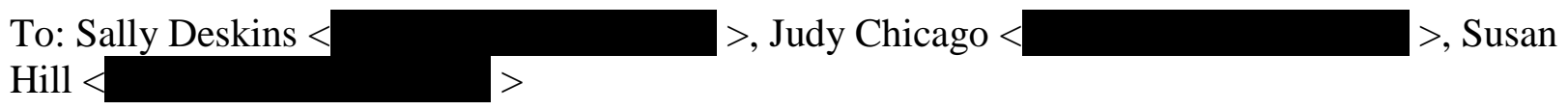


yes, the colours were all part of Judy Chicago's installation plan and choosing to better show off and highlight the artwork

and please ask Catherine Morris at the Sackler Center why they did not include the Documentary Panels etc in their permanent housing of the work. that was their curatorial decision so I cannot comment.

Diane

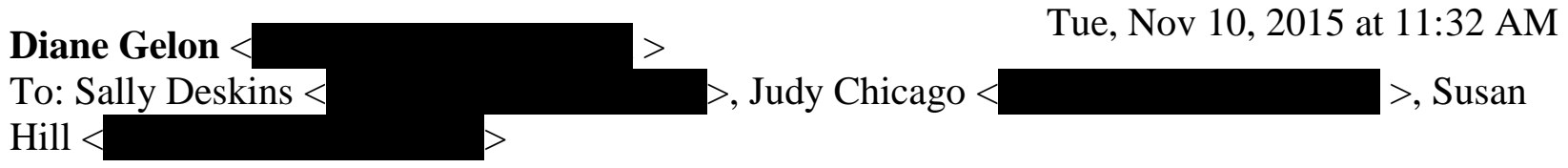

Sally - there was always an installation manual which was originally written by Peter Bunzick who travelled with me installing the exhibition along with Susan Hill. because we always travelled with the show the manual was probably not as extensive as it could have been and Donald improved it as a stand alone document. I am not sure I have ever really seen his version. Donald and I installed the show in Frankfurt and cannot remember if Susan Hill was also there; Peter didn't come to Frankfurt. This was the first time that Donald helped with the installation. Donald then installed the show on his own in Australia and that was the only installation I did not take part in (other than the permanent housing of course where none of us were consulted).

I have copied Susan Hill in on this email as she may remember a bit better than me.

hope this helps

\section{Diane Gelon}

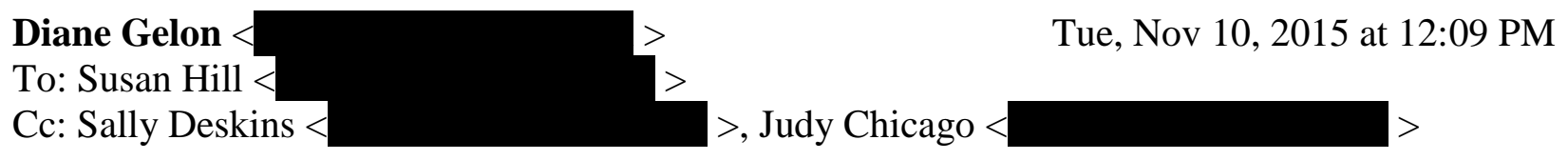

and for what it is worth (memory wise) - I did the final place setting of the table in LA and installed the quilt and as usual assisted with the lighting up to the point where Judy always did the final lighting to get the looks she wanted overall.

Donald and I installed the show in Brooklyn which was the extra show the museum did following Ms Sackler's gift; before it went on permanent view

Diane 
Telephone interview with Donald Woodman, Creator of 1987 exhibition manual

Transcribed in summary by the author, November 8, 2015, used with permission.

[Author]: I just returned from visiting the Sackler Center and noticed a change in the installation; the banners were moved to a tighter hallway, and The Heritage Panels were moved to the back white wall, arranged in reverse chronological order, before the banners and table artwork. I was wondering if Judy Chicago, you or any of The Dinner Party original team knew of these changes.

"We knew they were considering making changes but none of the plans that were presented to us were acceptable. We did not know that they had gone ahead and reconfigured the entrance to The Dinner Party.

I understand that you have talked to a lot of people involved with The Dinner Party, let me quickly tell you about my background. I have an undergraduate degree in architecture and was trained and have worked as architect but I did not pursue architecture as a career. One of my design professors saw my talent as photographer and suggested I might like to pursue architectural photography.

With regards to my history with The Dinner Party. Judy and I got married in 1985/86. By then, the installation team that Diane Gelon oversaw, had disbanded. Moreover, sending them to foreign countries was very expensive. From then on, I oversaw the installation of The Dinner Party starting in Frankfurt, Germany. I then worked with the exhibiting institutions, supervising installation design and overseeing the installation crew. When I took over there was some semblance of an installation manual. One of my goals was to create a fully illustrated installation manual. It was important to convey and codify both Judy's aesthetic intention for the display of the work and to document the complexity and systems used to install the work. We were very fortunate in Frankfurt to have an experienced installation crew with a theatrical background; they understood the intricacy of the installation and had a lot of experience with lighting. Many of the aesthetic issues of exhibiting The Dinner Party involve lighting. Using the existing light fixtures and connecting them to a theatrical lighting control board we created a simplified system to light the piece. I included this information in the installation manual that I wrote and completed in 1987. The photographs used were taken by me in Frankfurt so the manual was used in Australia in 1988, The Hammer Museum in Los Angeles in 1996, and in 2002 at the Brooklyn Museum.

\section{[Author]: What do you think of the installation at the Sackler Center?}

The installation design for The Dinner Party consists of the following elements: A sign 'Welcome to Judy Chicago's The Dinner Party; the six entry banners in a large open space which are intended to be viewed prior to entering the table; the Table installation which is intended to be entered at the Primordial Goddess Placesetting on wing 1 an exiting at the $O$ 'Keeffe Placesetting at the end of wing 3; a large room for the seven Heritage Panels and the 
three Acknowledgment Panels; finally a room to view the video A Tour of The Dinner Party. There were other elements that were included as space allowed. When The Dinner Party was acquired by the Brooklyn Museum the Banners, Table, Heritage Panels, Acknowledgment Panels and the video were the only elements they took. The Heritage Panels on exhibit at Brooklyn are photocopies of the original hand colored photo murals because of the preservation issue and concerns regarding fading and protecting them.

As I mentioned, there is other material that traveled with The Dinner Party: The International Honor Quilt which was recently given by Through the Flower to the Hite Art Center at the University of Louisville; Other photo-Documentary Panels that included documentation on how the piece was made, documentation about china painting; and a series of photo panels titled The China Painting Show. The Brooklyn Museum did not want any of this material, which recently was gifted to the National Museum for Women in the Arts in Washington, DC.

As I said, I acted as installation coordinator and designer for the 2002 exhibition in the rotunda of the Brooklyn Museum (where it was first exhibited in 1980). There were a lot of issues around the installation design and lighting for this exhibition and I had to educate the installation designer the museum had hired. I also worked as installation coordinator at the museum during the installation. The Brooklyn Museum is a difficult place to work as it is a union shop with many rules and regulations - unless you belong to the union, you couldn't do certain things. It takes a minimum of two weeks to install the piece and with the added union issues, it took longer.

Because the 2002 exhibition served as a trial for the 2007 permanent installation the museum brought in a theatrical lighting person to consult on the lighting. After long discussions and some testing - and in consultation with the museum conservation department - recommendation for a permanent light system were made. Apparently, these recommendations were not followed and the lighting is totally wrong.

\section{[Author]: Did you give any insight to the design or installation for its installation in 2007?}

The architect was forbidden from speaking with Judy or myself about the installation design and it is my understanding that the installation manual was not consulted. As I stated, an important aspect of the aesthetic presentation of The Dinner Party involves the lighting. Whoever the lighting designer was, he or she apparently never consulted the manual.

The 2002 theatrical lighting consultant recommended that multiple lighting fixtures be used to light the various elements of the piece; the textiles (runner tops and fronts), the plates and the floor. More specifically framing projector fixture would be used for the runner top and set back far enough from the edge of the table to light the front of the runner. A pinpoint spotlight would be used for each plate. And nine framing projector fixtures were to be used to create cross bounce lighting on the floor and the runner backs. This would also create the rainbow reflection on the runner backs from the luster glaze used on the floor (an important aesthetic element). All fixtures would be controlled individually using a theatrical light board.

The current installation disregards Judy's aesthetic intent for the experience of the piece. Most 
egregious is the lighting of the floor and the runner fronts. In addition, for the current installation, the museum added LED rope-lighting under the table with no concern for the color temperature (visible color). As a result, the different light sources emanate a different color from cool blue to warm red instead of a consistent light quality.

\section{[Author]: So Judy Chicago was not consulted for the installation in 2007?}

Judy wasn't consulted, but until now, had maintained a positive perspective about the permanent installation. I have spoken with many of the original The Dinner Party exhibition team and we were all shocked when we walked into Sackler Center space for first time. Our mouths fell to floor - how could this happen? But because the piece was permanently housed and the glass walls were clever and reflected Judy's original concept of a porcelain room, we all remained silent.

\section{[Author]: And did you or Chicago know about this current change, of altering The Heritage Panels and banners?}

We knew they were considering making changes but none of the plans that were presented to us were acceptable. We did not know that they had gone ahead and reconfigured the entrance to The Dinner Party. I can't remark about the changes because I haven't seen it. But it doesn't seem to honor any of Judy's original intent.

Moreover, I didn't think the original [Sackler Center] design for entry and the banners was very good. First, it brought you into The Dinner Party on the wrong side; It was originally conceived that you entered on the Wing 1 side and exit on the Wing 3 side. At the Sackler Center you were given a choice and often, people go the wrong way. The original concept for the Heritage Panels and Acknowledgment Panels was that they were always given their own space and seen after you saw the table. Visitors spend a lot of time reading the historical material on the panels. Also, there was a very popular 45 minute audio tour of The Dinner Party that was created when it was first shown in Brooklyn in 1980; Judy did and audio tour and people move around the table listening to her description of the piece. I later turned this into a video which was shown in a separate space. Viewers would watch the video, as they were quite interested in the historical information and perspective presented in Judy's voice

\section{[Author]: Was The Dinner Party a curatorial concept by Chicago, as well as an artwork?}

Judy had a very clear concept of how she wanted the work presented and the viewer to experience it. Part of writing the manual was to codify this intent. Everyone involved with the installation of The Dinner Party understood Judy's concept and worked to see that each installation presented the work accordingly.

\section{[Author]: Do you and Chicago also design exhibition instructions for other series of work?}

Yes, particularly the Holocaust Project. Judy and I have always worked together creating installation design and/or installation manuals with concepts for how her work is to be presented and I usually consult on the lighting of the art.

[Author]: Do you think The Dinner Party could serve-or has served-as direct or indirect 


\section{curatorial inspiration for contemporary curatorial models?}

With The Dinner Party, Judy has always been very clear about how it is to be presented and the intended aesthetic experience of the viewer. There aren't a lot of artists who do installations like this but it has to be taken within the art historical context, because Judy didn't have a lot of institutional support so she often had to do work that other artists didn't.

Judy has given a lot of thought about how to convey the historical information presented in The Dinner Party. She understood that there are many ways to present information and it is important to her to give the viewer access to different layers; to give an entry point into the historical material; and to allow viewers to go as deeply into the work as they want. We also did this with the Holocaust Project installation and material and I know that she did the same thing with the Birth Project."

\section{Email Conversation with Amelia Jones, PhD, Curator, Sexual Politics: Judy Chicago's Dinner Party in Feminist Art History, 1996, Armand Hammer Museum}

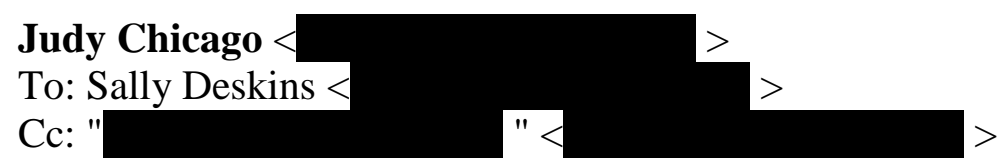

Dear Sally,

When Judy Chicago was in Bilbao for the opening of Why Not Judy Chicago? at Azkuna Zentroa, she spoke with Amelia Jones about putting you two in touch, as she is teaching a course on curatorial practices, and your thesis examines the curatorial implications of The Dinner Party. The presentation Amelia Jones gave in Bilbao for the conference that accompanied the exhibition was on Judy Chicago as a curator. I am copying her on this email so you have her contact information.

All the best,

Katie

Katie Schroeder

Curatorial Assistant to Judy Chicago

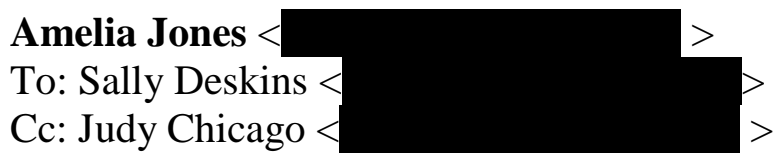

Hi, Sally,

I attach my talk here. It's not a final, publishable version, but feel free to cite it as follows:

"Judy Chicago's 'Will to Power' and the Invention of Feminist Art as a Curatorial Practice in 1970s Los Angeles," paper delivered at "Feminist Perspectives in Art Productions and 
Theories of Art public seminar series, organized by Xabier Arakistain and Lourdes Méndez, Centro Cultural Alhóndiga and Azkuna Zentroa, Bilbao, Spain.

My idea as you will see is less about Judy's "curatorial ideas" and a rereading of her overall practice as what we would now call "curatorial."

Let me know if you have any questions.

Best, Amelia

\author{
Amelia Jones \\ work \\ Robert A. Day Professor of Art and Design \\ Vice Dean of Critical Studies \\ USC Roski School of Art and Design \\ University of Southern California
}

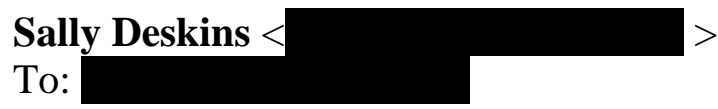

Sun, Sep 6, 2015 at 11:15 AM

Dear Dr. Jones,

I am an art history graduate student at West Virginia University. After having doing some research into feminist curating (including much of your work and interviews), and visiting The Dinner Party at the Sackler Center, I have focused my thesis examination on The Dinner Party and Chicago's various installation methods, in relation to the way it is now installed, to find a set of considerations for feminist curating.

I have read Sexual Politics, and some interviews and reviews of the exhibition as a very important part of feminist curating as well as an important part of curating The Dinner Party which has and will continue to aid my research.

I was fortunate to obtain your email (hopefully this was okay) via some other people helping me out with my research as you are obviously a significant part of this from many standpoints.

I know you have written and spoken a lot about it already, but if you had any time to write or Skype about your thoughts on The Dinner Party curatorially - of course, as you included all of the parts in your exhibition, you know it is not just the artwork - if this impacted you any, or if you have ever thought about these developments by Chicago as far as curating; and also any thoughts on its current installation (I have read, briefly, your thoughts, but any more insight is always helpful), and also, in general, any insight as to specific strategies you might think of for a way to curate in a feminist way. 
Attached is my formal/board approved inquiry letter and set of questions. If you have time within the next month or two to email or chat, maybe 20-30 minutes, it would be an honor and tremendously helpful!

Regardless, thank you for all of your wonderful work!!!

Respectfully,

Sally Deskins

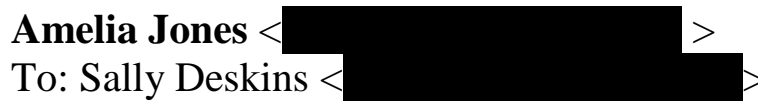

Wed, Sep 9, 2015 at 6:20 PM

Hi, Sally,

Sorry for the delay. Happy to try to help and love that you have used and appreciated my work. Makes my day.

Your questions and my quick answers are pasted below. Hope this helps! If you have key pointed questions after reading this feel free to email again. Best, Amelia

[Author]: Are you an academic curator (with advanced art history degrees)? Were you trained in museum studies/curatorial work? Are you an artist/curator or a critic/curator?

Yes. I was trained as an art historian, not as a curator per se.

\section{[Author]: Do you have a curatorial philosophy or strategy? If so, can you describe?}

I haven't really articulated one, but my curating and event programming (I see these as part of my "public interface" work that addresses the public more directly with themes, issues, art, and performances I care about and feel are important). My goal is always to address a problem. In Sexual Politics, for example, the problem was the negative position of Chicago's $D P$ in feminist discourse, particularly of the academic variety. What did this mean for the $D P$ ? For the discourse? What is going on when feminists gather to condemn a practice or an artist they decide isn't feminist in the right way? These kinds of issues are super important to me as they come down to how things mean (the Dinner Party, in this case, but also feminist arguments) and who gets to decide whether an art work is considered "good" or "bad" (in this case, feminist art).

[Author]: Do you consider yourself a feminist, or does feminism play a role in your curatorial strategy? If so, can you explain? 
Absolutely. Everything I do is guided by my feminism, which entails an attention to oppressions and inequalities ultimately relating to gender and sexuality. I consider racism to be a key issue for feminism. My feminism is broad but I hope also pointed.

[Author]: Speaking of this exhibition in particular, did you work with a team of individuals to curate (various departments within the museum or community, or different curators) and select the art? If so, what sort?

No. I was pretty much on my own and selected the checklist myself.

[Author]: What is your process for curating? / What was considered in the forming of this exhibition and in the selection of artists and works? Did you (or your team) employ any form of strategy when doing so? If so, what did you have in mind?

In the case of Sexual Politics my modus operandi was to select a range of feminist art that deployed key strategies that relate to the terms set up in feminist discourses, especially those rejecting the Dinner Party as "bad feminism." I was interested in setting up a dialogue across works as diverse as those by Adrian Piper, Mary Kelly, Lorraine O'Grady, and Judy Chicago. I wanted to cut through the negation of "central core imagery" by dominant academic feminist art discourse by showing other works and strategies speaking to this idea. Etc.

[Author]: With regards to this exhibition, did an exhibition designer install the selected work, or did you or someone else, after it was selected?

I installed the work, with the help of UCLA Hammer curator Elizabeth Shepherd, the on-the-site curator (I was working freelance for the Hammer, although I had a full-time job at UC Riverside at the time).

[Author]: If you installed the work, did you do so with a form of strategy, if so, what did you have in mind?

Yes, I had a very clear strategy for categorizing the works based on themes and strategies employed. This organization can be seen reflected in the catalogue organization and in my essays in the catalogue.

[Author]: How much involvement did you have with the exhibition text (labels, descriptions, promotional materials), and what information about the exhibition/artists did you relay?

I was entirely in charge of all wall text as I remember it. I was accused of being didactic, but the show was meant as a history lesson so I guess didacticism is perfectly fine in that context! I conveyed information about the art strategies in relation to feminist debates - those were the key parameters.

[Author]: What audience did you curate this exhibit for? Who did/do you hope visits? 
For a general audience, as well as a more specialized audience interested in feminist art.

\title{
[Author]: What discourse did/do you hope the exhibit creates for its viewers?
}

A more self-reflexive dialogue in feminism about how and why we set up arguments about what feminist art should or shouldn't do. Do we need or want to be prescriptive in defining or describing feminism? What happens when feminists themselves set up boundaries and exclude works or practices as not effectively feminist?

[Author]: Do/did you have any intentions for this exhibition with regards to the larger structure of art history and/or the art world today?

Yes, I was hoping to open the door for feminist art so that, in its richness and historical expanse, it could play a major role in how we understand contemporary art.

\author{
Amelia Jones \\ work \\ Robert A. Day Professor of Art and Design \\ Vice Dean of Critical Studies \\ USC Roski School of Art and Design \\ University of Southern California
}

\author{
Emails with Maura Reilly, Founding Curator, Elizabeth A. Sackler Center for Feminist \\ Art:
}

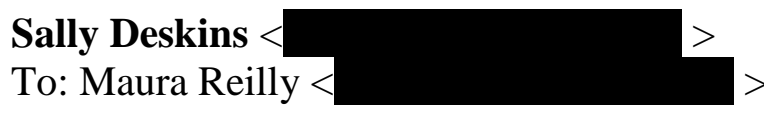

Thu, Jul 23, 2015 at 3:16 PM

Dear Ms. Reilly,

I know that you are quite busy with your new post and probably upcoming projects! I had emailed you earlier this spring about perhaps answering some questions for my thesis research looking at contemporary feminist curatorial methods.

I have further honed in my research to use The Dinner Party as a sort-of model, from its start to where it is currently installed, for feminist curatorial approach, as an installation/curated piece itself. I was wondering, as I'm about to give a presentation in August and would love a comment from you as an expert art historian and feminist curator, if you had any brief insight about your feminist approach to curating, and/or if The Dinner Party had any impact on your curatorial approach (whenever/wherever you saw it first).

Attached are my approved questions and inquiry letter, but if you have any brief comment, it would be so helpful! Otherwise have a lovely day and week and thanks for your stellar work!! 
Sally Deskins

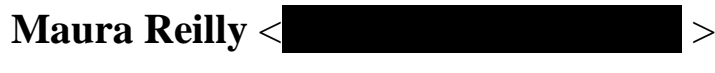

Sun, Jul 26, 2015 at 6:50 AM

To: Microsoft < >

Hello Sally,

Quickly, as I'm working like mad on a book manuscript, but the TDP has never influenced my curatorial approach. I never saw it in person until I personally installed it at the Brooklyn Museum, where it is now on permanent display.

My approach to curating is wholly informed by feminism and post colonialism - as my focus is injustice and inequality - hence my projects have all centered around artists who are either female, queer, or artists of color/non-western. This is to say that I focus my exhibitions on all artists other than straight white males - to put it bluntly!

Hope that helps.

Best,

Maura

MAURA REILLY, PhD

Interview with Catherine Morris, current Elizabeth A. Sackler Center curator

September 25, 2015, telephone conversation, transcribed by the author, used with permission.

[Author]: When did you see The Dinner Party for first time, what was your reaction?

I saw it when it was installed in the Brooklyn Museum before the Sackler Center was opened 2002, I didn't work there at that time. Seeing The Dinner Party, this work of art comes with so much history, so much life and reproduction for us with an interest in feminist art that seeing for first time is more of a confirmation. It is always a wonderful thing when you actually see a work of art for the first time, after you spent years reading and looking at it in pictures, it is always reassuring to realize the things you didn't know in the actual artwork.

[Author]: Did you think of it curatorially when you saw it then, as far as the Banners, Panels, etc? 
I saw in context of the Brooklyn Museum and wasn't thinking about it curatorially, I was thinking of it in terms of seeing the actual artwork for the first time. I didn't see it when I was young when it was first traveling around. It is one of those works of art that we think we know well in reproduction, but we really don’t usually.

At this time it was installed with Judy Chicago's specifications, so I experienced it with her specifications including the Heritage Panels. Though I don't think these are always described as being part of the work of art, I don't think of them that way. I understand the core of The Dinner Party is The Dinner Party table--everything about the table and the banners. The core components of The Dinner Party are the artwork and Banners. Other components I see are in support of the artwork and function as important asset to its understanding, but I feel like the Banners and table itself contain the significant components that encapsulate her ideas about history, research and presentation.

[Author]: Was this why the Sackler Center did not obtain the International Honor Quilts or the Documentary Panels, and does not exhibit the acknowledgement panels?

A lot of people ask me this. The Dinner Party was a gift to us, and our ability to acquire or not acquire the quilt, I don't know, because I came here afterward.

\section{[Author]: How do you see the installation of The Dinner Party as it fits in with feminist curating?}

I think any sort of intellectual ideas regarding any work of art by Judy Chicago are feminist. I don't think any decision by Judy Chicago can be separated from feminism.

[Author]: How do you see the installation of The Dinner Party as it fits in with the mission of Sackler Center?

The Dinner Party is central literally and figuratively to the Sackler Center itself. It's important because it situates The Sackler Center within a history and within the institution this is the most successful functions of it. This is a historical institution that reflects a similar type of history that Judy Chicago was correcting - visually important that we point to this and continue to correct. The Dinner Party is becoming a historical document. It's an interesting and important kind of object, and to see new generations discover it is enormously important.

\section{[Author]: Do you consider yourself a feminist curator? How might that different from just "curator?"}

I consider myself a curator who is a feminist. I bring it automatically to my thinking of what I do. I don't know if I need to put feminist in front of curator. When I talk about my job, Sackler's long-term value is not adopting some sort of role of designator of feminism, but like The Dinner Party and with the history of the institution, it is most important that we look at things differently, looking at through lens of a feminist methodology in my thinking. So I'm curating with feminist lens. It is not my job to be designator of feminism, or to convince anyone to be a feminist, but more to show people that if they're looking at culture in 2015, that feminism impacts the way they look at objects now. Of the exhibitions I've done since I've been here, 
some are more overtly feminist than others, expanding the idea of what a feminist methodology looks like. Feminism has impacted every other field certainly.

\section{[Author]: What is the significance of The Dinner Party to the Sackler Center's Herstory Gallery?}

The Herstory Gallery hosts smaller exhibitions in relation to the 1,038 names in The Dinner Party, a straightforward mandate. My interest and priorities, expanding on feminist methodology, has been to not do biographical exhibitions. It's not best use of the gallery, to tell the story of someone's life. I am interested in finding within the narrative of people in The Dinner Party, moments that have significance to tell larger story. The first show I curated at the Sackler Center was Healing the Wounds of War: Brooklyn Sanitary Fair of 1864 (2010), which grew out of Elizabeth Blackwell, the first woman to graduate from medical school in the United States and co-founder of the US Sanitary Commission. I did another exhibition on Lorraine Hansberry, ${ }^{449}$ including letters and publications addressing her identities as a feminist, a lesbian and a political playwright. ${ }^{450}$ These are the kinds of the almost historical footnotes that I'm interested in finding out. I curated an exhibit on Djuna Barnes, the moment at which she was a new reporter, ${ }^{451}$ these kind of projects. There are also collaborations with artists--historical examinations and projects with contemporary artists. The recent exhibit, Shared Dining, originated with a workshop with incarcerated women, who made a collective project inspired by The Dinner Party ${ }^{452}$. The next exhibit with be organized collectively with the staff - Agriprop including historical and contemporary references to The Dinner Party.

\section{[Author]: Does The Dinner Party offer anything more curatorially to the institution?}

Offers additional glimpses into history and feminism--beyond that, it offers the opportunity to orient the space around it.

\section{[Author]: What do you think of the mirrored walls surrounding The Dinner Party?}

The walls are not mirrors, they are black. The lighting is dramatic providing a strong reflection.

[Author]: In 2017, you will be hosting an exhibition in the whole Brooklyn Museum in celebration of the Sackler Center's $10^{\text {th }}$ anniversary. Will The Dinner Party play a direct role in the curating of this exhibition?

Sackler Center impacts the entire institution, and we will show that in much more overt way. The Dinner Party is the jump off point, as a revisionist project - a feminist project - always comes back to The Dinner Party - it is always part of discussion, in terms of rewriting history and making these types of projects. Curatorial projects in other galleries will exhibit how feminism has impacted various fields in institutions.

\footnotetext{
449 Twice Militant: Lorraine Hansberry's Letters to “The Ladder, 2013, author of Raisin In the Sun

450 Hansberry's name is on The Dinner Party porcelain floor.

${ }^{451}$ NEWSPAPER FICTION The New York Journalism of Djuna Barnes, 1913-1919, was on view at the Sackler Center in 2012.

452 Women of York: Shared Dining was on view in 2015 in the Sackler Center.
} 


\title{
Email from John P. Begley, Former Director, Hite Art Institute at University of Louisville
}

\author{
Fri, Sep 18, 2015 at 11:12 AM
}

To: Sally Deskins

Ms Deskins,

Since the IHQ is comprised of 540 individual panels and requires a great deal of gallery space to display and is primarily a fiber construction which is susceptible to degradation from light and dust, it is not on permanent display. It will be displayed in its entirety in our galleries mid January through mid March, 2016. This will be the first time it will be shown independent of the Dinner Party, and in fact includes panels that were added from Australia after the Dinner's Party's last exhibition venue there. We will keep you informed of the exact dates and any corollary events associated with the exhibit, lectures, etc.

Images of each of the individual panels are available online at the IHQ's Digital Collections webpage http://uofl.me/intl-honor-quilt. Perhaps that can answer your questions about individual panels. Each of pieces assemble independently to present the entire piece. An image is attached below showing a section. The database also includes what information we have from the makers of the individual pieces that was provided when they submitted their work to the project.

I am the recently retired Hite Art Institute gallery director and I have been coordinating the cataloging of the IHQ into our collection at the university and it's digitizing over the past year. This fall Margaret < > has been hired to direct the IHQ project and I remain here this semester to help with her transition, and I would happy to speak with you. My contact information is below, do not hesitate to contact me.

JPB

John P Begley, Project Assistant

IHQ Project

Hite Art Institute

University of Louisville

Louisville, KY 40292

July 24, 2015, online conversation with various scholars, curators and artists. 
Used with permission.

[Author]: Curators of the group! Question: I am a graduate student in art history at West Virginia University. My thesis is examining the curatorial implications of Judy Chicago's The Dinner Party, as a feminist contemporary approach to curating, from 1979-present (let me emphasize this is not about the content or her feminism, I may have an opinion on that but that is not what I'm looking at). She has been very helpful providing me with information about her creating her own curatorial context for exhibitions and specifically The Dinner Party. And I am also looking at a series of exhibitions and how they are curated to discuss different methods and techniques.

Here's the Question: if you have any insight about your (feminist?) approach to curating, and also, if The Dinner Party has impacted your curatorial vision (whenever/wherever you saw it/have seen it), if you even have any comments it would be so much appreciated!

If I can use your comment please let me know! I also have an official letter of inquiry and list of questions if you would prefer that, on WVU letterhead. Thanks for taking the time to read this and have a wonderful day!

: I'm sure you've seen this but Brooklyn Museum is doing a bit inspired by the dinner party in collaboration with a woman's prison. I'm cover it! Comes out in August.

[Author]: Thanks, I look forward to your review!

Is this your only question or are there others?

[Author]: There are others, but I didn't want to ask too much on Facebook. I can email you if you like!

Alexandra M. Kokoli: I saw it at the E.Sackler Museum in Nov 2008 and though the installation really emphasised the religious (or rather ritualistic) dimension of the work. Dimmed lights, everyone speaking in hushed tones... The plates looked quite sensual and very beautiful but the curatorial approach did not facilitate a critical (re) consideration of the work, opting rather for a promotion of its historical significance and its undeniable prettiness. My students loved it.

[Author]: Interesting! Thank you! Can you elaborate on why it does not?

Alexandra M. Kokoli: As the centrepiece of the then still new museum, the work was framed as a (the?) masterpiece of art informed by feminism and an invaluable part of feminist heritage (which of course it is). Compared to A.Jones' Sexual Politics, the installation (inc. info panels) did not seek to debate how the work should be contextualised or discussed but rather confidently framed it as the apex of feminist art.

Felicity Allen: As a Londoner I'm interested in thinking about how it was shown in London in the 80s. It was in a kind of pop up warehouse space, without any of the gradeur it now has, and there was a smaller exhibition curated in a space within the warehouse which showed, I think, 4 contemporary British women artists (I was one of them). There was an irritation that none of the 
museums would show it, and therefore women organised the pop-up space, but equally I think it felt more gritty and less hallowed (and therefore better) for that. The reverential quality that I've seen since then is more problemativ. I am sure that the London show affected my curatorial / educational thinking, but not in a way that can be directly attributed.

[Author]: Wow Thank you both so much! I will add too one of the things I'm looking at is how it itself is a curated piece, the table with the runers and the settings and the plates and the banners and the panels put together in a certain way to understand the piece.

Also, let me know if I may quote you.

Alexandra M. Kokoli: Very interesting contrast, Felicity Allen. And you may quote me, Sally Deskins. Your project sounds fascinating!

Felicity Allen: Yes, do quote me. The London exhibition (just checked my cv!) was in 1985the place was temporarily called The Warehouse (I think it was only used this once as a gallery space), and was near Chapel Market in Islington which in those days was not an area noted for galleries or artists (there were some of both in the environs but at this time it was the next borough (further out of centre and cheaper) Hackney which was more of an artists and pop-up studio gallery area. Islington was just on the turn to becoming the more middle class area it is today. I'm wracking my brains to remember the name of the woman who curated the whole project - I think I'm right in saying she was a feminist producer rather than a curator. The person who curated the British artists' section was Katy Sender (whose name for some reason Facebook isn't recognising but she's on Facebook, based in the south of Spain now). I think perhaps Hilary Rosen also showed but Katy would remember better. Katy was then working as a curator, either at the Air Gallery (which wasn't too far from The Warehouse) or at the ICA where I think her role was something maybe more managerial than curatorial. Sorry - far too much detail. She could tell you I'm sure who the producer was - my rather frail mental card index is coming up with various ideas, any of whom would be interesting because they are related to people who are now curators / producers etc. (ie sisters or mothers etc) but hav enot gone on to do curatorial work themselves. (Personally I find this interesting because I'm interested in how early steps into professional education are frequently familial, but it's not really relevant to your question.) I've just googled ' 1985 judy chicago islington The Warehouse' and there's quite a lot that comes up, including a sneering short piece in Art Monthly (a kind of trade mag for British artists) about the economics of the project. Also, it seems that one of the other artists showing with me was Suzan Swale. Sorry for the length of this entry - I hope some of it is useful.

: The South Lond Women Artists did a verion in 2013 - can put you in touch with the curators if you are interested.

Http://fwsablog.org.uk/.../07/12/south-london-women-artists/

[Link to FWSA Blog : South London Women Artists]

https:www.youtube.com/

[Link to Youtube: South Londom Women Artists: I'm Inside, Ring the Bell...] 
Hilary Robinson: I saw it in Edinburgh also in 1985, also in a warehouse, which was greatoverheating Morningside ladies sounding like Jean Brodie talking about the stitches and ignoring the imagery. But as I'd been working at the Whitechapel a couple of years earlier I asked why it didn't go there, and got the answer that they measured the downstairs space, and it wasn't big enough, with the columns, etc. so one of the reasons it didn't go into museum spaces was simply that it couldn't fit. The warehouse was dark and church-like too, but not as hagiograhpic as the Brookyln Museum has made it.

There were articles in spare rib, and I reprinted a piece about it in Visibly Female.

[Author]: @ yes, I'd love to talk to the curator. And thanks, Felicity Allen, that is very helpful - the book by Jane Gerhard has helped a lot with reviews, etc. but not with descriptions of the spaces/installations or even, especially for the European tour, the names of the venues which may not be necessary in her book but would be helpful for me to search for images. Most of the reviews also talk about content, not the space, so this is all extremely valuable and helpful. Hilary Robinson, I will look up those articles as well. (Can I quote you too?) Thank you so much!

Hilary Robinson: Absolutely! Not sure how you cite FB :)

[Author]: I'm thinking maybe 'online conversation'. I'm going to screenshot it all. Thanks again! 


\section{Bibliography}

Aagerstoun, Mary Jo and Elissa Auther. "Considering Feminist Activist Art." NWSA Journal, Vol. 19, No. 1 (Spring 2007): vii-xiv.

Abrams, Amah-Rose. "Valeria Napoleone Launches Global Project to Get Women Artists Into Museum Collections in the US and UK." ArtNet News 15 June 2015. Accessed August 25, 2015. Artnet.com.

Acuff, Joni Boyd and Laura Evans. Multiculturalism in Art Museums Today. New York and London: Rowman and Littlefield, 2014.

Adrian Piper. “Aspects of the Liberal Dilemma.” Accessed August 10, 2015. http://www.adrianpiper.com/art/aspects_of_the_liberal_dilemma.shtml\#.

Agnew, Flora and Alex MacDonald. "Dinner Party time.” The Globe and Mail (Canada), July 20, 1982.

Amend, Kate, director. Judy Chicago's The Dinner Party: A Tour of the Exhibition. DVD. New Mexico: Chicago Productions LLC, 2015.

Anderson, Chris. "The Smithsonian's Long Tail." Presented at Smithsonian 2.0 Conference, January 2009. Referenced in Proctor, 62.

Anderson, John. "Watch This! at the Smithsonian American Art Museum." Washington City Paper, 24 March 2011. Accessed October 14, 2014. washingtoncitypaper.com.

Andy Warhol Museum. "Events.” Accessed October 12, 2015. http://www.warhol.org/responsive/event.aspx?id=23764.

Art Agenda. "Why Not Judy Chicago?” Accessed November 10, 2015. http://www.artagenda.com/shows/why-not-judy-chicago-at-azkuna-zentroa/.

Artnet News. "We Asked 20 Women 'Is the Art World Biased?' Here's What They Said." 16 September 2014. Accessed September 16, 2014. Artnet.com

Artner, Alan G. "Inanity Outweighs the Controversy of 'Dinner Party." Chicago Tribune, 14 September 1981, B8. Quoted in Gerhard, The Dinner Party: Judy Chicago and the Power of Popular Feminism, 1970-2007, 329.

Askey, Ruth. "Judy Chicago: Pride in Women and in Herself." Artweek, January 1977. Quoted in Gail Levin. Becoming Judy Chicago: A Biography of the Artist. New York: Random House, 2007.

Auther, Elissa. “Bio.” http://elissaauther.com/bio.html. Accessed March 19, 2015. 
Azara, Nancy. "The Language of Art Is Still Defined by Men." The Brooklyn Rail, September 4, 2014. Accessed September 9, 2014. http://www.brooklynrail.org/2014/09/criticspage/thelanguage-of-art-is-still-defined-by-men.

Baker, Patricia and Rhoda Zuk. "Leaving the gallery, entering the fray: feminist curating in public space." Resources for Feminist Research, 30 (2003): 51-62.

Barlow, Margaret and Joan Marter. "Parallel Perspectives.” Woman's Art Journal 27, No. 2 (FallWinter, 2006): 2.

Barnes, Freire. "Judy Chicago Interview." TimeOut London, 9 September 2015. Accessed March 11, 2016. http://www.timeout.com/london/art/judy-chicago-interview.

BBC Radio 4. "Judy Chicago, Sexual Assaults in Schools, Boho Fashion, Tara J Lal.” Accessed March 11, 2016. http://www.bbc.co.uk/programmes/b06bng31.

Bee, Susan. "Frames.” The Brooklyn Rail, 4 September 2014. Accessed September 9, 2014. http://www.brooklynrail.org/2014/09/criticspage/frames-bee.

Belsey, Catherine and Jane Moore. The Feminist Reader: Essays in Gender and the Politics of Literary Criticism. New York: Basil Blackwell, 1989.

Bentley, John Mays. "Epic Dinner Party Strikes to the Core." The Globe and Mail (Canada): May 22, 1982.

Bishop, Jacqueline. “Catherine Morris Discusses Feminism's Enduring Contributions and Why Women Artists Should Think Ahead." Huffington Post 1 December 2014. Accessed December 2 2014. http://www.huffingtonpost.com/jacqueline-bishop/catherine-morrisof-the-e_b_6244258.html.

Borzello, Frances. "An Art History Sit-In: The Dinner Party in Its Artistic Context." In The Dinner Party: Restoring Women to History, edited by Judy Chicago. China: The Monacelli Press, 2014. 259-260.

Boucher, Brian. “25 Women Curators Shaking Things Up,” ArtNet News, March 17, 2015. http://news.artnet.com/people/25-women-curators-on-the-rise276386\#.VQhWhXFTqHI.facebook, accessed March 19, 2015.

Bowers, Andrea and Suzanne Lacy and Maria Elena Buszek. "'Necessary Positions' in Feminist Art: A Conversation.” CAA Art Journal (Spring 2012): 139-159.

Brand, Peg. "Feminist Art Epistemologies: Understanding Feminist Art." Hypatia, Vol. 21, No. 3 (Summer 2006): 166-189.

Brodsky, Judith K. and Ferris Olin. "Stepping out of the Beaten Path: Reassessing the Feminist Art Movement." Signs, 33 (Winter 2008): 329-342. 
Brooklyn Museum of Art. Judy Chicago: The Dinner Party. Exhibition pamphlet, 2002.

Brooklyn Museum: Elizabeth A. Sackler Center for Feminist Art. Museum label for Judy Chicago, The Dinner Party, New York, 22 February 2015.

Brooklyn Museum: Elizabeth A. Sackler Center for Feminist Art. "About the Benefactor." Accessed November 10, 2015. https://www.brooklynmuseum.org/eascfa/about/elizabeth_sackler/.

Brooklyn Museum: Elizabeth A. Sackler Center for Feminist Art. "About the Center." Accessed April 22, 2015. http://www.brooklynmuseum.org/eascfa/about/index.php.

Brooklyn Museum: Elizabeth A. Sackler Center. "Gallery Design.” Accessed October 7, 2015. https://www.brooklynmuseum.org/eascfa/about/gallery_design/.

Brooklyn Museum: Elizabeth A. Sackler Center. "Margaret Sanger.” Accessed October 9, 2015. https://www.brooklynmuseum.org/eascfa/dinner_party/place_settings/margaret_sanger.

Brooklyn Museum: Elizabeth A. Sackler Center for Feminist Art. "The Dinner Party: Acknowledgment Panels." Accessed October 6, 2015. https://www.brooklynmuseum.org/eascfa/dinner_party/acknowledgement_panels

Brooklyn Museum. "Collections." Accessed October 12, 2015. https://www.brooklynmuseum.org/opencollection/collections/.

Brooklyn Museum. "Judy Chicago's Rainbow Pickett.” Accessed April 17, 2015. http://www.brooklynmuseum.org/eascfa/feminist_art_base/gallery/judy_chicago.php?i=1 $\underline{564 .}$

Brooklyn Museum. “Chicago in LA: Judy Chicago's Early Work, 1963-74.” Accessed April 17, 2015.

http://www.brooklynmuseum.org/exhibitions/judy_chicago_los_angeles/\#!lb_uri=purple _atmosphere.php.

Brownell Mitic, Ginanne. "Where Art Is a Woman's World,” New York Times, 13 March 2015. Accessed March 19, 2015. http://mobile.nytimes.com/2015/03/14/arts/international/where-art-is-a-womansworld.html? r=2\&referrer.

Burr, James. "The Dinner Party: The Warehouse.” Apollo (May 1985): 349.

Butler, Cornelia, Griselda Pollock and Alexandra Schwartz. Modern Women: Women Artists at the Museum of Modern Art. New York: The Museum of Modern Art, 2010. 
Capps, Kriston. "Finally, a Woman-Focused Show That Doesn't Tokenize Its Artists!." Washington City Paper, 13 June 2014. Accessed October 14, 2014. http:/www.washingtoncitypaper.com/articles/45943/total-art-contemporary-video-at-thenational-museum-of-women/.

Castro, Jan Garden. “Review: 'Global Feminisms.”' Sculpture 26, No. 10 (2007): 72-73.

Chadwick, Whitney. Women, Art and Society. Singapore: Thames and Hudson: 2007.

Chaffee, Cathleen, Saisha Grayson, Norman Kleebat and Janelle Porter. "Working with and Through Collections: Curators in Conversation." Institute for Women in Art Panel at College Art Association Conference, Feb. 2013, recorded by Todd Schramke. http://vimeo.com/61801053.

Chicago, Judy. "A Journey of Discovery." National Council of Jewish Women Journal 21, No. 1 (April 30, 1998): 16.

Chicago, Judy. Beyond The Flower: The Autobiography of a Feminist Artist. New York: Viking, 1996.

Chicago, Judy. Deflowered: Judy Chicago. Los Angeles: Nye + Brown, 2012.

Chicago, Judy. Institutional Time: A Critique of Studio Art Education. China: The Monacelli Press, 2014.

Chicago, Judy. Interview with Frieze: Contemporary Art and Culture 176 (January-February 2016): 160 .

Chicago, Judy. The Birth Project. Garden City, NY: Doubleday, 1985.

Chicago, Judy. The Dinner Party. New York: Penguin Group, 1996.

Chicago, Judy. The Dinner Party: A Symbol of Our Heritage. Garden City, NY: Anchor Press/Doubleday, 1979.

Chicago, Judy. The Dinner Party: From Creation to Preservation. London/New York: Merrell Publishers Limited, 2007.

Chicago, Judy. The Dinner Party: Restoring Women to History. China: The Monacelli Press, 2014.

Chicago, Judy. Through the Flower: An Autobiography of a Feminist Artist. USA: Penguin Books, 1997. 
Chicago, Judy. "Judy Chicago: What I Learned From Male Chauvinists." LA Weekly, 22 July 2011. Accessed February 22, 2016. http://www.laweekly.com/arts/judy-chicago-what-ilearned-from-male-chauvinists-2172063.

Chicago, Judy, Johanna Demetrakas, and Miriam Schapiro. Womanhouse. DVD. New York: Women Make Movies, 2006.

Chicago, Judy and Susan Hill. Embroidering Our Heritage: The Dinner Party Needlework. Garden City, NY: Anchor Books, 1980.

Chicago, Judy, Lucy R. Lippard and Viki D. Thompson. Judy Chicago: Trials and Tributes. Tallahassee, FL: Florida State University Museum of Fine Arts, 1999.

Chicago, Judy and Edward Lucie-Smith. Judy Chicago: An American Vision. New York: WatsonGuptill Publications, 2000.

Cianfanelli, Gaia; Iaquinta, Caterina; and Isaak, Jo Anna. "Curatorial Practice as Collaboration in the United States and Italy." In Entering the Picture: Judy Chicago, the Fresno Feminist Art Program, and the Collective Vision of Women Artists, edited by Jill Fields. New York: Taylor and Francis, 2012. 292-311.

Clark, Nick. "What's the biggest problem with women artists? None of them can actually paint, says Georg Baselitz," The Independent, February 6, 2012. Accessed March 20, 2015. http://www.independent.co.uk/arts-entertainment/art/news/whats-the-biggest-problemwith-women-artists-none-of-them-can-actually-paint-says-georg-baselitz-8484019.html.

Colton, Elizabeth L. and Karen Offen. "The International Museum of Women.” Museum International 59, No. 4 (2007): 19-25.

Coni, Graciela Tejero. "Why Create a Museum on Women?” Museum International 59, No. 4 (2007): 63-69.

Cooper, Ashton. "The Problem of the Overlooked Female Artist: An Argument for Enlivening a Stale Model of Discussion." Hyperallergic 10 January 2015. Accessed January 22, 2015. http://hyperallergic.com/173963/the-problem-of-the-overlooked-female-artist-anargument-for-enlivening-a-stale-model-of-discussion/.

Cruz, Cynthia. "Words Fall Away: 'Judith Scott—Bound and Unbound.'” Hyperallergic, March 14, 2015. Accessed March 19, 2015. http://hyperallergic.com/190327/words-fall-awayjudith-scott-bound-and-unbound/.

Contemporary Art and Feminism. "Contemporary Art and Feminism." Accessed March 18, 2016. http://contemporaryartandfeminism.com/about/. 
Cooley, Alison. "Possible Utopias in Winnipeg Feminist Art Symposium." Canadian Art, 14 October 2014. Accessed October 1, 2014. http://canadianart.ca/features/mawa-feministart-symposium/.

Cork, Richard. “Monumental.” Listener, 21 March 1985.

Cott, Nancy. “An Experiment of Women, 1893.” New York Times, 19 July 1981, A9.

Dahn, Jo. “Dining In, Dining Out: Review.” Ceramic Review 225 (May/June 2007): 24-25.

Dallow, Jessica. "Bridging Feminist Art, Activism and Theory: A Review of Three Contemporary Texts: The Feminism and Visual Culture Reader by Amelia Jones; Insurgent Muse: Life and Art at the Woman's Building by Terry Wolverton; Modern Art in the USA: Issues and Controversies of the $20^{\text {th }}$ Century by Patricia Hills." National Women's Studies Association Journal 19, No. 1 (Spring 2007): 166-174.

Dancoff, Judith, director. Judy Chicago \& The California Girls. DVD. Los Angeles: California Girl Productions, 2013.

Deepwell, Katy, Maria Lind and Rosa Martinez. "Curatorial Strategies and Feminist politics: An interview with Rosa Martinez.” n.paradoxa 18 (July 2006): 5-15.

Deepwell, Katy. "Feminist Curatorial Strategies and Practices Since the 1970s." In New Museum Theory and Practice: An Introduction, edited by Janet Marstine. USA: John Wiley \& Sons, 2005: 64-84.

Deliso, Meredith. "ASK Brooklyn Museum app engages visitors with the artwork." amNewYork 17 April 2016. Accessed April 19, 2016. http://www.amny.com/lifestyle/ask-brooklynmuseum-app-engages-visitors-with-the-artwork-1.11701295.

Demetrakas, Johanna. "Feminists: What Were They Thinking?" Accessed November 10, 2015. https://www.kickstarter.com/projects/342423718/feminists-what-were-they-thinking.

Demetrakas, Johanna, director. Right Out of History: The Making of Judy Chicago's The Dinner Party. DVD. St. Louis: Phoenix Films, 1979.

Demos, T.J.. "The Politics of Sustainability," in Theory in Contemporary Art Since 1985, Eds. Zoya Kocur and Simon Leung. Oxford, UK: John Wiley \& Sons, Inc. 2013: 466-485.

Deutsche, Rosalyn and Aruna D'Souza, Miwon Kwon, Ulrike Muller, Mignon Nixon and Senam Okudzeto. "Feminist Time: A Conversation," Grey Room, No. 31 (Spring 2008): 32-67.

De Zegher, Catherine. "Introduction to Inside the Visible." In Inside the Visible: An Elliptical Traverse of Twentieth Century Art In, Of and From the Feminine, edited by Catherine de Zegher. Cambridge and London: MIT Press, 1996, 20. 
De Zegher, Catherine. Inside the Visible: An Elliptical Traverse of Twentieth Century Art In, Of and From the Feminine, edited by Catherine de Zegher. Cambridge and London: MIT Press, 1996.

Diehl, Sue. "The Dinner Party, San Francisco Museum of Modern Art, March 17-June 17, 1979." Frontiers: A Journal of Women's Studies 4, no. 2 (Summer 1979): 74-75.

Dimitrakaki, Angela and Lara Perry. Politics in a Glass Case: Feminism, Exhibition Cultures and Curatorial Transgressions. Liverpool: Liverpool University Press: 2014.

Dimitrakaki, Angela and Lara Perry. "How to be Seen: An Introduction to Feminist Politics, Exhibition Cultures and Curatorial Transgressions." In Politics in a Glass Case: Feminism, Exhibition Cultures and Curatorial Transgressions, edited by Angela Dimitrakaki and Lara Perry. Liverpool: Liverpool University Press: 2014, 1-21.

Dimitrakaki, Angela. "The Lessons of Sexual Politics: From the 1970s to Empire, An Interview with Amelia Jones." In Politics in a Glass Case: Feminism, Exhibition Cultures and Curatorial Transgressions, edited by Angela Dimitrakaki and Lara Perry. Liverpool: Liverpool University Press: 2013, 93-103.

Dumlao, Maria; Elaine Kaufmann, Danielle Mysliwjec and Anne Polashenski. "Brainstormers and Gender Inequity in the Art World," Women Studies Quarterly, 35 (Winter 2007): 144-149.

Duncan, Carol. “Art Institutions: Maybe Feminism Has Just Begun.” N.paradoxa 19 (May 2006): 123-135.

Eaton, AW. "Feminist Philosophy of Art." Philosophy Compass, $3 / 5$ (2008): 873-893.

Eler, Alicia. "Exhibit: Terrible Premise, Good Art: The Curatorial Conundrum of ' $X X$ ' at Subliminal Projects.” Crave Online, 29 September 2015. Accessed September 29, 2015. http://www.craveonline.com/art/906501-exhibit-terrible-premise-good-art-curatorialconundrum-xx-subliminal-projects\#uxhmiCCublErzj0k.99.

Elizabeth A. Sackler for Feminist Art. "The Dinner Party.” Accessed April 22, 2015. http://www.brooklynmuseum.org/eascfa/dinner_party/heritage_panels/.

Erste Foundation. "Gender Check.” Accessed April 19, 2016. http://www.erstestiftung.org/project/gender-check-femininity-and-masculinity-in-the-artof-eastern-europe/.

Feminist Curators United. "Feminist Curators United." Accessed November 12, 2015. http://www.feministcurators.org/.

Fields, Jill. "Frontiers in Feminist Art History.” Frontiers 33, No. 2 (2012): 1-21. 
Films for the Humanities and Sciences: Women Artists: The Other Side of the Picture. Princeton, NJ (2004).

Fineman, Mia. “Table for 39: The Dinner Party, Judy Chicago's Iconic Work of Feminist Art, Stands the Test of Time." Slate, 25 April 2007.

Fisher, Hal. "Review: The Dinner Party.” Artforum, Summer 1979, 6.

Fox, Catherine. “Guess Who’s Coming to Dinner?” Atlanta Constitution, 27 July 1982, IB. Quoted in Gail Levin. Becoming Judy Chicago: A Biography of the Artist. New York: Random House, 2007.

Former West. “After the Wall: Art and Culture in Post-Communist Europe.” Accessed November $10,2015$. http://www.formerwest.org/ResearchLibrary/AftertheWallArtandCultureinpostCommunis tEurope.

Fulflord, Robert. “Dinner Party’s Sweep is Breathtaking.” Toronto Star, 12 June 1982.

Gardner-Huggett, Joanna. "The Women Artists' Cooperative Space as a Site for Social Change." In Entering the Picture: Judy Chicago, the Fresno Feminist Art Program, and the Collective Vision of Women Artists, edited by Jill Fields. New York: Taylor and Francis, 2012, 171-183.

Garver, Thomas H. "Review: Judy Chicago, Art Gallery, California State College, Fullerton." Artforum (January 1971): 92-94.

Gelon, Diane. “The Critic’s Voice: Who Speaks for Us?” Sojourner, Oct. 1980, 5.

Gerhard, Jane. "From Controversy to Canonization: The Dinner Party's Journey to Brooklyn." In The Dinner Party: Restoring Women to History, ed. Judy Chicago. China: The Monacelli Press, 2014.

Gerhard, Jane H. The Dinner Party: Judy Chicago and the Power of Popular Feminism, 19702007. Athens, Georgia: University of Georgia Press, 2013.

Gilbert, Sophie. 'Wonder Women: 'Total Art-Contemporary Video' at National Museum of Women in the Arts." Washingtoninan, 4 June 2014. Accessed October 14, 2014. Washingtoninan.com.

Glaser, Jane R. and Zenetou, Artemis. Gender Perspectives: Essays on Women in Museums. Washington and London: Smithsonian Institution Press: 1994.

Glueck, Grace. "Judy Chicago and Trials of 'Dinner Party.” New York Times, 30 April 1979, D10. 
Goins, Andrea Severin. "Thoughtful Words.” In Multiculturalism in Museums Today, edited by Joni Boyd Acuff and Laura Evans. New York and London: Rowman and Littlefield, 2014.

Goldenhersh, Sheryn. “Judy Chicago Hosts Her 'Dinner Party' at the Brooklyn Art Museum.” St. Louis Jewish Light, 5 November 1980, 7.

Guerilla Girls. "Horror on the National Mall.” Accessed October 14, 2014. http://www.guerillagirls.com/posters/washposthorror.shtml.

Hallowell, Marta. “Chicago Comes to Brooklyn.” New York Times, 20 October 1980, 50-55.

Hamilton, Midred. "'The Dinner Party' Left without a Second Sitting." San Francisco Examiner and Chronicle, 1 July 1979, 6.

Hatt, Michael. "Space, Surface, Self: Homosexuality and the Aesthetic Interior." Visual Culture in Britain 8, No. 1 (Summer 2007): 105-128.

Hauser, Katherine. "The Anxiety of (Dis)respect: Names and Misnomers in the History of Women's Institutions." Women and Language 16 (Fall 1993): 2-22.

Heartney, Eleanor; Helaine Posner, Nancy Princenthal and Sue Scott. The Reckoning: Women Artists of the New Millennium, New York: Prestel: 2013.

Heath, Joanne. "Women Artists, Feminism and the Museum: Beyond the Blockbuster Retrospective." In Feminism Reframed, edited by Alexandra Kokoli. Newcastle: Cambridge Scholars, 2008, 20-40.

Hebron, Micol. "The Gallery Tally Poster Project: A Call for Gender Equity in the Art World," The Brooklyn Rail, 4 September 2014. Accessed October 14, 2014. brooklynrail.org.

Hershman, Lynn. “!Women Art Revolution: Interview with Maura Reilly.” Stanford University Digital Collection, February 7, 2007.

Hemus, Ruth. "Why Have There Been No Great Woman Dadaists?" in Feminism Reframed: Reflections on Art and Difference, edited by Alexandra Kokoli. Newcastle: Cambridge Scholars, 2008, 41-60.

Holland, Laura. "It's Art! It's Feminism! It's 'The Dinner Party!!!" Valley Advocate 3, no. 9, 23 July 1980, 18-19.

Hurtado, Laura Allred. "Motherhood and Representation At the Sackler Center for Feminist Art: Judy Chicago, Catherine Opie, Canon Senol." Thesis for Master of Arts in Art History, The University of Utah, August 2011. 
Itunes. "Itunes: ASK Brooklyn Museum.” Accessed November 10, 2015. https://itunes.apple.com/us/app/ask-brooklyn-museum/id949540325?mt=8.

Johnson, Ken. “Art In Review: Michelle Grabner,” New York Times, 23 October 2014. Accessed October 30, 2014. http://www.nytimes.com/2014/10/24/arts/design/michellegrabner.html? $\mathrm{r}=0$.

Johnson, Ken. “The Week Ahead,” New York Times, 7 Nov 2013. Accessed October 14, 2014. http://www.nytimes.com/2012/11/11/arts/nov-11-17.html.

Jones, Amelia and Martina Pachmanova. “Art's Sexual Politics.” N.paradoxa 19 (May 2006):5364.

Jones, Amelia. Sexual Politics: Judy Chicago's Dinner Party in Feminist Art History. Berkeley: University of California Press, 1996.

Jones, Amelia. “Judy Chicago's 'Will to Power' and the Invention of Feminist Art as a Curatorial Practice in 1970s Los Angeles." Paper presented at Feminist Perspectives in Art Productions and Theories of Art public seminar series, organized by Xabier Arakistain and Lourdes Méndez, Centro Cultural Alhóndiga and Azkuna Zentroa, Bilbao, Spain, October, 2015.

Joselit, David. “Exhibiting Gender.” Art in America 85 (January 1997): 37-40.

Judy Chicago. "Birth Project.” Accessed July 28, 2015. http://www.judychicago.com/gallery.php?name=Birth+Project+Gallery.

Judy Chicago. “Chicago Corner.” Accessed November 10, 2015. http://judychicago.com/news/chicago-corner.php.

Judy Chicago. “Heads Up.” Accessed November 10, 2015. http://judychicago.com/gallery.php?name=Holocaust+Project+Gallery

Judy Chicago. "Holocaust Project Gallery.” Accessed November 10, 2015. http://judychicago.com/gallery.php?name=Holocaust+Project+Gallery.

Judy Chicago. “Introduction by Judy Chicago: The Dinner Party Curriculum Project.” Accessed January 22, 2016. http://judychicago.arted.psu.edu/dpcp/.

Judy Chicago. "Resolutions: A Stitch in Time.” Accessed November 10, 2015. http://judychicago.com/gallery.php?name=Resolutions+Gallery.

Judy Chicago. "Studio.” Accessed January 22, 2016. http://judychicago.arted.psu.edu/dialogue/studio/. 
"Judy Chicago Birthday: Celebrating The Feminist Art Pioneer." Huffington Post, 20 July 2013. Accessed April 22, 2015, www.huffingtonpost.com/2013/07/20/judy-chicagobirthday_n_3623420.html

Judy Chicago Papers, 1947-2004. Schlesinger Library. Radcliffe Institute. Harvard University.

Kaufman, Betty. "Celebrating the History of Women." Boston Globe, 15 July 1980, Letters to the Editor.

Kearney, Julie. "The Plural Gaze: Reflections on Contemporary Feminist Curatorial Practice." Hecate (1997): 152-157.

Keifer-Boyd, Karen. “From Content to Form: Judy Chicago's Pedagogy with Reflections by Judy Chicago." Studies in Art Education 48, No. 2 (Winter 2007): 134-154.

Kim, Dakota. "Breaking the Frame: Five Curators on the Present and Future of Feminist Art." Bitch Magazine (Winter 2009): 40-42.

Kim, Eunsong and Maya Isabella Mackrandilal. "The Whitney Biennial for Angry Women," The New Inquiry, 4 April 2014.

King, Sarah S. "Judy Chicago at LewAllen Contemporary." Art in America (April 2005): 158159.

Kivimaa, Katrin and Bojana Pejic. "Gender Check, Feminism and Curating in Eastern Europe." In Politics in a Glass Case, edited by Angela Dimitrakaki and Lara Perry. Liverpool: Liverpool University Press: 2013, 173-183.

Klein, Sheri R. "Comic Liberation: The Feminist Face of Humor in Contemporary Art." Art Education 61, No. 2 (March 2008): 47-52.

Kokoli, Alexandra M. Feminism Reframed: Reflections on Art and Difference. Newcastle: Cambridge Scholars, 2008.

Kokoli, Alexandra M. "Looking On, Bouncing Back." In Feminism Reframed: Reflections on Art and Difference, edited by Alexandra Kokoli. Newcastle: Cambridge Scholars, 2008, 1-18.

Kokoli, Alexandra M. "The Woman Artist as Curatorial Effect." In Politics in a Glass Case, edited by Angela Dimitrakaki and Lara Perry. Liverpool: Liverpool University Press: 2013, 4-6.

Kokur, Zoya and Simon Leung. Theory in Contemporary Art Since 1985. Oxford, UK: John Wiley \& Sons, Inc. 2013.

Koplos, Janet. “'The Dinner Party' Revisited.” Art in America (May 2003): 75-77. 
Kovacs, Nora. “An Interview with Tina Sauerlander." Berlin Art Link, 24 June 2015. Accessed July 24, 2015. http://www.berlinartlink.com/2015/06/25/artfeminism-an-interview-withtina-sauerlander/.

Kramer, Hilton. "Judy Chicago's ‘Dinner Party’ Comes to Brooklyn Museum." New York Times, 17 October 1980, C1.

Krasny, Elke. "Feminist Thought and Curating: On Method." Curating Degree Zero Archive 26 (September 2015): 51-69.

Kuby, Lolette. "The Hoodwinking of the Women's Movement: Judy Chicago's 'Dinner Party." Frontiers: A Journal of Women's Studies 6, No. 3 (Autumn 1981): 127-129.

Lampe, Killy. "Judy Chicago Proves She's About More Than Vagina Plates at Brooklyn Museum Show." Village Voice, April 23, 2014.

Laneri, Raquel. "See Judy Chicago’s ‘The Dinner Party’ Done By Female Inmates.” MetroNews, 20 August 2015.

Lasky, Julie. "At Museum of Arts and Design, a Swan Song for Lowery Stokes Sims." New York Times, March 16, 2015. Accessed March 19, 2015. http://www.nytimes.com/2015/03/19/arts/artsspecial/at-museum-of-arts-and-design-aswan-song-for-lowery-stokes-sims.html? $\mathrm{r}=3$.

Larsen, Devon P. "Rethinking the Monumental: The Museum as Feminist Space in the Sexual Politics Exhibition, 1996.” Thesis for Master of Arts, University of South Florida, 2006.

Larson, Kay. "Under the Table: Duplicity, Alienation." Village Voice, 11 June 1979.

Leeson, Lynn Hershman. !W.A.R. !Women Art Revolution. USA: Zeigest Films, Ltd., 2012.

Levin, Gail. Becoming Judy Chicago: A Biography of the Artist. New York: Random House, 2007.

Lewis, Judith. "The Trouble with Judy: Reflections of The Dinner Party and the Artist Who Created It." Los Angeles Weekly, 18 April 1996, 32.

Level. "Level.” Accessed April 19, 2016. https://levelari.wordpress.com/.

Linton, Meg. "Foreword: Doin' It in Public: Feminism and the Art of the Woman's Building." In Doin' It in Public: Feminism and Art at the Woman's Building, edited by Meg Linton and Sue Maberry. Los Angeles: Otis College of Art and Design, 2011.

Lipinski, Ann Marie. "Public May Never Again Feast on Paean to Women." Chicago Tribune, 19 August 1979, L2. 
Lippard, Lucy. “Chicago's Dinner Party.” Art in America, 1980, 115.

Lippard, Lucy. "Dinner Party a Four-Star Retreat: A Feminist Counterpart of the Sistine Chapel." Seven Days, 27 April 1979, 27-29.

Lipton, Eunice. “Ain't Misbehavin': At Chicago's Dinner Party," Cleveland Beacon 1, no. 5, June 1981, 4-7.

Long, Judy. Telling Women's Lives: Subject/Narrator/Reader/Text. New York: New York University Press, 1999.

Lord, MG. “The Table Is Set, At Last, in a Home.” New York Times, 8 September 2002: 78A.

Lovelace, Carey. "A Feast of Feminist Art: Brookyln welcomes 'The Dinner Party' and LA reconsiders the "70s." Ms. (Fall 2004): 69-70.

Lucie-Smith, Edward. Judy Chicago: An American Vision. New York: Watson-Guptill Publications, 2000.

MacNeill, Kate. "When Historic Time Meets Julia Kristeva's Women's Time: The Reception of Judy Chicago's The Dinner Party in Australia." Outskirts: Feminisms Along the Edge 18 (May 2008): 1-20.

Maloney, Allison. "Art and Activism: The Compass Points of Elizabeth Sackler's Storied Career." New York Times, 8 January 2016. Accessed February 22, 2016. http://nytlive.nytimes.com/womenintheworld/2016/01/08/art-and-activism-intersectacross-elizabeth-sacklers-storied-career/.

Malvern, Sue. "Rethinking Inside the Visible." In Politics in a Glass Case. Eds. Dimitrakaki, Angela and Perry, Lara. Liverpool: Liverpool University Press: 2013, 104-119.

Mann, Susan Archer. Doing Feminist Theory: From Modernity to Postmodernity. Oxford: Oxford University Press, 2012.

Martinon, Jean-Paul and Irit Rogoff. The Curatorial: A Philosophy of Curating. New York: Bloomsbury Academic, 2013.

Mattera, Joanne. “Judy Chicago's The Dinner Party.” Fiberarts (1980): 16-17.

Maura Reilly. "Maura Reilly: Books.” Accessed November 12, 2015. http://maurareilly.com/books.html.

Mark, Lisa Gabrielle. WACK! Art and the Feminist Revolution. Los Angeles: The Museum of Contemporary Art, 2007. 
Mays, John Bentley. "Epic Dinner Party Strikes to the Core.” The Globe and Mail (Canada), 22 May 1982.

McNay, Anna. "Judy Chicago: I'll Leave It to Others to Change the World." Studio International. Accessed March 11, 2016. http://www.studiointernational.com/index.php/judy-chicago-interview-world-goes-poptate-modern.

McNeill, Kate. "When Historic Time Meets Julia Kristeva's Women's Time: the Reception of Judy Chicago's The Dinner Party in Australia.” Outskirts 18 (May 2008).

Meagher, Michelle. “Telling Stories About Feminist Art." Feminist Theory 12, No. 3 (2011): 297-316.

Melrod, George. “The Gender Gap.” Art Ltd, May 2015. Accessed July 24, 2015. http://www.artltdmag.com/index.php?subaction=showfull\&id=1431135955\&archive \&sta $\underline{\text { rt_from\&ucat }=28}$

Metropolitan Museum of Art. "Leonardo Da Vinci.” Accessed April 10, 2015. http://www.metmuseum.org/toah/hd/leon/hd_leon.htm.

Meyer, Laura. "Judy Chicago, Feminist Artist and Educator." Women \& Therapy 17, No. 1-2 (1995): 125.

Miranda, Carolina A. "Molesworth's Permanent Collection Show at MOCA is Upending the Story of Art." Los Angeles Times, 8 January 2016. Accessed February 22, 2016. http://www.latimes.com/entertainment/arts/miranda/la-et-cam-tour-of-moca-permanentcollection-helen-molesworth-20160107-htmlstory.html.

Molesworth, Helen. "How to Install Art as a Feminist." In Modern Women: Women Artists at the Museum of Modern Art, ed by Cornelia Butler, Griselda Pollock and Alexandra Schwartz. New York: The Museum of Modern Art, 2010: 499-513.

Moi, Toril. Sex, Gender and the Body: The student edition of What Is A Woman?. Oxford: Oxford University Press, 2005.

Morineau, Camille.elles@centrepompidou: Women Artists in the Collection of the Musee National d'Art Moderne. (Centre de Creation Industrielle, Paris: Editions du Centre Pompidou, 2009).

Muller, Dena. Review of Global Feminisms: New Directions in Contemporary Art, edited by Maura Reilly and Linda Nochlin. Signs 33, No. 2 (Winter 2008): 471-474.

Museum of Modern Art. "Claes Oldenburg's The Store and The Street.” Accessed July 7, 2015. http://www.moma.org/visit/calendar/exhibitions/1320.

National Museum of Women in the Arts. "Get The Facts.” Accessed October 14, 2014. http://nmwa.org/advocate/get-facts. 
National Museum of Women in the Arts. "Miriam Schapiro.” Accessed April 18, 2016. http://nmwa.org/explore/artist-profiles/miriam-schapiro.

National Museum of Women in the Arts. "Total Art: Contemporary Video." Accessed October 9, 2015. http://nmwa.org/exhibitions/total-art-contemporary-video.

National Museum of Women in the Arts. Exhibition wall text, Total Art: Contemporary Video, National Museum of Women in the Arts, photographed 9/11/14.

National Museum of Women in the Arts. Women Artists: The Other Side of the Picture. DVD. Princeton, NJ: Films for the Humanities \& Sciences, 2003.

New Mexica Art Museum. "Past Exhibitions.” Accessed October 9, 2015. http://nmartmuseum.org/site/exhibitions/past/past-exhibitions-2014/hunting-gatheringnew-additions-to-the-museums-collection.html.

Nochlin, Linda. "Art History and Historiography: Writing History 'Otherly." N.paradoxa 19 (May 2006): 14-21.

Nochlin, Linda. "Why Have There Been No Great Women Artists?" Women, Art and Power. Ed Linda Nochlin. Grand Rapids and Philadelphia: Harper \& Row, 1988.

Obrist, Hans Ulrich. A Brief History of Curating. Zurich: JRP, 2008.

O’Neill, Paul. The Culture of Curating and the Curating of Culture(s). Massachussetts: Massachusetts Institute of Technology, 2012.

O’Sullivan, Michael. "Editorial Review," Washington Post, 6 June 2014. Accessed October 14, 2014. washingtonpost.com.

O’Sullivan, Michael. “Editorial Review: Watch This!.” Washington Post, 16 December 2010. Accessed October 14, 2014. washintongpost.com.

Ozbilgin, Mustafa and Ahu Tatli. "Surprising Intersectionalities of Inequality and Privilege: The Case of the Arts and Cultural Sector." Equality, Diversity and Inclusion: An International Journal 31, No. 3 (2012): 249-265.

Pachmanova, Martina. "Mobile Fidelities: Conversations on Feminism, History and Visuality." N.paradoxa 19 (May 2006).

Parks, Jessica. "At the Pennsylvania Academy of the Fine Arts, a discussion of women artists' contributions." philly.com, 13 February 2013. Accessed October 14, 2014. http://articles.philly.com/2013-02-12/news/37041342 1 art-exhibition-fine-arts-art-critic.

Parker, Rozsika and Pollock, Griselda. Old Mistresses: Women, Art and Ideology. London: Pandora (1981). 
Pederson, Courtney and LEVEL. "Curating Feminism: Speaking to the Exhibit." Paper presented at Contemporary Feminism Conference, October 25, 2014.

Perault, John. "No Reservations.” SoHo News, 22 October 1980, 19.

Plagens, Peter. Review of Judith Gerowitz at Roff Nelson Gallery. Artforum 4 (April 1966): 14.

Platt, Susan. Review of The Dinner Party: From Creation to Preservation; Global Feminisms: New Directions in Contemporary Art; and Wack! Art and the Feminist Revolution. Journal of Compilation, 15 (May 2008): 41-43.

Pollock, Griselda. Encounters in the Virtual Feminist Museum: Time, Space and the Archive. New York: Routledge, 2007.

Pollock, Griselda. "The Politics of Theory: Generations and Geographies in Feminist Theory and the Histories of Art Histories." In Generations and Geographies in the Visual Arts:

Feminist Readings, edited by Griselda Pollock. London: Routledge, 1996, 3-21.

Pollock, Griselda. "What Is It That Feminist Interventions Do? Feminism and Difference In Retrospect and Prospect." In Feminism Reframed: Reflections on Art and Difference, edited by Alexandra Kokoli. Newcastle: Cambridge Scholars, 2008, 248-280.

Pollock, Griselda and Joyce Zemans. Museums After Modernism: Strategies of Engagement. Australia, UK and USA: Blackwell Publishing, 2007.

Princenthal, Nancy. "Feminism's Future Explored at MOMA." Art in America 95, No. 3 (March 2007): 37.

Proctor, Nancy. "Feminism, Participation and Matrixial Encounters: Towards a Radical, Sustainable Museum (Practice)." In Politics in a Glass Case, edited by Angela Dimitrakaki and Lara Perry. Liverpool: Liverpool University Press, 2013, 48-65.

Raven, Arlene. "Woman's Art: The Development of a Theoretical Perspective." Womanspace Journal 1, No. 1 (Feb/March 1973): 14-20.

RAW Art Archives. “The Dinner Party Photographs.” Accessed November 4, 2015. http://rawarchives.tumblr.com/post/22719048959/the-dinner-party-judy-chicagophotographs-of-the.

Reckitt, Helena. Art and Feminism. London: Phaidon Press, 2012.

Reid, Dennis. Interview in Women Artists: The Other Side of the Picture. DVD. Princeton, NJ: Films for the Humanities and Sciences, 2004.

Reilly, Maura. “Curating Transnational Feminisms.” Feminist Studies 36, no. 1 (2010): 156-173. 
Reilly, Maura. "Taking Measure of Sexism: Facts, Figures and Fixes in the Art Industry." ArtNews, May 26, 2015. Accessed November 12, 2015. http://www.artnews.com/2015/05/26/taking-the-measure-of-sexism-facts-figures-andfixes/.

Reilly, Maura. "Towards an Ethics of Curating." Power Lecture, October 24, 2014 at Curating Feminism Conference, Domain Theatre, Art Gallery of New South Wales. Recorded by Frances Barrett for Canvas on FBI Radio. Accessed November 10, 2015. https://soundcloud.com/the-cross-art-projects/dr-maura-reilly-2014-curatorial-activismtowards-an-ethics-of-curating.

Reilly, Maura. Interview by Lynn Hershman, "!Women Art Revolution: Interview with Maura Reilly," Stanford University Libraries Collection, Feb. 7, 2007.

Richmond, Susan. Review of Feminism Reframed: Reflections on Art and Difference, edited by Alexandra Kokoli. The ArtBook 16, No. 4 (November 2009): 40.

Rizvi, Uzma and Murtaza Vali. "The Fertile Goddess at the Brookyln Museum of Art: Excavating the Western Feminist Art Movement and Recontextualizing New Heritages." Near Eastern Archaeology 72, No. 3 (Sept 2009): 143-145.

Robinson, Hilary. "Feminism Meets the Big Exhibition: Museum Survey Shows Since 2005." Anglo Saxonica Ser. III, N. 6 (2013): 129-152.

Robinson, Hilary. "Reframing Women.” Circa, 72 (1995): 18-23.

Robinson, Hilary. "Within the Pale in from: Beyond the Pale: the construction of femininity in the curating of an exhibition season at the Irish Museum of Modern Art, Dublin." Journal of Gender Studies 6, No. 3 (1997): 255-267.

Robinson, Hilary. Feminism Art Theory: An Anthology, 1968-2000. London: Wiley-Blackwell, 2001.

Robinson, Kirsty. "Museums, Marginality and the Mainstream." 3 September 2013. Accessed March 19, 2015. http://kirstymairirobertson.com/2013/09/03/museums-marginality-andthe-mainstream/.

Rodriguez, Susan T. “A Triangular Gallery.” Brooklyn Museum: Elizabeth A. Sackler Center for Feminist Art. New York: Polshek Partnership, LLP, 2009.

Rooney, Kara L. “A Feminist Response: Gender Games and the Art Machine.” The Brooklyn Rail, September 4, 2014. Accessed September 9, 2014. broolynrail.org.

Russell, Carol K. “A Dinner Party in Brooklyn.” Fiberarts (Summer 2003): 16. 
Saltz, Jerry. "2 Big Things Wrong with the Art World As Demonstrated by the September Issue of Artforum," Vulture, 2 September 2014. Accessed October 14, 2014.

http://www.vulture.com/2014/09/artforum-september-issue-whats-wrong-with-artworld.html.

San Francisco Museum of Modern Art. "Judy Chicago: It's a Man's World.” Accessed March 11, 2016. https://www.sfmoma.org/watch/judy-chicago-its-a-mans-world/.

Schor, Mira. “Amnesia Return/ Amnesiac Return.” The Brooklyn Rail, September 4, 2014. Accessed September 9, 2014. http://www.brooklynrail.org/2014/09/criticspage/amnesiacreturn-amnesiac-return.

Smith, Roberta. "Art Review: For a Paean to Heroic Women, a Place at History's Table.” New York Times, 20 September 2002. Accessed March 19, 2015. http://www.nytimes.com/2002/09/20/arts/art-review-for-a-paean-to-heroic-women-aplace-at-history-s-table.html.

Smith, Terry. Thinking Contemporary Curating. New York: Independent Curators International, 2012.

Springer, Julie. "Deconstructing the Art Museum: Gender, Power, and Educational Reform." Gender Issues in Art and Education: Content, Contexts, and Strategies. Eds Collins, Georgia and Sandell, Renee. Reston, VA: National Art Association: 1996.

Strauss, Susan. Brooklyn Museum: Elizabeth A. Sackler Center for Feminist Art. New York: Polshek Partnership Architects, LLP, 2009.

Steadman, Kandace. "Status Quo? No! Women Moving from Marginalisation to Mainstream in the Arts." National Society for Education in Art and Design (1999): 271-280.

Steinhauer, Jillian. "Tallying Art World Inequality, One Gallery at a Time.” Hyperallergic, 14 October 2014. Accessed March 20, 2015. http://hyperallergic.com/117065/tallying-artworld-inequality-one-gallery-at-a-time/.

Steinhauer, Jillian. "New Tally Shows Sexism Alive and Well at Top NYC Galleries." Hyperallergic, February 19, 2015. Accessed March 20, 2015. http://hyperallergic.com/184113/new-tally-shows-sexism-alive-and-well-at-top-nyc-artgalleries/.

Swartz, Anne. "The Feminist Art Project.” In--. 281-287.

Sydney College of the Arts Galleries. "Curating Feminism: Contemporary Art and Feminism" (conference exhibition). Accessed September 12, 2015. http://contemporaryartandfeminism.com/events/conference-curating-feminism/. 
Tang, Jeannine. "The Problem of Equality, or Translating 'Woman' in the Age of Global Exhibitions." In Politics in a Glass Case, edited by Angela Dimitrakaki and Lara Perry. Liverpool: Liverpool University Press: 2013, 245-259.

Taylor, Kendall. "To Create Credibility, Women in Museums Owe a Collective Debt to the First Generation of Female Professionals Whose Competence Helped Open Up the Field." Museum News (Washington), 69 (July 1990): 41-42.

Taylor, Robert. “'The Dinner Party' Somewhat Unappetizing.” Boston Globe, 3 July 1980, sec. 3.2 .

Tennant, Donna. “A Monumental Work of Art.” Houston Chronicle, 9 March 1980, 14.

The Brooklyn Museum. The Dinner Party, Judy Chicago. Exhibition pamphlet, 1980.

The Dinner Party Project in Chicago. "The Dinner Party in Chicago." Accessed November 4, 2015. http://www.dinnerpartyprojectchicago.org/PageExhibition/Exhibiton.html.

The Metropolitan Museum of Art. “Gallery Map.” Accessed October 12, 2015. http://www.metmuseum.org/visit/museum-map.

The Sheela-na-gigs Project. "The Sheela-na-gigs.” Accessed October 14, 2014. http://sheelanagig.org/.

The Talks. "Judy Chicago: Get Used to It!” 2 September 2015. Accessed March 11, 2016. http://the-talks.com/interview/judy-chicago/.

The University of Sydney. "Sydney College of the Arts: Curating Feminism Conference, 2014." Accessed November 12, 2015. http://sydney.edu.au/sca/research/contemporary-artfeminism/curating-feminism-conference.shtml.

Thompson Wylder, Viki D. Judy Chicago: Trials and Tributes. Tallahassee: Florida State University Museum of Fine Arts Press, 1999.

Through the Flower. "Projects: International Honor Quilt.” Accessed April 17, 2015. http://www.throughtheflower.org/projects/international_honor_quilt.

Through the Flower. "Through the Flower." Accessed April 19, 2016. http://www.throughtheflower.org/.

University of Louisville Hite Art Institute. “International Honor Quilt.” Accessed October 7, 2015. http://louisville.edu/art/facilities-resources/international-honor-quilt.

University of Louisville Hite Art Institute. Extending the Spirit of The Dinner Party: International Honor Quilt. Pamphlet, 2015. 
van der Werve, Guido. "Heavily curated biennales really bother me as an artist." E-flux.com. July 1, 2015. Accessed July 24, 2015. http://conversations.e-flux.com/t/heavily-curatedbiennales-really-bother-me-as-an-artist/1715.

Viera, Pat and Alicia Villeneuve. "Embracing Cultural Diversity Through Inclusive Art Exhibitions." In Multiculturalism in Art Museums Today, edited by Joni Boyd Acuff and Laura Evans. New York: Rowman and Littlefield, 2014.

Wat, Kathryn and J. Rachel Gustafson, Total Art: Contemporary Video, exhibition pamphlet (National Museum for Women in the Arts, Washington DC: 2014): 1-10.

Weil, Harry J. "Great Women Artists: A Conversation with Catherine Morris." Afterimage, Vol. 38, No. 1 (Jul/Aug 2010): 14-18.

Wilson, Siona. "Destinations of Feminist Art: Past, Present, and Future." Women's Studies Quarterly 36 (2008): 324-330.

Wilson, William. “Art Walk: La Cienega Area.” Los Angeles Times, 28 January 1977, sec. 4, p.6. Quoted in Gail Levin. Becoming Judy Chicago: A Biography of the Artist. New York: Random House, 2007.

Withers, Josephine. "All Representation Is Political: Feminist Art Past and Present." Feminist Studies, Vol. 34, No. 3 (Fall 2008): 456-475.

Wolff, Janet. "Groundless Beauty Feminism and the Aesthetics of Uncertainty." Feminist Theory 7, no. 2 (August 2006): 143-158.

Wolf, Stephanie. "Denver Gallery Surveys Trailblazer Judy Chicago's Five-Decade Career." Colorado Public Radio, 23 October 2014.

Womanhouse. "Womanhouse.” Accessed April 20, 2015. http://womanhouse.refugia.net/.

Women's History. “Womanhouse.” Accessed April 18, 2016. http://womenshistory.about.com/od/feminism/a/womanhouse.htm.

Zapperi, Giovanna. "Woman's reappearance: Rethinking the Archive in Contemporary ArtFeminist Perspectives." Feminist Review, Vol. 105 (2013): 21-47.

Ziamou, Lilia. "Curator's Close-Up: Maura Reilly.” HuffPost Arts \& Culture, 26 August 2015. Accessed February 19, 2016. http://www.huffingtonpost.com/lilia-ziamou/curatorscloseup-maura-re b 8034736.html.

Zuk, Rhoda and Baker, Patricia. "Leaving the gallery, entering the fray: feminist curating in public space." Resources of Feminist Research. Vol. 20, Issue 1, (2003): 51-62. 


\section{SALLY DESKINS CV}

| sallydeskins@yahoo.com

\section{SUMMARY}

As a researcher and writer, my work focuses on women in art and feminist curatorial methods; researching, interviewing, reporting, examining and reviewing. As an event organizer, I curate, promote and market exhibitions, arts events and panels specializing in art and feminism. I enjoy volunteering and collaborating with nonprofit organizations. As an artist, my work examines the dichotomy of the female figure to relationships and social perspective with special attention to motherhood and feminism. I am seeking a position which I can use my skills of research, writing, project initiation and organization, with my passion and enthusiasm for the arts and community.

\section{EDUCATION}

MA, Art History West Virginia University

Graduate Certificate in Women's and Gender Studies

Master of Public Administration, Nonprofit Administration, University of Nebraska-Omaha

2003

BA, Studio Art, Minors: Art History, English, University of Nebraska-Lincoln

\section{PROFESSIONAL EXPERIENCE}

\section{8/14- Graduate Teaching Assistant, West Virginia University, College of Creative Arts, Department of} cur. Art History

Assist professor with preparations for undergraduate level art history course, tutor students as needed. Gave tour of Art Museum of West Virginia University to educators at West Virginia Art Educator Conference, 10/15.

Awards: Carl del Signore Award for Excellence in Research; College of Creative Arts Student-Faculty Mentored Research Award

10/16 Conference Session Chair, Southeast College Art conference, Fall, 2016, Roanoke, VA Session: 1970s Feminist Curatorial Activism

10/15 Fireside Chat, West Virginia University Center for Women's and Gender Studies public forum series Title: Judy Chicago's The Dinner Party \& Feminist Curatorial Considerations

10/15 Conference Session Chair, Southeast College Art Conference, Fall 2015, Pittsburgh Session: Feminism \& Curatorial Strategy

1/15- Editorial Contributor, Pittsburgh Articulate (Pittsburgh, PA)

1/16 Interview artists and curators, visit gallery exhibitions, writer interviews and reviews.

6/06- Editorial Contributor, Arts Columnist, The Reader (Omaha, NE)

12/12 Interviewed artists and curators, visited gallery shows and wrote weekly column on the visual arts. 
12/11- Editorial Contributor, KVNO Omaha Public Radio

12/12 Visited gallery shows, wrote and read reviews for public radio.

8/08- Instructor, Metropolitan Community College, Omaha

5/12 Designed curricula and taught Arts Administration and Grant Writing to undergraduate students.

11/09- Editor, Neighborhood News, Omaha

9/10 Researched, interviewed, wrote and edited a weekly community newspaper.

1/06- Associate Development Director, Big Brothers Big Sisters of the Midlands, Omaha

7/06 Managed fundraising events including 'Bowl for Kids' Sake;' increased profit 50\% from previous year.

Bowl for Kids' Sake responsibilities: business relations, volunteer relations, donor relations, marketing, public relations, database management, website management:, week-of event coordination.

Luncheon responsibilities: business relations, marketing, public relations, client relations, compose and design promotional materials, database and registration records management, scheduling. Edited grant proposals and researched potential grant funding sources.

Composed and sent press releases and press packets for organization news.

Managed department interns and volunteers.

Developed ideas for website design, marketing plan and general advertising designs.

1/07- Editorial Contributor, Women's Edition, Omaha

2/08 Researched, interviewed and wrote feature stories for community magazine.

3/05- Administrative Coordinator, KANEKO, Omaha

8/05 Researched and composed public relations documents regarding history of buildings, artists, and concept timeline.

Assisted Director with development, database management, tour schedules, client relations, board meetings, and functions.

Designed and implemented donation tracking system on E-Tapestry database.

10/03- Membership Specialist, Joslyn Art Museum, Omaha

3/05 Conducted email business drive, client relations and correspondence management, managed donor database, produced budget reports, managed records, managed office operations, mailings, campaigns, materials inventory, association liaison, supervised volunteers and intern.

Managed volunteer sales program, member benefit program, arts magazine discount program and North American Reciprocal Program.

Worked with marketing department in creating presentation for clients, assisted with off-site promotional events.

7/03- Development Assistant, Durham Western Heritage Museum, Omaha

10/03 Managed donor/activities database for all departments, managed membership bulk mailings, front desk operations.

Assisted Director with exhibition design, set-up, and promotional material design.

7/05- Arts Writer, The Gateway, Omaha

6/07 Researched, interviewed, visited gallery exhibitions and wrote arts feature stories and reviews.

1/02- Gallery Assistant, Haydon Art Gallery, Lincoln, NE

8/02 Assisted with exhibition set-up and take down, data management, artist communication and administrative tasks. 
1/02- Gallery Assistant, Eisentrager-Howard Gallery, Lincoln, NE

5/02 Assisted with exhibition set-up and take down, promotional materials and administrative tasks.

8/01- Artist, Daily Nebraskan, Lincoln, NE

5/02 Researched and drew feature illustrations.

\section{OTHER WRITING PUBLICATIONS}

\section{Reviews:}

"Feminist Technique of Michele Pred," TRIVIA: Voices of Feminism, 3/16

Drink by Laura Madeline Wiseman, Concho River Review, forthcoming, 5/16

Some Fatal Effects of Disobedience by Laura Madeline Wiseman, Calyx, 1/16

Jen Mussari at Paul Mesaros Gallery, Quail Bell Magazine, 12/15

"Strength in Imagery: She Who Tells a Story," Pittsburgh Articulate, 11/15

"Donna Legault: 'Transformations' in Feminism," Pittsburgh Articulate, 10/15

All Day Talking, by Sarah A. Chavez, Up the Staircase Quarterly, 8/15

A Reexamination of Jennie Augusta Brownscombe's "Love's Young Dream," Art on the Banks, 8/15

Wake, by Laura Madeline Wiseman, Rhizomatic Ideas, 7/15

"Gender and Animal Care in the artwork of Adelaide Paul," Art on the Banks, 6/15

LFF Tales, Quail Bell Magazine, 5/15

LFF Tales, Up the Staircase Quarterly, 5/15

BITCH LIST: Corita Kent, Bitch Magazine, 3/15

Spindrift by Laura Madeline Wiseman, Entropy, 6/14

Too Heavy to Carry by Cat Dixon, Weave, 4/14

Interior Sculpture by Kathleen Kirk, Stirring 4/14

A Sweeter Water by Sara Henning, Weave, 4/14

Hemming The Water by Yona Harvey, Gently Read Literature 5/14

Queen of the Platform by Laura Madeline Wiseman, Weave, 3/14

THE RECKONING: WOMEN ARTISTS IN THE NEW MILENNIUM (2013, Prestel USA), STORYACIOUS, 1/14

BITCH LIST Item: Paula Modersohn-Becker, BITCH MAGAZINE, 3/14

PAULA MODERSOHN-BECKER: THE FIRST MODERN WOMAN ARTIST by Diane Radycki, BOOKSLUT, 1/14

FIRST WIFE, by Laura Madeline Wiseman, STIRRING, 1/14

VOW by Kristina Marie Darling, GENTLY READ LITERATURE, 1/14

MEN AND THEIR WHIMS by Laura Madeline Wiseman, CACTUS HEART LITERARY MAGAZINE, 12/13

Mas-Tur-Ba-Tion by Marilyn Coffey, COTTAGE READER, 12/13

$X$ Marks the Dress by Kristina Marie Darling, PRICK OF THE SPINDLE, 10/13

HYSTERIA by Stephanie Wytovich, SEIN UND WERDEN, 9/13

\section{Other Writing:}

"Inventive Observation" HER KIND, blog by VIDA: Women in Literary Arts, 2/13

"VOICE," C.reative L.adies A.re P.owerful 3/12

"Wanda Ewing: Video Grrrlllz," Gender Across Borders 5/11

"A Lively Performance: Contact Magazine," Prairie Schooner Blog 3/11

"Does State Arts Spending Affect State Economic Activity?" Review of Regional Economics, 2009

"How Storytelling Saved Rita," Today's Omaha Woman, 2008

"How to keep your career-and family-moving," Today's Omaha Woman, 2007

"Omaha's Performing Arts Moves the Economy," B2B, 2007

"Paying Attention to Girls' Mental Health," Today's Omaha Woman, 2007

"He Says So," Laurus UNL literary journal, 2003 


\section{Interviews:}

With An Paenhuysen, An Paenhuysen Art Blog, 12/15

With artists Evelin Stermitz and Elise Kermani, n.paradoxa, 1/16

With poet Laura Madeline Wiseman and artist Lauren Rinaldi, Tinderbox Literary Journal, Summer 2015

With poet Laura Madeline Wiseman, Broad! Magazine, Summer 2015

With poet Laura Madeline Wiseman, Blotterature, 5/15

With artist/nonprofit administrator Lee Parker, Pittsburgh Articulate, 11/14

With artist Caroline Record, Pittsburgh Articulate, 10/14

With author Gabrielle Selz, Luna Luna, 10/14

With poet Laura Madeline Wiseman, Strange Horizons, 2/14

With poet Laura Madeline Wiseman, Wild Women Rising, 5/14

With poets Laura Madeline Wiseman and Kristina Marie Darling, American Microreviews and Interviews, 3/14

With poet Laura Madeline Wiseman, Storyacious, 1/14

With poet Kristina Marie Darling, HEAVY FEATHER REVIEW, 1/14

With poet/author Sally Ball, HER KIND, 7/13

With Wanda Ewing, Gender Across Borders, 5/11

\section{Copywriting:}

Contributing copywriter, Women Write Resistance: Poets Resist Gender Violence (Hyacinth Girl Press, 2013, editor: Laura Madeline Wiseman)

(continued below) 


\section{INITIATED PROJECTS:}

Les Femmes Folles: Women in Art, Journal and organization supporting women in the arts since 4/11 Founder, Curator, Writer, Events Organizer

Edit online journal featuring over 800 women of various career levels, genre and media, with interviews and stories.

Produce events such as: "Les Femmes Folles: A Curated Show featuring Wanda Ewing and Kim Reid Kuhn" Peerless Gallery, 7/11; "Les Femmes Folles: Voice" visual exhibit co-curated with and Megan Sanders, The New BLK Gallery, 4/12; "Les Femmes Folles Art Show for Women's Center for Advancement" House of Loom, 2/13; "Les Femmes Folles: CIAO!” group exhibit, Caesium Gallery, 5/13; "Les Femmes Folles: WV," group exhibit, Monongalia Art Center, 3/14; Over a dozen readings, panels and performances various venues in Omaha and Morgantown, 2011-14; “Art+Feminism Wikipediathon," 3/15; Les Femmes Folles Art + Poetry Salon, 3/15; "Les Femmes Folles: TALES," at Monongalia Art Center, 5/15.

Nonprofit collaborations: Rape and Domestic Violence Information Center of Morgantown, Monongalia Art Center, Art + Feminism, Lydia House for Women/Open Door Mission; Women's Center for Advancement; Nebraska Feminist Network; X-Rated: Women in Music, Public Radio; Omaha Public Library; Youth Emergency Services, WV Domestic Violence Information Center, Art + Feminism

Published five LES FEMMES FOLLES: THE WOMEN, anthologies of excerpts, poetry and art: 2011, 2012, $2013,2014,2015$.

Co-Created Les Femmes Folles Books, with Laura Madeline Wiseman, a feminist micro-press dedicated to collaborative projects INTIMATES AND FOOLS (2014), a book of poetry by Laura Madeline Wiseman and art by Sally Deskins; won Nebraska Honor Award for illustration by Nebraska Books, Nov. 2015

THE HUNGER OF THE CHEEKY SISTER: TEN TALES (2015, Laura Madeline Wiseman/Lauren Rinaldi)

BARED (forthcoming, 2016), an anthology of art/poetry on bras and breasts

Drink n Draw Omaha, monthly community drawing event Founder, manager, 12/10-5/13

Founded this event featuring two professional nude figure models for community artists to create in social atmosphere that continues in Omaha.

Lit Undressed, reading event in conjunction with (downtown) omaha lit fest, Founder/Director, 9/10-10/12

Produced literature event with authors, readers, and artists. "Undressed/Untold: A Body/Text Event," theme of body's use in literature; "Lit Undressed: Spirit of the Female Beats," theme of women writers of the Beat generation; "Lit Undressed: Fashion in Literature," theme of us of clothing in literature and "Lit Undressed: Women in Disguise" theme of women writers or characters in disguise.

Initiated four visual exhibitions in conjunction with each performance; "Body as Text," curated by Larry Ferguson and "Les Femmes Folles," 3/11 curated by Wanda Ewing, both at RNG Gallery in Omaha and nominated for Omaha Arts and Entertainment Awards for group show, 2012.

\section{OTHER EXPERIENCE/COMMUNITY WORK}

\section{Teaching Children:}

Camp Coholo, Gretna, NE, Art Instructor, 7/06

Pine Forest Camp, Greeley, PA, Art Instructor, 6/01-8/01

\section{Community Involvement/Volunteering:}

All Les Femmes Folles projects, Bemis Center for Contemporary Arts, Metropolitan Community College, Great Plains Theatre Conference, H Shops Art Center, Omaha PRIDE Festival, ServeNebraska, St. Thomas Church, Morgantown: Monongalia Art Center, St. Francis School Librar Art Museum of West Virginia University 
Illustrated Books:

Ten Speed (poetry by Laura Madeline Wiseman, Agape Publications, forthcoming Fall 2016)

Leaves of Absence: An Illustrated Guide to Common Garden Affections (poetry by Laura Madeline Wiseman, Red Dashboard Publishers, January 2016)

Intimates and Fools (poetry by Laura Madeline Wiseman, Les Femmes Folles Books, 2014)

Award: Nebraska Honor Award for Illustration and Design, 2015

\section{Solo exhibitions:}

Future Tenant Art Space, Pittsburgh, PA 8/14

Annex Gallery, Charleston, WV, 6-7/14

Ohio University East Campus Art Gallery, St. Clairesville, OH, 2/14

Star Gallery, Omaha, NE, 2/13

Shelterbelt Gallery, Omaha, 8/07

The Meeting Place Gallery, Omaha, 10/05

Mick's Gallery, Omaha, 7/05

Sur Tango Gallery, Lincoln, NE, 5-8/02

Group exhibitions:

Environs, Union Hall Gallery, Pittsburgh, 10/16-11/16

Gallery Tally, Los Angeles Contemporary Exhibitions, 3/16-6/16

Gallery Tally, Contemporary Art Center, Santa Fe, 12/15-1/16

The Art of Blogging, Most Wanted Fine Art, Pittsburgh, 11/15

Gallery Tally, Matucana 100, Santiago, Chile, 10-12/15

Looking Forward, Looking Back, New Mexico Museum of Art, Santa Fe, 9-12/15

Southeast College Art Conference Juried Exhibition, Future Tenant Gallery, Pittsburgh, 10/15 (Juror:

Jessica Beck, Assistant Curator of Art at the Andy Warhol Museum)

Wish You Were Here, AIR Gallery, New York, 6/15

Gallery Tally, Woman Made Gallery, Chicago, 5/15

Les Femmes Folles: TALES, Monongalia Art Center (artist/curator), 5/15

Gallery Tally, Área: Lugar de Proyectos in Caguas, Puerto Rico, 12/14 - 1/15

Bare, Monongalia Art Center, 11/14

Morgantown Art Walk: Glow Salon, 9/14

Boulevard's Art \& Words, Ft Worth, TX, 9/14

Bodies of Work, (artist/curator) Apollon Omaha, 4/14

Intimates and Fools, (artist/curator) Connect Omaha, 4/14

The Gallery Tally Poster Project, For Your Art, LA, 4/14

Les Femmes Folles: WV, (artist/curator) Monogalia Art Center, 3/14

Red-Pink Show, AIR Gallery, Brooklyn, 12/13

Wish You Were Here, 2013, AIR Gallery, Brooklyn

Stories We Tell, National Women's Caucus of Art, 2013

Bare, Monongalia Art Center, 11/13

Women's Rights: An Artist's Perspective; Unitewomen.org online exhibit, 6/13

Woman Made Gallery 21st Anniversary Gala exhibit, 4/13, Chicago

Artists from Anywhere but Illinois Show, 5/13, Chicago Urban Art Retreat Center

Ciao, (artist/curator) Caesium Gallery, Omaha, NE, 5/13

Femme Qui Bercent, Noyes Art Gallery, Lincoln, NE, 3/13 
Women of All Colors Art Show, Chicago Urban Art Retreat Center, 2-3/13

CLUB NO QUIET pop-up, Sweatshop Gallery, Omaha, 2/13

Create Chaos, Permanent Wave Philadelphia, 1-3/13

12/12/12, Caesium Gallery, Omaha, 12/12

Tone it Down a Notch: Minimalist exhibition, Shoe Factory Gallery, Rochester, NY, 11/12

PRIDE art show, Aksarben Village, Omaha, 7/12

Bemis Underground \$100 Art Sale, Omaha, 6/12

Indian Oven, work on view with work by Marcia Joffee Bouska and Megan Loudon Sanders, Omaha, 4-5/12

Les Femmes Folles: Voice, (artist/curator), The New BLK, Omaha, 4/12

Little Waves, University of Nebraska-Lincoln Rotunda Gallery, group show, 3/12

Amore, Imagewerks Gallery, Omaha, 2/11

Body as Text, (artist/curator) RNG Gallery, 9/10, Omaha *nominated for 2012 Omaha Arts and Entertainment Award

Associated Artists of Omaha, Field Club Art Sale, 4/07

Organization for the Advancement of the Arts, Red Chair Show, Omaha, 11/06

Bemis Center for Contemporary Arts, Valentine Auction, Omaha, 2/06

Bemis Center for Contemporary Arts, Annual Fall Auction, Omaha, 11/05

Bemis Center for Contemporary Arts, Valentine Auction, Omaha, 2/05

Jester's, (artist/curator) Dual Exhibition, Omaha, 9/05

East Campus Loft, (artist/curator) Dual Exhibition, Lincoln, NE, 1/03

Annual Juried UNL Undergraduate Show, accepted work, "Heidi," Lincoln, NE, Juror: Judith Burton, 2002

Art Publications:

Mom Egg, Spring 2016

Two Serious Ladies, 12/15

Helen Literary Magazine, forthcoming spring 2016

Meat for Tea, 9/15

Oddball Magazine, 8/15

Yellow Chair Review, 9/15

Word for Word, 9/15

San Francisco Museum of Modern Art Blog, 7/15

Magnolia Review, 7/15

Dali's Lovechild, 6/15

Blotterature, 5/15

Mom Egg Review, 5/15

Rogue Agent, 5/15 \& 6/15

Hysteria, 5/15

Thethe Poetry, 5/15

Hermerneutic Chaos, 1/15

The Account, 4/15

Mom Egg, 4/15

If and Only If, 1/15

Elsewhere, 12/14

Z-Composition, 10/14

Eyedrum Periodically, 9/14

Masque and Spectacle, 8/14

Extract(s): 7/14

UndergroundBooks, 4/14

Momentous Collective, 3/14

Luciferous, 1/14

Z-Composition, 1/14

INTIMATES \& FOOLS, LFF Books, 1/14

Foliate Oak, 2/14

Painters and Poets, 2/14

Sundress' Best Dressed, 2/14 
Wild Women Rising, 1/14; 11/13

Extract(s), 11/13

Miracle, $9 / 14$

ROLLING THUNDER MAGAZINE, 1/13

Certain Circuits Zine, 2013

Weave Magazine, $7 / 13$

Girls Get Busy Zine, Issue 17, 2013

Vagina, 2013

\section{Press Reviews/Interviews:}

Luna Luna Magazine, 4/16

Broadblogs, 3/16

THEthe Poetry Journal, 2/16

Balancing the Tide, 2/16

Dominion Post, 1/16

Story Circle Review, 1/16

An Paenhysen's Art Blog, 12/15

West Virginia University College of Arts Online Journal, 10/15

Cahaoodaloodaling, 9/15

The Dominion Post, Morgantown, WV, 5/15

WVU U92 Student Radio, 3/15

Coal Hill Review, 6/14

The Joy Factor (radio), 6/14

Mixtini Matrix, 6/14

[PANK], 3/14

Blotterature, $3 / 14$

Underrated Reads, 6/14

Luna Luna, 5/14

Connotation Press, 5/14

Busting and Droning Magazine, 4/14

Ivory Owl Reviews, 2/14

BroadBlogs, 1/14

CLAP, 2013, review of my body prints by Laura Madeline Wiseman

ArtNotes: Two poets, one artist collaborate on "Bodies of Work," Omaha World Herald, April 17, 2014

"Bodies of Work: A Collaboration Exhibit \& Reading," Omahype, April 21, 2014

"MAC presents Les Femmes Folles WV," The Dominion Post, Feb. 27, 2014

Omaha Public Library Youtube interview by Amy Mather for the 2013 Author Fair

Philly Art Blog "News Post," December 23, 2013

"Artists Urge: Break Limits, Follow Bliss" Broadblogs, Georgia Platts, May 4, 2013

"LFF...CIAO!" The Reader, Mary Day, May 1, 2013

"Josie Loza: Motherhood: 'What will her kids think?'" momaha.com February 27, 2013

"Deskins Les Femmes Folles," Mary Day, The Reader, December 16, 2012

"5th Edition of the Feminist Odyssey Blog Carnival: Having it All," The Mamafesto, Oct. 31, 2012

"It's the Beat" 1290 KOIL cultural radio show, Sept. 1. jmrproductions.com/itsthebeat

"Artists talk about juggling motherhood," Kevin Coffey, Omaha World Herald, June 7, 2012

"Adventures of Life as a mom, artist," Josie Loza, momaha.com, April, 2012

"Experiences of Womanhood," Omaha World-Herald, April 2012

"Dominance, Submission, Meaning \& Voice," by Georgia Platts, Broadblogs, April 2012

"Les Femmes Folles Presents: VOICE," Creative Ladies Are Powerful, April 2012

"Girl Crazy: Les Femmes Folles find their 'Voice' at New BLK Gallery," by Mary Day, The Reader, April 2012

"Pick: Les Femmes Folles Presents: VOICE," by Michael J. Krainak, The Reader, April 2012

"Les Femmes Folles: VOICE," Omahype.com, April 2012

"Exhibit focuses on feminism through artwork," by Krystal Sidzyik, UNO Gateway, April, 2012

"Les Femmes Folles Releases a Book: Preview" by Kystal Sidzyik, HearNebraska.org, March, 2012 
"Author/Blogger Sally Deskins" Morning Blend, (television) March 2012

"Les Femmes Folles" Morning Blend, July 19, 2011

Whatever Mathers on Blogging; interview Episode 4, December 2011

"Wild at Art: RNG Gallery gets its crazy on with Les Femmes Folles Show," by Michael J. Krainak, The Reader, April, 2011 